\title{
THE KINETICS OF ELEMENTARY REACTIONS
}

A thesis submitted for the degree of

Doctor of Science

in the University of Edinburgh

by

A.F.Trotman-Dickenson

M.A., B.Sc., Ph.D.

1957

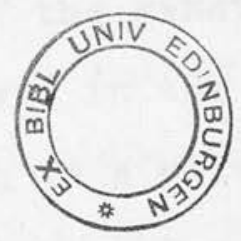




\section{THE KINETICS OF ELEMENTARY RGACTIONS}

The fundamental aim of the work contained in this thesis is the better understanding of the factors that govern the rates of chemical reactions. Most of the work is concerned with the investigation of reactions in the gas phase, because homogeneous gas reactions may be expected to yield most readily to theoretical treatment. True gas reactions are free from such complicating factors as solvation, adsorption and, except in special cases, diffusion. There are however some solution reactions which might be simple; they are the reactions for which the transfer of a proton is the rate-determining step. Some of the work in this thesis is concerned with

reactions of this type. It will be seen from the published papers that the most complex experimental techniques are often required to investigate the reactions of greatest formal simplicity. The rate constants of these simple reactions can usually only be measured when the experimental systems are carefully designed for this specific purpose.

The whole subject of the kinetics of elementary gas reactions has been surveyed in the writer's monograph 'Gas Kinetics'. This monograph is a critical account of all the literature on the subject that was available to the writer in July 1954. The investigations that were selected for discussion were chosen because they throw light on the probIem of why reactions occur at the rate they do. The book 
defines the attitude that has governed the writers approach to the subject of this thesis. Publication (14) contains a short summary of the present position in the-subject. The relevance of modern work to elementary teaching has also been discussed (15).

A fruitful approach to the understanding of the preexponential factors of elementary reactions lies in the consideration of the entropy changes involved. This approach has been discussed in general terms (2) for the major classes of gas reactions and specifically for the reactions of chlorine atoms (12) and methylene (22). Particular attention has been paid to the combination of free radicals. It has been shown that the reverse decompositions of normal molecules into radicals have remarkably pre-exponential factors; they are in several cases greater than $10^{15}$ sec. $^{-1}$

Unimolecular decompositions and the opposing combination reactions are among the simplest of all chemical processes. Our knowledge of them is more complete than it is for any other class of gas reaction. A problem on which much work still remains to be done is the elucidation of the conditions under which the rate of transfer of energy determines the rates of unimolecular reactions. Publications (3) and (4) bear directly on this point. The isomerization of cyclopropane has proved amenable to theoretical treatment and has provided the best test so far of N.B.Slater's theory 
of unimolecular reactions. The efficiency with which energy is transferred between molecules on collision is of great importance in connection with all such theoretical treatments. The work on the effect of added gases on the rates of the isomerization of cyclopropane (3) and the decomposition of cyclobutane (4) provides the first evidence that all complex molegules probably have unit efficiency in the transfer of energy on collision. This only applies to molecules that are chemically activated; the efficiency of transfer is much lower for molecules containing less energy. Two unsuccessful attempts to extend the present knowledge of the phenomena of energy transfer are recorded in publications (i3) and (24). The study of the thermal deconposition of azomethane (5) played an important part in the development of modern ideas on energy transfer. Some aspects of the decomposition, as described in the early papers appeared unusual in the light of modern knowleage. A fresh investigation was therefore undertaken using a flow system; hovever it seems that all the problems are not yet solved. The writer is presentlt engaged in funther work on this topic.

The activation energies for the unimolecular decomposition of molecules into radicals are closely equal to the strengths of the bonds broken. The fact that a knowledge of these bond strengths is necessary for a proper understanding of radical reactions has been a great stimulus to the investigation of the decompositions. The strengths of the methyl-carbon bonos 
in dimethyl mercury, dimehty 1 camium, dimethyl zine and methyl zine $(25,26)$ have been determined in this way. These results are the first fruits of a projected survey of the strengths of the bonds between methyl groups and many metals. The prabable values of the dissociation energies of the C-C bonds in cyclanes have been aiscussed. With reference to the mode of unimolecular decomposition (18,19). The strength of the $\mathrm{CF}_{3}-\mathrm{H}$ bond has also been determined (2I) and hence the heat of formation of the trifluoromethyl radical has been found.

Another class of thermal decompositions is that of the molecular eliminations, in which a molecule splits into two normal molecules in one step without the intextention of arec racicals. Jittle is as yet hnown of the factors wich control the rates and activation energies of these reactions. At the moment the principal heed seens to be for the investigation of more classes of compounds. The decomposition of eyclobutane is a reaction of this type. Similar reactions which have been studied by the writer are the decompositions of eyclopentyl bromide (11) into eyclopentere a d hyörogen bromide, the decomposition of $\underline{t-b u t y l}$ formate intofomic acid and iso-butene ${ }^{(29)}$ and the decomposition of $t$-butylamine/6). The last reaction is remarkable because two alternative sets of products coresponding to the elimination of methane and ammonia are formed in comparable quantities. The general 
features of these reactions are considered in the writer's book and the discussion is brought up to date in the paper on $t$-butyl formate. It is shown that similar factors determine the relative rates of many series of reactions of this type.

The adaition of methylene to alkanes (31) may be regarded as similar to those combination reactions which are the reverse of the molecular reactions that have just been discussed. No free radicals with only one unsatisfied valence are involved in either case. The study of the carbenes is just beginning, it promises to be a significant new field of radical chemistry.

A further class of simple reactions comprises those in which an atom is transferred from one radical group to another. They may be represented by the equation

$$
A+B C=A B+C
$$

where $A$ and $C$ are free radicals. The writer has examined three series of reactions of this type and measured their rate constants. The factors determing the magnitude of the preexponential terms in the Arrhenius equations for these reactions are fairly well understood. Greatest interest therefore attaches tothe problem of the magnitude of the activation energies. The experimental approach to-its solution lies in the measurement of these activation energies for a large number of members of as many different series 
of reactions as possible.

The writer has been responsible for the extensive investigation of three classes of such reaction. They are the reactions of methyl radicals, of trifluoromethyl radicals, and of chlorine atoms with compounds containing hydrogen. In general they have been studied by competitive techniques (30) which offer many advantages.

The basic papers on the reactions of methyl were written by the writer under the direction of Dr Steacie and consequently do not form part of this thesis. However the early work is summarized and discussed in a review (1). The more recent work of thewriter has been concerned with certain special problems. Thus the decomposition of di-t-butyl peroxide, which is generally an unsatisfactory source of the radicals, was used to investigate the reactions of thermal methyl radicals with ketones? $(7)$ This problem was of interest because the photolysis of ketones is frequently used as a source of free radicals. The reactions of methyl radicals with thiols have been studied (28) because these compounds are of importance as chain transfer reagents-in polymerisations. They react very rapidly with free radicals. Inded the reactions are too rapid for convenient estimation of their rates and the results have only semi-quantitative significance. The special case of the reaction of methyl with acetaldehyde has also been discussed (17).

The reactions of trifluoromethyl radicals have been 
studied $(10,90)$ using hexafluoroazomethane as the source of radicals. The results show that the trifluoro- radicals are more reactive than ordinary methyl radicals. The higher reactivity is reflected in activation energies which are 2 - $3 \mathrm{kcal}$. mole lower.

Chlorine atoms were found $(12,16)$ to be much more reactive than ordinary polyatomic radicals. The pre-exponential factors approach the rate of collisions between the atoms and the substrates. Furthermore the activation energies are very low; often they are of the order of 1 keal./moze. Some information on the reaetivity of thiyl radicals has been obtained from the study of the photo-initiated decomposition of acetaldehyde catalysed by thiols (28).

Our knowledge of transfer reactions will be very usefully increased when processes involving the transfer of atoms other than hydrogen have been investigated. An attempt to investigate the transfer reaction of iodine atoms-with methyl iodide (8) was unsuccessful because of an excessive heterogeneous reaction.

The rate-determining step of an acid-base-catalysed reaction is generally the transfer of a proton between two molecules or ions. These reactions therefore-bear a marked Besemblance to the hydrogen transfer reactions that have just been discussed. Most work on acid-base-catalysis has been performed in aqueous solutions. The properties of water are known to vary with temperature in an irregular 
manner. Accordingly it is not surprising that little work has been done on the measurment of the activation energies of acid-base catalysed reactions. However it should be possible to obtain useful information by working in nonaqueous solvents. A start has been made by investigating the temperature dependence of the decomposition of nitramide in anisole catalysed by anilines ( 27 ). The results indicate a linear relation between the activation energies and the logarithms of the rate constants.

The crystal structure of nitramide was determined (13) both because it is good to know the structure of the substances with which one is working and it seemed that a knowledge of the structure would throw light on the nature of N-H-O hyarogen bonds. Unfortunately the hyorogen atoms could not be accurately located. The precision of the analysis was lower than had been hoped because a pronounced anisotropic heat motion was found. 


\section{Publications.}

The remainder of this thesis consists of copies of the papers that have been referred to in the introduction. The writer was responsible for the general conception of the investigations. He designed the greater part of the apparatus, and did a considerable portion of the experimental work, especially in the construction of the equipment. He was the junior author of the publication on the crystal structure of nitramide; while investigating this problem he was learning the technique of $\mathrm{X}$-ray crystallography from Dr.C.A.Beevers. The writer wishes to express his gratitude to his colleagues and students who have contributed so largely to the work recorded here.

Those papers which are in manuscript have been submitted for publication, either to the Chemical Society or the Faraday Society.

The monograph on 'Gas Kinetics' is largely a critical survey of the literature, but the arrangement and treatment have not been attempted before. Much of the information lay scattered about the literature. The general significance of the experimental facts was not clear until they had been correlated. Nuch of the discussion in Chapter 5 is original. 
Book.

Gas Kinetics: An Introduction to the Kinetics of Homogeneous Gas Reactions.

Published Papers.

R 1. The Reactions of Methyl Radicals.

2. Entropy Changes in Free Radical Reactions.

3. Studies in Energy Transfer II. The Isomerization of Cyclopropane -a quasi- Unimolecular Reaction. with H.O.Pritchard and R.G.Sowden.

4. Studies in Energy Transfer III. The Effect of Added Gases on the Decomposition of Cyclobutane. with H.O.Pritchard and R.G.Sowden.

5. The Thermal Decomposition of Azomethane. with H.O.Pritchard and M.Page.

6. The Thermal Decomposition of $\neq$-Butylamine. with H.O.Pritchard and R.G.Sowden.

7. The Reactions of Nethyl Radicals with Acetone, Diethyl Ketone and Di-t-butyl Peroxide. with G.O.Pritchard and H.O.Pritchard.

8. The Exchange of Iodine Atoms between Iodine and Nethyl Iodide in the Temperature Range $150-375^{\circ}$. with D.Clark and H.O.Pritchard.

9. The Study of Chlorine Atom Reactions in the Gas Phase. with H.O.Pritchard and J.B.Pyke. 
10. The Reactions of Trifluoromethyl Radicals. with G.O.Pritchard, H.O.Pritchard and H.I.Schiff.

11. The Thermal Decomposition of Cyclopentyl Bromide. with S.J.W.Price and R. Shaw.

12. The Reactions of Chlorine Atoms - A Test of the Transition State Theory. with J.H.Knox.

13. The Crystal Structure of Nitramide, $\mathrm{NH}_{2} \mathrm{NO}_{2}$. with C.A.Beevers.

$R$ 14. Recent Developments of Gas Kineties. General.

R 15. The Teaching of Chemical Kinetics. Shorter Contributions.

16. A Method for the Study of Chlorine Atom Reaction. The Reaction $\mathrm{Cl}-\mathrm{CH}_{4}-\mathrm{CH}_{3}-\mathrm{HCl}$. with H.O.Pritchard and J.B.Pyke.

17. The Photolysis of Acetaldehide. with G.0.Pritchard and H.O.Pritchard.

18. The C-C Bond Dissociation Enegies in Cyclanes. with $\mathrm{H} \cdot 0$. Pritchard.

19. The C-C Bond Dissociation Energy in Cyclobutane. with H.O.Pritchard.

20. The Photolysis of Hexafluoroazomethane and the Reactions of $\mathrm{CF}_{3}$ Radicals with Methane and $\underline{n}-$ Butane . with G.0.Pritchard, and H.O.Pritchard. 
21. The $\mathrm{C}-\mathrm{H}$ Bond Dissociation Energy in Fluorofom. with G.O.Pritchard, H.O.Pritchard and H.I.Schiff.

22. The Reactions of Methylene. with J.H.Knox.

23. The Isomerization of Cyclopropane at very low Pressures.

with H.O.Pritchard and R.G.Sowden.

24. The Combination of Nitrogen Atoms. with G.Boocock and H.O.Pritchard.

Papers in the course of publication.

25. Carbon-Metal Bonds I. The Pyrolyses of Dimethyl Nercury and Dimethyl Cadmium. with S.J.W.Price.

26. Carbon Metal Bonds 2. The Pyrolysis of Dimethyl Zine.

with S.J.W.Price.

27. The Decomposition of Nitramide in Anisole Catalysed by Anilines.

with G.C.Fettes, J.A.Kerr, A.McClure, J.S.Slater and C.Steel.

28. The Photoinitiated Decomposition of Acetaldehyde Catalysed by Thiols. with R.N.Birrell, R.F.Smith and H.Wilkie. 29. The Pyrolysis of $\underline{t}$-Butyl Formate. with R.Gordon and S.J.W.Price. 
30. The Study of Free Radical Reaction by Competitive methods.

with J.H.Knox.

$L$ 31. The Reactions of Methylene with Alkanes, with J.H.Knox.

32. The Reactions of Methyl Radicals with Thiols. with J.A.Kerr. 


\title{
THE REACTIONS OF METHYL RADICALS
}

BY

A. F. TROTMAN-DICKENSON

Reprinted from Quarterly Reviews

1953, Vol. VII, No. 2

\author{
London
}

The Chemical Society 
Reprinted from the Quarterly Reviews of the Chemical Society, Vol. VII, No. 2, 1953. 


\title{
THE REACTIONS OF IMETHYL RADICALS
}

\author{
By A. F. Trotman-Dickenson, M.A., B.Sc., Ph.D.
}

(I.C.I. Research Fellow, University of Manchester)

A LARGE proportion of contemporary research on reaction kinetics is devoted to the study of atomic and free-radical reactions both in the gas phase and in solution. There are many reasons for this. First, atomic and free radical reactions are formally very simple ; they are less influenced by their environment than are ionic reactions; they exemplify clearly the factor governing reactivity; they are often very symmetrical and are suitable for theoretical study; they may provide the avenue by which we shall arrive at a fuller understanding of the factors influencing the rates $d$ reactions. Secondly, they are of extreme practical importance in the petroleum chemicals industry and in the production of high polymers Thirdly, they are involved in many combustion and oxidation processes Fourthly, they are relatively difficult to investigate and their study involve the use of many of the most advanced chemical techniques, so they provid: a challenge to the worker in reaction kinetics.

Here we shall be concerned with the reactions of methyl radicals if the gas phase, which have been more fully investigated and are better under stood than those of any other free radicals. As a result of intensive researd in five or six laboratories during the last seven years we now have som quantitative knowledge of most types of methyl-radical reaction. Conse quently, it is possible to write a fairly comprehensive review of thes reactions in the expectation that new work will amplify what is writtel here and fill in the many gaps but that drastic revision will not be required Here will be described the methods of research used in the study of methyl radical reactions and the results so obtained, in the hope that this particular account may be a general guide to free-radical research in the gas phase To this end the parallel behaviour of other radicals, which are much mor difficult to investigate, will be referred to when this seems to be illuminating

Early Work on Free Radicals.-The existence of short-lived alkyl fret radicals was first demonstrated twenty years ago by Paneth and his co workers. In the subsequent decade investigators were primarily con cerned in detecting the presence of free radicals in reacting systems. Panetl showed that when organic vapours were passed through a furnace at convenient temperature and over a metallic mirror, the mirror was remove and metallic alkyls were formed; by this means it was shown that aliphati free radicals were intermediates in a large number of pyrolyses and photo lyses. Two other methods were developed to accomplish this end. Hinshel wood showed in 1936 that the addition of very small quantities of nitri oxide to the reacting system greatly inhibited the pyrolysis of many organi vapours. Nitric oxide is a molecule containing an odd number of electron and it was expected that it would combine very rapidly with free radical 
to give a compound with the usual even number of electrons. Since the free-radical chain-carriers in a pyrolysis are present in very small concentrations (often of the order of $10^{-10}$ mole per l.), a very small quantity of nitrie oxide should greatly inhibit the overall reactions. Hinshelwood also showed that propene in larger quantities had a similar effect. Hence reactions which are inhibited by nitric oxide and propene probably involve free radicals. Patat and Sachsse showed that the reacting mixtures in pyrolyses would accelerate the ortho-para-hydrogen conversion, as would be expected if free radicals were involved. All of these techniques and their applications to particular systems are described fully in Steacie's definitive monograph. ${ }^{1}$

The theory needed to explain many of these observations was provided by Rice and Herzfeld, who showed that the experimental data on pyrolysis reactions could be interpreted on the basis of free-radical mechanisms involving several simple elementary processes about which reaśonable assumptions could be made. At that time no particular mechanism could be rigorously tested because not enough was known about the elementary reactions. Even today our knowledge of some of the postulated steps is inadequate for unequivocal judgments of the mechanisms favoured by Rice. However, it has been shown that Rice's anticipation was often remarkably accurate. Steacie ${ }^{1}$ gives very complete accounts of these mechanisms.

Modern Developments.-During the last decade the interest of most investigators has shifted from the qualitative study of complex systems to the quantitative study of the elementary processes occurring in pyrolyses, photolyses, and polymerisations. In order to avoid complicating side reactions, these reactions are normally carried to very low percentage conversions and in consequence the analytical problems are great. The researches have been made possible by advances in analytical technique and by the increasing availability of isotopic tracers. The important analytical techniques which were mostly developed for oil companies in the United States are low-temperature distillation, Blacet and Leighton's analysis system, ${ }^{2}$ and the analytical mass-spectrometer ; as yet, the recording infrared spectrometer has been comparatively little used in the study of freeradical reactions. As examples of the power of these methods it may be mentioned that by low-temperature distillation it is now possible to estimate $0 \cdot 1 \mathrm{ml}$. (S.T.P.) of ethane in the presence of $15 \mathrm{ml}$. of propane to an accuracy of $\pm 3 \%$ in $1 \frac{1}{2}$ hours. The proportion of ethylene in an ethylene-ethane sample of $20 \mu \mathrm{l}$. may be determined in 40 minutes to an accuracy of $\pm 0.05 \mu \mathrm{l}$. with Blacet and Leighton's apparatus. Under favourable conditions the proportion of $\mathrm{CD}_{3} \mathrm{H}$ in $\mathrm{CD}_{4}$ may be determined in 15 minutes to better than $0 \cdot 1 \%$ on a mass-spectrometer. These are powerful new tools for the investigation of gas-reactions.

The Types of Methyl-radical Reaction.-There are three principal classes of methyl-radical reaction:

1. Combination reactions: $\mathrm{CH}_{3}+\mathrm{XY} \rightarrow \mathrm{CH}_{3} \mathrm{XY}$, e.g., $\mathrm{CH}_{3}+\mathrm{CH}_{3} \rightarrow$ $\mathrm{C}_{2} \mathrm{H}_{6}$. Methyl radicals will combine with methyl radicals, other free 1 "Atomie and Free Radical Reactions", Reinhold, New York, 1947.

${ }^{2}$ Ind. Eng. Chem. Anal., 1931, 3, 266. 
radicals, atoms, or "odd electron" molecules to give normal saturated molecules.

2. Metathetical reactions:

$$
\mathrm{CH}_{3}+\mathrm{XY} \rightarrow \mathrm{CH}_{3} \mathrm{X}+\mathrm{Y}, \text { e.g., } \mathrm{CH}_{3}+\mathrm{C}_{2} \mathrm{H}_{6} \rightarrow \mathrm{CH}_{4}+\mathrm{C}_{2} \mathrm{H}_{5} \text {. }
$$

Methyl radicals will extract atoms from molecules to produce saturated methyl derivatives and a new free radical or atom. This class of methyl. radical reaction has been intensively studied, especially those reactions in which a hydrogen atom is extracted. At least two cases of the extraction of a radical from a molecule are known, namely, that of acetyl from diacetyl and that of methyl from dimethylmercury.

3. Addition reactions: $\mathrm{CH}_{3}+\mathrm{XY} \rightarrow \mathrm{CH}_{3} \mathrm{XY}$, e.g., $\mathrm{CH}_{3}+\mathrm{C}_{2} \mathrm{H}_{4} \rightarrow \mathrm{C}_{3} \mathrm{H}_{\text {, }}$ Methyl radicals will add to molecules containing multiple bonds to givi more complex free radicals.

Only these three types of methyl-radical reaction have been establishei beyond reasonable doubt. All the more complex alkyl radicals ean underg the following two other sorts of reaction which make the study of theil behaviour very difficult.

4. Decomposition reactions: e.g., $\mathrm{C}_{2} \mathrm{H}_{5} \rightarrow \mathrm{C}_{2} \mathrm{H}_{4}+\mathrm{H}$. That decomposition reactions of this type occur has been established, but very fer have been studied quantitatively because there are few suitable radical sources. Mercury photosensitisation has so far proved to be the best source and the decomposition of the radicals derived from the abstraction of : hydrogen atom from ethane, ${ }^{3}$ propane ${ }^{4}$-butane, 2 -methylpropane; methyl alcohol, ${ }^{6}$ and dimethyl ether ${ }^{7}$ has been studied in this way. Th reaction $\mathrm{CH}_{3} \rightarrow \mathrm{CH}_{2}+\mathrm{H}$ is theoretically possible but probably has at activation energy of at least $80 \mathrm{kcal}$. and will not become appreciable unt temperatures of $1000^{\circ} \mathrm{K}$ are reached. By contrast, the decomposition c the $n$-butyl radical can be detected at $500^{\circ} \mathrm{K}$.

5. Disproportionation reactions: e.g., $\mathrm{C}_{2} \mathrm{H}_{5}+\mathrm{C}_{2} \mathrm{H}_{5} \rightarrow \mathrm{C}_{2} \mathrm{H}_{6}+\mathrm{C}_{2} \mathrm{H}_{4}$ Very little is known about reactions of this type, but they certainly occir under some conditions, for Ivin and Steacie ${ }^{8}$ have accurately studied thr disproportionation of ethyl radicals in the photolysis of diethylmercury The only evidence for the reaction $\mathrm{CH}_{3}+\mathrm{CH}_{3} \rightarrow \mathrm{CH}_{4}+\mathrm{CH}_{2}$ come from the work of Bawn and Tipping ${ }^{9}$ which appears to be quite unrelated to normal work on homogeneous gas-phase reactions, probably because thr reaction was studied in an atmosphere of sodium vapour.

From this list we can see that all known reactions of methyl radical are bimolecular at high pressures. Consequently, the reactions may br

$$
\begin{aligned}
& \mathrm{CH}_{3}+\mathrm{A} \rightarrow \mathrm{B} \\
& \mathrm{CH}_{3}+\mathrm{X} \rightarrow \mathrm{Y}+\mathrm{Z}
\end{aligned}
$$

${ }^{3}$ Bywater and Steacie, J. Chem. Physics, 1951, 19, 172.

${ }^{4}$ Idem, ibid., p. 319.

${ }^{5}$ Idem, ibid., p. 326.

6 Phibbs and Darwent, ibid., 1950, 18, 495.

7 Marcus, Darwent, and Steacie, ibid., 1948, 16, 987.

${ }^{8}$ Proc. Roy. Soc., 1951, A, 208, 25.

'Discuss. Faraday Soc., 1947, 2, 104. 
represented by equation $(a)$ or $(b)$. In these two cases the respective rate constants $k_{a}$ and $k_{b}$ are defined by the equations

$$
R_{b} \equiv \mathrm{d}[\mathrm{B}] / \mathrm{d} t=-\mathrm{d}[\mathrm{A}] / \mathrm{d} t=k_{a}\left[\mathrm{CH}_{3}\right][\mathrm{A}]
$$

and

$$
R_{y} \equiv \mathrm{d}[\mathrm{Y}] / \mathrm{d} t=R_{z} \equiv \mathrm{d}[\mathrm{Z}] / \mathrm{d} t=-\mathrm{d}[\mathrm{X}] \mathrm{d} t=k_{b}\left[\mathrm{CH}_{3}\right][\mathrm{X}]
$$

where the letters in brackets are the concentrations of the substances and $R_{y}$ is the rate of formation of $Y$, and so on : this notation will be used throughout. Hence if the methyl-radical concentration is known, the rate constant in the first case can be found by measuring the formation of $B$ or the disappearance of $\mathrm{A}$, and in the second case by the disappearance of $\mathrm{X}$ or the formation of $\mathrm{Y}$ or $\mathrm{Z}$.

The rate constants all obey the Arrhenius equation $k=A \exp (-E / R T)$ within the limits of experimental error, where $E$ is the activation energy of the reaction and $A$, which is usually called the pre-exponential or $A$ factor, is a number having the dimensions of a rate constant. The Arrhenius equation may be written in terms of the collision theory of chemical kinetics for a bimolecular reaction as $k=P Z \exp (-E / R T)$, where $P$ is known as the steric factor, and $Z$, the collision frequency of the reacting species, is given by

$$
Z=\sigma_{x, y}{ }^{2}\left[8 \pi k T \frac{\left(m_{x}+m_{y}\right)}{m_{x} m_{y}}\right]^{\frac{1}{2}}
$$

where $\sigma_{x, y}$ is the mean molecular (collision) diameter of $\mathrm{X}$ and $\mathrm{Y} ; m_{x}$ and $m_{y}$ are the masses of the respective molecules, and $k$ is Boltzmann's constant.

The great value of the collision theory is that it provides a very simple picture of chemical kinetics, as a large number of reactions is known in which $P=1$. A weakness is that $Z$ is not a well-defined quantity, because of the uncertainty as to the appropriate values for the collision diameters. To preserve the simplicity of the theory, collision diameters which might be determined by viscosity and other methods depending on the transport properties of the gases should be selected. Almost all workers on methyl radicals have done this when calculating steric factors, but despite the uniformity of practice it is probably less likely to cause confusion if the directly determinable $A$ factors are given. Throughout this Review, $A$ factors will be quoted but for purposes of comparison and as an aide-mémoire the two following values of $Z$ are given :

$Z$ for the collision of two methyl radicals at $455^{\circ} \mathrm{K}$ with collision diameters of $3.5 \AA=2 \times 10^{-10}$ molecules $^{-1}$ c.c. sec. ${ }^{-1}=1 \times 10^{14}$ mole $^{-1}$ c.c. bi sec. $^{-1}$.

$Z$ for the collision of a methyl radical at $455^{\circ} \mathrm{K}$ with a molecule of molecular weight 50 and a collision diameter of $5 \cdot 5 \AA=6 \times 10^{-10}$ molecules $^{-1}$ c.c. sec. $^{-1}=4 \times 10^{14}$ mole $^{-1}$ c.c. sec. $^{-1}$.

There are two principal difficulties which must now be considered in the study of methyl radicals : first, a suitable source of them must be selected, and secondly, some way of determining the steady state concentration of methyl radicals, usually about $10^{-12}$ mole/c.c., must be found.

Sources of Methyl Radicals.-Hitherto the methyl radicals required for 
of the type $\mathrm{M}+h v=n \mathrm{~A}, \mathrm{~A}+\mathrm{B}=\mathrm{X}$, and $2 \mathrm{~A}=\mathrm{Y}$, so that the rate of formation of one product is dependent upon the first power of the concentration of A and the rate of formation of the second is dependent upon the second power of this concentration, it is possible to use the method of intermittent illumination to find the two rate constants involved. In two recent articles ${ }^{15}$ reference has been made to the application of the method of intermittent illumination to the determination of absolute rate constants in polymerisation and liquid-phase oxidation reactions. A full description of the mathematical theory of the method has been given by Burnett and Melville. ${ }^{16}$ A "pilot" reaction of the type $A+B=X$ is used to measure the average concentration of the transient radical A during the run, for if $\mathrm{B}$ is in excess the average concentration of $\mathrm{A}$ is directly proportional to the rate of production of $X$. However, while sufficient quantities of $\mathrm{X}$ must be obtained for accurate analysis it is essential that the concentration of $\mathrm{A}$ in the system should not be appreciably disturbed owing to formation of $\mathrm{X}$. In the polymerisations and oxidations this difficulty does not arise because the over-all chain process may be used as the " pilot " reaction, in which a new radical is formed each time the radical A reacts with B ; but for the study of methyl-radical reactions, high light intensities and low temperatures must be used, so the amount of methyl reacting with $\mathrm{B}$ is a negligible $(\mathrm{ca} .0 .5 \%)$ part of the total amount of methyl released in the system. All the accurate absolute rate constants of methyl-radical reactions are based upon rotating sector determinations of the rate of methyl-radical combination.

When a mixture of acetone and another hydrogen-containing compound

$$
\mathrm{CH}_{3}+\mathrm{RH} \rightarrow \mathrm{CH}_{4}+\mathrm{R}
$$

is photolysed the reaction (1) will take place as well as reactions (2) and (3). Now

and

$$
\begin{aligned}
R_{\mathrm{CH}_{4}} & =k_{3}\left[\mathrm{CH}_{3}\right]\left[\mathrm{CH}_{3} \cdot \mathrm{CO} \cdot \mathrm{CH}_{3}\right]+k_{1}\left[\mathrm{CH}_{3}\right][\mathrm{RH}] \\
R_{\mathrm{CH}_{4}} / R_{\mathrm{C}_{2} \mathrm{H}_{4}}^{1} & =k_{3}\left[\mathrm{CH}_{3} \cdot \mathrm{CO} \cdot \mathrm{CH}_{3}\right] / k_{2}^{1}+k_{1}[\mathrm{RH}] / k_{2}^{\frac{1}{2}}
\end{aligned}
$$

But the term $k_{3}\left[\mathrm{CH}_{3} \cdot \mathrm{CO} \cdot \mathrm{CH}_{3}\right] / k_{2}^{1}$ has already been determined, so $k_{1} / k_{2}^{k}$ and consequently $E_{1}-\frac{1}{2} E_{2}$ and $A_{1} / A_{2}^{\frac{1}{2}}$ can be found. All the results listed in Tables 3 and 4 , for which the radical source was acetone or dimethylmercury, were obtained in this way.

An alternative procedure is to use fully-deuterated acetone, for which $k_{3}^{*} / k_{2}^{* 1}$ may be obtained as before for reactions $\left(3^{*}\right)$ and $\left(2^{*}\right)$ :

$$
\begin{aligned}
\mathrm{CD}_{3}+\mathrm{CD}_{3} & \rightarrow \mathrm{C}_{2} \mathrm{D}_{6} \quad(2 *) \\
\mathrm{CD}_{3}+\mathrm{CD}_{3} \cdot \mathrm{CO} \cdot \mathrm{CD}_{3} & \rightarrow \mathrm{CD}_{4}+\mathrm{CD}_{2} \cdot \mathrm{CO} \cdot \mathrm{CD}_{3}
\end{aligned}
$$

In the presence of a hydrogen-containing compound, reaction $\left(1^{*}\right)$ occurs :

$$
\mathrm{CD}_{3}+\mathrm{RH} \rightarrow \mathrm{CD}_{3} \mathrm{H}+\mathrm{R}
$$

Hence

$$
k_{1} * / k_{3} *=R_{\mathrm{CD}_{3} \mathrm{H}}\left[\mathrm{CD}_{3} \cdot \mathrm{CO} \cdot \mathrm{CH}_{3}\right] / R_{\mathrm{CD}_{4}}[\mathrm{RH}]
$$

The ratio $R_{\mathrm{CD}_{3} \mathrm{H}} / R_{\mathrm{CD}_{4}}$ ean be rapidly and accurately determined, so $k_{1} * / k_{3} *$ 15 Bolland, Quart. Reviews, 1949, 3, 1; Burnett, ibid., 19550, 4, 292.

16 Proc. Roy. Soc., 1947, A, 189, 456. 
can be found. Since the relation between $k_{3}{ }^{*}$ and $k_{3}$ has been determined, this is a method of finding $k_{1}$. All the results listed in Tables 3 and 4, for which the radical source was hexadeuteroacetone, were obtained in this way.

An extension of this principle is involved in the method which has been used for the study of very fast methyl reactions. If the number of methyl radicals produced in a system is known, and there are only two methods by which the radicals can disappear, such as reactions (4) and (5)

then

$$
\begin{aligned}
\mathrm{CH}_{3}+\mathrm{I}_{2} & \rightarrow \mathrm{CH}_{3} \mathrm{I}+\mathrm{I} \\
\mathrm{CH}_{3}+\mathrm{HI} & \rightarrow \mathrm{CH}_{4}+\mathrm{I}
\end{aligned}
$$

$$
R_{\mathrm{CH}_{4}}=k_{5}\left[\mathrm{CH}_{3}\right][\mathrm{HI}]
$$

$$
R_{\mathrm{CH}_{3} \mathrm{I}}=\text { Rate of methyl production }-R_{\mathrm{CH}_{4}}=k_{4}\left[\mathrm{CH}_{3}\right]\left[\mathrm{I}_{2}\right]
$$

Therefore $\quad k_{5} / k_{4}=\frac{R_{\mathrm{CH}_{4}}\left[\mathrm{I}_{2}\right]}{\left.\text { [Rate of methyl production - }-R_{\mathrm{CH}_{4}}\right][\mathrm{HI}]}$

Unfortunately, $k_{4}$ has not yet been determined absolutely, so only relativ constants are obtained by this method.

The Combination Reactions of Methyl Radicals. - Because the methy radical contains only four atoms, one of them heavy and three light, ther is a possibility that the rate of methyl-radical combination with othe: small radicals and atoms will be markedly dependent on the pressure, in the system in which the reaction is studied owing to third-body effects This phenomenon is the exact converse of that observed in those unimolecula: decomposition reactions the rate of which falls off at low pressures, and is similar to the third-body effect observed in the combination of hydrogen bromine, and iodine atoms. Lindemann, O. K. Rice, Ramsperger, and Kassel ${ }^{18}$ have developed the basic quantitative treatment of these " quasi unimolecular" reactions. It is usually convenient when dealing with combination reactions to make use of the relation $k_{f} / k_{b}=K$, where the rate and equilibrium constants refer to the reactions

$$
\mathrm{A}+\mathrm{B}+\mathrm{M} \underset{k_{b}}{\stackrel{k_{f}}{\rightleftarrows}} \mathrm{C}+\mathrm{M}
$$

The problem of the combination of $\mathrm{A}+\mathrm{B}$ in the presence of a third bods can then be "inverted" so as to be the problem of the decomposition of 0 in the presence of a neutral gas. Thus stated, the problem is more tractable for a number of reasons including the fact that the definition of a two-body collision is clear-cut whereas that of a three-body collision is not. Marcus and Rice ${ }^{19}$ recently considered the effect of pressure in the combination of methyl radicals with other methyl radicals and with iodine atoms. They concluded that energy-transfer effects should become important in the region of a few millimetres' pressure for the combination of methyl radicals

${ }_{17} \mathrm{~J}$. Chem. Physics, 1951, 19, 85.

${ }^{18}$ See L. S. Kassel, "Kinetics of Homogeneous Gas Reactions ", Chemical Catalog Co., New York, 1932.

${ }^{19}$ J. Phys. Colloid Chem., 1951, 55, 894 ; see also Marcus, J. Chem. Physics, 195? 20,359 . 
and at pressures of hundreds of millimetres for the combination of methyl with an iodine atom.

The most important combination reaction of methyl radicals is that in which two of them combine to give ethane. This reaction has been very accurately studied by Gomer and Kistiakowsky, ${ }^{17}$ who used the photolysis of both acetone and dimethylmercury as radical sources, the total pressure in the reaction system being $10-50 \mathrm{~mm}$. Using the rotating sector technique, they found the rate constants given in Table 1 , where $k_{2}$ is in mole $^{-1}$ c.c. sec. ${ }^{-1}$. From these figures it may be seen that the activation

TABLE 1. Rate constants for the combination of methyl radicals

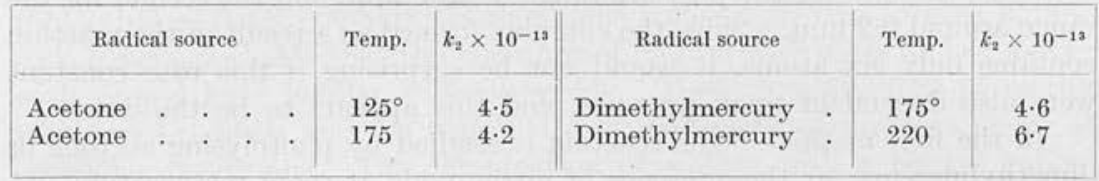

energy of the reaction is very low and that the collision yield for the reaction is about $0 \cdot 5$. This work seems to be very reliable, and the results obtained will be used throughout this Review for the calculation of rate constants based on the rate of formation of ethane in systems at relatively high pressures. In fact, most methyl-radical reactions have been investigated in systems at pressures of $50-100 \mathrm{~mm}$. where the rate constant for the combination reaction is almost independent of pressure. The first attempts to detect the falling-off of the rate constant for methyl combination were not conclusive ${ }^{20}$ largely because experimental errors and complications increased markedly as the pressure was lowered so that it was difficult to be sure that the observed trend was not fortuitous. However, Kistiakowsky and Kirk Roberts ${ }^{21}$ have now found that the rate constant for the combination of methyl radicals definitely falls to about one-third of its high-pressure value when the total pressure in the system is reduced to $1 \mathrm{~mm}$. This is in good agreement with Marcus's prediction. ${ }^{19}$

Lossing, Tickner, and Ingold have also measured the rate of combination of methyl radicals by a mass-spectrometric method ${ }^{22}$ by which it is possible to observe directly the concentration of methyl radicals and ethane in a flow-reaction vessel attached to the ionisation chamber of the mass-spectrometer. Di-tert.-butyl peroxide, dimethylmercury, and ethylene oxide at a few microns' pressure in the presence of 5-19 $\mathrm{mm}$. of helium as a carrier gas have been used as radical sources. The rate constant found at $160^{\circ} \mathrm{C}$ agrees within $50 \%$ with those of Gomer and Kistiakowsky at high pressures. The rate constant decreases with increasing temperature according to the equation $k \propto \exp [(2200 \pm 500) / R T]$ over the range from $160^{\circ}$ to $800^{\circ} \mathrm{C}$.

${ }_{20}$ Trotman-Dickenson and Steacie, J. Chem. Physics, 1950, 19, 1097; Nicholson J. Amer. Chem. Soc., 1951, '73, 3981 ; Linnell and W. A. Noyes, junr., ibid., p. 3986.

21 Personal communication.

${ }^{22}$ Lossing and Tickner, J. Chem. Physics, 1952, 20, 907 ; Lossing, K. U. Ingold, and Tickner, Discuss. Faraday Soc., 1953, 14; also personal communication from Dr. Lossing. 
Surprisingly, no evidence was found for the variation of rate with helium pressure.

The only other combination reaction which has been quantitatively studied is that of methyl with nitric oxide. The products of the reaction (6) are not known with certainty and are complex. Formaldoxime, ammonia,

$$
\mathrm{CH}_{3}+\mathrm{NO} \rightarrow \mathrm{X}
$$

hydrogen cyanide, and carbon monoxide have all been detected, so it is likely that a single molecule, perhaps $\mathrm{CH}_{3} \cdot \mathrm{NO}$, is first formed, which is un. stable under the conditions of the experiment and rearranges or decomposes to give the observed products. The reaction has been studied by two methods, the first for the pressure range $5-100 \mathrm{~mm}$. and the second for the range around $0 \cdot 2 \mathrm{~mm}$. Since the complex formed as a result of the reaction contains only six atoms, it would not be surprising if this rate constant were also dependent upon pressure, and this appears to be the case.

In the first method ${ }^{23}$ the reaction is studied by photolysing acetone of dimethylmercury in the presence of nitric oxide at room temperature. A very low concentration of nitric oxide is kept constant by steadily leaking a known quantity of the gas into the reaction vessel during the run. After a convenient time $(t)$ the reaction mixture was analysed for ethane and nitric oxide. Now

$$
\left[\mathrm{C}_{2} \mathrm{H}_{6}\right]=t k_{2}\left[\mathrm{CH}_{3}\right]^{2}
$$

and

$$
\text { total NO consumed }=t k_{6}\left[\mathrm{CH}_{3}\right][\mathrm{NO}]
$$

The amount of nitric oxide found on analysis may be regarded as the steady. state concentration, for some 200 times this amount is added during the course of the run. From these equations and the accepted value of $k_{2}, k_{i}$ is found to be $2 \times 10^{11}$ mole $^{-1}$ c.c. sec. ${ }^{-1}$ at $28^{\circ} \mathrm{C}$ over the whole range of pressure.

The second method, first used by Forsyth, ${ }^{24}$ has been greatly improved by Durham and Steacie, ${ }^{25}$ who produced the methyl radicals by passing 8 stream of di-tert.-butyl peroxide through a furnace and down a tube into which nitric oxide could be injected. The concentration of methyl radicals at any point in the tube could be measured by following the rate of removal of a radioactive tellurium mirror. In this way the effect of the pressure of nitric oxide on the radical concentration along the reaction tube could be found, and hence the rate constant for the reaction of the radicals with nitric oxide. The value of $k_{6}=3.3 \times 10^{10}$ mole $^{-1}$ c.c. sec. ${ }^{-1}$ at $25^{\circ} \mathrm{c}$ is much lower than the high-pressure value, but as there is no reason to suspect the experimental accuracy of either determination, this difference must be ascribed to the pressure dependence of the rate constant. Unfortunately, insufficient is known about the products of reaction (6) for the phenomenon to be treated theoretically.

A mass-spectrometer can also be used for methyl-radical detection, ${ }^{2:}$

${ }^{23}$ Marcus and Steacie, Z. Naturforsch., 1949, 4, a, 332 ; Miller and Steacie, J. Chem. Physics, 1951, 19, 73.

24 Forsyth, Trans. Faraday Soc., 1941, 37, 312.

${ }^{25} \mathrm{~J}$. Chem. Physics, 1952, 20, 582. 
and in this way the rate constant was found to be $10^{11}$ mole $^{-1}$ c.c. sec. ${ }^{-1}$ at $950^{\circ} \mathrm{c}$, with rather a large experimental error; however, this figure may be taken as good evidence that the activation energy of the reaction is very small indeed.

It is generally believed that a large number of combinations of methyl radicals with other radicals occur, but only in a few cases have the products been identified, because of the analytical difficulties involved in the separation of small quantities of $\mathrm{R} \cdot \mathrm{CH}_{3}$ from large quantities of $\mathrm{RH}$, where $\mathrm{R}$ is a large radical. However, the products of the combination of methyl with acetyl, acetonyl, $n$-propyl, and isopropyl have all been found, though none of the rate constants has been measured. Ivin and Steacie ${ }^{8}$ have found that ethyl radicals combine on about one collision in two to give butane, so it is very probable that the reactions of methyl with ethyl and of methyl with propyl have similar collision yields. These combinations of methyl with large radicals may be regarded as independent of pressure under all accessible conditions. The combination of methyl with a benzyl radical, reaction (7), has not been detected but there is no reason to suppose that it

$$
\mathrm{CH}_{3}+\mathrm{C}_{6} \mathrm{H}_{5} \cdot \mathrm{CH}_{2} \rightarrow \mathrm{C}_{6} \mathrm{H}_{5} \cdot \mathrm{C}_{2} \mathrm{H}_{5}
$$

does not occur. The activation energy for the decomposition of ethylbenzene as measured by Szware ${ }^{26}$ may be combined with the $\mathrm{C}-\mathrm{H}$ bond strengths in toluene and methane and the heats of formation of toluene, methane, and ethylbenzene to give the activation energy of reaction (7) as $1 \pm 4 \mathrm{kcal}$. Furthermore, if reasonable assumptions are made about the properties of the methyl and benzyl radicals, the entropy change in the reaction may be calculated and hence the equilibrium between methyl and benzyl radicals and ethylbenzene. On this basis the rate constant of reaction (7) at $182^{\circ} \mathrm{c}$ has been found to be $10^{12}$ mole $^{-1}$ c.c. sec. ${ }^{-1}, E_{7}$ being assumed equal to $0 \mathrm{kcal}$. This result is probably not very accurate.

It may be supposed that under suitable conditions methyl radicals would combine with atoms, but there is little direct evidence for such reactions. The rate constants will certainly be very dependent upon the total pressure of gas in the system, and it is likely that the " high-pressure " rate will only be approached at several atmospheres, which is not a usual pressure at which to study free radicals. Under the normal conditions of flow pyrolysis, the rates of the reverse reactions, the decompositions of methyl bromide ${ }^{27}$ and methyl iodide, ${ }^{28}$ are markedly dependent upon the overall pressure.

The quantitative data on the combination of methyl radicals are summarised in Table 2, where $k$ and $A$ are in mole $^{-1}$ c.c. sec. ${ }^{-1}$. There is very little quantitative information on the rates of combination of other small radicals, though in a fair number of cases the products have been detected. The satisfactory interpretation of a very large amount of information on pyrolysis reactions such as have been described by Szwarc ${ }^{29}$ has been based

${ }^{26} \mathrm{~J}$. Chem. Priysics, 1949, 17, 431.

27 Sehon and Szwarc, Proc. Roy. Soc., 1951, A, 209, 110.

${ }^{28}$ Horrex and Lapage, Discuss. Faraday Soc., 1951, 10, 233.

${ }^{29}$ Chem. Reviews, 1950, 47, 75. 
upon the supposition that small radicals always combine with zero activation energy. On these grounds, rather than as a result of direct experiments, we must conclude that simple radicals combine with very low activation energies. At the other end of the scale of molecular size it is known ${ }^{15}$ that growing polymer radicals combine with low activation energies but that the rate constants are usually lower than for small radicals, being of the order of $10^{10}$ mole $^{-1}$ c.c. sec. ${ }^{-1}$.

TABLE 2. Combination reactions of methyl radicals

\begin{tabular}{|c|c|c|c|}
\hline Reaction & $k$ at $182^{\circ} \mathrm{c}$ & A & $E$, kcal. \\
\hline 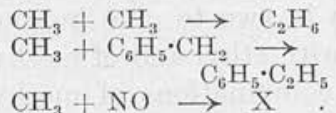 & $\begin{array}{c}4.5 \times 10^{13} \\
\left(10^{12}\right)\end{array}$ & $\begin{array}{c}4.5 \times 10^{13} \\
\left(10^{12}\right)\end{array}$ & $\begin{array}{c}0 \pm 0 \cdot 7 \\
1 \pm 4 \\
4 \cdot 5(\max )\end{array}$ \\
\hline
\end{tabular}

Metathetical Reactions of Methyl Radicals.-As yet only the class of metathetical methyl radical reactions represented by the general equation $\mathrm{CH}_{3}+\mathrm{RH} \rightarrow \mathrm{CH}_{4}+\mathrm{R}$ has been comprehensively studied in a quanti tative manner. There are two good reasons for this, the first being that the important products of these reactions from the point of view of a kinetic study, viz., methane and ethane, are fairly easily separated from the rest of the reaction mixture by distillation. Other difficulties apart, an investi. gation of, for example, the reaction $\mathrm{CH}_{3}+\mathrm{C}_{5} \mathrm{~F}_{12} \rightarrow \mathrm{CH}_{3} \mathrm{~F}+\mathrm{C}_{5} \mathrm{~F}_{11}$ would be complicated because $\mathrm{CH}_{3} \mathrm{~F}$ and $\mathrm{C}_{2} \mathrm{H}_{6}$ have boiling points which are ver! close together, so a mass-spectrometer is needed for analysis. The second reason is that our knowledge of the dissociation energies of $\mathrm{C}-\mathrm{H}$ bonds is more extensive ${ }^{29}$ than of those between any other two atoms. It has long been thought that there should be a relation between the strength of a bond and the ease with which the atom attached by the bond can be removed by free-radical attack. Much research has been carried out with this possibility in mind.

The first extensive work on reactions of the type mentioned was that of H. S. Taylor with Cunningham ${ }^{30}$ and with Smith. ${ }^{31}$ They investigated the photolysis of dimethylmercury in the presence of hydrogen, deuterium, ethane, $n$-butane, 2 -methylpropane, and neopentane and several unsaturated and aromatic compounds. It has been shown ${ }^{32}$ that in the majority of $\mathrm{r}$ cases not very much reliance can be placed upon the quantitative aspects ${ }^{2}$ of the work, but the general pattern of the results which they obtained was undoubtedly correct. They found that the activation energy for the reaction of methyl with an alkane containing only primary hydrogen atoms ${ }^{e}$ was greater than that for reaction with one containing secondary hydrogen ${ }^{r}$ atoms which in turn was greater than that for one containing a tertiar!

${ }^{30} \mathrm{~J}$. Chem. Physics, 1938, 6, 359.

${ }^{31}$ Ibid., 1939, 7, 390 ; 1940, 8, 543.

32 Steacie, Darwent, and Trost, Discuss. Faraday Soc., 1947, 2, 79; Trotman. Dickenson and Steacie, J. Phys. Colloid Chem., 1951, 55, 908. 
hydrogen. In addition it was found that the reaction with toluene and propene was rapid, while that with benzene was slow. All these points have been verified by later investigations.

Shortly afterwards, Allen ${ }^{33}$ used the photolysis of acetone to investigate the reactions of methyl with propane. The investigation was cursory and the results obtained are not of quantitative significance.

In the last few years a large number of methyl-radical reactions of this type have been investigated, chiefly at the University of Rochester, N.Y., and in the laboratories of the National Research Council of Canada in Ottawa. The results were obtained by the methods outlined above. All of the results which are suitable for tabular presentation are included in Tables 3 and 4 . Before considering their significance, we will try to assess their accuracy.

\section{TABLE 3. Reactions of methyl radicals with hydrogen}

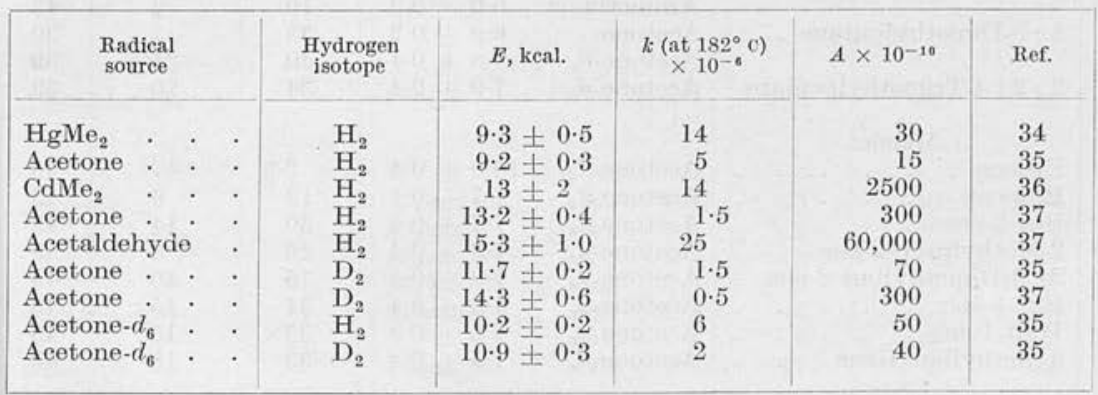

The most remarkable feature of the figures is the excellence of the agreement obtained by different workers using different sources of methyl radicals and usually different types of radiation when the same substance is photolysed. This gives us great confidence that the results are accurate and that no complications due to "hot" radicals arise. The rate constant $k$ at $182^{\circ} \mathrm{C}$ is the most directly determinable quantity; this temperature is chosen as being near the middle of the temperature range of most investigations. Different workers usually agree on the magnitude of this rate within a factor of $1 \cdot 5$. In a series of experiments values can usually be reproduced to within $\pm 10 \%$. The probable errors in the activation energies are given in the table; these errors are derived solely from the deviations of the points from the Arrhenius relationship; no weight is given to uncertainties in the assumed mechanism. The values for the activation energy are based on $E_{2}=0$ kcal., and the values of $A_{1}$ on $A_{2}=4.5 \times 10^{13}$ moles $^{-1}$ c.c. sec. ${ }^{-1}$. It should be noted that errors in the differences of

${ }^{33}$ J. Amer. Chem. Soc., 1941, 63, 708.

${ }^{34}$ Phibbs and Darwent, Trans. Faraday Soc., 1949, 45, 541.

${ }^{35}$ Majury and Steacie, Discuss. Faraday Soc., 1953, 14.

${ }^{36}$ Anderson and H. A. Taylor, J. Phys. Chem., 1952, 56, 498.

37 Davison and Burton, J. Amer. Chem. Soc., 1952, 74, 2307. 
TABLE 4. Metathetical reactions of methyl radicals*

\begin{tabular}{|c|c|c|c|c|c|c|c|c|c|}
\hline \multicolumn{5}{|c|}{ Reactant } & $\begin{array}{l}\text { Radical } \\
\text { source } \dagger\end{array}$ & $E$, kcal. & $k \times 10^{-6}$ & $A \times 10^{-10}$ & Ref \\
\hline \multicolumn{5}{|c|}{ Alkanes } & & & & & \\
\hline $\begin{array}{l}\text { Methane } \\
\text { Ethane. }\end{array}$ & & . & . & & Acetone- $d_{6}$ & $12 \cdot 8$ & $0 \cdot 17$ & (Assumed) & 00 \\
\hline $\begin{array}{l}\text { Ethane . } \\
\text { neoPentane. }\end{array}$ & · & . & - & & Acetone- $d_{6}$ & $10 \cdot 4 \pm 0 \cdot 4$ & $\begin{array}{l}2 \cdot 0 \\
3 \cdot 3\end{array}$ & 19 & 39 \\
\hline & & & & & $\begin{array}{l}\text { Acetone and } \\
\text { acetone }-d_{6}\end{array}$ & $10 \cdot 0 \pm 0.3$ & $3 \cdot 3$ & 20 & \\
\hline \multicolumn{5}{|c|}{$\begin{array}{l}2: 2: 3: 3 \text {-Tetramethyl- } \\
\text { butane }\end{array}$} & Acetone $-d_{6}$ & $9 \cdot 5 \pm 0 \cdot 4$ & $5 \cdot 2$ & 17 & \\
\hline$n$-Butane . & & . & . & . & Acetone & $8 \cdot 3 \pm 0 \cdot 2$ & 11 & 11 & \\
\hline & & & & & $\begin{array}{l}\mathrm{HgMe}_{2} \\
\mathrm{HgMe}\end{array}$ & $8 \cdot 2 \pm 0 \cdot 5$ & 22 & 18 & \\
\hline & & & & & $\begin{array}{l}\mathrm{HgMe}_{2} \\
\mathrm{HgMe}_{2}\end{array}$ & $9 \cdot 5 \pm 0.5$ & $\begin{array}{l}10 \\
13\end{array}$ & 33 & \\
\hline n-Pentane . & & . & . & . & Acetone & $8 \cdot 1 \pm 0 \cdot 2$ & 14 & $\overline{10}$ & 39 \\
\hline n-Hexane . & & . & . & & Acetone & $8 \cdot 1 \pm 0.2$ & 17 & 12 & \\
\hline 2-Methylprope & & . & . & & Acetone & $7 \cdot 6 \pm 0 \cdot 2$ & 22 & 10 & 53 \\
\hline & & & & & $\mathrm{HgMe}_{2}$ & $7 \cdot 3 \pm 0 \cdot 3$ & 16 & 6 & 41 \\
\hline 2: 3-Dimethy & but & ane & . & . & $\begin{array}{l}\text { Azomethane } \\
\text { Acetone }\end{array}$ & $\begin{array}{l}6 \cdot 6 \pm 0 \cdot 3 \\
6 \cdot 9 \pm 0 \cdot 2\end{array}$ & $\begin{array}{l}10 \\
35\end{array}$ & $\frac{2}{7}$ & 19. \\
\hline & & & & & Acetone- $d_{6}$ & $7 \cdot 8 \pm 0.4$ & 40 & 21 & \\
\hline $2: 3: 4$-Trime & hyl & pen & tane & & Acetone- $d_{6}^{0}$ & $7 \cdot 9 \pm 0 \cdot 4$ & 34 & 20 & \\
\hline Alke & hes & & & & & & & & \\
\hline Ethene . . & & . & . & & Acetone- $d_{6}$ & $10 \cdot 0 \pm 0.4$ & $2 \cdot 9$ & 17 & \\
\hline Propene & & . & . & . & Acetone- $d_{6}$ & $7 \cdot 7 \pm 0.4$ & 12 & 6 & \\
\hline But-2-ene . & & . & · & . & Acetone- $d_{6}$ & $7 \cdot 7 \pm 0 \cdot 4$ & 30 & 14 & \\
\hline 2-Methylprop- & -er & & $\dot{0}$ & · & Acetone- $d_{6}$ & $7 \cdot 3 \pm 0 \cdot 4$ & 26 & 8 & \\
\hline 2: 3-Dimethy & but. & -2 -el & & · & Acetone- $d_{6}$ & $7 \cdot 8 \pm 0.4$ & 76 & 40 & \\
\hline But-1-ene . & . & . & . & · & Acetone- $d_{6}$ & $7 \cdot 6 \pm 0.4$ & 34 & 15 & \\
\hline $\begin{array}{l}\text { Pent-1-ene : } \\
\text { 3-Methylbut-1 }\end{array}$ & ene & . & $\dot{r}$ & $\dot{.}$ & $\begin{array}{l}\text { Acetone- } d_{6} \\
\text { Acetone- } d_{6}\end{array}$ & $\begin{array}{l}7 \cdot 6 \pm 0 \cdot 4 \\
7 \cdot 4 \pm 0 \cdot 4\end{array}$ & $\begin{array}{l}35 \\
53\end{array}$ & $\begin{array}{l}15 \\
18\end{array}$ & \\
\hline Alky & nes & & & & & & & & \\
\hline But-2-yne . & 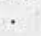 & . & & & Acetone- $d_{6}$ & $8 \cdot 6 \pm 0 \cdot 4$ & 33 & 42 & \\
\hline But-1-yne. & 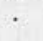 & . & . & . & Acetone- $d_{6}$ & $9 \cdot 1 \pm 0 \cdot 4$ & 34 & 76 & \\
\hline Cycl & nes & & & & & & & & \\
\hline cycloPropane & & 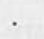 & . & . & Acetone- $d_{6}$ & $10.3 \pm 0.4$ & $1 \cdot 1$ & 9 & \\
\hline & & & & & $\mathrm{HgMe}_{2}$ & $10 \cdot 2 \pm 1 \cdot 0$ & 1.5 & 12 & \\
\hline cycloButane & . & . & . & . & Acetone- $d_{6}$ & $9 \cdot 3 \pm 0 \cdot 4$ & 11 & 28 & \\
\hline cycloPentane & . & . & . & . & $\begin{array}{l}\text { Acetone and } \\
\text { acetone- } d_{6}\end{array}$ & $8 \cdot 3 \pm 0 \cdot 2$ & 24 & 24 & \\
\hline cycloHexane & . & . & & . & Acetone & $8 \cdot 3 \pm 0 \cdot 2$ & 22 & 22 & \\
\hline Aromatic hy & dro & a & ons & & & & & & \\
\hline Benzene & . & . & " & & Acetone- $d_{6}$ & $9 \cdot 2 \pm 0 \cdot 4$ & $1 \cdot 0$ & $2 \cdot 5$ & \\
\hline Toluene. & . & . & . & . & Acetone- $d_{6}$ & $8 \cdot 3 \pm 0 \cdot 3$ & 14 & 14 & \\
\hline & & & & & $\begin{array}{l}\mathrm{HgMe}_{2} \\
\text { DTBP }\end{array}$ & $\begin{array}{r}7 \pm 2 \\
11 \pm 2\end{array}$ & 5 & 1 & \\
\hline Aleo & ols & & & & & & & & \\
\hline Methanol . & 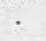 & . & . & . & Acetone & $8 \cdot 2 \pm 0.2$ & 6 & $4 \cdot 8$ & \\
\hline 1. & . & & & & $\mathrm{HgMe}_{2}$ & $8 \cdot 2 \pm 0.5$ & 5 & $4 \cdot 4$ & \\
\hline $\begin{array}{l}\text { Ethanol } \\
\text { Propan-2-ol }\end{array}$ & & . & . & . & Acetone- $d_{6}$ & $8.7 \pm 0.4$ & 20 & 29 & \\
\hline Propan-2-ol & & . & . & . & Acetone- $d_{6}$ & $7 \cdot 3 \pm 0 \cdot 4$ & 31 & 10 & \\
\hline
\end{tabular}

* Values of $k$ refer to $182^{\circ} \mathrm{c}$, and both $k$ and $A$ are expressed in terms of moles c.c. sec. $^{-1}$.

+ DTBP $=$ Di-tert.-butyl peroxide.

¥ Where this mark is appended to the reference it indicates that the quantit were not calculated in this manner by the original authors. 
TABLE 4. Metathetical reactions of methyl radicals* (continued)

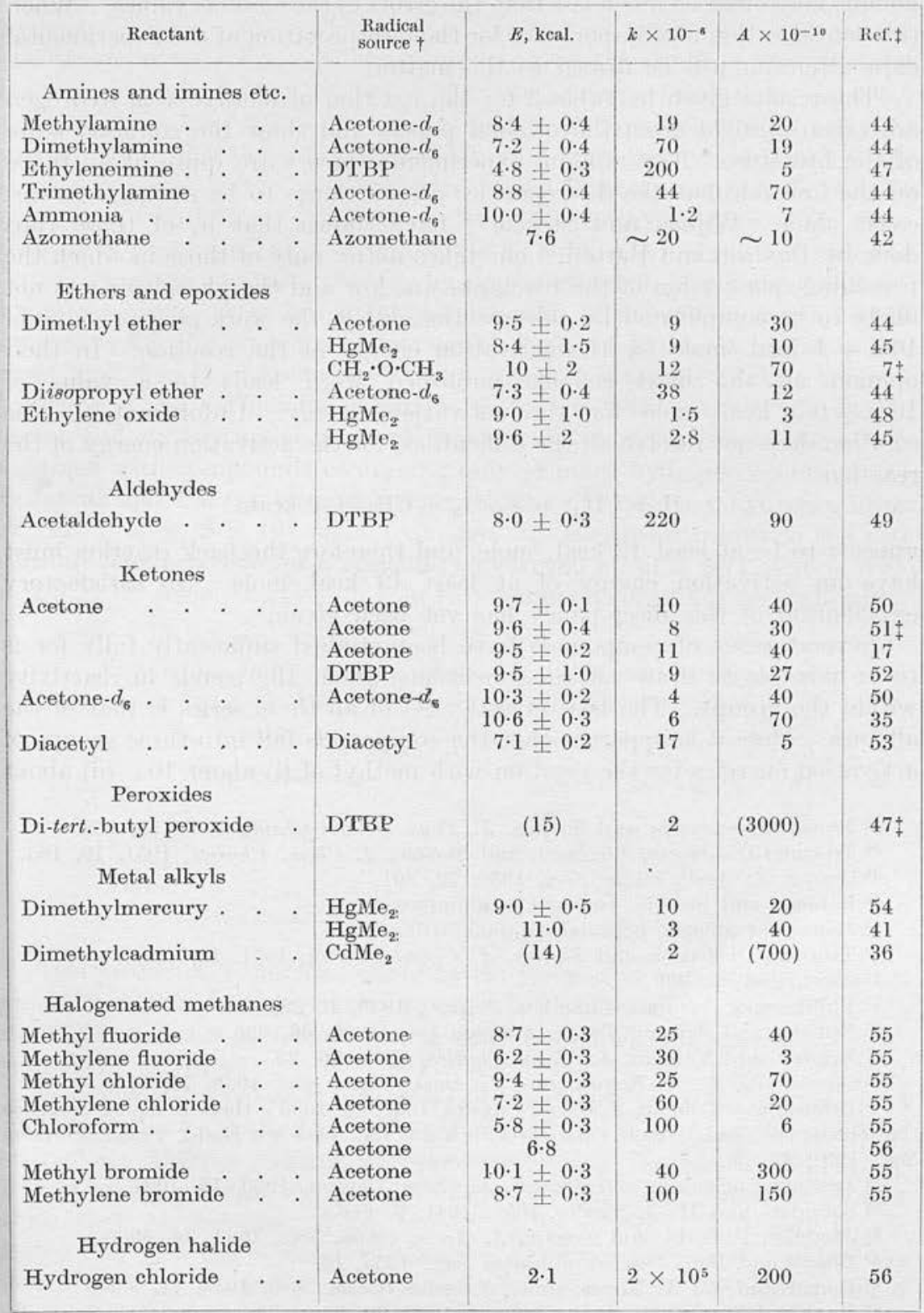

* Values of $k$ refer to $182^{\circ} \mathrm{c}$, and both $k$ and $A$ are expressed in terms of moles $^{-1}$ c.c. sec. $^{-1}$

+ DTBP $=$ Di-tert - butyl peroxide.

‡ Where this mark is appended to the reference it indicates that the quantities were not calculated in this manner by the original authors. 
activation energies derived from a series of experiments on different com pounds may often be much less than the errors in the absolute values. When this consideration is of importance for the interpretation of the experimental data attention will be drawn to the matter.

The results given in Table 3 for the reaction of methyl with hydrogen are taken straight from the original papers and show the confused state of the literature.' The random experimental errors are quite likely to be on the low side but the discrepancies are too large to be assigned to thi cause alone. Wijnen and Steacie ${ }^{57}$ have shown that if, of those rur done by Davison and Burton, ${ }^{37}$ one takes notice only of those in which the percentage conversion of the reactants was low and the photolysis was no likely to be complicated by side reactions, then the work gives a value of $10 \cdot 5 \pm 1 \mathrm{kcal}$./mole for the activation energy of the reaction. In the opinion all the most reliable published work leads to a value $10 \cdot 0 \pm 0.5 \mathrm{kcal} . /$ mole for the activation energy. Unfortunately, thi solution does not resolve all the difficulties, for the activation energy of th: reaction

$$
\mathrm{H}+\mathrm{CH}_{4} \rightarrow \mathrm{H}_{2}+\mathrm{CH}_{3}+1 \text { keal. }
$$

appears to be at least $12 \mathrm{kcal}$./mole, and therefore the back reaction mus have an activation energy of at least $13 \mathrm{kcal} . / \mathrm{mole}$. No satisfactor explanation of this discrepancy has yet been given.

Several series of compounds have been studied sufficiently fully for to be possible to draw certain conclusions about the trends in reactivit within the groups. The best investigated of all these series is that of th alkanes. Here it is apparent that the compounds fall into three groups s activation energies for the reaction with methyl of (i) about 10 ; (ii) abor

38 Trotman-Dickenson and Steacie, J. Phys. Colloid Chem., 1951, 55, 908.

${ }^{39}$ Trotman-Dickenson, Birchard, and Steacie, J. Chem. Physics, 1951, 19, 163.

${ }^{40}$ Gomer, J. Amer. Chem. Soc., 1950, 72, 201.

${ }^{41}$ Rebbert and Steacie, personal communication.

${ }^{42}$ Jones and Steacie, personal communication.

43 Trotman-Dickenson and Steacie, J. Chem. Physics, 1951, 19, 169.

44 Idem, ibid., p. 329.

45 Phibbs and Darwent, Canadian J. Res., 1950, B, 28, 395.

46 Roberts and Szwarc, Trans. Faraday Soc., 1950, 46, 625.

${ }^{47}$ Brinton and Volman, J. Chem. Physics, 1952, 20, 25.

${ }^{48}$ Gomer and W. A. Noyes, jun., J. Amer. Chem. Soc., 1949, 71, 3390.

49 Brinton and Volman, J. Chem. Physics, 1952, 20, 1053; there is strong evident that this is the most reliable value, but for a different view see Dodd, Trans. Farad Soc., 1951, 47, 56 .

50 Trotman-Dickenson and Steacie, J. Chem. Physics, 1950, 18, 1097.

${ }^{51}$ Saunders and H. A. Taylor, ibid., 1941, 9, 616.

52 Jacquiss, Roberts, and Szware, J. Amer. Chem. Soc., 1952, 74, 6005.

${ }_{53}$ Blacet and Bell, Discuss. Faraday Soc., 1953, 14.

${ }^{54}$ Gomer and W. A. Noyes, junr., J. Amer. Chem. Soc., 1949, 71, 3390.

55 Raal and Steacie, J. Chem. Physics, 1952, 20, 578. The error in these resulal is in some cases probably greater than is indicated because complicating side reactio ar may have occurred.

${ }_{56}$ Cvetanovic̀ and Steacie, Canad. J. Chem., 1953, 31, 158.

57 Discuss. Faraday Soc., 1953, 14. 
$8 \cdot 2$, and (iii) less than $8 \mathrm{kcal} . / \mathrm{mole}$, and that these contain, respectively, (i) only primary, (ii) primary and secondary, (iii) primary and tertiary hydrogen atoms. Furthermore, since the $A$ factors do not vary widely, this trend in activation energies is reflected by the trend in the rate constants. Now $2: 2: 3: 3$-tetramethylbutane contains three times as many primary hydrogen atoms as ethane, and 2:2-dimethylpropane twice as many. Since the three compounds all react with methyl with nearly the same activation energy, the hydrogen atoms in these compounds may be considered equivalent. Similarly, 2:3:4-trimethylpentane has three reactive tertiary hydrogen atoms, while $2: 3$-dimethylbutane has two and 2-methylpropane has one. We can by inspection decide how many " active " hydrogen atoms there are in an alkane and, after making a very small correction for the presence of less active types of hydrogen atoms in the compound, find by division the reaction rate characteristic of the "active " hydrogen atom. Thus for $n$-butane there are four " active" hydrogen atoms and six less active primary atoms. By consideration of the results obtained with compounds containing only primary hydrogen atoms, it can be found that the rate constant characteristic of a primary hydrogen atom at $182^{\circ} \mathrm{c}$ is ca. $3 \times 10^{6} \mathrm{~mole}^{-1}$ c.c. sec. ${ }^{-1}$. Hence for $n$-butane the rate constant characteristic of a secondary hydrogen atom is $\frac{1}{4}[11-(6 \times 0.3)]$ $=2.3 \times 10^{6}$ mole $^{-1}$ c.c. sec. ${ }^{-1}$. In this manner Table 5 has been obtained.

\section{TABLE 5. Rate constants characteristic of various types of hydrogen atoms in alkanes}

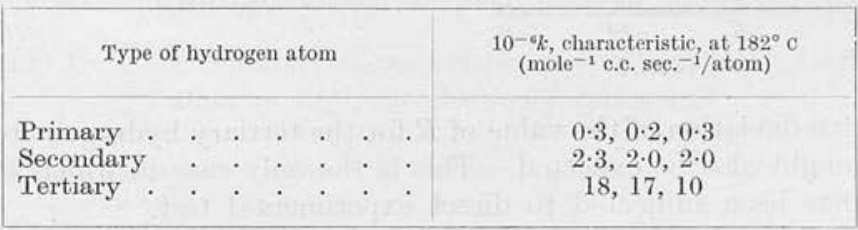

This procedure is justified solely by the interesting nature of the results, which show that it is reasonable to regard the different types of hydrogen atom in a molecule as if they were present in separate molecules in a multicomponent mixture.

In two recent reviews ${ }^{58}$ reference has been made to a relation suggested den by Polanyi between the heat of one reaction in a series and its energy of activation. Polanyi stated that, where there is no resonance stabilisation in the transition complex or a constant amount of stabilisation throughout a series, then for reactions of the type $\mathrm{X}+\mathrm{YZ} \rightarrow \mathrm{XY}+\mathrm{Z}$ it may be expected that $E=\alpha H+$ const., where $E$ is the activation energy and $H$ the heat of the reaction, and $\alpha$ has a value between 0 and 1 . The results quoted above indicate that all primary $\mathrm{C}-\mathrm{H}$ bonds and all secondary $\mathrm{C}-\mathrm{H}$ bonds actiare very similar ; if this uniformity is accepted, where the evidence is less

58 Warhurst, Quart. Reviews, 1951, 5, 44 ; Bolland, ibid., 1950, 4, 292. 
good, for all tertiary C-H bonds we may generalise Stevenson's electron impact data ${ }^{59}$ as follows :

\begin{tabular}{l}
$\mathrm{D}\left(\mathrm{CH}_{3}-\mathrm{H}\right) . \quad . \quad . \quad$ \\
$\mathrm{D}(\mathrm{C}-\mathrm{H})$, primary . \\
\hline
\end{tabular}

From these figures, heats of reaction can be obtained for the reaction methyl with each type of hydrogen atom; these values for the heats at plotted against the activation energies in Fig. 1. The value of $E$ fo $\mathrm{CH}_{3}+\mathrm{CH}_{4} \rightarrow \mathrm{CH}_{4}+\mathrm{CH}_{3}$ was not determined directly, as the rate he effectively only been measured at one temperature. The straight lin drawn in Fig. 1 is for $\alpha=0 \cdot 5$, which would be expected from consideration of symmetry based upon the similarity of the bonds broken and formed

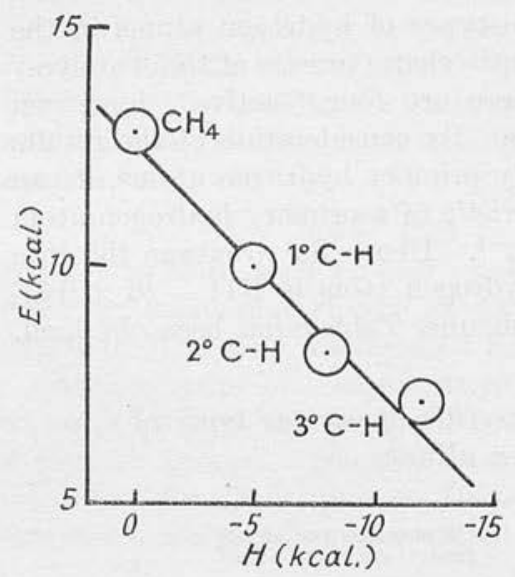

FIG. 1

The relation between activation energy and he of reaction for the reactions of methyl radios with alkanes: $E=12 \cdot 5+0.5 H$.

the positive deviation of the value of $E$ for the tertiary hydrogen atom fro the line might also be expected. This is the only case in which Polany relation has been subjected to direct experimental test.

The striking fact about the results obtained from the study of $t$ alkenes is that, apart from ethene, they all react with methyl with the sar activation energy within the rather small limits of experimental error ( $t$ relative values of the activation energies are here good to $0.2 \mathrm{kcal} . / \mathrm{mol}$ It may be seen that, where possible, it is always the $\alpha$-methylenic hydrog atom which reacts. Thus there are three "active" hydrogen atoms propene, twelve in 2:3-dimethylbut-2-ene, two in but-1-ene and one 3 -methylbut-1-ene. In Table 6 are given the rate constants per act hydrogen atom for primary, secondary, and tertiary $\alpha$-methylenic hydrog atoms and, assuming a constant value of $E$ of $7.6 \mathrm{kcal}$., the values of divided by the number of active hydrogen atoms. This table shows, fir that each type of hydroger atom has a particular rate constant for react ${ }^{0}$ with methyl in the alkene as well as in the alkane series. Secondly, $t^{\mathrm{s}}$ the changes in reactivity are due to changes in the $A$ factor and not

59 Discuss. Faraday Soc., 1951, 10, 35 ; for a different view ef. Leigh and Szwi J. Chem. Physics, 1952, 20, 407. 
activation energy, as was the case with the alkanes. No explanation for this most interesting fact has yet been advanced.

No other series of compounds has been investigated thoroughly apart from the cyclanes, where the variations are of a different kind from those previously considered. It is noteworthy that the variations in rate found among the cyclanes had been previously predicted by Brown ${ }^{60}$ by consideration of the strains involved in the molecule and in the transition state. It is possible, however, that other attractive explanations could be found.

TABLE 6. Rate constants at $182^{\circ} \mathrm{C}$ and frequency factors per hyảrogen atom characteristic of different types of hydrogen atoms in alkenes (both in mole ${ }^{-1}$ c.c. sec. ${ }^{-1}$ )

\begin{tabular}{|c|c|c|}
\hline $\begin{array}{c}\text { Type of } \\
\text { hydrogen atom }\end{array}$ & $10^{-} \% / \mathrm{H}$ & $10^{-10} \mathrm{~A} / \mathrm{H}$ \\
\hline $\begin{array}{l}\text { Primary } \\
\text { Secondary : } \\
\text { Tertiary }\end{array}$ & $\begin{array}{c}4,5,4,6 \\
17,18 \\
53\end{array}$ & $\begin{array}{r}2 \\
7 \\
23\end{array}$ \\
\hline
\end{tabular}

From the results in Table 4 as a whole, three facts stand out. First, that the spread of activation energies is small, only $8 \mathrm{kcal} . /$ mole, whereas the spread of $\mathrm{C}-\mathrm{H}$ bond strengths is between the weakest bond in toluene and that in methane. Secondly, the general rule that primary hydrogen atoms react less readily than secondary, and these in turn less readily than tertiary, holds throughout, as shown by the values of the rate constant/number of "active" hydrogen atoms for each class of compound in Table 7.

\section{TABLE 7. Rate constants characteristic of various types of hydrogen atom in different classes of compound}

\begin{tabular}{|c|c|c|c|c|c|}
\hline Class of compound : & Alkane & Alkene & Alkyne & Ether & Alcohol \\
\hline $\begin{array}{c}\text { Type of } \\
\text { hydrogen atom }\end{array}$ & \multicolumn{5}{|c|}{$10^{-6} \mathrm{k} / \mathrm{H}$ at $182^{\circ} \mathrm{c}\left(\mathrm{mole}^{-1}\right.$ c.c. sec. ${ }^{-1} /$ atom $)$} \\
\hline $\begin{array}{l}\text { Primary . } \\
\text { Secondary } \\
\text { Tertiary }\end{array}$ & $\begin{array}{l}0 \cdot 3 \\
2 \cdot 1 \\
15\end{array}$ & $\begin{array}{r}5 \\
17 \\
53\end{array}$ & $\begin{array}{r}7 \\
38 \\
\end{array}$ & $\frac{1 \cdot 5}{19}$ & $\begin{array}{r}2 \\
10 \\
31\end{array}$ \\
\hline
\end{tabular}

Thirdly, although there is a considerable variation in the $A$ factors, yet they all, except for two doubtful cases, lie in the range $10^{10 \cdot 4}-10^{12 \cdot 5}$ as is shown by Fig. 2. This means that the steric factors lie between $10^{-2}$ and $10^{-4}$. The figures show that the concept of reactivity as applied to free-radical reactions is very vague when studies have only been made at one temperature. Whenever possible, activation energies and $A$ factors should be determined, and if this cannot be accomplished, great caution should be exereised in interpreting the results.

The rates of three reactions of methyl radicals relative to the rate of ${ }^{60} \mathrm{~J}$. Amer. Chem. Soc., 1951, 73, 212. 
reaction (4) (p. 204) have been studied. The method (described in the section on methods) was first used by Anderson and Kistiakowsky ${ }^{61}$ and later by Williams and Ogg. ${ }^{62}$ The later work was considerably more

$$
\mathrm{CH}_{3}+\mathrm{HX} \rightarrow \mathrm{CH}_{4}+\mathrm{X}
$$

extensive and involved the determination of the relative rates of reactions

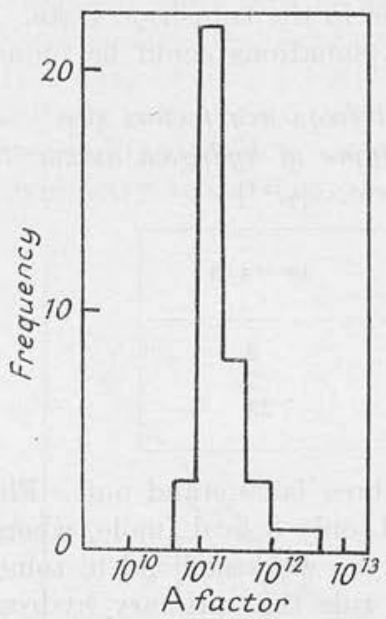

FIG. 2

The frequency of occurrence of $A$ factors for methyl-radical reactions.

(4) and (8), where $\mathrm{X}$ is $\mathrm{Cl}, \mathrm{Br}$ or $\mathrm{I}$, over a range of temperatures. Thus $E_{8}-E_{4}$ and $A_{8} / A_{4}$ were found; the values are given below:

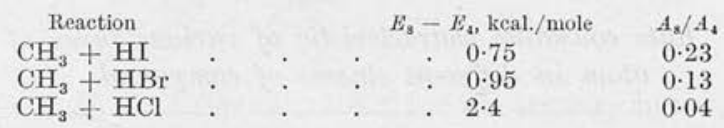

Williams and Ogg considered that "hot" methyl radicals were involved in the reaction with hydrogen chloride, so the meaning of the figures : doubtful. For this reason the results cannot be directly compared witl those obtained from the photolysis of acetone in the presence of hydroger chloride. ${ }^{56}$ The experiments are very difficult to conduct and to interpret. so little reliance should be placed upon the precise numerical values obtained The supposition that reaction (4) takes place on every collision is reasonable but not proven.

Large numbers of other gas-phase reactions of methyl radicals involvin hydrogen abstraction have been postulated but not quantitatively investi gated. Steacie ${ }^{1}$ lists many of these.

No metathetical reactions of methyl in the gas phase have been quanti tatively investigated in which atoms other than hydrogen are abstracted though these certainly occur. Of particular importance are the reaction with the halogens which occur so rapidly that they cannot be studied b? present techniques. 
Two reactions have been found in which a methyl radical extracts a radical from a molecule. They are

$$
\mathrm{CH}_{3}+\mathrm{CH}_{3} \cdot \mathrm{Hg} \cdot \mathrm{CH}_{3} \rightarrow \mathrm{C}_{2} \mathrm{H}_{6}+\mathrm{Hg}+\mathrm{CH}_{3}
$$

and $\mathrm{CH}_{3}+\mathrm{CH}_{3} \cdot \mathrm{CO} \cdot \mathrm{CO} \cdot \mathrm{CH}_{3} \longrightarrow \mathrm{CH}_{3} \cdot \mathrm{CO} \cdot \mathrm{CH}_{3}+\mathrm{CO} \cdot \mathrm{CH}_{3}$

The rate constant of the first is approximately represented by the equation $k=10^{7} \mathrm{e}^{-1000 / \boldsymbol{R} T}$ and of the second by $k=4 \cdot 8 \times 10^{10} \mathrm{e}^{-5600 / \boldsymbol{R} T}$ mole $\mathrm{e}^{-1}$ c.c. sec. $^{-1}$. Reactions of this type seem to be very rare and until more are found it is not possible to state with what sort of molecules they are likely to occur.

No methyl-radical reactions have been investigated in solution sufficiently fully to determine rate constants. Indeed, apart from the greater analytical difficulties, it is to be expected that in many cases complications may be caused by the fact that two methyl radicals released as a pair from a molecule by photolysis (as in the case of acetone and dimethylmercury) may be caged in and have a greater probability of combining than would be expected from the overall concentration of methyls and the rate constants in the gas phase, so that the rate of formation of ethane is not a reliable guide to radical concentration. Edwards and Mayo ${ }^{13}$ have investigated the rates

$$
\mathrm{CH}_{3}+\mathrm{CCl}_{4} \rightarrow \mathrm{CH}_{3} \mathrm{Cl}+\mathrm{CCl}_{3}
$$

of a number of reactions of type (1) relative to the rate of reaction (9) at $100^{\circ}$ c. The radicals were produced by pyrolysis of acetyl peroxide, and the reactions were followed by the relative rates of production of methane and methyl chloride. The rate constants $k_{1} / k_{9}$ in solution are compared in Table 8 with the rate constants, $k_{1}$, determined by Trotman-Dickenson and Steacie ${ }^{44}$ for the five compounds common to the two investigations (the $k_{1}$ value for oct-1-ene was assumed equal to $k_{\text {pent-1-ene }}+k_{n \text {-pentane }}-$ $\left.k_{\text {ethane }}\right)$. The table shows a remarkable parallelism between the two sets of data: cyclohexane apart, the constancy of the last column is much

TABLE 8. Relative rate constants for the reactions of methyl radicals in the gas phase and in solution

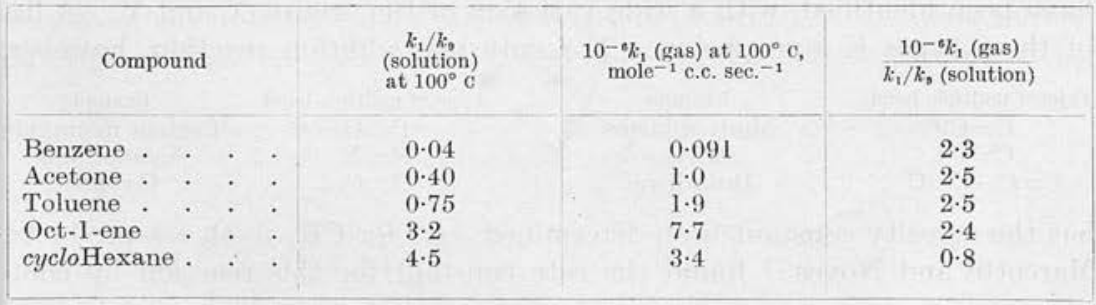

better than the reliability of the figures would lead one to expect. The result is of importance because it is the first case in which a free-radical reaction has been accurately studied in the gas phase and in solution. However, there is some evidence that the reacting species in Mayo's work is not a methyl radical at all but the $\mathrm{CH}_{3} \cdot \mathrm{CO} \cdot \mathrm{O}$ radical. This difficulty is characteristic of reactions in solution. 
The metathetical reactions of other radicals or atoms have been ver little investigated in the gas phase or in solution. In Table 9 are collectei the data on some of the other metathetical reactions in the gas phase whic may be compared with the methyl reactions. The information is fragment ary, but as far as it goes it leads us to suppose that the gradations in th reactivity of methyl radicals with various compounds will be reflected : the reactivity of other radicals with the compounds. On the other han there are some notable exceptions to this rule, and even for the reaction presented in the table there exist data which conflict with this conclusion In solution the transfer-reaction velocity constants which have ber measured for the thermal polymerisation of styrene in various solvents correspond to metathetical reactions of the polystyrene radicals. In thi case, where an extreme difference in molecular size is involved, there appear to be little correlation with the methyl reactions.

TABLE 9. Activation energies (in kcal./mole) of various metathetical reactions

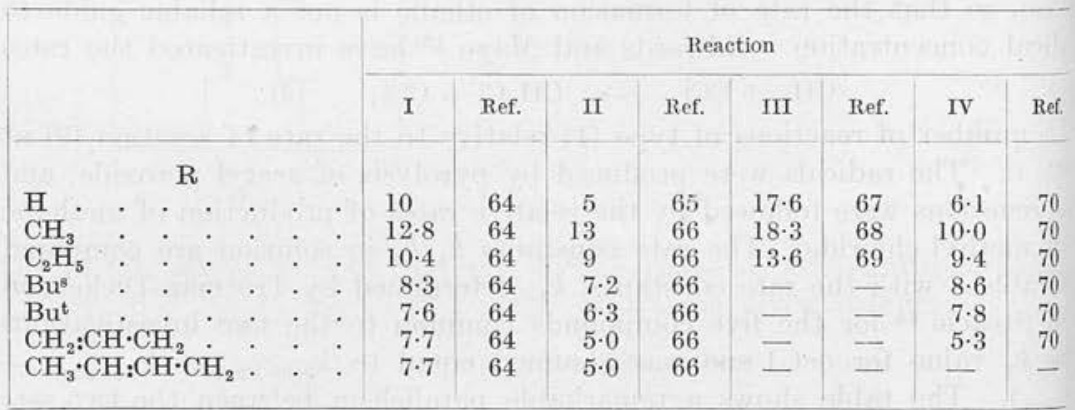

(I) $\mathrm{CH}_{3}+\mathrm{RH} \rightarrow \mathrm{CH}_{4}+\mathrm{R}$

(II) $\mathrm{H}+\mathrm{RH} \rightarrow \mathrm{H}_{2}+\mathrm{R}$
(III) $\mathrm{Br}+\mathrm{RH} \rightarrow \mathrm{HBr}+\mathrm{R}$

(IV) $\mathrm{Na}+\mathrm{RCl} \rightarrow \mathrm{NaCl}+\mathrm{R}$

Addition Reactions of Methyl Radicals.-Large numbers of additi reactions of methyl radicals of the type $\mathrm{CH}_{3}+\mathrm{X}=\mathrm{Y} \rightarrow \mathrm{CH}_{3}-\mathrm{X}-\mathrm{I}$ have been identified, with a wide variation of the groups $\mathrm{X}$ and $\mathrm{Y}$. A l of these types is given below. For only one addition reaction, howere

Type of multiple bond

$\begin{gathered}\mathrm{C}=\mathrm{C} \\ \mathrm{C} \equiv \mathrm{C}\end{gathered} \mathrm{C}=\mathrm{C}=\mathrm{C}=\mathrm{C} \quad \cdot \begin{gathered}\text { Many alkenes } \\ \text { Ethyne } \\ \text { Butadiene }\end{gathered}$

Type of multiple bond

$\mathrm{C}=\mathrm{O} . \quad$
$\mathrm{N}=\mathrm{N} . \quad$
$\mathrm{O}=\mathrm{O} . \quad$

Example

Carbon monoxi Azomethane - Oxygen

has the velocity constant been determined, viz., for $\mathrm{CH}_{3}+\mathrm{O}_{2} \rightarrow$ produci Marcotte and Noyes ${ }^{71}$ found the rate constant for this reaction by cot

${ }^{63}$ Burnett, Quart. Reviews, 1950, 4, 292.

${ }^{64}$ See Tables 3 and 4.

65 Farkas and Farkas, Proc. Roy. Soc., 1935, A, 152, 124.

${ }_{66}$ Darwent and Roberts, Discuss. Faraday Soc., 1953, 14.

67 Bodenstein and Lütkemeyer, Z. physikal. Chem., 1935, 114, 208.

${ }^{68}$ Kistiakowsky and Van Artsdalen, J. Chem. Physics, 1944, 12, 469.

69 Anderson and Van Artsdalen, ibid., p. 479.

70 Warhurst, Quart. Reviews, 1951, 5, 44.

${ }^{71} \mathrm{~J}$. Amer. Chem. Soc. 1952, 74, 783. 
paring the rate of disappearance of oxygen from an illuminated acetoneoxygen mixture with the rate of production of methane. They found the activation energy of the reaction to be $0 \pm 0.5 \mathrm{kcal} . / \mathrm{mole}$ and that $A=8 \times 10^{10}$ mole $^{-1}$ c.c. sec. ${ }^{-1}$.

The reason why it has been impossible to determine the velocity constant of reaction $(10)$ is that the propyl radical rapidly reacts with another

$$
\mathrm{CH}_{3}+\mathrm{C}_{2} \mathrm{H}_{4} \rightarrow \mathrm{C}_{3} \mathrm{H}_{7}
$$

ethene molecule, combines or disproportionates with a methyl, propyl, or higher radical, or, at temperatures above $520^{\circ} \mathrm{K}$, decomposes at an appreciable rate. The situation is thus extremely complicated and cannot be sorted out by our present techniques. An attempt has been made ${ }^{72}$ to give a general kinetic treatment of the reactions which occur when acetaldehyde is photolysed in the presence of a number of different alkenes. No reliable rate constants for the individual steps have been derived by this method, and the study illustrates clearly the great difficulties which have to be overcome before quantitative results can be obtained by this straightforward approach.

Some information about the addition of methyl radicals to alkenes may be obtained indirectly by studying the kinetics of the reverse reaction. Thus although it has not been possible to determine the activation energy of (10), yet the activation energy of the reverse reaction (11) can be measured.

$$
\mathrm{C}_{3} \mathrm{H}_{7} \rightarrow \mathrm{C}_{2} \mathrm{H}_{4}+\mathrm{CH}_{3}
$$

This has been done by Bywater and Steacie, ${ }^{3,4,5}$ who produced the propyl radicals by mercury photosensitisation. They found $E=20 \mathrm{kcal} . / \mathrm{mole}$. If the $\mathrm{C}_{3} \mathrm{H}_{7}-\mathrm{H}$ and $\mathrm{CH}_{3}-\mathrm{H}$ bond strengths are known, it is possible to calculate $\Delta H$ for reaction (11) from well-established thermochemical data. The data due to Stevenson ${ }^{45}$ on the $\mathrm{CH}_{3}-\mathrm{H}$ and primary, secondary, and tertiary $\mathrm{C}-\mathrm{H}$ bonds, which have been referred to above, can be used for this purpose. Hence $\Delta H=23$ kcals.

$$
\text { Now } \quad \Delta H=E_{11}-E_{10} \text {, therefore } E_{10}=-3 \mathrm{kcal} \text {. }
$$

In Table 10 all the information is set out which can be calculated in this I way from the published data for the addition of hydrogen atoms or methyl er or ethyl radicals to alkenes. All the data on the decomposition of the

\begin{tabular}{|c|c|c|c|c|c|}
\hline Alkene radic: & & & Hydrogen-atom & Methyl radical & Ethyl radical \\
\hline $\begin{array}{l}\text { Ethene : } \\
\text { Propene : } \\
\text { 2-Methylpropene }\end{array}$ & : & $: \quad:$ & $\begin{array}{l}+2 \\
+1,(+4) \\
-1,(-8)\end{array}$ & $-1,\left(\begin{array}{l}-3 \\
-2\end{array}\right),-3$ & $\begin{array}{l}+2 \\
-\end{array}$ \\
\hline
\end{tabular}

\section{TABLE 10. Activation energies (kcal./mole) for the addition of radicals to alkenes}

radicals come from the papers by Bywater and Steacie; Stevenson's bond strengths ${ }^{59}$ nave been used. When the decomposition mechanism assumed

72 Raal, Danby, and Hinshelwood, J., 1949, 2225. 
involves the internal rearrangement of one of the fragments, the result placed in parentheses as being of doubtful value. The results in the tabl are uncertain to about \pm 4 kcal., so the only conclusion which can be draw is that these addition reactions have very small activation energies.

The entropy change in the equilibrium formed by reactions (10) and (11) for example, can be calculated with a reasonable degree of confidene because most of the uncertainties due to our lack of knowledge of the pro perties of the radicals occur on both sides of the equilibrium. So if $A_{1}$ and $E_{11}$ are known we can calculate $A_{10}$ and $E_{10}$ from bond-strength an thermodynamic data. Thus we find ${ }^{73}$ that the additions of methy radicals to ethylene and propene have frequency factors of the order $10^{6} \mathrm{~mole}^{-1}$ c.c. sec. ${ }^{-1}$. This remarkable conclusion is supported by the fae that similar calculations for the reactions of hydrogen atoms give result which are in good agreement with the measured rates.

${ }^{73}$ Trotman-Dickenson, Discuss. Faraday Soc., 1953, 14. 
Reprinted from The Journal of Chemical Physics, Vol. 21, No. 2, 211-214, February, 1953

Printed in U. S. A.

\title{
Entropy Changes in Free Radical Reactions
}

\author{
A. F. Trotman-Dickenson \\ Chemistry Department, The University, Manchester, England
}

(Received August 28, 1952)

\begin{abstract}
The entropies of alkyl and other simple free radicals may be estimated with sufficient accuracy to make informative calculations about the equilibria involved in the reactions of these radicals. Such calculations have been made for metathetical reactions, the decomposition of saturated molecules, and the decomposition of free radicals. The method provides a means of obtaining knowledge about reactions which are not readily susceptible to direct experimental investigation. The deviations of the frequency factors of some unimolecular decompositions from a value of $10^{13 \pm 1}$ are discussed.
\end{abstract}

$\mathrm{O}$ $\mathrm{NE}$ of the principal reasons for studying free radical reactions is that they are, because of their formal simplicity, very suitable for testing theories of chemical kinetics.

Free radical reactions may be divided into three classes represented by the equilibria (1), (2), and (3)

$$
\begin{aligned}
& R^{\prime}-+ A R^{\prime \prime} \leftrightarrows R^{\prime} A+R^{\prime \prime}-, \\
& R^{\prime} R^{\prime \prime} \rightleftarrows R^{\prime}-+R^{\prime \prime}-, \\
& R^{\prime}-A-B-\leftrightarrows R^{\prime}-+A=B .
\end{aligned}
$$

Type (1) represents a metathetical reaction, type (2) represents the decomposition of a saturated molecule and the combination of two radicals, and type (3) represents the addition of a radical to a double bond and the decomposition of a radical into a smaller radical and an unsaturated molecule. At the present time examples of all these types of free radical reaction are known; in some cases it has been possible to measure their rate constants and even to obtain their frequency factors and activation energies, but in very few cases have the forward and reverse processes for the same reaction been quantitatively studied. This discussion will be confined to a consideration of the "temperature independent" factors of reactions of the types (1), (2), and (3).

It has been found that the Arrhenius equation

$$
k=A \exp (-E / R T)
$$

adequately describes the variation of the velocity constant of a gas reaction with temperature (the symbols have their usual meaning). Hence for the reaction

$$
\begin{gathered}
\mathrm{A}+\mathrm{B} \underset{k_{b}}{\stackrel{k_{f}}{\rightleftharpoons}} \mathrm{C}+\mathrm{D}, \\
-R T \ln k_{f} / k_{b}=\left(E_{f}-E_{b}\right)-R T \ln A_{f} / A_{b}=\Delta H-T \Delta S \\
R \ln A_{f} / A_{b}=\Delta S .
\end{gathered}
$$

This relation is strictly true if the activation energy is defined by

$$
R T^{2}(d \ln k / d T)=E,
$$

and the temperature independent factor is defined by

$$
R T \ln A=\partial\left(R T^{2} \ln k\right) / \partial T .
$$

These definitions relate to a particular temperature, whereas experimentally $A$ and $E$ are derived from the integrated form of the Arrhenius equation. However, it has been found that for gas phase reactions, these two derivations give the same values for $A$ and $E$ within the limits of experimental error. In addition the most popular theories indicate that for bimolecular and unimolecular reactions, the form of the temperature dependence of the $A$ factors should be the same and hence the ratio $A_{f} / A_{b}$ will be temperature independent. This type of treatment results from the work of Van t'Hoff and has been recently used by Dainton and Ivin ${ }^{1}$ when discussing polymerization reactions, though they arrive at the same expression by consideration of

${ }^{1}$ F. S. Dainton and K. J. Ivin, Trans. Faraday Soc. 46, 331 (1950). 
the theory of absolute reaction rates, which is unnecessary.

Here we will calculate values of $\Delta S$ and hence of $A_{f} / A_{b}$ for a number of reactions for which either $A_{f}$ or $A_{b}$ are known. The entropies of the radicals are often not known accurately, but because of the symmetry of many of the reactions, many of the errors which may occur resulting from arbitrary assumptions about the character of the radicals balance out and fairly definite conclusions may be drawn. Unless it is specifically stated to the contrary, the calculations have been carried out using entropies at $298^{\circ} \mathrm{K}$; where it is convenient the calculations have been repeated for temperatures closer to those at which the reactions were studied experimentally. It can be seen that this does not alter the character of the results. The evaluation of entropy changes involves a knowledge of three species (a) of ordinary saturated molecules, (b) of atoms, and (c) of free radicals.

(a) The entropies of ordinary saturated molecules are taken from the tables published by the National Bureau of Standards. ${ }^{2}$

(b) The entropies of atoms may be calculated to the desired accuracy by the use of standard methods.

(c) The entropies of the large free radicals $R$, that is, other than ethyl and methyl, are taken as being the same as those of the compounds $\mathrm{RH}$ with an allowance made of the electron degeneracy of the radical owing to the presence of an unpaired electron. In most cases this is probably a very good approximation, for the translational entropy because of the very small differences in mass; for the rotational entropy because of the small change in the moments of inertia and because the symmetry number is unlikely to vary by more than a factor of two; and for the vibrational entropy because although an inversion vibration analogous to that in ammonia may make a considerable contribution to the vibrational entropy of an alkyl radical, this entropy is only a small fraction of the total. As an illustration of this point let us consider the entropy of a methyl radical (neglecting for the moment the contribution of the electron degeneracy). We have the following figures, at $298^{\circ} \mathrm{K}$.

$$
S^{0}(\text { methane })=44.5 \mathrm{eu}, \quad S^{\circ}(\text { ammonia })=45.9 \mathrm{eu},
$$

for a planar methyl radical (symmetry number 6)

$$
S^{0}{ }_{\text {trans }}(\text { methyl })=34.1 \mathrm{eu}, \quad S^{0}{ }_{\text {rot }}(\text { methyl })=9.9 \mathrm{eu},
$$

for a methyl radical with a very high inversion frequency

$$
S_{\text {trans }}^{0}+S^{0}{ }_{\text {rot }}+S^{0}{ }_{\text {vib }}(\text { methyl })=44.1 \mathrm{eu} \text {, }
$$

for a methyl radical with very low inversion frequency

$$
S_{\text {trans }}^{0}+S_{\text {rot }}^{0}+S^{0}{ }_{\text {vib }}(\text { methyl })=45.5 \text { eu. }
$$

From these figures it can be seen that the value of $45.5 \mathrm{eu}$ which has been adopted here for the total

${ }^{2}$ Natl. Bur. Standards (U. S.), Circ. C. 461, 1947, Washington D. C. entropy of the methyl radical, may be too low but can hardly be too high.

Similarly the value adopted for the ethyl radical of 56.3 eu may be seen to be about as small a value as could reasonably be selected when compared with $S^{0} \mathrm{C}_{2} \mathrm{H}_{6}=54.9 \mathrm{eu}, S^{0} \mathrm{C}_{2} \mathrm{H}_{4}=52.5 \mathrm{eu}$, and $S^{0} \mathrm{CH}_{3} \mathrm{NH}_{2}=57.7 \mathrm{eu}$.

We can now use these values to derive the $A$ factors of reactions which are not in general experimentally accessible. It will be seen that in some cases there is an experimental value which agrees satisfactorily with that calculated.

\section{METATHETICAL REACTIONS}

\section{(a) The Reactions of Methyl Radicals with Alkanes}

A large number of reactions of the type

$$
\mathrm{CH}_{3}+\mathrm{RH} \rightarrow \mathrm{CH}_{4}+\mathrm{R}-
$$

have been studied ${ }^{3}$ and it has been found ${ }^{4}$ that the $A$ factors are of the order of $10^{11}$ (all velocity constants are given in $\mathrm{g}$ mole, $\mathrm{cc}$ and $\mathrm{sec}$ ). Since the entropy change in these reactions is almost zero, reactions of the type

$$
R+\mathrm{CH}_{4} \rightarrow \mathrm{CH}_{3}+\mathrm{RH}
$$

will also have $A$ factors of the order of $10^{11}$. Hence the $A$ factor for the reaction

$$
\mathrm{C}_{2} \mathrm{H}_{5}+\mathrm{CH}_{4} \rightarrow \mathrm{C}_{2} \mathrm{H}_{6}+\mathrm{CH}_{3}
$$

may be expected to be of the order of $10^{11}$. It is therefore very surprising that Ivin and Steacie ${ }^{5}$ find that $A=10^{13.3}$ for the very similar reaction

$$
\mathrm{C}_{2} \mathrm{H}_{5}+\mathrm{C}_{2} \mathrm{H}_{5} \rightarrow \mathrm{C}_{2} \mathrm{H}_{4}+\mathrm{C}_{2} \mathrm{H}_{6} \text {. }
$$

\section{(b) The Reactions of Hydrogen Atoms with Alkanes}

In these reactions the entropy change is not zero because of the large difference between the entropies of the hydrogen atom and the hydrogen molecule. Rather exact calculations may be made for the equilibrium

$$
\mathrm{H}+\mathrm{CH}_{4} \underset{k_{b}}{\stackrel{k_{f}}{\rightleftarrows}} \mathrm{H}_{2}+\mathrm{CH}_{3},
$$

because of the simplicity of the species. We find that $A_{f} \geqslant 10 A_{b}$ in good agreement with the latest experimental data which indicates that $A_{f}$ is between 10 and 100 times as great as $A_{b}{ }^{6}$ It has often been assumed when the results of hydrogen atom reactions studied by the Wood-Bonhoeffer method are considered

${ }^{3}$ A. F. Trotman-Dickenson and E. W. R. Steacie, J. Chem. Phys. 19, 329 (1951)

${ }_{4}^{4}$ R. Gomer and G. B. Kistiakowsky, J. Chem. Phys. 19, 85 (1951)

${ }^{5}$ K. J. Ivin and E. W. R. Steacie, Proc. Roy. Soc. (London) A208, 25 (1951).

${ }^{6}$ E. W. R. Steacie, Atomic and Free Radical Reactions (Reinhold Publishing Corporation, New York, 1947); T. G. Majury and E. W. R. Steacie, J. Chem. Phys. 20, 197 (1952). 
that reactions of the type

$$
\mathrm{H}+\mathrm{RH} \rightarrow \mathrm{H}_{2} \mathrm{R}
$$

have frequency factors of the order of $10^{13}$. If that assumption is correct the frequency factors of the back reactions for alkyl radicals should be $10^{12}$, since $A_{b} / A_{f} \approx 1 / 10$.

\section{UNIMOLECULAR DECOMPOSITIONS}

Szwarc and his collaborators have recently measured the rates of a large number of reactions of the type

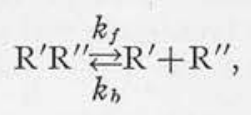

and in some cases have been able to measure the frequency factors of the reactions. When this has been impossible very fruitful interpretations of the data have been obtained by assuming that $A_{f}$ is constant for a series of similar reactions in which $\mathrm{R}^{\prime}$ is unchanged. We will consider two series, the alkyl benzenes and the bromomethanes.

\section{(a) The Alkyl Benzenes}

In treating the alkyl benzenes it has been assumed that the entropy of the benzyl radical is the same as that of toluene, however, this doubtful assumption does not affect conclusions about variations among members of the series. The results are given in Table I. The variation of $A_{b}$ (calc) in this table is not in agreement with the general belief that the association of more complex radicals will involve a lower $A$ factor. To obtain a value of $A_{b}$ of $10^{9}$ would mean that $A_{f}$ would be $3 \times 10^{12}$, this value of $A_{f}$ combined with the experimental value for $k_{f}$ leads to an activation energy consistent with an equality of strengths for the $\mathrm{C}_{2} \mathrm{H}_{5}-\mathrm{H}$ and $n-\mathrm{C}_{3} \mathrm{H}_{7}-\mathrm{H}$ bonds, which is a more reasonable result than that of $\mathrm{D}\left(\mathrm{C}_{3} \mathrm{H}_{7}-\mathrm{H}\right)-\mathrm{D}\left(\mathrm{C}_{2} \mathrm{H}_{5}-\mathrm{H}\right)=4 \mathrm{kcal}$ given by Szwarc and Leigh (see Table I, references c and d).

\section{(b) The Bromomethanes}

Similar calculations for the decompositions of the series of bromomethanes ${ }^{7}$ have been made on the assumption that $S_{\mathrm{RH}}=S_{\mathrm{R}}-. A_{f}$ has been taken as $10^{13}$, there being good experimental evidence that this value is correct for $\mathrm{CH}_{3} \mathrm{Br}$ and $\mathrm{CCl}_{3} \mathrm{Br}$. The results in the table are probably reliable and form a series which conforms with the general idea that the association of more complex radicals involves lower $A$ factors:

$\begin{array}{rc}\text { Reaction } & A \\ \mathrm{CH}_{3}+\mathrm{Br} & 4 \times 10^{11} \\ \mathrm{CH}_{2} \mathrm{Br}+\mathrm{Br} & 1 \times 10^{11} \\ \mathrm{CHBr}_{2}+\mathrm{Br} & 3 \times 10^{10} \\ \mathrm{CBr}_{3}+\mathrm{Br} & 7 \times 10^{9} .\end{array}$

${ }^{7}$ M. Szwarc and A. H. Sehon, Proc. Roy. Soc. (London) A209, ${ }^{7}$ M. Szw
$110(1951)$.

TABLE I. $A$ factors for the decomposition of alkyl benzenes.

\begin{tabular}{llrrr}
\hline \hline \multicolumn{1}{c}{ Substance } & Af expt) & $\begin{array}{r}A_{f} / A_{\mathrm{b}} \text { at } \\
298^{\circ} \mathrm{K}\end{array}$ & $\begin{array}{c}A_{f} / A_{\mathrm{b}} \text { at } \\
1000^{\circ} \mathrm{K}\end{array}$ & $\begin{array}{r}A_{\mathrm{b}}(\mathrm{calc}) \\
1000^{\circ} \mathrm{K}\end{array}$ \\
\hline Toluene & $10^{13 \mathrm{a}}$ & 40 & 240 & $4 \times 10^{10}$ \\
Ethyl benzene & $10^{13 \mathrm{~b}}$ & 1000 & 2900 & $3 \times 10^{9}$ \\
$n$-Propyl benzene & $3 \times 10^{12 \mathrm{o}}$ & 2500 & 2300 & $1 \times 10^{9}$ \\
$n$-Butyl benzene & $3 \times 10^{14 \mathrm{~d}}$ & 3000 & 3000 & $1 \times 10^{11}$ \\
\hline \hline
\end{tabular}

A M. Szwarc. J Chem. Phys. 16. 128 (1948).

b M. Szwarc, J. Chem. Phys. 17. 431 (1949).

- C. H. Leigh and M. Szwarc, J. Chem. Phys. 20. 403 (1952).

d C. H. Leigh and M. Szwarc, J. Chem. Phys. 20, 407 (1952).

\section{(c) The Combination of Alkyl Radicals}

Only two rate constants and $A$ factors have been determined for the combination of radicals in the gas phase. They relate to the combination of methyl and the combination of ethyl radicals. From these results the minimum values of the $A$ factors for the symmetrical decomposition of ethane and $n$-butane may be calculated with certainty and are given in the table.

Decomposition of ethane
Decomposition of butane

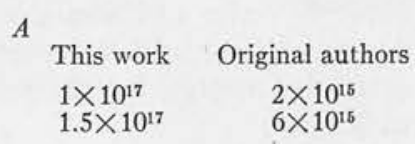

The values given by the original authors are rather low because Ivin and Steacie $^{5}$ seem to have chosen an improbably low value for the entropy of the ethyl radical, and Gomer and Kistiakowsky ${ }^{4}$ used the equilibrium constant calculated by Glasstone, Laidler, and Eyring, ${ }^{8}$ who made no allowance for the electron degeneracy of the free radicals and so obtained an answer which is probably too small.

\section{THE DECOMPOSITION OF FREE RADICALS}

Bywater and Steacie ${ }^{9}$ have studied the decomposition of the free radicals produced by the mercury photosensitization of ethane, propane, and 2-methyl propane and determined the activation energies of the decompositions on the assumption that the dimerization of the free radicals requires no activation energy. In each of these cases it is possible to estimate from the experimental data the number of alkyl radicals decomposing and the number dimerizing, the error being of the order of 20-30 percent. If these two quantities are known, then it is possible ${ }^{10}$ to calculate the relative values of the rate constant $k_{4 f}$ and $k_{5}$ for the reactions (4) and (5) by using the

$$
\begin{array}{r}
\mathrm{RA} \underset{k_{4 b}}{\stackrel{k_{4 f}}{\rightleftarrows}} \mathrm{R}+\mathrm{A} \\
2 \mathrm{RA} \stackrel{k_{5}}{\longrightarrow}(\mathrm{RA})_{2},
\end{array}
$$

${ }^{8}$ Glasstone, Laidler, and Eyring, Theory of Rate Processes (McGraw-Hill Book Company, Inc., New York, 1941), p. 263.

${ }^{9}$ S. Bywater and E. W. R. Steacie, J. Chem. Phys. 19, 172, 319, 326 (1951).

${ }_{10}$ A. F. Trotman-Dickenson, J. Chem. Phys. 19, 261 (1951). 
formula $d \mathrm{R} / d t / d(\mathrm{RA})_{2} / d t=k_{4 j} / k_{5}{ }^{1}$. Since the activation energy of reaction $(4 f)$ is known a maximum value of $A_{4 f}$ may be obtained by supposing reaction (5) to take place on every collision. The annexed table given the values found for $A_{4 f}$.

\begin{tabular}{lcc}
\multicolumn{1}{c}{ Reaction } & $A_{f}$ & $A_{b}$ \\
$\mathrm{C}_{2} \mathrm{H}_{5} \rightarrow \mathrm{C}_{2} \mathrm{H}_{4}+\mathrm{H}$ & $2 \times 10^{14}$ & $2 \times 10^{13}$ \\
$\mathrm{C}_{3} \mathrm{H}_{7} \rightarrow \mathrm{C}_{2} \mathrm{H}_{4}+\mathrm{CH}_{3}$ & $3 \times 10^{9}$ & $6 \times 10^{6}$ \\
$\mathrm{C}_{4} \mathrm{H}_{9} \rightarrow \mathrm{C}_{3} \mathrm{H}_{6}+\mathrm{CH}_{3}$ & $1 \times 10^{9}$ & $1 \times 10^{5}$
\end{tabular}

By the methods outlined above the entropy changes in these reactions may be found, and hence $A_{4 b}$ calculated; the values found are given in the table. Full experimental data to check these calculations are not yet available, but two pieces of work provide some comparison.

Melville and Robb" have found that the collision yield for the reaction of hydrogen with ethylene at room temperature is $10^{-3}$, this would agree with the above results if the activation energy for the reaction is $3 \mathrm{kcal}$. From Bywater and Steacie's activation energy for the decomposition, and Stevenson's ${ }^{12}$ bond strengths the activation energy for the addition may be calculated as 2 kcals.

Trotman-Dickenson and Steacie ${ }^{13}$ found that at $180^{\circ} \mathrm{C}$ the addition of a methyl radical to ethylene took place at the same speed to within a factor of two or three as the abstraction of a hydrogen atom. The rate constant for the abstraction reaction is $3 \times 10^{6} \mathrm{~g} \mathrm{~mole}^{-1}$ cc $\sec ^{-1}$. Our slight knowledge of bond strengths and activation energies for the decomposition of radicals indicates that reaction $\left(7_{b}\right)$ will have very small or zero activation energy. If the reaction requires zero activation energy then $A_{7 b}=3 \times 10^{6}$ in remarkable agreement with the value calculated above.

The frequency factors for the decomposition of the propyl and butyl radicals differ markedly from the value of $10^{13}$ which has been regarded as a norm. Two other cases of such low frequency factors in similar reactions are known, as has been pointed out by TrotmanDickenson ${ }^{10}$; they are the decomposition of the radicals of dimethyl ether and of methyl alcohol,

$$
\begin{aligned}
& \mathrm{CH}_{2} \mathrm{OCH}_{3} \rightarrow \mathrm{CH}_{3} \mathrm{CH}_{2} \mathrm{O} \\
& \mathrm{CH}_{2} \mathrm{OH} \rightarrow \mathrm{CH}_{2} \mathrm{O}+\mathrm{H},
\end{aligned}
$$

where the maximum possible values for the $A$ factors

${ }^{11}$ H. W. Melville and J. C. Robb, Proc. Roy. Soc. (London) A202, 181 (1950).

${ }^{12}$ D. P. Stevenson, Disc. Faraday Soc. 10, 35 (1951).

${ }^{13}$ A. F. Trotman-Dickenson and E. W. R. Steacie, J. Chem. Phys. 19, 169 (1951). were found to be $1.5 \times 10^{10}$ and $1.7 \times 10^{10}$, respectively. In all of these cases the errors are probably quite large and amount to about one power of ten. Consequently although the fact that the frequencies factors are very low is well established, little reliance can be placed on the exact numerical values.

The decomposition of ethane and butane discussed above are examples of the opposite phenomenon for they have very high frequency factors. The experimental data seem very reliable and a minimum value for the frequency factor has been deliberately calculated. A further somewhat similar example of a high frequency factor has recently been confirmed by Carrington and Davidson, ${ }^{14}$ who find that the reaction

$$
\mathrm{N}_{2} \mathrm{O}_{4} \rightarrow 2 \mathrm{NO}_{2}
$$

has a frequency factor of about $10^{16}$ if the reverse reaction has no energy of activation.

These two classes of deviation of the $A$ factor of a reaction from the accepted value of $10^{13 \pm 1}$ raise considerable problems. It may be that special explanations apply to these cases, for example, the decompositions of radicals in which one fragment has to rearrange to form an unsaturated compound are slightly reminiscent of the cases of cis-trans isomerism in which low frequency factors were found. Harman and Eyring ${ }^{15}$ suggested that this effect might be the cause of the $A$ factors which are found for the propagation reactions in polymerizations, those reactions are the reverse of the decompositions. However, Baxendale and Evans ${ }^{16}$ have shown that in this case the low $A$ factors are understandable in terms of the ordinary theory of absolute reaction rates. They show in the same manner that for reactions in solution the symmetrical decomposition of a polymer molecule should have an $A$ factor of approximately $10^{13}$, if the combination (or disproportionation) of two polymer radicals has an $A$ factor of $10^{11}$. This is in marked contrast to the behavior of ethane and butane discussed above. The reason for this is that the large polymer molecules and radicals cannot rotate freely but only librate or vibrate. Since these forms of motion are little affected by the size of the species there is no effect to correspond to the loss of rotational entropy in the case of the combination of two small radicals.

The author wishes to thank Professor M. G. Evans and Dr. M. Szwarc for numerous discussions.

${ }^{14} \mathrm{~T}$. Carrington and N. R. Davidson, J. Chem. Phys. 19, 1313 (1951)

${ }_{15}$ R. A. Harman and H. Eyring, J. Chem. Phys. 10, 557 (1942).

${ }^{16} \mathrm{~J}$. H. Baxendale and M. G. Evans, Trans. Faraday Soc. 43, 210 (1947). 


\title{
Studies in energy transfer \\ III. The effect of added gases on the decomposition of cyclobutane
}

\author{
By H. O. Pritchard, R. G. Sowden and A. F. Tromman-Dickenson \\ Chemistry Department, University of Manchester
}

(Communicated by M. Polanyi, F.R.S.-Received 21 March 1953)

\begin{abstract}
The effect of the addition of hydrogen, helium, neon, argon, nitrogen, methane, water, benzotrifluoride, toluene and mesitylene on the first-order rate constant for the decomposition of cyclobutane at low pressures has been measured. The results are compared with those obtained for the same gases under similar conditions for the isomerization of cyclopropane.
\end{abstract}

\section{INTRODUCTION}

Genaux \& Walters (195I) have shown that the decomposition of cyclobutane to ethylene is a first-order gas-phase reaction, whose rate is given by the Arrhenius equation

$$
k=10^{15 \cdot 71} \exp (62800 / R T) .
$$

Furthermore, Kern \& Walters ( $195^{2}$ ) have shown that the rate of reaction is little affected by packing the reaction vessel or by the addition of chain inhibitors such as propylene, nitric oxide or toluene. They concluded that the reaction is a clean unimolecular decomposition whose rate constant falls off at low pressures because the rate of collisional energy transfer is insufficient to maintain the Maxwell-Boltzmann energy distribution in the face of the reaction. They also found that the addition of non-reactive gases tends to restore the low-pressure rate constant to the high-pressure value. Accordingly, we thought it interesting to measure the effect of various gases under the same conditions and with the same apparatus that we had used in the study of the analogous isomerization of cyclopropane at low pressures (Pritchard, Sowden \& Trotman-Dickenson 1952, I953, part II). 


\section{EXPERTMENTAL}

\section{Materials}

The cyclobutane was kindly given to us by the National Research Council of Canada; the high purity of this sample had been confirmed both by low-temperature distillation and by mass-spectrographic analysis. The inert gases were prepared and purified as described in part II.

\section{Apparatus and procedure}

The rate of decomposition of cyclobutane alone at pressures above $1 \mathrm{~cm}$ was followed by pressure measurements on a simple manometer attached to the reaction vessel. The low-pressure experiments were carried out in an exactly similar manner to those with cyclopropane, which were described in part II. No change was made for the study of the effect of the high-boiling additives. However, it was necessary to alter the apparatus to study the effect of the non-condensable additives, because the ethylene formed in this reaction is more volatile than the propylene produced in the isomerization of cyclopropane. Now the reaction was arrested by pumping the contents of the reaction vessel through a two-stage mercury diffusion pump into a large backing volume. Then the cyclobutaneethylene mixture was separated from the non-condensable foreign gas by circulation for about $15 \mathrm{~min}$ through a trap cooled by liquid nitrogen boiling under reduced pressure. Control runs with known ethylene-argon mixtures showed that this procedure was satisfactory. When the additive was methane care was taken that the temperature did not fall below $70^{\circ} \mathrm{K}$.

The cyclobutane-ethylene mixture was analyzed on a Blacet-Leighton apparatus (Blacet \& Leighton I93 I) by absorbing the ethylene on a mercuric acetate bead (Pyke, Kahn \& LeRoy 1947). Tests showed that the ethylene was completely absorbed within $5 \mathrm{~min}$; no absorption of the cyclobutane could be detected. This method of following the reaction is very convenient, especially for studying the effect of additives at low pressures of cyclobutane; it is probably not as accurate for following the decomposition of pure cyclobutane as the method used by Kern \& Walters (1952), who followed the pressure change during the reaction.

No evidence of any side reaction was found after the reaction vessel had been aged; no non-condensable gas was formed and, in a run taken to completion, the contents of the reaction vessel were completely absorbed by a mercuric acetate bead. Mass-spectrographic evidence for the absence of side reactions has been given by Kern \& Walters (1952).

\section{Results}

\section{Experiments with cyclobutane alone}

The rate of decomposition of cyclobutane at temperatures between $448 \cdot 2$ and $448 \cdot 6^{\circ} \mathrm{C}$ was measured in the pressure range from 10 to $0.0057 \mathrm{~cm}$. In this region the rate constant fell from $3.8 \times 10^{-4}$ to $1.06 \times 10^{-4} \mathrm{~s}^{-1}$. The results are presented in figure 1 as a plot of $\log _{10} k / k_{\infty}$ against the decadic logarithm of the pressure in centimetres. The value of $k_{\infty}$ was found by extrapolating a plot of $k^{-1}$ against 
$p^{-1}$ to infinite pressure. Most of the runs were to approximately $25 \%$ conversion, but no detectable difference in the rate constant was observed when runs were carried to $60 \%$ conversion. Within the accuracy of our experiments this can be explained if the collisional efficiency of ethylene in maintaining the rate constant of the reaction is half that of cyclobutane.

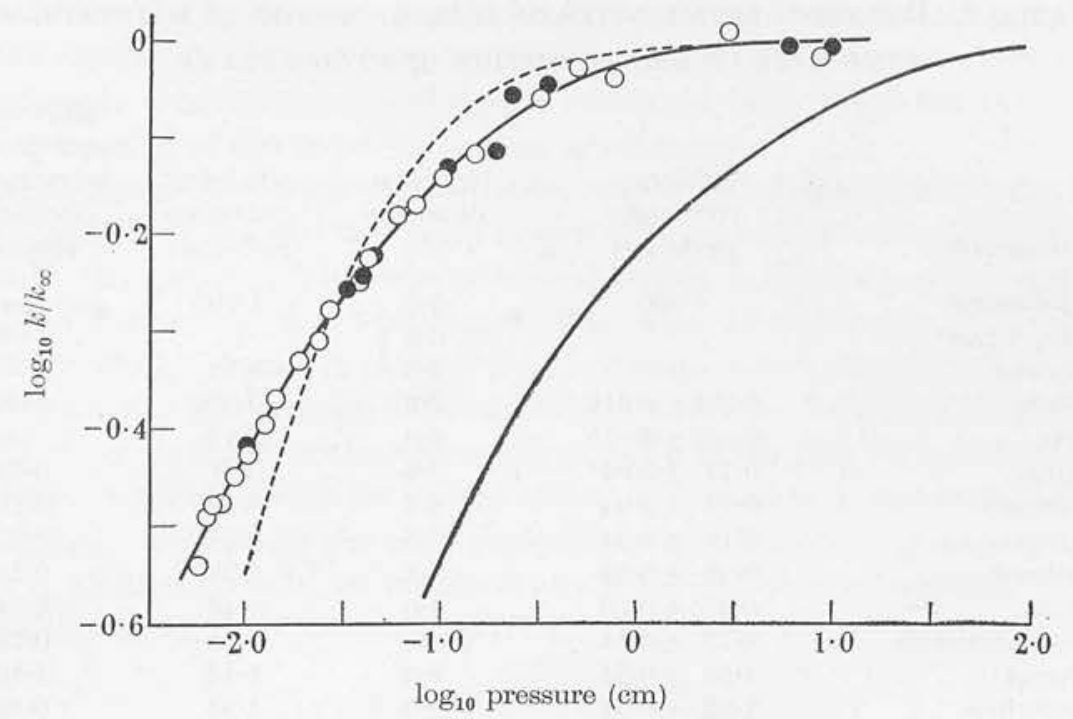

Figure 1. The dependence of the rate of decomposition of cyclobutane on pressure. O, runs to about $20 \%$ conversion; - , runs to about $50 \%$ conversion; ---, calculated Hinshelwood curve; —_, eurve for cyclopropane.

\section{Experiments with added gases}

The experiments on the effect of added gases were carried out at cyclobutane pressures between $0 \cdot 01$ and $0.1 \mathrm{~cm}$, a region in which the rate constant varies rapidly with pressure, and with pressures of additive between 0.2 and $1.0 \mathrm{~cm}$. The typical results obtained for hydrogen are given in table 1, the final column of which shows the efficiency of hydrogen relative to cyclobutane, pressure for pressure, in maintaining the value of the rate constant. The results for all the

\section{Table 1. The effect of the addition OF Hydrogen ON THE} RATE OF DECOMPOSITION OF CYCLOBUTANE

$\begin{array}{ccccccc}\begin{array}{c}\text { temp. } \\ \left({ }^{\circ} \mathrm{C}\right)\end{array} & \begin{array}{c}\text { cyclobutane } \\ \text { pressure } \\ (\mathrm{em})\end{array} & \begin{array}{c}\text { hydrogen } \\ \text { pressure } \\ (\mathrm{cm})\end{array} & \begin{array}{c}\text { time } \\ (\mathrm{sec})\end{array} & \begin{array}{c}\% \\ \text { eonversion }\end{array} & \begin{array}{c}10^{4} \mathrm{k} \\ \left(\mathrm{sec}^{-1}\right)\end{array} & \begin{array}{c}\text { relative } \\ \text { efficiency } \\ \text { of hydrogen }\end{array} \\ 448 \cdot 1 & 0 \cdot 040 & 0 \cdot 60 & 1490 & 34 \cdot 9 & 2 \cdot 88 & 0 \cdot 24 \\ 447 \cdot 8 & 0 \cdot 036 & 0 \cdot 49 & 1690 & 37 \cdot 6 & 2 \cdot 79 & 0 \cdot 31 \\ 447 \cdot 9 & 0 \cdot 043 & 0 \cdot 62 & 1445 & 34 \cdot 7 & 2 \cdot 91 & 0 \cdot 28 \\ 448 \cdot 2 & 0 \cdot 023 & 0 \cdot 82 & 1931 & 44 \cdot 6 & 3 \cdot 06 & 0 \cdot 27 \\ 448 \cdot 3 & 0 \cdot 039 & 0 \cdot 69 & 1685 & 40 \cdot 3 & 3 \cdot 06 & 0 \cdot 31\end{array}$

Efficiency of hydrogen relative to cyclobutane $=0 \cdot 28 \pm 0 \cdot 03$ (calculated on equivalent pressures). 
additives studied are collected together in table 2. The choice of additive is severely restricted, not only because they must be both stable and unreactive at the working temperature, but also because they must be readily separable from the cyclobutane-ethylene mixture by low-temperature distillation. The errors quoted are the root-mean-square errors of five or six determinations.

\section{Table 2. Relative efFiciencies of FOREIGN BODIES IN MATNTATNING THE RATE OF DECOMPOSITION OF CFCLOBUTANE}

\begin{tabular}{|c|c|c|c|c|}
\hline molecule & $\begin{array}{l}\text { efficiency } \\
\text { (pressure/ } \\
\text { pressure) }\end{array}$ & $\begin{array}{l}\text { collision } \\
\text { diameter } \\
(\AA)\end{array}$ & $\begin{array}{l}\text { efficiency } \\
\text { (collision/ } \\
\text { collision) }\end{array}$ & $\begin{array}{c}\text { cyclopropane } \\
\text { isomerization } \\
\text { (collision/ } \\
\text { collision) }\end{array}$ \\
\hline cyclobutane & $1 \cdot 000$ & $5 \cdot 5$ & $1 \cdot 000$ & - \\
\hline cyclopropane & - & $5 \cdot 0$ & - & 1.000 \\
\hline ethylene & $\sim 0.50$ & $4 \cdot 5$ & $\sim 0.49$ & - \\
\hline helium & $0.096 \pm 0.016$ & $2 \cdot 2$ & $0 \cdot 072$ & 0.048 \\
\hline neon & $0 \cdot 097 \pm 0 \cdot 015$ & $3 \cdot 0$ & $0 \cdot 12$ & - \\
\hline argon & $0.17 \pm 0.04$ & $3 \cdot 6$ & $0 \cdot 21$ & $0 \cdot 070$ \\
\hline hydrogen & $0.28 \pm 0.03$ & $2 \cdot 7$ & $0 \cdot 10$ & $0 \cdot 12$ \\
\hline nitrogen & $0.18 \pm 0.04$ & $3 \cdot 8$ & $0 \cdot 21$ & 0.070 \\
\hline methane & $0.50 \pm 0.08$ & $4 \cdot 1$ & $0 \cdot 38$ & $0 \cdot 24$ \\
\hline water & $0 \cdot 47 \pm 0 \cdot 10$ & $4 \cdot 0$ & 0.44 & 0.74 \\
\hline benzotrifluoride & $1 \cdot 15 \pm 0 \cdot 14$ & $8 \cdot 5$ & 0.85 & 0.75 \\
\hline toluene & $1.50 \pm 0.34$ & $8 \cdot 0$ & $1 \cdot 12$ & $1 \cdot 10$ \\
\hline mesitylene & $1.82 \pm 0.34$ & $9 \cdot 0$ & $1 \cdot 23$ & 0.89 \\
\hline
\end{tabular}

\section{Discussion}

The general shape of the curve for the decomposition of cyclobutane shown in figure 1 is as expected for a reaction whose rate falls at low pressures because the concentration of more energetic molecules is not being maintained. Moreover, this curve bears the expected relation to that for cyclopropane (shown by the solid line). No quantitative treatment of the cyclobutane decomposition has yet been reported, but the similar shape of the curve and its displacement to lower pressures are entirely in accord with the anticipated behaviour of a slightly more complex molecule.

For comparison, the curve derived from the simple Hinshelwood-Lindemann expression is shown by the dashed line. This expression predicts an incorrect shape for the curve, probably because the assumption that all molecules with energy in excess of the critical amount react at the same rate is inadequate.

There is some discrepancy between our results and those of Kern \& Walters ( $195^{2}$ ) which might be caused by a $4^{\circ} \mathrm{C}$ difference in our temperature scales. Our six-junction chromel-alumel thermocouple was calibrated against the temperature of boiling sulphur and should not be in error by more than $\pm 0 \cdot 3^{\circ} \mathrm{C}$, which is about the accuracy of the thermocouple used by Kern \& Walters. It is not a simple matter to determine accurately the mean temperature of large Pyrex reaction vessels, but we do not think that we could have estimated our temperature $4^{\circ} \mathrm{C}$ too high, for the temperature in the reaction vessel did not vary by 
more than $0 \cdot 5^{\circ} \mathrm{C}$ between the centre and the ends. However, for our present purpose the discrepancy is not serious because the shape of the plot of $\log k / k_{\infty}$ against $\log p$ does not vary appreciably with temperature changes of the order of $20^{\circ} \mathrm{C}$.

In table 2 are shown the efficiencies of the gases relative to cyclobutane expressed in terms of collisions (the collision diameters used in these calculations are given in the table). The figures run closely parallel to those obtained with cyclopropane, and the conclusion that all large molecules cause deactivation on every collision is reinforced. Our present knowledge of collisional processes is too restricted for useful discussion of the minor variations in efficiency.

The intramolecular mechanism of the decomposition of cyclobutane is not known, but a consideration of the thermochemistry of the process is interesting. The heat of combustion has recently been measured (Coops \& Kaarsemaker 1950) giving a $\Delta H$ for formation of $6.3 \mathrm{kcal} / \mathrm{mole}$. The heat of formation of $n$-butane is $-29.8 \mathrm{kcal} / \mathrm{mole}$ (Prosen \& Rossini 1945), and the assumption of approximately $100 \mathrm{kcal}$ each for the primary $\mathrm{C}-\mathrm{H}$ dissociation energies (cf. Mortimer, Pritchard \& Skinner 1952) leads to the value $\Delta \mathrm{H}_{f}\left(-\mathrm{CH}_{2} \mathrm{CH}_{2} \mathrm{CH}_{2} \mathrm{CH}_{2}-\right)=66 \mathrm{kcal}$. Hence the energy required for simple carbon-carbon bond fission in cyclobutane is about $60 \mathrm{kcal} / \mathrm{mole}$. Essentially the same conclusion may be derived by considering that the heat of formation of an idealized strainless cyclobutane molecule would be approximately four $\mathrm{CH}_{2}$ increments (Prosen \& Rossini 1945), i.e. about

$$
-(4 \times 4 \cdot 9)=-19 \cdot 6 \mathrm{kcal} / \mathrm{mole} .
$$

Hence, there is approximately $26 \mathrm{kcal} / \mathrm{mole}$ strain energy in cyclobutane, and if the normal carbon-carbon bond energy is $85 \mathrm{kcal}$, then the minimum energy required for simple bond fission in cyclobutane is $85-26=59 \mathrm{kcal} / \mathrm{mole}$; the experimental activation energy is $62.8 \mathrm{kcal}$.

Similar arguments based on the $\Delta H$ of formation of cyclopropane of $12 \cdot 7 \mathrm{kcal} /$ mole (Knowlton \& Rossini 1949) lead to the value of about $59 \mathrm{kcal}$ for the simple carbon-carbon bond fission to give a trimethylene radical, whereas the experimental activation energy is $65 \mathrm{kcal} / \mathrm{mole}$. Crude calculations using a carboncarbon bond of $85 \mathrm{kcal}$ having a force constant of $4.5 \times 10^{5}$ dynes/cm (Crawford \& Brinkley I94I) and allowing for the variation of strain energy with configuration (calibrated at $\mathrm{C}-\mathrm{C}-\mathrm{C}$ bond angles of $0,60,90,108$ and $120^{\circ}$ from the heats of formation of ethylene, cyclopropane, etc.) show that the activation energy for the simple bond fission is not likely to be greater than the endothermicity.

However, there is some evidence that the trimethylene diradical is not involved in the reaction; Slater (1953), assuming that the transition state is determined by the approach of a hydrogen atom attached to one carbon atom to within a critical distance of an adjacent carbon atom, has explained the high frequency factor of this reaction $\left(10^{15 \cdot 2}\right)$, and predicted its quasi-unimolecular behaviour in excellent agreement with the experimental results. According to Slater's treatment, if the first step in the reaction is a carbon-carbon bond fission, the molecule may be regarded virtually as a triatomic molecule, and in this case the rate would have fallen off to a small fraction of its high-pressure value at these pressures; thus, if 
the bond fission reaction has a frequency factor of about $10^{13}$, as seems reasonable, the combined effect of the falling off and the lower frequency factor might be expected to outweigh the effect of the lower activation energy and reduce its rate to insignificant proportions compared with the other mechanism. Furthermore, it is difficult to see how the cleanliness of the reaction could be maintained in the presence of such molecules as methane, toluene and mesitylene if free radicals were involved.

If this is the case for cyclopropane, we might suspect with cyclobutane, despite the close agreement between the energy required for carbon-carbon bond fission and the experimental activation energy, that the reaction does not proceed in this way. A plausible mechanism is that two sides of the square formed by the four carbon atoms contract, while the other two stretch until two ethylene molecules separate. In this case, since the fission into two dimethylene radicals would require about $144 \mathrm{kcal}(2 \times 85-26)$, the two shortened sides of the square, which are the latent ethylene molecules, must possess very considerable double-bond character in the transition state. Some evidence for this mechanism lies in the high frequency factor of this reaction $\left(10^{15 \cdot 7}\right)$ which may be explained by an increase in entropy due to the greater freedom of movement (possibly nearly free rotation) of the latent ethylene molecules in the transition state.

\section{REFERENCES}

Blacet, F. E. \& Leighton, P. A. I93 I Industr. Engng Chem. (Anal. ed.), 3, 266.

Coops, J. \& Kaarsemaker, Sj. 1950 Rec. Trav. chim. Pays-Bas, 69, 1364.

Crawford, B. L. \& Brinkley, S. R. I94I J. Chem. Phys. 9, 69.

Genaux, C. T. \& Walters, W. D. 195I J. Amer. Chem. Soc. 73, 4497.

Kern, F. \& Walters, W. D. 1952 Proc. Nat. Acad. Sci., Wash., 38, 937.

Knowlton, J. W. \& Rossini, F. D. 1949 Bur. Stand. J. Res., Wash., 43, 113.

Mortimer, C. T., Pritchard, H. O. \& Skinner, H. A. 1952 Trans. Faraday Soc. 48, 220.

Pritchard, H. O., Sowden, R. G. \& Trotman-Dickenson, A. F. 1952 J. Amer. Chem. Soc. 74, 4472 .

Pritchard, H. O., Sowden, R. G. \& Trotman-Dickenson, A. F. 1953 Proc. Roy. Soc. A, 217, 563 (part II).

Prosen, E. J. \& Rossini, F. D. 1945 Bur. Stand. J. Res., Wash., 34, 263.

Pyke, R., Kahn, A. \& LeRoy, D. J. 1947 Industr. Engng Chem. (Anal. ed.), 19, 65.

Slater, N. B. 1953 Proc. Roy. Soc. A, 218, 224. 


\title{
Studies in energy transfer \\ II. The isomerization of cyclopropane-a quasi-unimolecular reaction
}

\author{
By H. O. Pritchard, R. G. Sowden and A. F. Trotman-Dickenson \\ Department of Chemistry, University of Manchester
}

(Communicated by M. G. Evans, * F.R.S.-Received 14 January 1953)

\begin{abstract}
The thermal isomerization of cyclopropane to propylene is a homogeneous unimolecular reaction at $490^{\circ} \mathrm{C}$ and at pressures down of $0.007 \mathrm{~cm}$. The rate constant of the unimolecular reaction falls off by a factor of ten as the pressure in the reaction system is decreased from 8.4 to $0.007 \mathrm{~cm}$. The results are compared with various theories of quasi-unimolecular reactions.

The addition of a non-reacting gas to the system counteracts the falling off. The relative efficiencies of a number of gases for maintaining the unimolecular rate constant have been measured.
\end{abstract}

One of the methods of obtaining information on the collisional transfer of energy between molecules in the gas phase is the study of the dependence of the rate of unimolecular reactions on pressure. The principle of this method is straighiforward and may be briefly stated. The rate of reaction of a particular molecule is a function of its energy content alone. The number of molecules, in a system at equilibrium, containing a particular amount of energy is given by the MaxwellBoltzmann distribution. This equilibrium distribution is maintained by collisional energy transfer. The overall observed rate of the unimolecular reaction may be expressed as the sum of the products of the number of molecules in a given energy level multiplied by the specific rate constant for the reaction of a molecule in that level. Now, at low pressure the rate of energy transfer by collision may not be sufficiently rapid to maintain the Maxwell-Boltzmann distribution in the face of the reaction of the most energetic molecules. This depopulation of the higher energy levels results in the decline of the overall rate constant. Hence if a suitable expression can be found for the specific rate constants of molecules with particular energy contents, much information on the rate of energy transfer on collision may be gained. There are a number of treatments of this point which we shall consider more fully in the discussion in connexion with our results.

A prerequisite for this approach is the discovery of a suitable reaction in which only one molecule is involved in the chemical change and which may be studied conveniently and accurately over a very large range of pressures and which involves comparatively simple molecules containing not more than a dozen or so atoms. Most of the large number of investigations which have been made can be faulted on these points. Indeed, Pease (I942) considered that no reaction had yet been discovered, with the possible exception of the isomerization of cyclopropane, 1952.

* Professor Evans had agreed to communicate this paper before his death on 25 December 
which fulfilled the necessary conditions for a satisfactory test of the theory to be made.

The thermal isomerization of cyclopropane was first studied from this point of view by Chambers \& Kistiakowsky (1934). Their observations only covered the range from 1 to $100 \mathrm{~cm}$ pressure, but did indicate a decline in the rate constant of a factor of 1.4 in that region. They concluded that this was a genuine example of quasi-unimolecular behaviour, but Corner \& Pease (1945) showed that the results, together with more data in the same pressure range obtained by them, could be equally well explained on the basis of a simple three-stage mechanism,

$$
\begin{array}{r}
C \stackrel{k_{1}}{\longrightarrow} R, \\
R \stackrel{k_{2}}{\longrightarrow} C, \\
R \stackrel{k_{3}}{\longrightarrow} P, \\
R+C \stackrel{k_{4}}{\longrightarrow} 2 P,
\end{array}
$$

where $C$ represents cyclopropane, $R$ the trimethylene biradical and $P$ propylene. One feature of this mechanism is that added non-reacting gases should have no effect upon the first-order rate constant, whereas they should increase the rate of a quasi-unimolecular reaction. Accordingly in support of their theory Corner \& Pease pointed out that the addition of hydrogen had no effect upon the rate constant. However, as will be seen the effective pressure of hydrogen added relative to that of cyclopropane was so low that the effect would be within the experimental error, which was rather large. Furthermore, there is no evidence for the existence of radicals in the system. Using the steady-state approximation, Corner \& Pease deduced an expression for the first-order rate constant $k_{1}$ from results if $k_{3} /\left(k_{2}+k_{3}\right)=0.88$ and $k_{3}=12 k_{4}$ and from the results of Chambers \& Kistiakowsky if $k_{3} /\left(k_{2}+k_{3}\right)=0 \cdot 34$ and $k_{3}=12 k_{4}$. (There appears to be an arithmetical error in their working here, for the recommended values of $k_{3} /\left(k_{2}+k_{3}\right)$ and $k_{3} / k_{4}$ do not give a constant value for $k_{1}$ when taken in conjunction with Chambers \& Kistiakowsky's results. Furthermore, the values of $k_{1}$ given in their paper as deduced from the work of Chambers \& Kistiakowsky differ greatly from those deduced from their own work despite the fact that the experimental observations were concordant. However, if $k_{3} /\left(k_{2}+k_{3}\right)$ is taken as 0.60 the results of Chambers \& Kistiakowsky may be recalculated to give a constant value of $k_{1}$ in excellent agreement with that derived from Corner \& Pease's experiments.) There is one critical feature of Corner \& Pease's mechanism, in that it predicts that at sufficiently low, as at sufficiently high, pressures, the observed first-order rate constant should become independent of pressure. Taking their parameters we find that at low pressures the logarithm of the ratio of the first-order rate constant, $k$, to the rate constant at high pressure, $k_{\infty}$, should approach the value $-0 \cdot 80$. We have followed the reaction down to values of $\log _{10} k / k_{\infty}$ below -1.0 at which there is no sign that the ratio is tending to a constant value. This fact, taken in conjunction with the effect of added gases at high relative effective pressures observed by us and described in the experimental part of this paper, leads us to reject the mechanism of Corner \& Pease as quite unsatisfactory. 
The experimental part of this paper describes the extension of the measurements of the rate of thermal isomerization of cyclopropane to a new low-pressure range and the effect of added gases on the rate constant in this range. This extension of the range was made possible by the adoption of an improved technique for analyzing the very small quantities of gases involved at the lowest pressures.

\section{EXPERTMENTAL}

\section{Materials}

The cyclopropane was an I.C.I. product of B.P. anaesthetic quality; a batch analysis showed that $99.6 \%$ of the gas was absorbed by concentrated sulphuric acid, and that less than $0.06 \%$ of propylene was present. Mass-spectrometer analysis showed that no more than $0.01 \%$ of propane could be present. The cyclopropane was carefully degassed before use.

Hydrogen was purified by passing it through a palladium thimble. Helium, argon, nitrogen and methane were commercially pure samples, further purified by contact with a sodium mirror. Carbon monoxide was prepared from anhydrous formic acid and concentrated sulphuric acid, and was also purified using a sodium mirror. The toluene was a highly purified sample; mesitylene was shaken twice with concentrated sulphuric acid, sodium carbonate solution and then water, and dried over calcium chloride; benzotrifluoride was washed with sodium hydroxide and water, dried with magnesium sulphate and distilled. Before being used, the liquids were degassed by bulb to bulb distillation in vacuo.

\section{Apparatus and procedure}

The reaction vessel was a cylindrical Pyrex bulb of 21 . capacity, which was supported in a furnace thermostatically controlled at approximately $490^{\circ} \mathrm{C}$. The main furnace element was wound on a cylindrical iron former, with provision for extra heating at the ends. The temperature was maintained constant by a gas thermometer which controlled a subsidiary heater winding (Taylor \& Sickman 1932). The gas thermometer consisted of a Pyrex Dewar flask, which was a close fit round the reaction vessel, the subsidiary heater winding being wound directly on the outside of the flask. The annular space contained air under about $120 \mathrm{~cm}$ pressure, and was connected by capillary tubing to a mercury contact manometer which operated the secondary heater winding through an electronic relay. By adjusting the amount of air in the annular space, any convenient temperature could be maintained. Using this arrangement, the temperature of the reaction vessel measured with a standardized six-junction chromel-alumel thermocouple, could be maintained constant to within $\pm 0.04^{\circ} \mathrm{C}$; the temperature variation along the length of the reaction vessel was less than $\pm 0 \cdot 5^{\circ} \mathrm{C}$.

The cyclopropane and the added gas were introduced into the reaction vessel through capillaries from a pair of calibrated gas burettes; this process took from 10 to $20 \mathrm{~s}$, for which a slight correction was applied; each gas burette was isolated from the reaction vessel by a mercury-sealed magnetic cut-off. In those cases when the second body being studied was a liquid, the vapour was bled into the 


\section{H. O. Pritchard, R. G. Sowden and A. F. Trotman-Dickenson}

reaction vessel until the required pressure, as indicated on a modified Pearson manometer (Pearson I93I), was reached. In all experiments where second bodies were used, the cyclopropane was introduced into the reaction vessel first, to exclude mixing difficulties, since the pressure of foreign gas used was always considerably higher than the pressure of cyclopropane; otherwise, the greater portion of the cyclopropane would tend to remain in the dead space, and not enter the reaction vessel.

At the end of a run, the contents of the reaction vessel were admitted to two wide-bore traps cooled in liquid nitrogen, any non-condensable foreign gas, if added, being pumped away at the same time. Since the reaction was arrested in this way, the connexion from the reaction vessel to the analysis section was made of wide-bore tubing, through a mercury float-valve cut-off constructed from $18 \mathrm{~mm}$ diameter tubing. This was done so that the gas should flow from the reaction vessel in a time which was short compared with the length of the runs even at the lowest pressures used; the results had to be corrected by $2 \%$ to allow for the rather large dead space thus introduced. In those cases where the second body was not a permanent gas, the cyclopropane-propylene mixture was separated off by lowtemperature fractionation at this juncture. The cyclopropane-propylene mixture was then passed through a mercury float-valve cut-off into a small trap, and samples were transferred to the gas-holders of a Blacet-Leighton micro-analysis apparatus (Blacet \& Leighton r93I) using a Toepler pump.

The propylene was absorbed on a mercuric acetate bead, as recommended by Pyke, Kahn \& LeRoy (I947). Tests showed that while the propylene was completely absorbed within $5 \mathrm{~min}$, there was only a very small absorption of cyclopropare, amounting to less than $0.5 \%$ of the sample. This uncertainty only becomes serious in runs going to high conversions, for the rate constant is then very sensitive to the accuracy of the analysis; most runs were carried to about $35 \%$ conversion, although some were continued to conversions as high as $70 \%$ to test the unimolecularity of the reaction. When large quantities of product were available, considerable care was taken to obtain a representative sample for analysis, because a slight fractionation of the cyclopropane-propylene mixture during the low-temperature distillations was observed in the early runs carried out at higher pressures. In no case did the reactants or the products come into contact with a greased tap from the time they were measured out to the end of the analysis, thereby eliminating the possibility of incurring any loss of materials. The calculated rate constants represent the mean of either two or three separate micro-analyses for each run at all but the very lowest pressures.

Experiments were carried out to ensure that there were no side reactions of any importance. Tests showed that no non-condensable gases were produced in the reaction, and that no condensation took place. For $\mathrm{C}_{3}$ hydrocarbons, this is a rigorous test, since side reactions must lead either to condensation or to lower hydrocarbons which are permanent gases. In the early experiments, condensation was observed in the runs immediately following the admission of air to the reaction vessel, but when this had been realized, the vessel was always 'aged' by leaving cyclopropane in it overnight, after which no appreciable loss could be detected. 


\section{Results}

\section{Experiments with cyclopropane alone}

Experiments using cyclopropane alone were carried out at pressures ranging from 8.41 to $0.0067 \mathrm{~cm}$ of mercury, the rate constant falling from $3 \cdot 15 \times 10^{-4} \mathrm{~s}^{-1}$ to $3 \cdot 19 \times 10^{-5} \mathrm{~s}^{-1}$. The results of these measurements, together with those of Chambers \& Kistiakowsky (1934), are presented in figure 1 as a plot of $\log _{10} k / k_{\infty}$ against the decadic logarithm of the cyclopropane pressure in $\mathrm{cm}$, where (Chambers \& Kistiakowsky r934)

$$
\log _{10} k_{\infty}=15 \cdot 17-65000 / 2 \cdot 3 R T \text {. }
$$

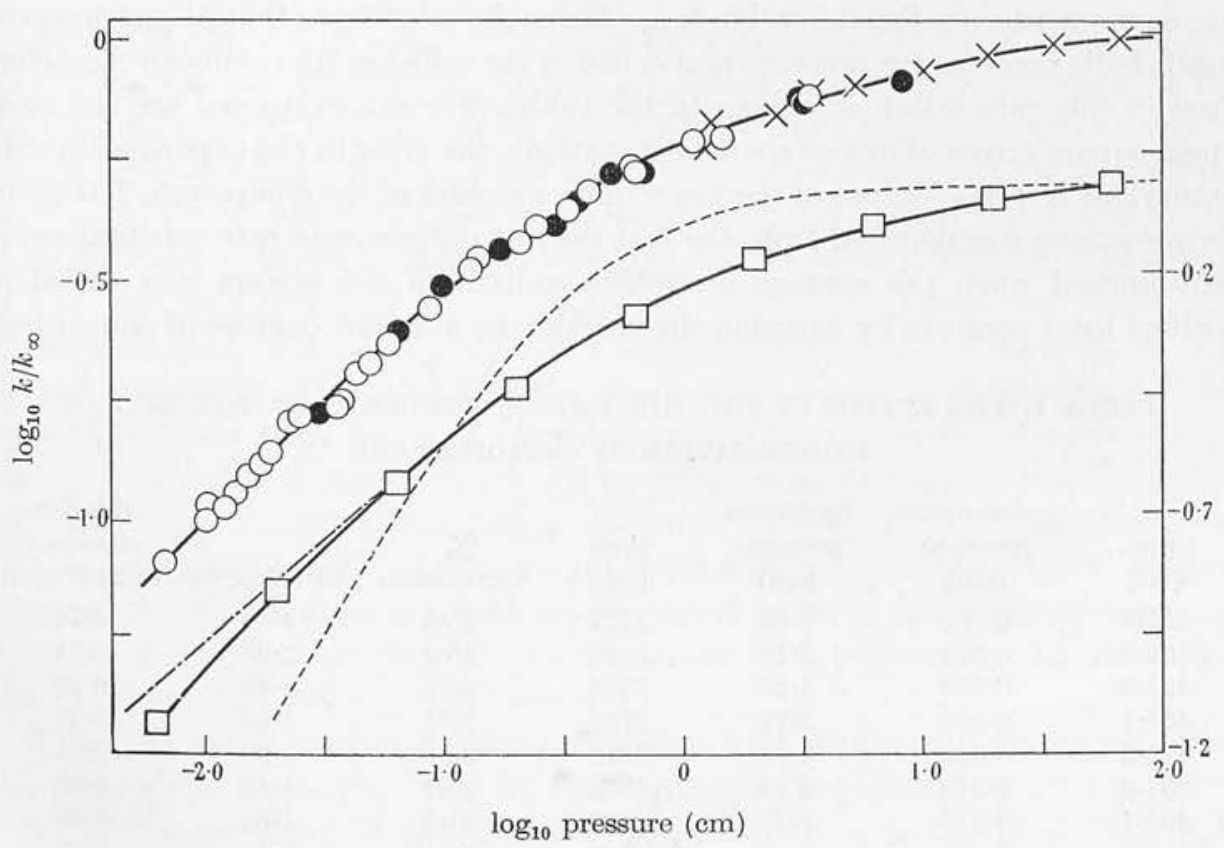

FIGURE 1. The dependence of the rate of isomerization of cyclopropane on pressure. Upper curve: $\bigcirc$, runs to about $30 \%$ conversion; $\bullet$, runs to about $70 \%$ conversion; $x$, results of Chambers \& Kistiakowsky. Lower curves: -, experimental results displaced by $0.3 \log$ units; ...., calculated Hinshelwood curve; -......, calculated Kassel curve; $\square$, points calculated by Slater.

This value is in excellent agreement with the value obtained by extrapolating a plot of $k^{-1}$ against $p^{-1}$ to infinite pressure for our own results; this concordance must be largely fortuitous, since Chambers \& Kistiakowsky imply that their temperature scale may be in error by as much as $2^{\circ} \mathrm{C}\left( \pm 12 \%\right.$ in $\left.k_{\infty}\right)$, and although we took considerable care to arrive at the best value for the temperature of the gas in our reaction vessel, an absolute error of as much as $1^{\circ} \mathrm{C}$ cannot be definitely ruled out. The points in figure 1 represent runs carried out at near $491^{\circ} \mathrm{C}$; a number of experiments carried out for selected pressures at $470^{\circ} \mathrm{C}$ showed that the variation in the ratio of $k / k_{\infty}$ was not sensitive to temperature. 


\section{Experiments with added gases}

Experiments in which added gases were used were carried out for cyclopropane pressures of from 0.01 to $0.1 \mathrm{~cm}$, a region where the rate constant shows considerable falling off, and for various pressures of additive. The choice of additive was restricted by two important requirements, first that the substance should be stable at the temperature of the experiment, and secondly that it should be readily separable from the cyclopropane-propylene mixture by low-temperature distillation. The results for hydrogen are given in table 1, the final column representing the efficiency of hydrogen relative to cyclopropane, pressure for pressure, in maintaining the value of the rate constant. The results obtained for a series of additives, representing a wide variation in collision diameters, vibrational frequencies and dipole moments, are listed in table 2, as efficiencies relative to that of cyclopropane itself, both pressure for pressure and collision for collision (the collision diameters used in this calculation are given in the table). The errors quoted are the rootmean-square errors of five or six determinations, the error in the experiments with mesitylene is large because of the low vapour pressure of the compound. The value for propylene was deduced from the fact that no difference in rate constant could be observed when the average propylene content of the system was varied at a given total pressure by carrying the reaction to different degrees of conversion.

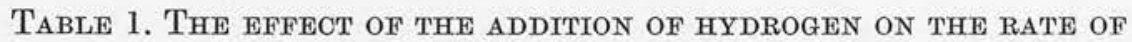
ISOMERIZATION OF CYCLOPROPANE

$\begin{array}{ccccccc}\begin{array}{c}\text { temp. } \\ \left({ }^{\circ} \mathrm{C}\right)\end{array} & \begin{array}{c}\text { cyclopropane } \\ \text { pressure } \\ (\mathrm{cm})\end{array} & \begin{array}{c}\text { hydrogen } \\ \text { pressure } \\ (\mathrm{cm})\end{array} & \begin{array}{c}\text { time } \\ (\mathrm{sec})\end{array} & \begin{array}{c}\% \\ \text { conversion }\end{array} & 10^{4} k\left(\mathrm{sec}^{-1}\right) & \begin{array}{c}\text { relative } \\ \text { efficiency } \\ \text { of hydrogen }\end{array} \\ 492 \cdot 6 & 0 \cdot 098 & 0.93 & 2727 & 38 \cdot 8 & 1 \cdot 80 & 0 \cdot 24 \\ 492 \cdot 8 & 0 \cdot 071 & 2 \cdot 19 & 2494 & 40 \cdot 5 & 2 \cdot 08 & 0 \cdot 21 \\ 493 \cdot 5 & 0 \cdot 078 & 3 \cdot 25 & 2726 & 48 \cdot 1 & 2 \cdot 40 & 0 \cdot 22 \\ 491 \cdot 1 & 0 \cdot 026 & 0 \cdot 71 & 2704 & 32 \cdot 5 & 1 \cdot 45 & 0 \cdot 27 \\ 491 \cdot 3 & 0 \cdot 025 & 1 \cdot 91 & 2312 & 35 \cdot 5 & 1.90 & 0 \cdot 24 \\ 491 \cdot 4 & 0 \cdot 018 & 0 \cdot 43 & 3665 & 37 \cdot 1 & 1 \cdot 26 & 0 \cdot 26 \\ 492 \cdot 1 & 0 \cdot 017 & 1 \cdot 27 & 2286 & 31 \cdot 9 & 1 \cdot 68 & 0 \cdot 20 \\ 491 \cdot 7 & 0 \cdot 020 & 3 \cdot 14 & 2107 & 38 \cdot 1 & 2 \cdot 28 & 0 \cdot 29\end{array}$

Efficiency of hydrogen relative to cyclopropane $=0.24 \pm 0.03$ (calculated on equivalent pressures).

At high pressures it has been found that the rate of isomerization is unaffected by packing the reaction vessel. The reproducibility of the relative efficiences of hydrogen, as recorded in table 1 , and of other added gases over a wide range of pressure cyclopropane and added gas indicates that no heterogeneous reaction is occurring at the lowest pressures.

\section{Discussion}

In figure 1 we have compared our experimental results with the predictions of three closely related theories of unimolecular reaction. The first is the original Hinshelwood-Lindemann (Hinshelwood 1940) theory in which no allowance is made for the possibility that molecules containing energy $(E)$ in excess of the 
minimum critical energy $\left(E_{0}\right)$ for reaction will have specific rate constants greater than those with only the minimum energy content. The marked divergence of the dotted curve, computed for a molecule of $5 \AA$ collision diameter and with energy content distributed among 11 square terms, from the solid curve shows that the assumption made is oversimplified. The more complex the molecule the more unsatisfactory this assumption will become.

The second theory tested is the classical form of the theory due to Kassel (1932) in which the observed unimolecular rate constant is given by the expression,

$$
\frac{k}{k_{\infty}}=\frac{1}{(N-1) !} \int_{0}^{\infty} \frac{x^{N-1} \mathrm{e}^{-x} \mathrm{~d} x}{1+\frac{A}{Z}\left(\frac{x}{b+x}\right)^{N-1}},
$$

where $b=E_{0} / k T, x=\left(E-E_{0}\right) / k T, A$ is the pre-exponential factor in the Arrhenius equation, $N$ is the number of effective oscillators in the molecule and $Z$ is the collision frequency. The number of effective oscillators can be chosen at will to give the best possible fit between the theoretical and experimental curves with the proviso that $N$ should not exceed $3 a-6$, which is the number of vibrational modes of a non-linear molecule containing $a$ atoms. As it is usually considered that $N$ is of the order of one-half of $3 a-6$, this is not a serious or useful restriction. The theories of Rice \& Ramsperger (Kassel I932) give very similar expressions. The dashed curve was obtained (following Chambers \& Kistiakowsky) using $N=13$, $E_{0}=65 \mathrm{kcal}$ and $3.9 \AA$ for the collision diameter of cyclopropane. A more convex curve which would be a better fit would be obtained by taking $N=12$ and a corresponding larger value for the collision diameter. As the calculations are laborious this was not done because the important point had been established that a treatment of the Kassel type in which an allowance is made for the greater rate of reaction of the more energetic molecules, was a much better approximation than the Hinshelwood-Lindemann treatment.

Slater (1953) has made a considerabie advance by producing a theory by which it is possible to define precisely the number of effective oscillators given a knowledge of the structure of the molecule. In addition, a complete spectroscopic vibrational analysis of the molecule is necessary for the application of the theory which is fully described by Slater (1953). The points are plotted as squares in figure 1 from the expression, which is closely related to that of Kassel,

$$
\frac{k}{k_{\infty}}=\frac{1}{\Gamma\left(\frac{n+1}{2}\right)} \int_{0}^{\infty} \frac{x^{1(n-1)} \mathrm{e}^{-x} \mathrm{~d} x}{1+\frac{x^{1}(n-1)}{\theta}},
$$

where $n$ is the effective number of non-degenerate vibrational modes in the molecule, for cyclopropane $n=13, \theta=3 \cdot 6 Z \beta \mid A, \beta=\Gamma\left(\frac{n+1}{2}\right) \mu_{1} \mu_{2} \ldots \mu_{n}(4 \pi b)^{\frac{1}{(n-1)}}$ and $\mu_{s}$ is a dimensionless parameter characteristic of the vibrational properties of the molecule; its derivation is fully discussed in Slater's paper. The factor 3.6 in the expression for $\theta$ has been introduced arbitrarily as a shift in the $\log p$ axis to make the theoretical and experimental curves coincide when the collision diameter of cyclopropane is taken as 5.0 $\AA$. The important point, however, which seems to be 
established is that the theory which involves no arbitrary parameters at all, predicts with a high degree of accuracy the shape of the curve of $\log k / k_{\infty}$ against $\log p$.

Howlett (1952) has attempted to discriminate between the Hinshelwood-Lindemann and Rice-Ramsperger theories in rather the same manner as is done here using the dehydrochlorination of 1:1-dichloroethane as a test case. His arguments, however, are not convincing. In his figure 3 he shows a plot which is similar to our figure 1, wherein he plots his experimental points and smoothed curve together with points (series B) calculated from the Hinshelwood-Lindemann expression

$$
k / k_{\infty}=1 /(1+6 \cdot 87 / p)
$$

where $p$ is the pressure in mm of mercury, and points (series A) calculated from the Rice-Ramsperger expression. The points of series A admittedly fall much closer to the experimental curve than do those of series B, which he claims shows that the Rice-Ramsperger theory gives a truer explanation of the facts than that of Hinshelwood \& Lindemann. But this comparison is not fair because the points which may be calculated from the Hinshelwood-Lindemann expression,

$$
k / k_{\infty}=1 /(1+1 \cdot 3 / p),
$$

fit the experimental results quite as well as the points of series A. Since the constant $\beta$ in the expression $\quad k / k_{\infty}=1 /(1+\beta / p)$

is always adjusted to fit the experimental points, this formula is quite as acceptable as that chosen by Howlett. In fact, the fit of the Hinshelwood-Lindemann plot is so good that it may be doubted if the reaction is as simple as it is claimed to be. Furthermore, the points which may be calculated in series A for $k$ at 15 and $20 \mathrm{~mm}$ which Howlett does not plot fall rather badly off the experimental curve. The most reasonable conclusion seems to be that, allowing for the scatter of the experimental points, there is little to choose between the two theories. Lastly, it may be pointed out that it is very difficult to decide between the theories of unimolecular reaction when the range of $k / k_{\infty}$ observed only lies between unity and one-third, unless the experimental work is of extremely high accuracy.

One of the principal uncertainties in applying any of the theories of unimolecular reactions is that the collision diameter for which a numerical value must be selected

\section{Table 2. Relative efficiencies of Foreign bodies in MaINTAINing}

\begin{tabular}{|c|c|c|c|}
\hline molecule & $\begin{array}{c}\text { efficiency } \\
\text { (pressure/pressure) }\end{array}$ & $\begin{array}{c}\text { collision } \\
\text { dicmeter }(\AA)\end{array}$ & $\begin{array}{c}\text { efficiency } \\
\text { (collision/collision) }\end{array}$ \\
\hline cyclopropane & $1 \cdot 000$ & $5 \cdot 0$ & $1 \cdot 000$ \\
\hline helium & $0.060 \pm 0.011$ & $2 \cdot 2$ & $0 \cdot 048$ \\
\hline argon & $0.053 \pm 0.007$ & $3 \cdot 6$ & 0.070 \\
\hline hydrogen & $0.24 \pm 0.03$ & $2 \cdot 7$ & $0 \cdot 12$ \\
\hline nitrogen & $0.060 \pm 0.003$ & $3 \cdot 8$ & 0.070 \\
\hline carbon monoxide & $0.072 \pm 0.009$ & $3 \cdot 8$ & $0 \cdot 084$ \\
\hline methane & $0.27 \pm 0.03$ & $4 \cdot 1$ & $0 \cdot 24$ \\
\hline water & $0.79 \pm 0.11$ & $4 \cdot 0$ & 0.74 \\
\hline propylene & $\sim 1.0$ & $5 \cdot 0$ & $\sim 1 \cdot 0$ \\
\hline benzotrifluoride & $1.09 \pm 0.13$ & $8 \cdot 5$ & 0.75 \\
\hline toluene & $1 \cdot 59 \pm 0.13$ & $8 \cdot 0$ & $1 \cdot 10$ \\
\hline mesitylene & $1 \cdot 43 \pm 0 \cdot 26$ & $9 \cdot 0$ & $0 \cdot 89$ \\
\hline
\end{tabular}
THE RATE OF ISOMERIZATION OF CYCLOPROPANE 
is an unknown quantity. Usually a value corresponding to the gas kinetic collision diameter is used, but it is by no means certain that every gas kinetic collision results in the transfer of internal energy. In most cases it is impossible to obtain direct evidence on this point; however, some information can be gleaned from the values of the relative efficiencies of the various gases recorded in table 2 . The efficiencies calculated on a pressure basis are directly determined, but it seems that efficiencies based upon the number of gas kinetic collisions between the various types of molecule will be more illuminating; accordingly, we have tabulated these efficiencies in the last column. No statistical correction was made to allow for counting all collisions between the like cyclopropane molecules twice because here we are not concerned with collisions between like molecules, but with collisions between the relatively few energized cyclopropane molecules and the rest of the molecules in the system. The reasonable assumption is made that the collision diameters of the energized molecules are the same as those of the ordinary molecules. It can be seen that the simpler molecules have efficiencies considerably less than that of cyclopropane but that all the more complex molecules have similar efficiencies. The simplest interpretation of this fact is that significant internal energy transfer occurs between the energized cyclopropane molecule and another complex molecule on every collision but less often when the collision is with a small and simple molecule. The usual assumption of the theories, therefore, receives some confirmation from our results. This is the first evidence on this point which has been obtained and is therefore, of some importance. We hope to be able to find out whether the same order and magnitude of the efficiencies occur for other reactions.

The efficiencies found for the added gases have another and more practical interest. Several of the gases studied have been used as carrier gases in flow pyrolyses. When pyrolyzing simple molecules with a comparatively small number of internal vibrations it is quite possible that the pressure in the system, usually about 5 to $20 \mathrm{~mm}$, is so low that the Maxwell-Boltzmann distribution of energy is not maintained. Then the rate of energy transfer may become the rate-determining factor in the reaction. Toluene appears to be capable of transferring energy by collision far more efficiently than say nitrogen, hydrogen or helium, which have also often been used as carriers, and consequently has great advantages as a carrier when the rate of thermal decomposition of small molecules is being investigated.

\section{ReFerences}

Blacet, F. E. \& Leighton, P. A. 193 I Industr. Engng Chem. (Anal. ed.), 3, 266.

Chambers, T. S. \& Kistiakowsky, G. B. 1934 J. Amer. Chem. Soc. 56, 399.

Corner, E. S. \& Pease, R. N. I945 J. Amer. Chem. Soc. 67, 2067.

Hinshelwood, C. N. 1940 Kinetics of chemical change. Oxford Univ. Press (Chap. IV).

Howlett, K. E. I952 J. Chem. Soc. p. 3695.

Kassel, L. S. 1932 Kinetics of homogeneous gas reactions. New York: Chemical Catalog Co. Pearson, T. G. I93I Z. phys. Chem. A, 200, 284.

Pease, R. N. 1942 Equilibrium and kinetics of gas reactions. Princeton (Chap. VI).

Pyke, R., Kahn, A. \& LeRoy, D. J. I947 Anal. Chem. 19, 65.

Slater, N. B. 1953 In course of publication.

Taylor, H. S. \& Sickman, D. V. 1932 J. Amer. Chem. Soc. 54, 602. 


\title{
Preprinted from the Journal of the Chemical Society, December, 1953, (792), pages $3878-3881$.
}

\section{The Thermal Decomposition of Azomethane.}

\author{
By M. Page, H. O. Pritchard, and A. F. Trotman-Dickenson.
}

\begin{abstract}
The thermal decomposition of azomethane has been reinvestigated in the temperature range $390-450^{\circ}$ by the "toluene-carrier" flow technique. The rate constant for the decomposition in $15 \mathrm{~mm}$. of toluene is given by $k=10^{14} \mathrm{e}^{-46,000 / R T} \mathrm{sec}^{-1}$. The experiments provide strong evidence that the primary step in the decomposition is the splittingoff of a methyl radical. The reason for the discrepancy between these results and those obtained in static systems and the bond strengths in azomethane are discussed.
\end{abstract}

THE thermal decomposition of azomethane has been investigated by several workers (Schumacher, "Chemische Gasreaktionen," Steinkopf, Dresden, 1938) because there was good evidence that it is a unimolecular reaction whose rate is dependent on the overall pressure in the reaction system, at pressures which are readily accessible to experiment. It has frequently been supposed that the azomethane molecule splits directly into an ethane and a nitrogen molecule, but this view receives no support from Riblett and Rubin (J. Amer. Chem. Soc., 1937, 59, 1537) who analysed the products formed in the decomposition and found considerable quantities of methane, some ethylene, and some unidentified involatile products. There are very few undoubtedly unimolecular reactions whose rates have been found to depend on the overall pressure and it is important to know if the decomposition of azomethane occurs so simply that it may be used to test theories of unimolecular reactions and of energy transfer.

There is a second point of interest in connection with this reaction : the rate constant has been given as $k=3.1 \times 10^{16} \exp (-52,000 / \boldsymbol{R} T) \mathrm{sec}^{-1}$ (Ramsperger, ibid., 1927, 49, 912; Kassel, "Kinetics of Homogeneous Gas Reactions," Chemical Catalog Co., New York, 1932) and alternatively as $k=8 \times 10^{15} \exp (-50,200 / \boldsymbol{R} T)$ (Rice and Sickman, J. Chem. Phys., 1936, 4, 242); in either case the pre-exponential or $A$ factor is very much larger than that which has been considered "normal" on theoretical grounds. It is understandable that such high $A$ factors should be found for chain reactions and it has been suggested that this reaction is a chain decomposition.

By studying the decomposition in a flow system in the presence of toluene we hoped to isolate the initial step of the azomethane decomposition and so throw light on these matters.

\section{EXPERIMENTAL}

Materials.-NN'-Dimethylhydrazine dihydrochloride (Hatt, Org. Synth., 1936, 16, 18) was converted into the cuprous chloride addition compound of azomethane (Diels and Koll, Annalen, 1925, 443, 262) which when heated at $120-140^{\circ}$ yielded azomethane; the gas was purified by bulb-to-bulb distillation in a vacuum-system. The toluene was twice pyrolysed and distilled before it was used for kinetic experiments.

Apparatus.-This was of the type used by Sehon and Szwarc (Proc. Roy. Soc., 1950, A, 202, 263).

Procedure.-The products of the pyrolysis flowed through an ice-salt trap which removed the dibenzyl, then through liquid-nitrogen traps which removed the condensable products; the methane and nitrogen were pumped into a storage and analytical system. The proportion of methane in the non-condensable gases was found by burning the mixture in oxygen over a platinum filament and measuring the carbon dioxide formed. As the analytical system was not very suitable for the determination of ethane the amount formed was taken as equal to $\left(\mathrm{N}_{2}-\frac{1}{2} \mathrm{CH}_{4}\right)$. Ethane was identified by its vapour pressure in the system. 
The toluene pressure in the flow system varied between 11 and $16 \mathrm{~mm}$., the toluene: azomethane ratio between 10 and 30 , and the contact time was between $1 \cdot 2$ and $1.4 \mathrm{sec}$. Between 10 and $50 \%$ of the azomethane was decomposed in a run. In calculating the results in the usual way on the basis of the nitrogen formed in the decomposition it was assumed that azomethane obeyed the perfect-gas laws.

\section{RESULTS AND DISCUSSION}

A plot of the logarithms of the rate constants against the absolute temperature is shown in the Figure. The solid line corresponds to the Arrhenius equation, $k=10^{14} \exp (-46,000 / \boldsymbol{R T}) \mathrm{sec}^{-1}$. The amount of methane formed varied from $30 \%$ of the non-condensables at the lower temperatures to $50 \%$ at the higher. It must be supposed that all this methane is produced from methyl radicals released in the primary decomposition which abstract hydrogen atoms from the toluene carrier gas. The ethane found could be produced either by a partial initial split of the molecule into ethane and nitrogen or by the combination of methyl radicals. It is not possible to decide directly by which path it is formed but it can be shown that the rate of formation of ethane is such that it may readily be accounted for by the combination of methyl radicals present in the concentrations corresponding to the rate of production of methane. If the rate constant for the reaction of methyl radicals with toluene is given by $k=1.4 \times 10^{11} \exp (-8300 / \boldsymbol{R T})$ mole $^{-1}$ c.c. sec. $^{-1}$ (Trotman-Dickenson and Steacie, J. Chem. Phys., 1951, 19, 329; Gomer and Kistiakowsky, ibid., p. 85), then the concentration of methyl radicals in a typical experiment in the middle of the temperature range, at $417^{\circ}$, was $1.07 \times 10^{-11}$ mole c.c. ${ }^{-1}$ in the reaction zone. This

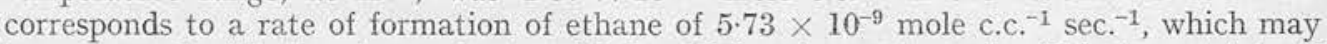
be compared with the observed rate of $3.2 \times 10^{-9}$ mole c.c. ${ }^{-1} \mathrm{sec}^{-1}$. This is certainiy of the correct order of magnitude and the difference probably arises partly because the effective volume of the reactor for the reactions of methyl radicals is rather larger than the effective volume for the decomposition. The positions of the limits of the reaction zone are determined by the temperature profile in the furnace and consequently will be rather further from the hottest region for reactions with low activation energies. Because of this uncertainty and because the experimental errors in the determination of the methane : ethane ratio are rather large, a reliable value for the rate of reaction of methyl radicals with toluene cannot be calculated from our results, but the findings are strong evidence that all the ethane comes from the combination of methyl radicals.

Our results are compared with those of other workers and this is done in the Figure. The points for $15 \mathrm{~mm}$. total pressure are taken from the smoothed curves obtained by the authors for the variation of rate constant with pressure at the different temperatures. It has been assumed that toluene and azomethane have approximately equal efficiencies for purposes of energy transfer; this has not been proved for azomethane but the efficiencies are very similar for toluene, and indeed all large molecules, with cyclopropane (Pritchard, Sowden, and Trotman-Dickenson, Proc. Roy. Soc., 1953, A, 217, 563) and cyclobutane (idem, ibid., 218, 416). The agreement between the three sets of results is excellent.

A reason may be suggested for the discrepancy between these results and those obtained at high pressures, and for the complexity of the products from pure azomethane. The near identity of the rates measured by us and those obtained by the workers in static systems suggests that the same process, which is the fission of a $\mathrm{C}-\mathrm{N}$ bond, is rate-determining in each case. In pure azomethane, the methyl radicals will abstract hydrogen atoms from the substrate and will combine with the $\mathrm{Me} \cdot \mathrm{N}: \mathrm{N} \cdot \mathrm{CH}_{2} \cdot$ radicals so formed. Ethyl radicals, and hence ethylene, may be formed by the subsequent decomposition of $\mathrm{C}_{2} \mathrm{H}_{5} \cdot \mathrm{N}: \mathrm{NMe}$; the high-boiling products are probably formed by the addition of radicals to the nitrogen double bond (Taylor and Jahn, J. Chem. Phys., 1939, 7, 474). The higher activation energy found at high pressures is probably caused by the decomposition of some of the $\mathrm{Me} \cdot \mathrm{N}: \mathrm{N} \cdot \mathrm{CH}_{2} \cdot$ radicals which are formed in greater numbers at high pressures. The rate of decomposition of this chain-carrying radical will be markedly temperature-dependent. The number decomposing cannot be large as the quantum yield for the photolysis 
of azomethane is only slightly dependent upon temperature (Burton, Davis, and Taylor, $J$. Amer. Chem. Soc., 1937, 59, 1989). This decomposition will explain the high activation energies which lead to the abnormal frequency factors.

The activation energy of a unimolecular reaction whose rate is a function of pressure is also dependent on pressure, but the dependence is not sufficiently marked to be the cause of the difference found here (Slater, Phil. Trans., 1953, 246, A, 57). Probably the best expression for the high-pressure rate constant is $k=1.5 \times 10^{14} \exp (-46,000 / \boldsymbol{R} T)$ sec. ${ }^{-1}$. In view of these results it seems that the dependence of the rate constants on pressure is real but that the shape of the pressure-rate-constant curve is influenced by factors other than energy transfer. Consequently this decomposition is not an ideal reaction on which to test theories of unimolecular reactions.

Arrienius plot for the decomposition of azonithane in a system at approx. $15 \mathrm{~mm}$. total pressure.

This work.

6 Ramsperger (loc. cit.).

$\triangle$ Sickman and Rice (loc. cit.) - Ramsperger's results (loc. cil.) at infinite pressure.

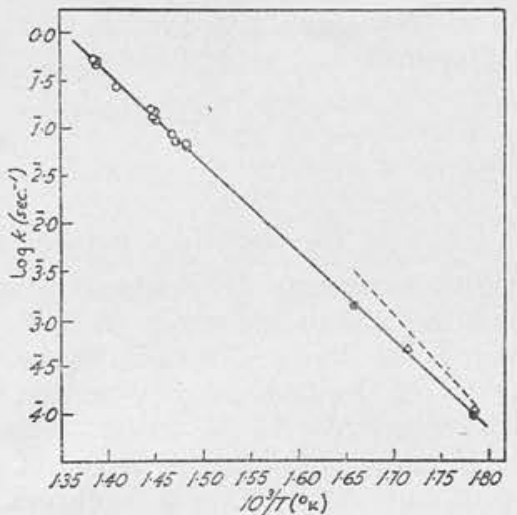

The heat of formation of azomethane is not known, but the heat of combustion of azoisopropane, $\operatorname{Pr}^{\mathrm{i}} \cdot \mathrm{N}: \mathrm{N} \cdot \mathrm{Pr}^{\mathrm{i}}$, has been found (Coates and Sutton, $J ., 1948,1187$ ) to be $\Delta H f\left(\mathrm{Pr}^{\mathrm{i}} \cdot \mathrm{N}: \mathrm{N} \cdot \mathrm{Pr}^{\mathrm{i}}\right.$,gas $)=19.4 \pm 0.8 \mathrm{kcal}$. mole. Comparison with the substitution heats for olefins ("Selected Values of Properties of Hydrocarbons," Nat. Bur. Stand., Circular No C461, Washington, 1947) leads to the value $\Delta H f(\mathrm{Me} \cdot \mathrm{N}: \mathrm{N} \cdot \mathrm{Me}, \mathrm{gas})=43 \cdot 2 \mathrm{kcal} . / \mathrm{mole}$, an estimate which is unlikely to be in error by much more than $\pm 2 \mathrm{kcal} . / \mathrm{mole}$. If $\Delta H f\left(\mathrm{CH}_{3}, \mathrm{gas}\right)=32.6 \mathrm{kcal}$. (Mortimer, Pritchard, and Skinner, Trans. Faraday Soc., $1952,48,220$ ) is then used, this leads to a value of $D_{1}+D_{2}$ (i.e., the heat of the process $\mathrm{Me} \cdot \mathrm{N}: \mathrm{N} \cdot \mathrm{Me} \longrightarrow \mathrm{N}_{2}+2 \mathrm{Me}$ ) of $22 \mathrm{kcal}$. mole. Making the usual assumptions (Szwarc, Chem. Reviews, $1950,47,75)$, we identify the activation energy of $46 \mathrm{kcal}$. with $D_{1}$. The situation where $D_{1}$ is very much greater than $D_{2}$ exists in the alkylmercury series (Mortimer, Pritchard, and Skinner, loc. cit.), where, for example, $D_{1}+D_{2}$ for $\mathrm{HgMe}_{2}$ is $57 \mathrm{kcal}$, $D(\mathrm{Me}-\mathrm{HgMe}$ ) being $51 \mathrm{kcal}$.mole (Gowenlock, Polanyi, and Warhust, Proc. Roy. Soc., $1953, A, 218,269)$. Azomethane is the only known case in which $D_{1}$ is greater than $D_{1}+D_{2}$; however, this extreme result is not entirely unexpected in view of the very large amount of energy required to raise the nitrogen molecule to a bivalent state from its zero-valent ground state. The lowest triplet state of $\mathrm{N}_{2}$ is $\mathrm{A}^{3} \Sigma_{u}{ }^{+}$which is $143.5 \mathrm{kcal}$. above the ground state (Herzberg, "Diatomic Molecules," Van Nostrand, New York, 1950 ) and it is reasonable to assume that the valency state is not far removed from this level. We can form an estimate of this excitation energy from the thermochemical data in the following way: the strength of a normal $\mathrm{C}-\mathrm{N}$ single bond is approximately 83 kcal./mole (Roberts and Skinner, Trans. Faraday Soc., 1949, 45, 339), so that $D_{1}+D_{2}$ for azomethane should be $166 \mathrm{kcal}$. if no excitation energy were regained by $\mathrm{N}_{2}$ in returning to its zero-valent state; the actual value of $D_{1}+D_{2}$ is $22 \mathrm{kcal}$., so that the excitation energy involved is $166-22=144 \mathrm{kcal}$. $/$ mole, which is very close to the spectroscopic estimate, although this agreement is probably fortuitous.

It is possible that the molecule does not initially lose one methyl group closely followed by a second, but that both methyl groups split off simultaneously. It has hitherto not been necessary to postulate such a mechanism for any other reaction and it can be shown 
by thermochemical argument that it is not necessary in this case either. Compare the bond strengths in the two analogous molecules

$$
\text { Me-N: } \quad \mathrm{Me}_{\mathrm{Me}}>\mathrm{C}=\mathrm{O}:
$$

To the first approximation the $\mathrm{Me}-\mathrm{N}$ dissociation energy in azomethane should be 83 kcal., and the $\mathrm{Me}-\mathrm{C}$ dissociation energy in acetone should be $84 \mathrm{kcal}$. (Roberts and Skinner, loc. cit.); however, the $\mathrm{C}-\mathrm{C}$ dissociation energy in acetone is only $73 \mathrm{kcal}$. ; this weakening of $11 \mathrm{kcal}$. may be ascribed to a three-electron bond formed by conjugation of the free electron on the carbon atom with one of the lone pairs on the oxygen atom in the $\mathrm{Me} \cdot \mathrm{CO}$. radical. That this resonance energy is of the correct order of magnitude may be seen from a study of the annexed Table, in which the relevant dissociation energies (in $\mathrm{kcal} . / \mathrm{mole}$ ) are collected ; they are all based on the values given by Gaydon ("Dissociation Energies," 2nd edn., Chapman and Hall, London, 1953) which, although they may not be correct,

$$
\begin{array}{cr}
\text { Azomethane } & \text { Acetone } \\
D(-\mathrm{N}=\mathrm{N}-)=82^{a} & D(-\mathrm{C}: \mathrm{O})=178^{a} \\
D\left(-\mathrm{N}=\mathrm{N}^{+}\right)=201^{\circ} & D\left(\cdot \mathrm{C}: \mathrm{O}^{+}\right)=194^{\circ} \\
D(\mathrm{~N} \equiv \mathrm{N})=225^{\circ} & D(\mathrm{C} \overline{\mathrm{O}})=256^{\circ} \\
{ }^{\circ} \text { Thermochemical estimate. } & \text { GFrom Gaydon, op. cit. }
\end{array}
$$

are internally consistent. The strengthening due to three-electron bond resonance in $\mathrm{CO}^{+}$relative to $>\mathrm{CO}$ in acetone is $16 \mathrm{kcal}$., which is of the same order of magnitude as the stabilisation of the $\mathrm{Me} \cdot \mathrm{CO} \cdot$ radical (the stabilisation of $\mathrm{Me} \cdot \mathrm{CO} \cdot$ is about two-thirds of that in $\mathrm{CO}^{+}$). In the azomethane case, the stabilisation by three-electron bond resonance of $\mathrm{N}_{2}{ }^{+}$with respect to $-\mathrm{N}=\mathrm{N}-$ in azomethane itself is $119 \mathrm{kcal}$. If again we take twothirds of this as the stabilisation energy of the $\mathrm{Me} \cdot \mathrm{N}: \mathrm{N} \cdot$ radical, we get $80 \mathrm{kcal}$, leaving the dissociation energy $D(\mathrm{Me}-\mathrm{N}: \mathrm{N} \cdot \mathrm{Me})$ of the order of $83-80=3 \mathrm{kcal} . / \mathrm{mole}$. This calculation merely serves to show that $46 \mathrm{kcal}$. $/$ mole is not an unreasonably low value for the dissociation energy of this single $\mathrm{C}-\mathrm{N}$ bond : no significance should be ascribed to the exact calculated value.

The idea of this investigation was suggested during a discussion between one of the authors and Professors O. K. Rice and M. Szwarc.

Chemistry Department, University of Manchester.

[Received, July 10th, 1953.] 


\section{Preprinted from the Journal of the Chemical Society, February, 1954, (4651), pages 546-549.}

\section{The Thermal Decomposition of tert.-Butylamine.}

By H. O. Pritchard, R. G. Sowden, and A. F. Trotman-Dickenson.

[Reprint Order No. 4651.]

The thermal decomposition of tert.-butylamine has been studied in a static system in the temperature range $498-541^{\circ}$ and over the pressure range $5-18 \mathrm{~cm}$. The reaction was followed by pressure measurements and by analysis of the products. The pressure increase is due to the alternative simultaneous homogeneous first-order molecular scissions :

and

$$
\begin{aligned}
& \mathrm{CMe}_{3} \cdot \mathrm{NH}_{2} \longrightarrow \mathrm{CMe}_{2}: \mathrm{CH}_{2}+\mathrm{NH}_{3} \text {. . . . . } \\
& \mathrm{CMe}_{3} \cdot \mathrm{NH}_{2} \longrightarrow \mathrm{C}_{3} \mathrm{NH}_{7}+\mathrm{CH}_{4} \text {. . . . . . }
\end{aligned}
$$

together with a subsequent slow reaction of the products, for which a correction can be readily applied. The ratio of ammonia to methane was $1: 2.5 \pm$ $0 \cdot 1$ over the temperature range studied, indicating that the activation energies of reactions (1) and (2) do not differ by more than $1 \mathrm{kcal} . / \mathrm{mole}$. A leastsquares Arrhenius plot gave an overall rate constant

$$
k=10^{14 \cdot 79} \exp (-67,100 / \boldsymbol{R T}) \mathrm{sec}^{-1} .
$$

A LARGE number of unimolecular decompositions are known in which one molecule splits directly into two normal molecules. These reactions may be called " molecular-split" reactions, to distinguish them from reactions in which free radicals are formed. The simplest reactions of this class are those which occur through a transition state containing a ring of four atoms and they are often called four-centre reactions. The activation energies of many of these reactions have been measured. In Table 1 are given the activation energies of some of the simplest of them (including the results of this research).

\begin{tabular}{|c|c|c|c|c|c|}
\hline \multirow[b]{2}{*}{$\mathrm{CH}_{3} \cdot \mathrm{CR}_{2} \mathrm{X}$} & \\
\hline & $\mathrm{HCl}$ & $\mathrm{HBr}$ & $\mathrm{H}_{2} \mathrm{O}$ & $\mathrm{NH}_{3}$ & $\mathrm{CH}_{4}$ \\
\hline …........................... & $60 \cdot 8^{a}$ & $53 \cdot 9^{d}$ & - & - & 一 \\
\hline 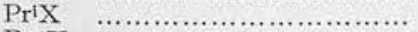 & $50 \cdot 5^{b}$ & $47 \cdot 8^{d}$ & 一 & - & - \\
\hline ButX …............................ & $41.4^{\circ}$ & $42 \cdot 2^{d}$ & $65.5^{\mathrm{e}}$ & $67 \cdot 1^{f}$ & $59 \cdot 3 ?$ \\
\hline $\mathrm{u}^{\mathrm{t}} \cdot \mathrm{NH}_{2} \ldots$ & - & - & - & $67 \cdot 1^{f}$ & $67 \cdot 1^{f}$ \\
\hline
\end{tabular}

TABLE 1. Activation energies (in kcal./mole) of reaction of the type

$$
\mathrm{CH}_{3} \cdot \mathrm{CR}_{2} \mathrm{X} \longrightarrow \mathrm{CH}_{2}: \mathrm{CR}_{2}+\mathrm{HX} \text {. }
$$

a Barton and Howlett, $J ., 1949,148$. 'Barton and Head, Trans. Faraday Soc., 1950, $46,114$. e Barton and Onyon, ibid., 1949, 45, 725. ¿ Blades and Murphy, J. Amer. Chem. Soc., 1952, 74, 6220; Green, Harden, Maccoll, and Thomas, J. Chem. Phys., 1953, 21, 178. ' Schultz and Kistiakowsky, J. Amer. Chem. Soc., 1934, 56, 395. 'f This work. 'g Peard, Stubbs, and Hinshelwood, Proc. Roy. Soc., 1952, A, 214, 330 .

However, no satisfactory interpretation of the variations in their activation energies has yet been given. In an attempt to throw light on the general theoretical problem by provision of further results the decompositions of ethanethiol and isobutanethiol (2-methylpropane-2-thiol) were examined. Our experimental results with the former are exactly similar to those of Trenner and H. A. Taylor (J. Chem. Phys., 1933, 1, 77), though we regard their mechanism involving the initial formation of polysulphides as rather improbable since the sulphur-sulphur bond is not strong. Very similar results were found by us with isobutanethiol so that it was not suitable for the present purpose either. This was disappointing, as a consideration of the bond strengths might lead one to suppose that the behaviour of the alkanethiols would be similar to that of the alkyl chlorides and bromides. The decomposition of tert.-butylamine was expected to occur smoothly because 
of its similarity to tert.-butanol. It was found that tert.-butylamine decomposed by way of the two molecular-split mechanisms (1) and (2) (above), having rate constants given respectively by the expressions $k_{1}=1.7 \times 10^{14} \exp (-67,000 / \boldsymbol{R T}) \mathrm{sec}^{-1}$ and $k_{2}=4.4 \times$ $10^{14} \exp (-67,000 / \boldsymbol{R} T) \mathrm{sec}^{-1}$. This is of interest because examples of a molecule reacting by two distinct molecular-split mechanisms are rare, though of course, numerous reactions are known which proceed by different ionic or free-radical mechanisms.

However, this work has complicated rather than clarified the general problem of the factors affecting the activation energy of molecular-split reactions.

\section{Experimental and Results}

Materials.-tert.-Butylamine (B.D.H.), distilled through a 30 -plate column (reflux ratio $8: 1$ ), had b. p. $64 \cdot 2^{\circ} / 757 \mathrm{~mm}$. The toluene was a highly purified sample. Before use the reagents were carefully degassed by bulb-to-bulb distillation in vacuo.

Fig. I. Typical plot of logarithm of (initial pressure-pressure increase) against time.
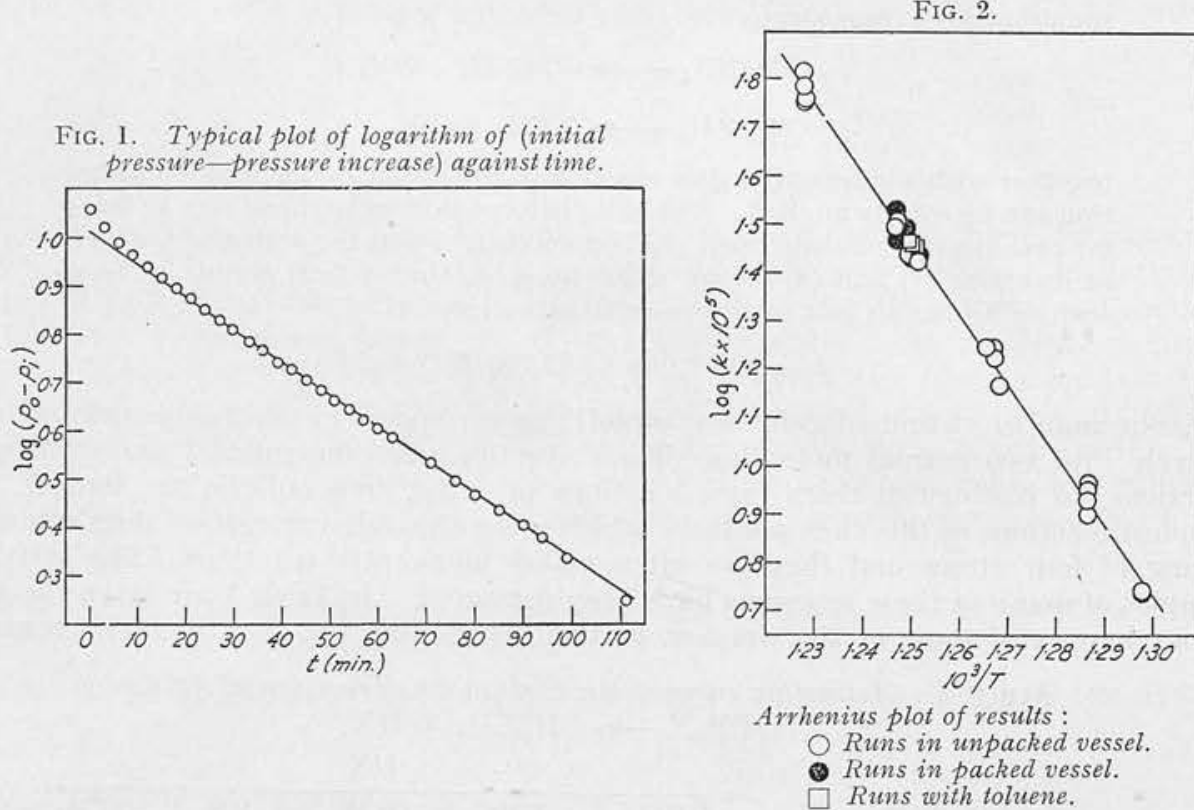

Apparatus and Procedure.-The reaction vessel was a 2-1. Pyrex bulb supported in a thermostatically controlled furnace, as used in our previous work (Proc. Roy. Soc., 1953, A, 217, 563). The reaction was followed by means of a mercury manometer connected to the reaction vessel.

Results.-A typical plot of the logarithm of (initial pressure - pressure increase) against time is shown in Fig. 1. An initial fast reaction is observed, followed by a first-order reaction represented by the linear portion of the curve, which appears to accelerate after about two half-lives as is shown by the downward curvature of the plot. This curvature is believed to be caused by a secondary reaction of the products of the main reaction. The addition of toluene had no effect on the slope of the linear portion of the graph but eliminated the initial fast reaction. This was therefore supposed to be an alternative method of decomposition which proceeded by a free-radical chain mechanism; it was suppressed by the toluene when it was present or, when no toluene had been added, by the chain inhibitors (such as butene) produced in the decomposition. This hypothesis was tested by admitting more tert.-butylamine into the reaction vessel during a run. As predicted, the fast reaction did not recur.

The rate constant $\left(k_{3}\right)$ for the secondary reaction $(3)$ (the nature of which is discussed in a later section of this paper), was found by following the pressure increase after the main reaction had proceeded virtually to completion. It was assumed that this reaction also was a molecular split in which one of the product molecules split in two. Any other reasonable assumption would be equally good for the present purpose. Let $k$ be the rate constant of the principal reaction; then $k \gg k_{3}$, and it can be shown that a correction for the second reaction may be 
made by subtracting a quantity $p_{0}\left(1-\mathrm{e}^{-k_{3} t}\right)$ from the observed pressure at a time $t$, where $p_{0}$ is the initial pressure of the reactant. At $527^{\circ}, k_{3}$ was less than $0.05 k$ and this simple correction was shown to be justified. $k_{3}$ was determined only at $527^{\circ}$ because the measurement was lengthy and little error could be introduced by assuming that reaction (3) has the same temperature coefficient as the main reaction. An Arrhenius plot of the results is given in Fig. 2 for runs with initial pressures of reactant between 5 and $18 \mathrm{~cm}$. The straight line corresponding to the equation $k=6 \cdot 1 \times 10^{14} \exp (-67,100 / \boldsymbol{R} T) \mathrm{sec}^{-1}$ was obtained by the method of least squares, based only on the values obtained in an unpacked vessel in the absence of toluene. It can be seen that the values obtained in the presence of toluene and in a packed vessel of eight times the surface area of the unpacked vessel show no deviations outside the experimental error.

Analysis.-At the end of a run the stopcock $S_{1}$ was opened to admit the products into the analysis system shown in Fig. 3. At first with stopcocks $S_{2}$ and $S_{4}$ closed the gases were pumped by the two-stage mercury-diffusion pump $P$, through the pumped-down nitrogen-cooled trap

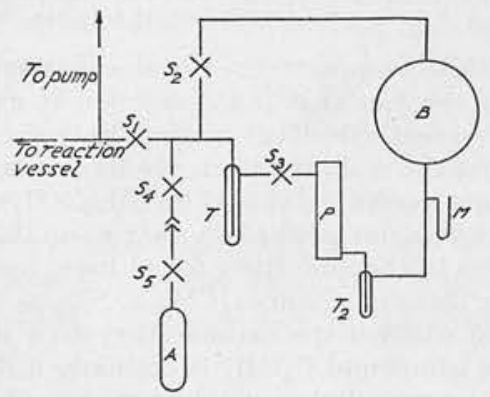

FIG. 3. Diagram of analysis apparatus.

$T$ at $-217^{\circ}$, into the $2-1$. bulb $B$, to which a manometer $M$ was attached. All the products except the hydrogen, which was subsequently identified by absorption in the heated copper oxide tube $T_{2}$, were condensed out and the pressure of the hydrogen was measured.

$T$ was then warmed to the temperature of liquid oxygen, and the pressure of methane measured, after which the non-condensable gases were pumped away. The pressures in the system when $T$ was at a temperature of $-78^{\circ}$ and at room temperature were then measured. These measurements gave the pressure of products whose composition will be considered later, and the total amount of gas withdrawn from the reaction vessel. The whole mixture was then distilled into the bulb $A$, which contained an excess of previously degassed dilute sulphuric acid; $A$ was removed from the system, allowed to warm, shaken to ensure satisfactory gas absorption, reattached to the vacuum-system, and cooled with solid carbon dioxide. Then the pressure of non-basic volatile gases was measured. As the amines present in the products were not volatile at $-78^{\circ}$, the difference in the pressures read with the products at this temperature, before and after absorption, gave the pressure of ammonia in the products. The volatile products were then shaken with concentrated sulphuric acid to absorb unsaturated compounds. It was found that an amount of gas equal to the amount of hydrogen formed in the reaction was not absorbed by the acid. By its vapour pressure this gas was identified as propane. It was established empirically for seven runs that the identity

Pressure of gas volatile at $-78^{\circ}=2 \times$ pressure of $\mathrm{NH}_{3}+2 \times$ pressure of $\mathrm{H}_{2}$

held. This was used for calculating the ratios of methane to ammonia produced. It may be interpreted by supposing that an amount of $i$ sobutene is formed equal to the amount of ammonia as is required by reaction (1), and that the hydrogen is produced by the secondary reaction (3) by which an equivalent amount of propane and of some other gas that is absorbed by sulphuric acid are also produced. We have not been able to continue a plausible reaction scheme to account for these products and they may be produced by a rather complex mechanism. However, the gases only represent some $4 \%$ of the total products. The hypothesis receives some confirmation from the reasonable agreement between the amount of hydrogen produced and the amount calculated by assuming that it is produced by reaction (3) (cf. cols. 5 and 6 of Table 2).

The complete analytical results, given in Table 2 , show that the conversion calculated from the pressure change in the reaction vessel is always some $10-15 \%$ higher than that calculated from the analytical results except for the two runs to which toluene was added. We believe that the discrepancy is caused by the formation by the initial rapid reaction of products which 
TABLE 2.

\begin{tabular}{|c|c|c|c|c|c|c|c|c|c|c|}
\hline Run & Temp. & $\begin{array}{l}\text { Total } \\
\text { press.* }\end{array}$ & $\mathrm{H}_{2} *$ & $\frac{\mathrm{H}_{2}}{\text { Total }}, \%$ & $\begin{array}{l}\text { Calc. \% } \\
\text { corr. }\end{array}$ & $\mathrm{CH}_{4} *$ & $\mathrm{NH}_{3}$ * & $\frac{\mathrm{CH}_{4}}{\mathrm{NH}_{3}}$ & $\begin{array}{l}\text { Conversion, } \\
\text { pressure change }\end{array}$ & $\begin{array}{l}\% \text {, by: } \\
\text { analysis }\end{array}$ \\
\hline 16 & $498^{\circ}$ & $5 \cdot 033$ & 0.111 & $2 \cdot 2$ & $2 \cdot 6$ & $1 \cdot 107$ & 0.436 & $2 \cdot 54$ & $37 \cdot 8$ & $32 \cdot 8$ \\
\hline 20 & 498 & $4 \cdot 738$ & $0 \cdot 117$ & $2 \cdot 5$ & $2 \cdot 6$ & 0.971 & $0 \cdot 406$ & $2 \cdot 39$ & $34 \cdot 9$ & $31 \cdot 5$ \\
\hline 21 & 498 & & 0.075 & & & 1.031 & 0.418 & $2 \cdot 47$ & & \\
\hline $26 \mathrm{~A}$ & 516 & $4 \cdot 868$ & 0.091 & 1.9 & $1 \cdot 2$ & $0 \cdot 845$ & $0 \cdot 3$ & $2 \cdot 56$ & $29 \cdot 6$ & $26 \cdot 0$ \\
\hline 29 & 516 & $4 \cdot 715$ & $0 \cdot 110$ & $2 \cdot 3$ & 1 . & 0.965 & 0.378 & $2 \cdot 55$ & $35 \cdot 0$ & \\
\hline 30 & 516 & $5 \cdot 120$ & $0 \cdot 1$ & $2 \cdot 3$ & $1 \cdot 7$ & 0.984 & $0 \cdot 374$ & $2 \cdot 63$ & $34 \cdot 9$ & 28.8 \\
\hline 33 & 541 & 一 & $0 \cdot 108$ & - & & 0.911 & $0 \cdot 348$ & $2 \cdot 62$ & 一 & - \\
\hline 35 & 541 & - & 0.084 & - & & $0 \cdot 781$ & $0 \cdot 336$ & $2 \cdot 32$ & - & - \\
\hline 37 & 541 & - & $0 \cdot 1$ & - & 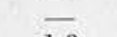 & 0.948 & $0 \cdot 3$ & 2 & - & - \\
\hline 48 & 527 & 3.938 & $0 \cdot 1$ & $2 \cdot 6$ & $1 \cdot$ & 0.700 & $0 \cdot 2$ & 2 . & 28.0 & $27 \cdot 1$ \\
\hline & $\$ 527$ & $3 \cdot 824$ & 0.091 & $2 \cdot 4$ & $1 \cdot 6$ & 0.671 & $0 \cdot 289$ & $2 \cdot 3$ & 28.8 & 27.8 \\
\hline B & 527 & $5 \cdot 148$ & $0 \cdot 116$ & $2 \cdot 3$ & 1 . & 1.116 & 0.433 & $2 \cdot$ & 34.9 & $32 \cdot 3$ \\
\hline & & $5 \cdot 061$ & 0 & & & 1.047 & 0.366 & 6 & & \\
\hline
\end{tabular}

* These pressures are in $\mathrm{cm}$. in the analysis system and have no absolute significance.

$\dagger$ Run in packed vessel.

$\S$ Run with added toluene.

polymerise on leaving the reaction vessel. This view is supported by the observation of a deposit in the connecting tubes and the trap $T$, and by the fact that if a correction is made for the products formed in the free-radical reaction the two methods of calculating the conversions agree very well. Accordingly, it may be concluded that the main reactions are those suggested here.

The exact nature of the substance $\mathrm{C}_{3} \mathrm{NH}_{7}$ is not known. It could be $\mathrm{CMe}_{2}: \mathrm{NH}$, which might well exist in the gas phase, or $\mathrm{NH}_{2} \cdot \mathrm{CMe} \cdot \mathrm{CH}_{2}$. It does not seem likely that a suitable analytical method could be devised to detect these products in the quantities found here, but some light might be thrown on this problem by studying the decomposition of $\left(\mathrm{CH}_{3}\right)_{3} \mathrm{C} \cdot \mathrm{ND}_{2}$ as the methane formed would be $\mathrm{CH}_{4}$ or $\mathrm{CH}_{3} \mathrm{D}$, depending upon whether the carbon atom drew its hydrogen from the amino- or from a methyl group. The compound $\mathrm{C}_{3} \mathrm{NH}_{7}$ is certainly a derivative of either the keto- or the enol form of acetone, for acetone diphenylhydrazone was obtained from the solution of the amine in dilute sulphuric acid.

The University, Manchester, 13.

[Received, September 14th, 1953.] 


\title{
Preprinted from the Journal of the Chemical Society, May, 1954, (4765), pages 1425-1428.
}

\section{The Reactions of Methyl Radicals with Acetone, Diethyl Ketone, and Di-tert.-butyl Peroxide.}

By G. O. Pritchard, H. O. Pritchard, and A. F. Trotman-Dickenson.

\author{
[Reprint Order No. 4765.]
}

The thermal decomposition of di-tert.-butyl peroxide between $130^{\circ}$ and $155^{\circ}$ has been reinvestigated and the rate constant for the initial fission of the $\mathrm{O}-\mathrm{O}$ bond found to be $4 \times 10^{16} \mathrm{e}^{-39,1000} \boldsymbol{R T} \mathrm{sec} .^{-1}$.

The rate constants for the hydrogen abstraction reactions of thermal methyl radicals with di-tert.-butyl peroxide, acetone, and diethyl ketone are given by $25 \times 10^{11} \mathrm{e}^{-11,700 / \boldsymbol{R} T}, 6 \cdot 4 \times 10^{11} \mathrm{e}^{-9500 / \boldsymbol{R} T}$, and $6.4 \times 10^{11} \mathrm{e}^{-8000 / \boldsymbol{R} T}$ mole ${ }^{-1}$ c.c. sec $^{-1}$, respectively.

Raley, Rust, and Vaughan ( $J$. Amer. Chem. Soc., 1948, 70, 88) have shown that the thermal decomposition of di-tert.-butyl peroxide is an essentially non-chain unimolecular process, leading predominantly to the formation of acetone and ethane by the following mechanism :

$$
\begin{aligned}
& \mathrm{CMe}_{3} \cdot \mathrm{O} \cdot \mathrm{O} \cdot \mathrm{CMe}_{3} \stackrel{k_{1}}{\longrightarrow} 2 \mathrm{CMe}_{3} \cdot \mathrm{O} \cdot . .+. .+. .+(1) \\
& \mathrm{CMe}_{3} \cdot \mathrm{O} \cdot \stackrel{k_{2}}{\longrightarrow} \mathrm{COMe}_{2}+\mathrm{CH}_{3} \cdot \quad \text {. . . . . . . } \\
& \mathrm{CH}_{3}+\mathrm{CH}_{3} \cdot \stackrel{k_{7}}{\longrightarrow} \mathrm{C}_{2} \mathrm{H}_{6} \text {. . . . . . . . . . }
\end{aligned}
$$

A small amount of methane was formed, probably by the reactions

$$
\begin{aligned}
\mathrm{CH}_{3}+\mathrm{CMe}_{3} \cdot \mathrm{O} \cdot \mathrm{O} \cdot \mathrm{CMe}_{3} & \longrightarrow \mathrm{CH}_{4}+\mathrm{CMe}_{3} \cdot \mathrm{O} \cdot \mathrm{O} \cdot \mathrm{CMe}_{2} \cdot \mathrm{CH}_{2} \cdot \\
\mathrm{CMe}_{3} \cdot \mathrm{O} \cdot \mathrm{O} \cdot \mathrm{CMe}_{2} \cdot \mathrm{CH}_{2} \cdot+\mathrm{CH}_{3} \cdot & \longrightarrow \mathrm{CMe}_{3} \cdot \mathrm{O} \cdot \mathrm{O} \cdot \mathrm{CMe}_{2} \cdot \mathrm{CH}_{2} \mathrm{Me}
\end{aligned}
$$

In the gas phase, in the presence of various organic substrates RH, the tert.-butoxyradical is presumed to exhibit no other reactions than (2), which is very fast, but additional reactions of the type (6) can occur.

$$
\mathrm{CH}_{3} \cdot \mathrm{RH} \stackrel{k_{6}}{\longrightarrow} \mathrm{R} \cdot+\mathrm{CH}_{4}
$$

The purpose of this investigation was to use thermal methyl radicals to study reaction (6) for substances (RH) which are photolytic sources of higher radicals, and whose absorption spectra are such that they themselves would be photolysed if the usual photolytic sources of methyl radicals, dimethylmercury and acetone, were used.

Incidentally, the thermal decomposition of the peroxide was again studied, the rate being measured by the formation of ethane and methane, since the decomposition of each molecule of peroxide leads to the formation of either one molecule of ethane or one of methane.

If $\mathrm{RH}$ is acetone, (6) becomes

$$
\mathrm{CH}_{3} \cdot \mathrm{CO} \cdot \mathrm{CH}_{3}+\mathrm{CH}_{3} \cdot \mathrm{CH}_{3} \cdot \mathrm{CO} \cdot \mathrm{CH}_{2} \cdot \mathrm{CH}_{4} \text {. . . . . . }
$$

The acetonyl radical then reacts with a methyl radical

$$
\mathrm{CH}_{3} \cdot \mathrm{CO} \cdot \mathrm{CH}_{2} \cdot \mathrm{CH}_{3} \cdot \longrightarrow \mathrm{CH}_{3} \cdot \mathrm{CO} \cdot \mathrm{C}_{2} \mathrm{H}_{5}
$$

to form ethyl methyl ketone. This compound was isolated by Raley, Rust, and Vaughan (loc. cit.) from the reaction products of the complete decomposition of the peroxide and was 
presumably formed by the products of (2) reacting together according to (7) and (8). Consequently, to evaluate correctly the methane formed in (6), the methane formed from the products of $(2)$ must be effectively suppressed. For this reason a high RH concentration is used, and only a small percentage of the peroxide is decomposed. The latter requirement is most important in the investigation of (4), because RH is now di-tert.butyl peroxide itself, and increase of its concentration only serves to increase the rate of (1) and thus the rate of ( 2 ) by a proportionate amount.

From the above reaction scheme the rate of methane formation is given by

and of ethane by

$$
\begin{aligned}
& \mathrm{d}\left[\mathrm{CH}_{4}\right] / \mathrm{d} t=R_{\mathrm{CH}_{4}}=k_{6}\left[\mathrm{CH}_{3} \cdot\right][\mathrm{RH}] \\
& \mathrm{d}\left[\mathrm{C}_{2} \mathrm{H}_{6}\right] / \mathrm{d} t=R_{\mathrm{C}_{4} \mathrm{H}_{6}}=k_{3}\left[\mathrm{CH}_{3} \cdot\right]^{2} \\
& k_{6} / R_{3} \frac{1}{2}=R_{\mathrm{CH}_{4}} / R^{!}{ }_{\mathrm{C}_{2} \mathrm{H}_{6}}\left[\mathrm{RH}_{]}\right.
\end{aligned}
$$

whence

The plot of $\log k_{6} / k_{3}{ }^{4}$ against $1 / T$ gives $E_{6}-\frac{1}{2} E_{3}$ and $A_{6} / A_{3}{ }^{4}$, where $T$ is the absolute temperature, $E$ is the activation energy, and $A$ is the frequency factor. By using Gomer and Kistiakowsky's values $(J$. Chem. Physics, $1951,19,85)$ of $E_{3}=0 \mathrm{kcal} . / \mathrm{mole}$ and $A_{3}=4.5 \times 10^{13}$ mole $^{-1}$ c.c. sec. $^{-1}$ for the recombination of methyl radicals, $E_{6}$ and $A_{6}$ can be obtained.

Experimental.-The method was to mix measured pressures of the peroxide and ketone in a 2-1. volume surrounded by a steam jacket. This mixture was expanded into a 3-1. reaction vessel immersed in an oil-bath thermostat which could be controlled to $\pm 0 \cdot 1^{\circ}$ for the period of an experiment. The reaction was terminated by pumping the reactants and products through wide-bore tubing and a liquid-nitrogen trap into a 3-1. bulb. The ethane was collected in liquid-nitrogen traps, and the methane was pumped from the collecting system by a mercury diffusion pump into an analysis system, which consisted of a Töpler pump and a gas burette. When the volume of methane had been measured, the ethane was pumped into the analysis system through traps kept at $-160^{\circ}$, and its volume measured.

\section{Results AND Discussion}

In all the runs about $10 \%$ of the peroxide was decomposed. When $\mathrm{RH}$ was ketone, [RH] was taken as the initial concentration, which was always $1.5-3$ times greater than the peroxide concentration. Not more than $0.5 \%$ of the acetone reacted, yielding $7-14 \%$ of methane of the total methane and ethane formed, and between 2 and $4 \%$ of the diethyl ketone reacted, the amount of methane formed varying between 31 and $55 \%$.

When $\mathrm{RH}$ was di-tert.-butyl peroxide, $[\mathrm{RH}]$ was taken as the arithmetic mean of the initial and final concentrations of the peroxide, the proportion of methane formed being between 2 and $3 \%$.

The values of $E_{1}, A_{1}$, and $k_{1}$ at $145^{\circ}$ which have been obtained from Fig. 1 are given in Table 1 , together with experimental values of other workers. The present results are

\begin{tabular}{|c|c|c|c|c|c|}
\hline System * & $E_{1}$, kcal./mole & & $A_{1}, \sec ^{-1}$ & $k_{1}, \sec ^{-1}\left(145^{\circ}\right)$ & Source $\dagger$ \\
\hline Peroxide... & $38 \cdot 6$ & & $1.9 \times 10^{16}$ & $1.3 \times 10^{-4}$ & This work \\
\hline Peroxide-acetone & $39 \cdot 5$ & & $5.9 \times 10^{16}$ & $1.3 \times 10^{-4}$ & \\
\hline Peroxide-diethyl ketone ............ & $39 \cdot 5$ & & $6 \cdot 8 \times 10^{16}$ & $1.5 \times 10^{-4}$ & \\
\hline Peroxide $, \ldots \ldots \ldots \ldots \ldots \ldots \ldots, \ldots \ldots \ldots$ & $39 \cdot 1$ & & $3.2 \times 10^{16}$ & $1.1 \times 10^{-4}$ & a \\
\hline Peroxide ... & $36-40$ & 6 & $\times 10^{14}-6 \times 10^{16}$ & $1 \times 10^{-1}$ & $b$ \\
\hline Peroxide-acetone .... & 37 & & $9 \times 10^{14}$ & $0.6 \times 10^{-4}$ & $c$ \\
\hline Peroxide-toluene (flow system) $\ldots$ & $36 \pm 1$ & 4 & $\times 10^{14}-7 \times 10^{14}$ & $1.3 \times 10^{-4}$ & $d$ \\
\hline Peroxide-toluene (static system)... & $34 \pm 2$ & & $4 \times 10^{13}$ & $0.6 \times 10^{-4}$ & $d$ \\
\hline Peroxide .......................... & 38 & & $7 \times 10^{15}$ & 一 & $e$ \\
\hline
\end{tabular}
seen to lead to a value of $E_{1}$ of $39 \pm 0.5 \mathrm{kcal}$. $/$ mole, with $A_{1}$ about $4 \times 10^{16} \mathrm{sec}^{-1}$.

TABLE 1.

* Peroxide $=$ di-tert.-butyl peroxide.

$\dagger a$, Raley, Rust, and Vaughan, loc. cit.; b. Brinton and Volman, J. Chem. Physics, 1952, 20, 25: c. Jaquiss, Roberts, and Szwarc, J. Amer. Chem. Soc., 1952, 74, 6005; d, Murawski, Roberts, and Szwarc, J. Chem. Physics, 1951, 19, 698; e, Lossing and Tickner, J. Chem. Physics, 1952, 20, 907 [this is a composite result of the high-temperature runs $\left(280-350^{\circ}\right)$ of these authors together with the results of $a$ and $d$. 
In Table 2 the values of $E_{6}, A_{6}$, and $k_{6}$ at $182^{\circ}$ obtained from Fig. 2 are given, together with the results of other workers.

The activation energy obtained for the reaction of methyl radicals with acetone is in excellent agreement with the results of other workers, using both photolytic and thermal methyl radicals. There is a sensible decrease in the activation energy obtained for the reaction with diethyl ketone, in accordance with the general trend exhibited by compounds containing only primary hydrogen atoms, and those containing both primary and secondary hydrogen atoms.

TABLE 2.

\begin{tabular}{|c|c|c|}
\hline \multicolumn{2}{|c|}{$\mathrm{RH}$ * } & $E_{6}$, kcal. $/$ mole \\
\hline Acetone & …........... & $9 \cdot 5 \pm 0.3$ \\
\hline " & ….. & $9 \cdot 7 \pm 0 \cdot 1$ \\
\hline " & ………... & $9 \cdot 6 \pm 0.4$ \\
\hline " & ……..... & $9 \cdot 5 \pm 0 \cdot 2$ \\
\hline & & $9 \cdot 5 \pm 1 \cdot$ \\
\hline & ne.. & $8 \cdot 0 \pm 0 \cdot 2$ \\
\hline roxid & & $11 \cdot 7 \pm 0 \cdot 3$ \\
\hline
\end{tabular}

$\begin{array}{cc}A_{6}, \text { mole }^{-1} \text { c.c. sec. }{ }^{-1} & k_{6}, \text { mole }^{-1} \text { c.c. sec. } \\ 6 \cdot 4 \times 10^{11} & 1.6 \times 10^{7} \\ 4 \cdot 0 \times 10^{11} & 1 \cdot 0 \times 10^{7} \\ 3 \cdot 0 \times 10^{11} & 0 \cdot 8 \times 10^{7} \\ 4 \cdot 0 \times 10^{11} & 1 \cdot 1 \times 10^{7} \\ 2 \cdot 7 \times 10^{11} & 0 \cdot 9 \times 10^{7} \\ 6 \cdot 4 \times 10^{11} & 9 \cdot 1 \times 10^{7} \\ 25 \times 10^{11} & 0 \cdot 6 \times 10^{7} \\ \left(300 \times 10^{11}\right) & 0 \cdot 2 \times 10^{7}\end{array}$

Source

This work $a$ $b$ c

This work $\ddot{e} \S$

* Peroxide $=$ di-tert.-butyl peroxide.

+ The probable errors in the activation energies are derived solely from consideration of the deviations of the points from the Arrhenius relationship.

$\ddagger a$, Trotman-Dickenson and Steacie, $J$. Chem. Physics, 1950, 18, 1097; b. Saunders and H. A. Taylor, ibid., 1941, 9, 616; c, Gomer and Kistiakowsky, loc. cit.; d, Jaquiss, Roberts, and Szwarc, loc. cit.; $\varepsilon$, Brinton and Volman, loc. cit.

$\S$ These quantities were not calculated in this manner by the original authors (see TrotmanDickenson, Quart. Reviews, 1953, 7, 198).

FIG. 2.

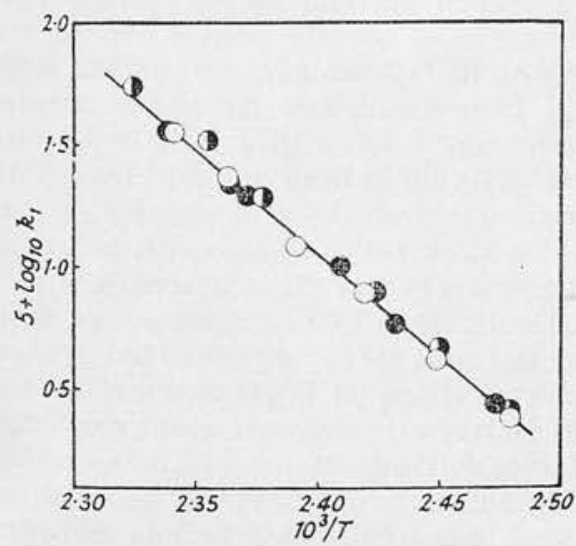

Arrhenius plots for the thermal decomposition of di-tert.-butyl peroxide: alone, $\bigcirc$ in the presence of acetone, and in the presence of diethyl ketone.

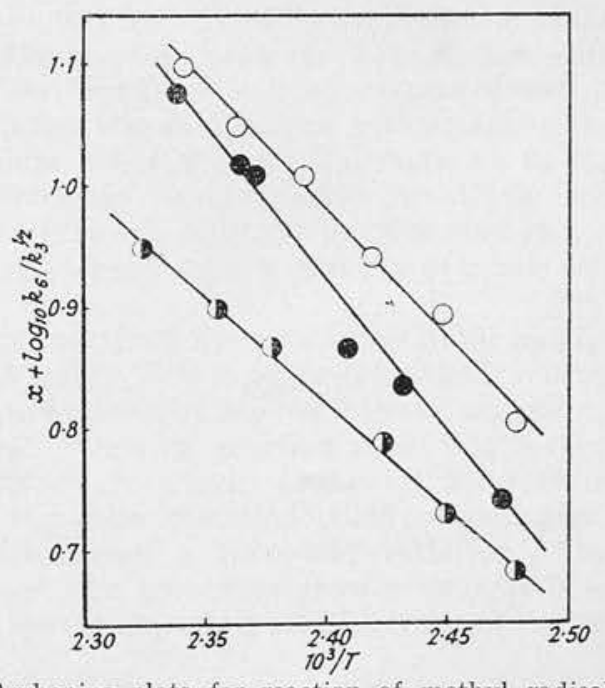

Arrhenius plots for reaction of methyl radicals with : Acetone, $x=1,0$ diethyl ketone, $x=0$, and di-tert.-butyl peroxide, $x=1 \cdot 48$.

Kutschke, Wijnen, and Steacie (J.Amer. Chem. Soc., 1952, 74, 714), using diethyl ketone as a source of ethyl radicals, studied the reaction

$$
\mathrm{C}_{2} \mathrm{H}_{5} \cdot+\mathrm{C}_{2} \mathrm{H}_{5} \cdot \mathrm{CO} \cdot \mathrm{C}_{2} \mathrm{H}_{5} \longrightarrow \mathrm{C}_{2} \mathrm{H}_{6}+\text { etc. }
$$

They found $E_{9}=7 \cdot 4 \mathrm{kcal}$. $/$ mole, with a steric factor of about $3 \times 10^{-4}$. The greater energy of activation required for the methyl $(8.0 \mathrm{kcal} . / \mathrm{mole})$ than the ethyl $(7 \cdot 4 \mathrm{kcal} . / \mathrm{mole})$ radical reaction is surprising, for one would expect that the ethyl radical reaction would require, if anything, a slightly higher activation energy than the methyl radical reaction, because the $\mathrm{C}-\mathrm{H}$ bond strength in methane exceeds that in ethane by about $5 \mathrm{kcal} . / \mathrm{mole}$.

The activation energy for methyl radical attack on di-tert.-butyl peroxide is surprisingly 
high, only methane requiring a higher activation energy of approximately $12.8 \mathrm{kcal} . / \mathrm{mole}$ (Trotman-Dickenson and Steacie, J. Phys. Colloid Chem., 1951, 55, 908), whilst other compounds containing only primary $\mathrm{C}-\mathrm{H}$ bonds have lower activation energies than the $11.7 \mathrm{kcal}$./mole required for di-tert.-butyl peroxide; e.g., ethane 10.4 and 2:2:3:3tetramethylbutane $9.5 \mathrm{kcal}$./mole (Trotman-Dickenson, Birchard, and Steacie, J. Chem. Physics, 1951, 19, 163). The reason why this should be is not clear.

One of us (G. O. P.) wishes to thank the Department of Scientific and Industrial Research for a maintenance grant.

UNIVERSITY OF MANCHESTER.

[Received, November 3rd, 1953.]

Printed in Great Britain by Richard Clay and Company, Ltd., Bungay, SUFFolK. 


\title{
Preprinted from the Journal of the Chemical Society, July, 1954, (4863), pages 2633-2635.
}

\section{The Exchange of Iodine Atoms between Iodine and Methyl Iodide in the Temperature Range $150-375^{\circ}$.}

\author{
By Douglas Clark, H. O. Pritchard, and A. F. Trotman-Dickenson.
}

[Reprint Order No. 4863.]

OGg and Polanyi (Trans. Faraday Soc., 1935, 31, 482) showed that the reaction between iodine atoms and sec.-butyl iodide leads to optical inversion of the butyl iodide molecule. They found that below $200^{\circ}$ the racemisation was a heterogeneous reaction of low activation energy ( $8 \mathrm{kcal} . / \mathrm{mole})$, but that in the temperature range $240-280^{\circ}$ the homogeneous inversion by iodine atoms predominated because of its considerably higher activation energy $(32 \cdot 2 \mathrm{kcal}$./mole); the investigation was complicated, however, by the fact that at these temperatures the butyl iodide molecule is unstable. In an attempt to gain a better understanding of the factors affecting these inversion reactions, we have studied the exchange of ${ }^{131} \mathrm{I}$ atoms between iodine and methyl iodide vapours, hoping to follow the very simplest example of an inversion reaction, i.e.,

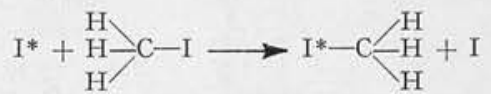

The reaction was studied over the temperature range $185-250^{\circ}$ in a Pyrex bulb of about 1 1. capacity: known pressures of methyl iodide $(c a .50 \mathrm{~cm}$.) and of radio-iodine (ca. $1 \mathrm{~cm}$.) were introduced into the bulb (at constant temperature; thermostat) and allowed to react; after a known time, the reaction was terminated by condensation of the iodine-methyl iodide mixture in liquid air. The reaction products were shaken with mercury and a little acetone to remove free iodine, and the remaining mixture of methyl iodide and acetone was distilled off and made up to a standard volume with acetone; the mercuric iodide left was dissolved in $10 \%$ sodium iodide solution and made up to the standard volume with water. The extent to which the reaction had occurred was then determined from the ratio of the $\gamma$-ray activities of the two solutions (tests showed only a minute difference between the $\gamma$-ray assay obtained when a known quantity of iodine was counted in either aqueous or acetone solution).

It was found that the rate of transference of radioactivity from the iodine to the methyl iodide was represented by the equation Rate $=k[\mathrm{MeI}]\left[\mathrm{I}_{2}\right]^{\frac{1}{2}}$, as is required for the inversion reaction, but that a plot of $\log k$ against $1 / T$ was not a straight line (see Figure), suggesting that the reaction might be partly heterogeneous. When the reaction vessel was packed with Pyrex tubes, increasing the surface to volume ratio by a factor of about 8 , the reaction rate increased 30 -fold; the reaction remained of first order in methyl iodide concentration, but became independent of iodine concentration over a three-fold variation. The Arrhenius plot of these first-order, heterogeneous rate constants gives a straight line, roughly parallel to the lower portion of the plot for the unpacked vessel, corresponding to an activation energy of about $17 \mathrm{kcal} . / \mathrm{mole}$.

By analogy with Ogg and Polanyi's results, we assumed that the reaction occurred by two mechanisms, one heterogeneous having an activation energy of about $17 \mathrm{kcal} . / \mathrm{mole}$, the other homogeneous having a higher activation energy; if this were the case, higher temperatures would favour the latter reaction, and in order to try to isolate this reaction, experiments were carried out at $375^{\circ}$ in a conventional flow pyrolysis apparatus (Leigh, Sehon, and Szwarc, Proc. Roy. Soc., 1951, A, 209, 97). The reactants were introduced into the reaction zone, methyl iodide vapour at about $8 \mathrm{~mm}$. pressure being used as a carrier for the iodine; the rate of flow of methyl iodide was adjusted to give a contact time of about $\frac{3}{4}$ sec., and the iodine pressure was adjusted to give about the same ratio of $[\mathrm{MeI}] /\left[\mathrm{I}_{2}\right]$ as in the static experiments. A point representing the mean of several bimolecular rate constants is shown in the Figure as a continuation of the Arrhenius curve, since the surface to volume ratios for the two unpacked reaction vessels were not very different. However, packing the reaction vessel showed that even at this temperature the 
reaction was largely heterogeneous, and the heterogeneous rate was still dependent only on the methyl iodide concentration. Two types of packing were used in testing for heterogeneity in the flow system. In one set of experiments the reaction zone was packed completely with short lengths of Pyrex tube, resulting in a 6-fold increase in surface to volume ratio; the rate of the reaction increased by a factor of 6 as a result. The rate constants obtained were scaled up in the ratio of 8 to 6 to allow for the disparity in surface to volume ratios of the two packed reaction vessels, and the mean point thus obtained was found to lie very close to the continuation of the Arrhenius plot for the heterogeneous reaction observed at lower temperatures; the best line through all these points represents an activation energy of $17.0 \mathrm{kcal} . / \mathrm{mole}$.

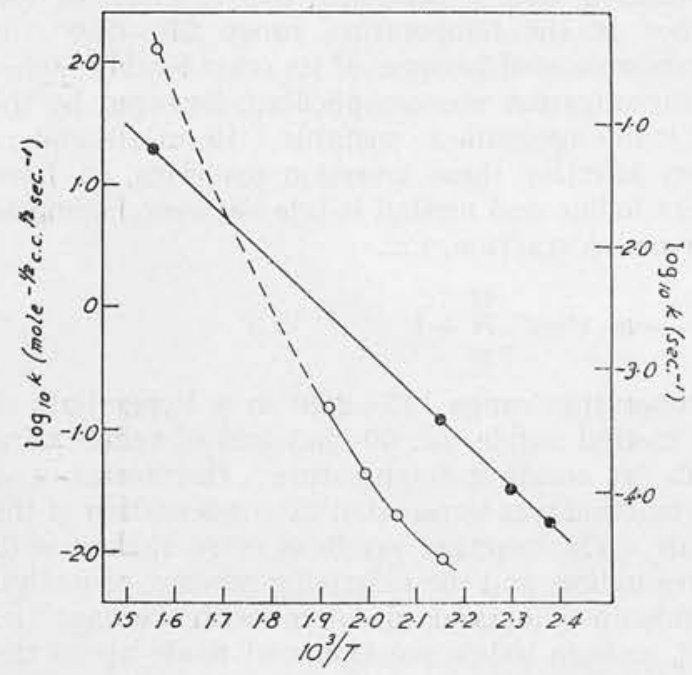

Arrhenius plots for the exchange of radioiodine with methyl iodide:

O in an unpacked reaction vessel,

- in a packed reaction vessel.

A second type of packing, which has sometimes been used in kinetic studies, was also tried : enough quartz fibre to increase the surface area of the effective reaction zone by a factor of $4-5$ was introduced into the vessel; the volume of this packing was quite small and it lay on the floor of the reaction vessel, occupying only about one-fifth of the volume of the reaction zone. No increase in reaction rate was observed under these conditions, suggesting that with contact times as short as those used here, the main body of the gas streams through the reaction vessel without coming into contact with the fibre packing. Such observations must cast some doubt on the interpretation of those kinetic measurements in which this type of packing was used, as it seems only to provide a stringent test for heterogeneity when it is distributed throughout the whole cross-section of the reaction zone.

These experiments show that it is not possible to isolate the reaction of higher activation energy, which probably represents the inversion of methyl iodide by iodine atoms (because of the nature of the kinetics in the unpacked vessels) at temperatures at which methyl iodide is stable; the only conclusion we can draw is that, from the slope of the upper portion of the Arrhenius curve, the activation energy is certainly not less than the $32 \cdot 2 \mathrm{kcal}$./mole observed by Ogg and Polanyi for sec.-butyl iodide.

We thank Professor Geoffrey Gee, F.R.S., for his interest, Manchester University for the award of an I.C.I. Fellowship to one of us (A. F. T.-D.), and the D.S.I.R. for the award of a maintenance grant (D. C.).

Chemistry Department, Manchester University.

[Present address (A. F. T.-D,): E. I. DUPONT DE

Nemours and Co., Niagara Falls.]

[Received, December 4th, 1953.]

Printed in Great Britain by Righard Clay and Company, Litd, Bungay, Suffolk. 
[Reprinted from the Journal of the American Chemical Society, 77, 2629 (1955).]

Copyright 1955 by the American Chemical Society and reprinted by permission of the copyright owner.

[CONtribution from the Department of Chemistry, University of Manchester]

\title{
The Study of Chlorine Atom Reactions in the Gas Phase
}

\author{
By H. O. Pritchard, J. B. Pyke ${ }^{1 a}$ and A. F. Trotman-Dickenson ${ }^{1 b}$ \\ Received November 19, 1954
}

The rates of chlorine atom attack on the following compounds: methane, ethane, propane, 2-methylpropane, 2,2-dimethylpropane, cyclopentane, methyl chloride and ethyl chloride, have been related to the rate of the reaction $\mathrm{Cl}+\mathrm{H}_{2} \rightarrow$ $\mathrm{HCl}+\mathrm{H}$. The rate factors listed in Table II were deduced from measurements made in the temperature range from 0 to $300^{\circ}$. The activation energies are lowest for those compounds which contain the weakest C-H bonds, but the activation energies and bond strengths are not linearly related. The most reactive compounds react with activation energies less than $1 \mathrm{kcal}$. No evidence is found for $A$ (pre-exponential) factors greater than the collision rates.

The reactions of chlorine atoms with hydrogencontaining compounds are chain reactions, and as such their over-all rates are very sensitive to the presence of small traces of impurity, to the condition of the surface of the reaction vessel and, in photochemical systems, to the intensity of the absorbed light. Consequently the many attempts which have been made to determine rate constants for the elementary reactions of chlorine atoms have met with disproportionately little success. However, Tamura ${ }^{2}$ was able to set an upper limit of 6

(1) (a) College of Forestry, N. Y. State University, Syracuse 10, N. Y.; (b) Chemistry Department, The University, West Mains Road, Edinburgh 9.

(2) M. Tamura, Rev. Phys. Chem. Japan, 15, 86 (1941). kcal. for the activation energy of reaction 1 a.

$$
\mathrm{Cl}+\mathrm{CH}_{4} \longrightarrow \mathrm{HCl}+\mathrm{CH}_{3}
$$

Schumacher and Wolff ${ }^{3}$ obtained $E<4.3 \mathrm{kcal}$. for the similar reaction with chloroform.

The rate constant of reaction $1 \mathrm{~b}$ is known accurately over the temperature range 273 to $1050^{\circ} \mathrm{K}$.

$$
\mathrm{Cl}+\mathrm{H}_{2} \longrightarrow \mathrm{HCl}+\mathrm{H}
$$

from the work of Ashmore and Chanmugam, ${ }^{4 a}$ Steiner and Rideal ${ }^{4 \mathrm{~b}}$ and Rodebush and Klingel-

(3) H. J. Schumacher and K. Wolff, Z. physik. Chem., B25, 161 (1934).

(4) (a) P. G. Ashmore and J. Chanmugam, Trans. Faraday Soc., 49, 254 (1953); (b) H. Steiner and E. K. Rideal, Proc. Roy. Soc. (Londox), A173, 503 (1939). 
hoeffer. ${ }^{5}$ When methane reacts with chlorine in the presence of hydrogen, it is possible to determine accurately the rate of the reaction 1a without any direct knowledge of the chlorine atom concentration, solely by measurement of the relative proportions of hydrogen and methane used up. Similarly the rate of reaction of methane can be compared with that of another hydrocarbon RH. Thus a whole series of reaction rates, based on the assumed value for the rate constant of reaction $1 \mathrm{~b}$, may be established.

When a mixture of two hydrocarbons and chlorine is illuminated, the following reactions are possible

$$
\begin{gathered}
\mathrm{Cl}_{2}+h \nu \longrightarrow \mathrm{Cl}+\mathrm{Cl} \\
\mathrm{Cl}+\mathrm{RH} \longrightarrow \mathrm{HCl}+\mathrm{R} \\
\mathrm{Cl}+\mathrm{R}^{\prime} \mathrm{H} \longrightarrow \mathrm{HCl}+\mathrm{R}^{\prime} \\
\mathrm{R}+\mathrm{Cl}_{2} \longrightarrow \mathrm{RCl}+\mathrm{Cl} \\
\mathrm{R}^{\prime}+\mathrm{Cl}_{2} \longrightarrow \mathrm{R}^{\prime} \mathrm{Cl}+\mathrm{Cl} \\
\mathrm{Cl}+\mathrm{Cl}+\mathrm{M} \longrightarrow \mathrm{Cl}_{2}+\mathrm{M} \\
\mathrm{R}+\mathrm{R}+\mathrm{M} \longrightarrow \mathrm{R}_{2}+\mathrm{M} \\
\mathrm{R}+\mathrm{Cl}+\mathrm{M} \longrightarrow \mathrm{RCl}+\mathrm{M} \\
\mathrm{RCl} \text { etc. }+\mathrm{Cl} \longrightarrow \mathrm{HCl}+\text { etc. }
\end{gathered}
$$

$\mathrm{RH}$ and $\mathrm{R}^{\prime} \mathrm{H}$ are only removed by reactions 1 and $1^{\prime}$. Now it can be readily shown ${ }^{6}$ that if

$$
-\frac{\mathrm{d}[\mathrm{RH}]}{\mathrm{d} t}=k_{1}[\mathrm{RH}][\mathrm{Cl}] \text { and }-\frac{\mathrm{d}\left[\mathrm{R}^{\prime} \mathrm{H}\right]}{\mathrm{d} t}=k_{1}^{\prime}\left[\mathrm{R}^{\prime} \mathrm{H}\right][\mathrm{Cl}]
$$

then

$$
\frac{k_{1}}{k_{1}^{\prime}}=\log \frac{[\mathrm{RH}]_{\mathrm{i}}}{[\mathrm{RH}]_{\mathrm{t}}} / \log \frac{\left[\mathrm{R}^{\prime} \mathrm{H}\right]_{\mathrm{i}}}{\left[\mathrm{R}^{\prime} \mathrm{H}\right]_{\mathrm{f}}}
$$

where the subscripts $i$ and $f$ refer to the initial and final concentrations of the reactants. Equation I will only break down if there is a significant back reaction -1 or $-1^{\prime}$; evidence on this point will be presented later.

We originally hoped to establish a complete series of reactivities starting from hydrogen and working upwards, but there was a large difference in the reactivities of methane and ethane. A number of likely substances were tried which we thought might be of intermediate reactivity, but it was found impossible to bridge the gap indirectly. We were forced to compete methane and ethane directly; this comparison is therefore rather less accurate than the others.

\section{Experimental}

Approximately $2.5 \times 10^{-4}$ mole of chlorine was measured out and distilled into a $160-\mathrm{ml}$. Pyrex reaction vessel cooled in liquid nitrogen. Known quantities of the two competing gases were then admitted and the vessel was sealed off from the vacuum system. The reaction vessel was placed in one of a number of constant temperature baths and allowed to warm up to bath temperature in complete darkness. It was then strongly illuminated for about an hour with light from a tungsten filament lamp to ensure complete reaction of the chlorine. Finally the reaction vessel was reattached to the vacuum system, the seal broken and the contents analyzed by fractional distillation as follows (the optimum conditions being determined by trial on known mixtures).

Methane-Hydrogen Mixtures.-The contents of the vessel were hydrogen chloride, methyl chloride (and some polychlorinated methanes) together with the residual methane and hydrogen. The further chlorination of the methyl chloride does not invalidate equation 1 , but means that the

(5) W. H. Rodebush and W. K. Klingelhoeffer, THIs JourNaL, 55, 130 (1933).

(6) W. M. Jones, J. Chem. Phys., 19, 78 (1951). amounts of $\mathrm{HCl}$ and $\mathrm{CH}_{3} \mathrm{Cl}$ produced cannot be used as a check on the results. The methane and hydrogen were separated easily from the other compounds because they are volatile at the boiling point of liquid nitrogen. They were pumped through a trap containing silica $\mathrm{gel}^{7}$ at $-193^{\circ}$; this removed the methane quantitatively, and upon warming up to room temperature released it completely. The volumes of residual hydrogen and methane were then measured separately. Runs were carried out at $20,60,100$, $135,146,168,211^{\circ}$; for range of concentrations used, see Table I.

\section{TABLE I}

Methane + hydrogen at $100^{\circ}$; amount of $\mathrm{Cl}_{2}$ added $=15.5$

\begin{tabular}{ccccc}
\multicolumn{5}{c}{$( \pm 1.0) \times 10^{-7}$ mole/cc. } \\
$\begin{array}{c}\text { Initial concn., } \\
\text { moles/cc. }\end{array}$ & $\begin{array}{c}\text { Amount reacted, } \\
\text { moles } / \mathrm{cc}^{7}\end{array}$ \\
$10^{7}\left[\mathrm{H}_{2}\right]$ & $10^{7}\left[\mathrm{CH}_{4}\right]$ & $10^{7} \Delta\left[\mathrm{H}_{2}\right]$ & $10^{7} \Delta\left[\mathrm{CH}_{4}\right]$ & $k_{1} / k_{1}{ }^{\prime}$ \\
28.34 & 27.96 & 2.22 & 6.96 & 2.76 \\
35.98 & 44.81 & 2.75 & 8.98 & 2.81 \\
58.15 & 52.19 & 4.72 & 7.54 & 3.01 \\
66.57 & 33.80 & 5.27 & 6.46 & 2.57 \\
76.77 & 33.27 & 5.24 & 7.72 & 2.88 \\
81.34 & 51.16 & 4.09 & 8.62 & 2.79
\end{tabular}

Methane-Methyl Chloride Mixtures.-The residual methane was removed by pumping at liquid nitrogen temperature. The rest of the contents were then distilled on to solid $\mathrm{KOH}$ to remove the $\mathrm{HCl}$ leaving methyl chloride and substituted methyl chlorides, the former being collected by controlled distillation at $-125^{\circ}$. Runs were carried out at $25,76,100,146,211^{\circ}$; range of concentrations used; $\left[\mathrm{CH}_{4}\right]=30-90 \times 10^{-7},\left[\mathrm{CH}_{3} \mathrm{Cl}\right]=25-72 \times 10^{-7} \mathrm{~mole} / \mathrm{cc}$.

Methane-Ethane Mixtures.-The procedure was as for methane-methyl chloride mixtures except that ethane for analysis was pumped off at $-165^{\circ}$. Runs were carried out at $76,100,146,211,290^{\circ}$; range of concentrations used: $\left[\mathrm{CH}_{4}\right]=65-81 \times 10^{-7},\left[\mathrm{C}_{2} \mathrm{H}_{6}\right]=14-20 \times 10^{-7} \mathrm{~mole} / \mathrm{cc}$.

Ethane-Ethyl Chloride Mixtures.-After the $\mathrm{HCl}$ had been removed the ethane was pumped off at $-165^{\circ}$ and the ethyl chloride at $-102^{\circ}$. Runs were carried out at 25,100 $146,211^{\circ}$; range of concentrations used: $\left[\mathrm{C}_{2} \mathrm{H}_{6}\right]=34-64$ $\times 10^{-7},\left[\mathrm{C}_{2} \mathrm{H}_{5} \mathrm{Cl}\right]=43-95 \times 10^{-7} \mathrm{~mole} / \mathrm{cc}$.

Ethane-Propane Mixtures.-The propane was removed at $-133^{\circ}$. Runs were carried out at $25,100,146,211^{\circ}$; range of concentrations used: $\left[\mathrm{C}_{2} \mathrm{H}_{6}\right]=18-36 \times 10^{-7}$, $\left[\mathrm{C}_{3} \mathrm{H}_{8}\right]=19-66 \times 10^{-7} \mathrm{~mole} / \mathrm{cc}$.

Ethane-Butane and Ethane-Pentane Mixtures.-Because the heavier hydrocarbons and ethyl chloride have similar boiling points, they were collected together and measured. The amount of the heavier hydrocarbon was then found by subtraction of the amount of ethyl chloride present, which was calculable from the amount of ethane used up. Runs with these mixtures were carried out at $25,76,146,211^{\circ}$; range of concentrations used: $\left[\mathrm{C}_{2} \mathrm{H}_{6}\right]=20-60 \times 10^{-7},{ }^{\prime}\left[\mathrm{C}_{4} \mathrm{H}_{10}\right]$ $=20-28 \times 10^{-7},\left[\mathrm{C}_{6} \mathrm{H}_{10}\right]=18-29 \times 10^{-7},\left[\mathrm{C}_{5} \mathrm{H}_{12}\right]=33-$ $65 \times 10^{-7} \mathrm{~mole} / \mathrm{cc}$.

Very considerable care was taken in all cases that the components of the reacting mixtures were of the highest possible purity.

\section{Results}

The calculation of results according to equation I was quite straightforward except when methanemethyl chloride and ethane-ethyl chloride mixtures were being investigated. Then one of the products of chlorination was the other member of the mixture. Consequently equation I had to be modified. Some three to six runs were performed at each temperature. A specimen set of results for methane and hycirogen are given in Table I. The complete activation energy difference plot is shown in Fig. 1.

When $\mathrm{R}^{\prime} \mathrm{H} \equiv \mathrm{RCl}$ a more complicated form of expression is needed, viz.

$$
\frac{k_{1}}{k_{1}^{\prime}}=\frac{\log \left(A_{\mathrm{i}} / A_{\mathrm{f}}\right)}{\log \frac{B_{\mathrm{i}}-k_{1} A_{\mathrm{i}} /\left(k_{1}^{\prime}-k_{1}\right)}{B_{\mathrm{f}}-k_{1} A_{\mathrm{f}} /\left(k_{1}^{\prime}-k_{1}\right)}}
$$




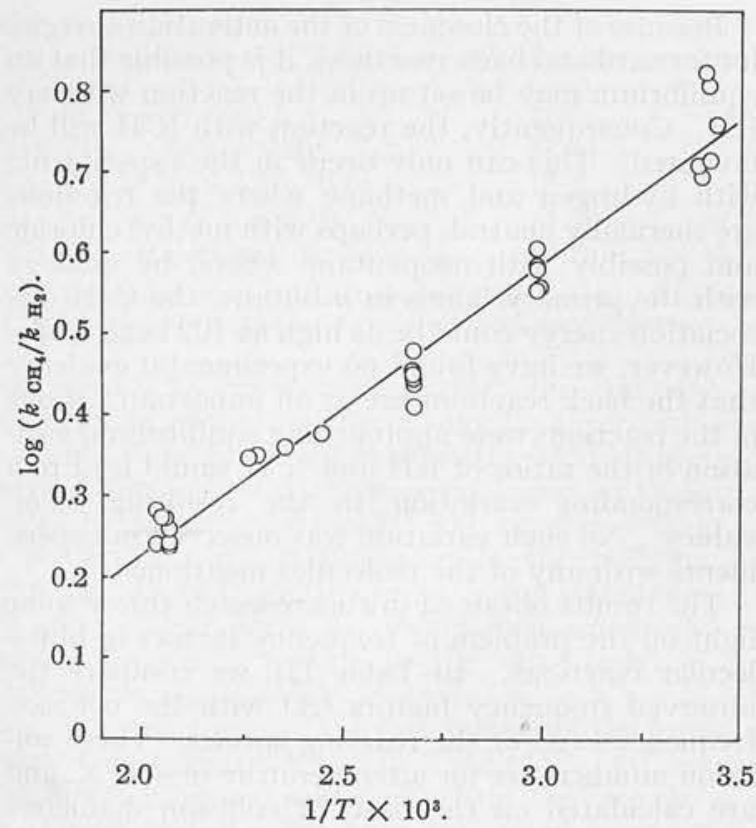

Fig. 1.-The relative rates of chlorination of hydrogenmethane mixtures.

where $A$ is [RH] and $B$ is [RC1]. The expression cannot be simplified to obtain $k_{1} / k_{1}{ }^{\prime}$ explicitly. Furthermore, in our experiments, it was found that the optimum experimental conditions for ease of analysis led to a situation where $A / B$ was of the same order of magnitude as $\left(k_{1}{ }^{\prime}-k_{1}\right) / k_{1}$, so that expression II became extremely sensitive to small experimental errors. This difficulty was overcome by considering the two limiting cases (a) that the $\mathrm{RCl}$ produced from $\mathrm{RH}$ does not react, and (b) that all the $\mathrm{RCl}$ produced from $\mathrm{RH}$ is available for reaction from the commencement of the run, leading to

and

$$
\frac{k_{1}}{k_{1}{ }^{\prime}}=\frac{\log \left(A_{\mathrm{i}} / A_{\mathrm{f}}\right)}{\log \frac{B_{\mathrm{i}}}{B_{\mathrm{f}}-\left(A_{\mathrm{i}}-A_{\mathrm{f}}\right)}}
$$

$$
\frac{k_{1}}{k_{1}^{\prime}}=\frac{\log \left(A_{\mathrm{i}} / A_{\mathrm{f}}\right)}{\log \frac{B_{\mathrm{f}}+\left(A_{\mathrm{i}}-A_{\mathrm{f}}\right)}{B_{\mathrm{f}}}}
$$

In practice these two estimates of the rate ratios did not differ by more than $12 \%$ when $\mathrm{R}$ was $\mathrm{CH}_{3}$ and they were often much closer than this. When $\mathrm{R}$ was $\mathrm{C}_{2} \mathrm{H}_{5}$, the differences were of the order of 10 $20 \%$. In each case, the average result from (IIa) and (IIb) was used to calculate activation energy differences.

When $B_{\mathrm{i}}=0$, equation II becomes

$$
B_{i}=\frac{k_{1} A_{\mathrm{f}}}{k_{1}^{\prime}-k_{1}}\left\{1-\left(\frac{A_{\mathrm{i}}}{A_{\mathrm{f}}}\right)^{\left(k_{1}-k_{1}^{\prime}\right) / k_{1}}\right\}
$$

Sometimes the ethyl chloride produced was not separable from the residual gases, as when the ethane-pentane systems were studied. Then the amount of ethyl chloride was estimated from equation IIc, using the values of $k_{1}$ and $k_{1}{ }^{\prime}$ which had previously been determined.

The mixtures investigated and the experimental

\begin{tabular}{|c|c|c|c|c|}
\hline $\begin{array}{c}\text { Mixture } \\
R H+R^{\prime} H\end{array}$ & $A_{1}^{\prime} / A_{1}$ & $\begin{array}{l}E_{1}-E_{1}^{\prime} \\
\text { cal./mole }\end{array}$ & $\begin{array}{l}\text { cc. } \\
\sec ^{-1}\end{array}$ & $\mathrm{~m}$ \\
\hline$+\mathrm{CH}_{4}$ & 0.32 & $1650 \pm 150$ & 0.26 & 38 \\
\hline $\mathrm{H}_{4}+\mathrm{CH}$ & 2.22 & $490 \pm 150$ & 0. & \\
\hline $\mathrm{C}_{2} \mathrm{H}_{6}$ & 4.67 & $2850 \pm 370$ & 1.20 & \\
\hline $\mathrm{H}_{6}+\mathrm{C}_{2} \mathrm{H}_{5} \mathrm{Cl}$ & 0.38 & $-490 \pm 90$ & 0.46 & 14 \\
\hline $\mathrm{CH}_{2}\left(\mathrm{CH}_{3}\right)_{2}$ & 1.47 & $330 \pm 200$ & 1.76 & 4 \\
\hline $\mathrm{CH}\left(\mathrm{CH}_{3}\right)_{3}$ & 1.64 & $140 \pm 20$ & 1.96 & \\
\hline $\mathrm{C}\left(\mathrm{CH}_{3}\right)_{4}$ & 1.03 & $300 \pm 40$ & 1.23 & \\
\hline cyclo- $\mathrm{C}_{b} \mathrm{H}$ & 2.45 & $420 \pm 40$ & 2.93 & \\
\hline
\end{tabular}
temperature coefficients are listed in Table II and
TABLE II

the experimental points are plotted in Fig. 2. The experimental uncertainties are represented by an error quoted on the activation energy differences; these errors were estimated from the scatter of the Arrhenius plots. The values in the columns headed $A_{1}{ }^{\prime}$ and $E_{1}{ }^{\prime}$ are calculated from columns two and three of the table together with the rate expression for hydrogen itself, viz., $k / 1 \mathrm{~b}=0.79 \times 10^{14}$ exp. $(-5500 \pm 200 / R T)$ mole $^{-1}$ cc. sec. ${ }^{-1}$.

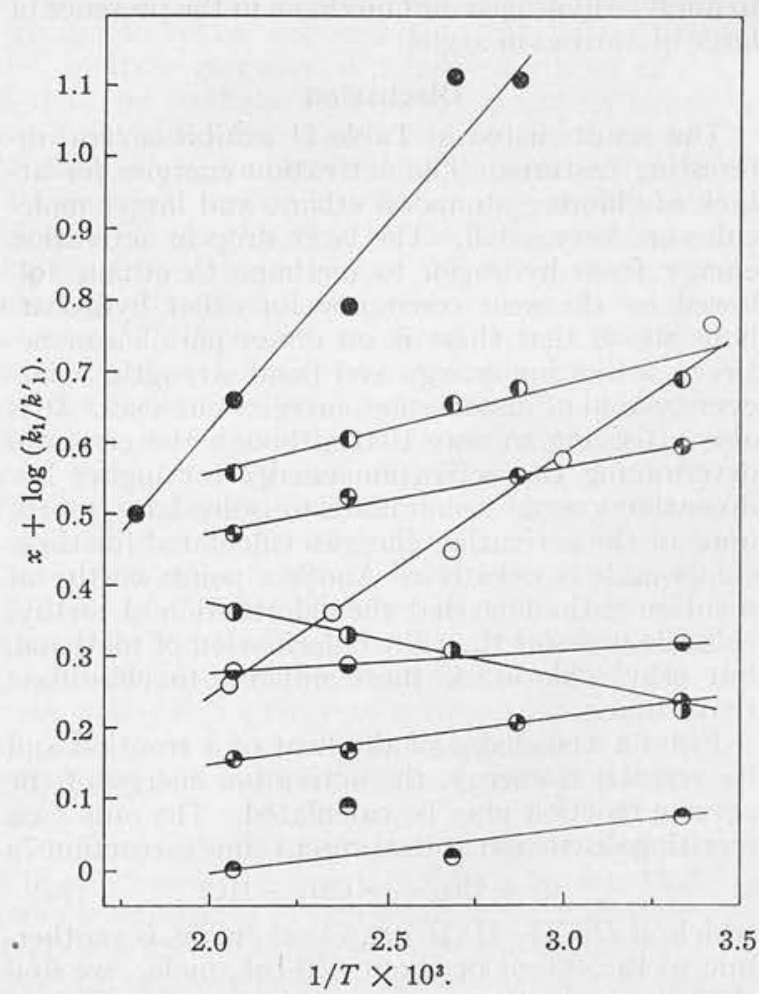

Fig. 2.-The relative rates of chlorination of mixtures: 0 , hydrogen + methane $(x=0) ; 0$, methane + methyl chloride $(x=0)$; 0 , methane + ethane $(x=-1.3)$; ๑, ethane + ethyl chloride $(x=1.0)$; $\Theta$, ethane + propane $(x=-0.3) ; \ominus$, ethane + isobutane $(x=0) ; \theta$, ethane + neopentane $(x=0) ; \theta$, ethane + cyclopentane $(x=-0.1)$. (Each point represents the mean of all experiments carried out at that temperature; the relative rate equations were calculated from the data for the individual experiments by the method of least squares.)

Returning to the problem of bridging the gap in reactivity between methane and ethane, it might be thought from the results in Table II that methyl chloride would provide the answer. But the values 
of $k_{\mathrm{MeCl}} / k_{\mathrm{EtH}}$ apparently showed a maximum at $100^{\circ}$ and fell away at both higher and lower temperatures. Probably this strange result was obtained because it was impossible to separate ethyl chloride, methyl chloride and methylene dichloride by distillation, so that the extent of the reaction had to be estimated indirectly. Experiments were also carried out with ethane and chloroform, ethane and dimethyl ether and with ethane and benzene mixtures. Dimethyl ether chlorinates approximately twice as fast as ethane both at 25 and $146^{\circ}$; benzene and chloroform appeared to react at about the same rate as ethane, but more moles of ethane were used up than the number of moles of chlorine originally added. We have not sufficient analytical evidence to account satisfactorily for this.

The possibility that "hot" chlorine atoms may be involved was investigated by adding about $20 \mathrm{~cm}$. of argon to some of the ethane-isobutane mixtures. No difference in rate ratios was observed. The addition of an inert gas to hydrogen-methane mixtures would have been a more rigorous test, but it is difficult to analyze hydrogen and methane in the presence of large quantities of argon.

\section{Discussion}

The results listed in Table II exhibit several interesting features. The activation energies for attack of chlorine atoms on ethane and larger molecules are very small. The large drop in activation energy from hydrogen to methane to ethane followed by the near constancy for other hydrocarbons shows that there is no direct parallelism between activation energy and bond strength, whatever system of dissociation energies one uses. It is also satisfying to note that although the errors in determining the activation energy for higher hydrocarbons could accumulate to quite large totals, none of the activation energies calculated for these compounds is negative. Another point worthy of mention is the fact that the chlorination of methyl chloride is easier than the chlorination of methane, but ethyl chloride is more difficult to chlorinate than ethane.

From a knowledge of the heat of a reaction and its activation energy, the activation energy of the reverse reaction may be calculated. The only case meriting discussion at the present time is reaction $7 \mathrm{a}$

$$
\mathrm{Cl}+\mathrm{CH}_{4} \longrightarrow \mathrm{CH}_{3}+\mathrm{HCl}
$$

whicit, if $D\left(\mathrm{CH}_{3}-\mathrm{H}\right)$ is $102.5 \mathrm{kcal} . /$ mole, is exothermic to the extent of about $650 \mathrm{cal} . / \mathrm{mole}$; we find that the activation energy of the reaction is 3850 cal. /mole, so that the activation energy of reaction $-7 \mathrm{a}$

$$
\mathrm{CH}_{3}+\mathrm{HCl} \longrightarrow \mathrm{Cl}+\mathrm{CH}_{4} \quad(-7 \mathrm{a})
$$

must be $4.5 \mathrm{kcal}$. The reaction of methyl radicals with hydrogen chloride has been studied recently by Cvetanović and Steacie $^{8}$ who concluded that the activation energy was about $2.1 \mathrm{kcal} . / \mathrm{mole}$, but their results were not very reproducible. From their experiments at $28^{\circ}$ they quote an upper limit of $5.1 \mathrm{kcal}$. which is consistent with our observations. $^{9}$

(8) R. J. Cvetanovic and E. W. R. Steacie, Can. J. Chem,, 31, 518 (1953).

(9) A preliminary note ${ }^{10}$ on this topic contained some arithmetical
Because of the closeness of the activation energies for forward and back reactions, it is possible that an equilibrium may be set up in the reaction with say $R H$. Consequently, the reaction with $R^{\prime} H$ will be favoured. This can only occur in the experiments with hydrogen and methane where the reactions are thermally neutral, perhaps with methyl chloride and possibly with neopentane where, by analogy with the primary bonds in $n$-butane, the $\mathrm{C}-\mathrm{H}$ dissociation energy could be as high as $102 \mathrm{kcal} . / \mathrm{mole}$. However, we have found no experimental evidence that the back reactions are at all important; if one of the reactions were approaching equilibrium, variation of the ratios of $\mathrm{RH}$ and $\mathrm{R}^{\prime} \mathrm{H}$ would lead to a corresponding variation in the resulting $k_{1} / k_{1}{ }^{\prime}$ values. No such variation was observed in experiments with any of the molecules mentioned.

The results obtained in this research throw some light on the problem of frequency factors in bimolecular reactions. In Table III we compare the observed frequency factors $(A)$ with the collision frequencies $(Z)$ of the reacting species. These collision numbers are for a temperature of $400^{\circ} \mathrm{K}$. and are calculated on the basis of collision diameters taken from a recent paper by Rowlinson ${ }^{11}$; the collision diameter for chlorine has been taken to be the same as that for argon $(3.42 \AA$.). In the final column of Table III, the quantities $A / Z$ are listed and we will loosely identify these ratios with the steric factors for the reactions; to attach any precise significance to the ratio $A / Z$ involves a knowledge of the number of square terms contributing to the reaction. The quantity $A / Z$ is never significantly greater than unity and we may therefore conclude that the chlorine atom reactions studied here do not have steric factors greater than unity. However, steric factors considerably greater than unity have been reported for the corresponding reactions of bromine atoms. ${ }^{12}$ It is interesting that bromine should react with 2-methylpropane or 2,2-dimethylpropane with frequency factors of the order of $10^{17} \mathrm{~mole}^{-1} \mathrm{cc}$. sec. ${ }^{-1}$ whereas chlorine reacts with the same substances with "normal" frequency factors. This large difference cannot be

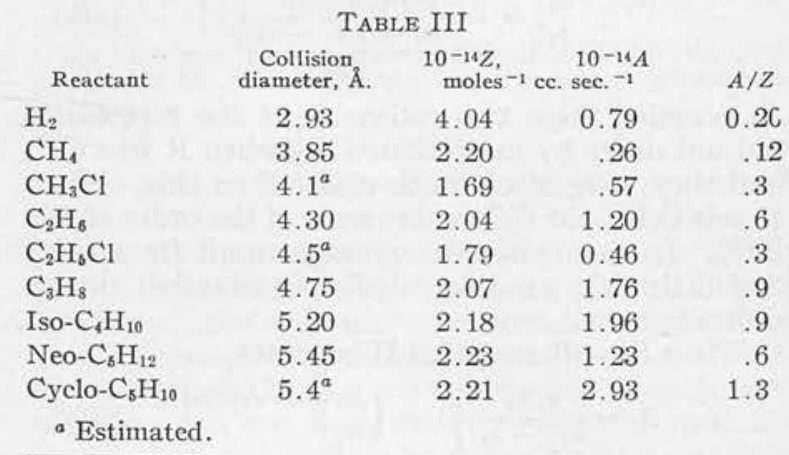

errors. $k 7_{\Omega}$ was given as 104.5 exp. $(-3800 / R T)$ mole ${ }^{-1} \mathrm{cc}$. sec. ${ }^{-1}$, whereas $10^{13.4} \exp (-3850 / R T)$ is correct. Consequently, $k-7_{\mathrm{B}}$ should have been $10^{12.1} \exp$. $(-4510 / R T)$ which is equal to $10^{9.3}$ at $150^{\circ}$. The agreement with the value of $10^{10.4}$ given by Cvetanovic and Steacie is as good as was reported previously.

(10) H. O. Pritchard, J. B. Pyke and A. F. Trotman-Dickenson, ThIS JoURNAL, 76, 1201 (1954).

(11) J. S. Rowlinson, Quart. Rev., 8, 168 (1954),

(12) B. H. Eckstein, H. A. Scheraga and E. R. Van Artsdalen, $J$. Chem. Phys., 22, 29 (1954). 
TABLE IV

$A$ 's in mole ${ }^{-1}$ cc. $\mathrm{sec}^{-1}, E^{\prime}$ 's in kcal./mole.

$\begin{array}{lcccc}\begin{array}{l}\log A \\ \text { expt. }\end{array} & E & \begin{array}{c}\log A \\ \text { calc. }\end{array} & \text { Ref. } \\ 13.4 & 3.9 & \text { This work } & 13.0 & \text { This work } \\ 12.5 & 9.0 & \text { See discussion } & 13.3 & 16 \\ 11.5 & 14.3 & 14 & 10.9 & 16 \\ 13.7 & 18.3 & 15 & 13.7 & 15\end{array}$

$$
\begin{aligned}
& \quad \text { Reaction } \\
& \mathrm{Cl}+\mathrm{CH}_{4} \rightarrow \mathrm{HCl}+\mathrm{CH}_{2} \quad \text { (7a) } \\
& \mathrm{H}+\mathrm{CH}_{4} \rightarrow \mathrm{H}_{2}+\mathrm{CH}_{3} \quad \text { (7b) } \\
& \mathrm{CH}_{3}+\mathrm{CH}_{4} \rightarrow \mathrm{CH}_{4}+\mathrm{CH}_{3} \quad \text { (7c) } \\
& \mathrm{Br}+\mathrm{CH}_{4} \rightarrow \mathrm{HBr}+\mathrm{CH}_{3} \text { (7d) }
\end{aligned}
$$

3.9

14.3

a The transition state calculation was made by standard methods. ${ }^{15}$ The $\mathrm{H}-\mathrm{Cl}$ distance was assumed to be $1.65 \AA$. and the $\mathrm{C}-\mathrm{H}-\mathrm{Cl}$ doubly degenerate bending frequency was taken as $500 \mathrm{~cm}^{-1}$.

accounted for by experimental errors, but the possibility still remains that there may be an error in the assumed reaction mechanisms (the bromination of neopentane experiments were criticised on these grounds by Benson and $\mathrm{Graff}^{13}$ who suggested that the neopentyl radicals produced in the reaction might decompose to methyl radicals and isobutene; they showed that such an assumption would reduce the frequency factors to the same order of magnitude as the collision number).

We may now consider the rate factors of the four reactions of methane listed in Table IV. All are taken directly from the sources except the rate factors of reaction $7 \mathrm{~b}$. We have estimated these as follows: The activation energy of reaction $-7 \mathrm{~b}$ is $10.0 \mathrm{kcal} . /$ mole $^{,{ }^{17}}$ and reaction $7 \mathrm{~b}$ is approximately $1 \mathrm{kcal} . /$ mole exothermic. Therefore the activation energy of reaction $7 \mathrm{~b}$ is $9 \mathrm{kcal}$./mole. The $A$ factor of reaction $-7 \mathrm{~b}$ is $10^{11.5}$ mole $^{-1}$ cc. sec. ${ }^{-1}$. From considerations of the entropies of the substances involved in the reaction ${ }^{18}$ we can show that $A_{7 \mathrm{~b}} / A_{-7 \mathrm{~b}} \approx$ 10. Therefore $A_{7 \mathrm{~b}}$ is $10^{12.5} \mathrm{~mole}^{-1}$ cc. sec. ${ }^{-1}$; if anything this value is likely to be a little high. These rate factors give $k_{7 \mathrm{~b}}=10^{7.7} \mathrm{~mole}^{-1} \mathrm{cc}$. sec. ${ }^{-1}$ at $140^{\circ}$, which value agrees far better than could be reasonably hoped with the value of $10^{7.6} \mathrm{~mole}^{-1}$ cc. sec. ${ }^{-1}$ measured by Berlie and LeRoy. ${ }^{19}$ They found that $k_{7 \mathrm{~b}}=10^{10.0} \exp .(-4500 / R T) \mathrm{mole}^{-1} \mathrm{cc}$. sec. ${ }^{-1}$, but placed much more reliance on their measurement of the reaction rate than of its temperature dependence. Indeed, measurements of rates are generally much more reliable than measurements of temperature coefficients. It can be seen from the table that all of these $A$ factors are in reasonable agreement with the predictions of transition state theory listed in the fifth column.

It is often suggested, as a rough corollary of the supposed activation energy-dissociation energy relationship, that in a reaction of the type

$$
\mathrm{X}+\mathrm{RH} \rightarrow \mathrm{HX}+\mathrm{R}
$$

the stronger the HX bond, the lower the activation energy and it is instructive to examine this hypothe-

(13) S. W. Benson and H. Graff, J. Chem. Phys., 20, 1182 (1952).

(14) J. R. MeNesby and A. S. Gordon, Thrs Journal, 76, 4196 (1954).

(15) G. B. Kistiakowsky and E. R. Van Artsdalen, J. Chem. Phys., 12, 469 (1944).

(16) S. Bywater and R. Roberts, Can. J. Chem., 30, 773 (1952).

(17) E. Whittle and E. W. R. Steacie, J. Chem. Phys., 21, 993 (1953).

(18) A. F. Trotman-Dickenson, ibid., 21, 211 (1953).

(19) M. R. Berlie and D. J. LeRoy, Can, J. Chem., 32, 650 (1954). sis in the light of data now available. Consider the activation energies of the three reactions $7 \mathrm{a}, 7 \mathrm{~b}$ and 7c. The bonds formed in the three reactions have identical dissociation energies to within about $\pm 1 \%$; hence thermochemistry alone cannot account for the steady gradation in activation energy along the series $7 \mathrm{a}, 7 \mathrm{~b}$ and $7 \mathrm{c}$. It is interesting to speculate on the cause of the wide variation in activation energy for these reactions. Presumably it arises from differences in the repulsion energies upon close approach of the reacting particles, chlorine being the least repelled and methyl the most. If we are to retain the idea that the "transition state" in these reactions is a fairly localized affair and that the methane molecule does not fly apart when a chlorine atom passes nearby, we must accept that the chlorine atom can approach very close to the methane molecule without any marked repulsion. We imagine that this is only possible because the free electron on the chlorine atom has a significant attraction for the electrons in the methane molecule. Therefore, we should expect that the greater the electroaffinity of the singly occupied orbital, the easier the close approach of the two centers would be. If the methyl radical is flat, it should have an electroaffinity of about 6 e.v. ${ }^{20}$; the values for the hydrogen and chlorine atoms are 7.2 and 9.5 e.v., respectively. ${ }^{21}$ Thus the relative values of the activation energies of reactions $7 \mathrm{a}, 7 \mathrm{~b}$ and $7 \mathrm{c}$ can be understood in terms of the electroaffinities of the approaching particles. It seems that we can distinguish at least two factors which govern the activation energy of reaction 7 for a constant RH, these being the thermochemistry of the reaction and the electroaffinity of the abstracting particle.

In spite of the difficulties in analysis without resort to mass-spectrometric techniques, we feel that the numerical results presented here are essentially correct: the further exploitation of the competitive method using physicochemical methods of analysis is not feasible. But with a mass-spectrometer available, the range of substances investigated could be considerably extended, the accuracy improved, and interesting results on the relative rates of reactions 2 and 4 could be collected.

MANCHESTER, ENGLAND

(20) H. O. Pritchard and H. A. Skinner, Chem. Rev., in press.

(21) H. A. Skinner and H. O. Pritchard, Trans. Faraday Soc., 49, 1254 (1953). 
Reprinted from the Transactions of the Faraday Society,

No. 402, Vol. 52, Part 6, June, 1956

THE REACTIONS OF TRIFLUOROMETHYL RADICALS 


\title{
THE REACTIONS OF TRIFLUOROMETHYL RADICALS
}

\author{
By G. O. Pritchard, * H. O. Pritchard, ${ }^{*}$ H. I. Schiff $\dagger$ \\ AND A. F. TROTMAN-DICKENSON $\S$ \\ Received 4th October, 1955
}

(a) The photolysis of hexafluoroazomethane yields trifluoromethyl radicals which both combine (2) and add to the $\mathrm{N}$ : $\mathrm{N}$ bond (3):

$$
\begin{gathered}
2 \mathrm{CF}_{3} \bullet \stackrel{k_{2}}{\rightarrow} \mathrm{C}_{2} \mathrm{~F}_{6}, \\
\mathrm{CF}_{3} \cdot+\mathrm{CF}_{3} \mathrm{~N}: \mathrm{NCF}_{3} \stackrel{k_{3}}{\rightarrow}\left(\mathrm{CF}_{3}\right)_{2} \mathrm{~N} \cdot \dot{\mathrm{N} C F}{ }_{3} .
\end{gathered}
$$

In the presence of a hydrogen-containing compound, $\mathrm{RH}, \mathrm{CF}_{3} \mathrm{H}$ is produced by (1):

$$
\mathrm{CF}_{3} \bullet+\mathrm{RH} \stackrel{k_{1}}{\rightarrow} \mathrm{CF}_{3} \mathrm{H}+\mathrm{R} \bullet .
$$

So many of the radicals add to the parent compound (3) that $k_{1}$ cannot be accurately compared with $k_{2}$; the rate of this addition is given by

$$
k_{3} / k_{2} \frac{1}{2}=3.0 \times 10^{3} \exp [-(3,500 \pm 200) / R T] \mathrm{mole}^{-\frac{1}{2}} \mathrm{~cm}^{\frac{3}{2}} \mathrm{sec}^{-\frac{1}{2}}
$$

beiween $-70^{\circ}$ and $100^{\circ} \mathrm{C}$.

(b) The rate constants $k_{1}$ for a number of compounds have been compared with $k_{5}$,

$$
\mathrm{CF}_{3} \cdot+\mathrm{D}_{2} \rightarrow \mathrm{CF}_{3} \mathrm{D}+\mathrm{D} \cdot
$$

by measurement of the relative rates of production of $\mathrm{CF}_{3} \mathrm{H}$ and $\mathrm{CF}_{3} \mathrm{D}$ in a photolytic system containing RH, deuterium and hexafluoroazomethane. $A_{1}$ and $E_{1}$ have been determined from the Arrhenius equations. It is found that $E_{1}$ is in general 2 or $3 \mathrm{kcal} / \mathrm{mole}$ lower than the activation energy for the corresponding methyl radical reactions.

(c) The heat of the reaction $\mathrm{CF}_{3}{ }^{\bullet}+\mathrm{CH}_{4} \rightarrow \mathrm{CF}_{3} \mathrm{H}+\mathrm{CH}_{3}{ }^{\bullet}$ has been derived from the activation energies of the forward and reverse reactions, leading to the value

$$
D\left(\mathrm{CF}_{3}-\mathrm{H}\right)=D\left(\mathrm{CH}_{3}-\mathrm{H}\right)-0.5 \mathrm{kcal} / \mathrm{mole} \text {. }
$$

In recent years much work has been done to determine the Arrhenius parameters of reactions involving atoms and small free radicals. Most progress has been made in the determination of the rate constants of those reactions in which the atom or radical abstracts a hydrogen atom from a hydrogen-containing compound-usually a hydrocarbon. The reactions of methyl radicals 1 have been very fully investigated. Less is known about the reactions of chlorine, ${ }^{2}$ hydrogen and bromine atoms and ethyl radicals. 3,4 The ultimate object of much of this work has been to discover the factors determining the rates of reactions through the study of many series of similar reactions and the correlation of their rates with the thermodynamic and structural properties of the reactants. Particular interest attaches to the reactions of the trifluoromethyl radical because (as is shown in the present work) the $\mathrm{CF}_{3}-\mathrm{H}$ bond is almost the same strength as the $\mathrm{CH}_{3}-\mathrm{H}$ bond, though the $\mathrm{CF}_{3}{ }^{\circ}$ radical is probably much more electronegative than the $\mathrm{CH}_{3} \cdot$ radical. Also, $\mathrm{CF}_{3} \cdot$ has a much higher moment of inertia (and hence rotational entropy) than $\mathrm{CH}_{3}{ }^{\circ}$. Consequently, the entropy change occurring in the symmetrical dissociation of $\mathrm{C}_{2} \mathrm{~F}_{6}$ is much greater than that which occurs when $\mathrm{C}_{2} \mathrm{H}_{6}$ dissociates, so that either the Arrhenius $A$ factors for the two

\footnotetext{
* present address: Chemistry Dept., Manchester University, Manchester, 13.

$\dagger$ present address: Chemistry Dept., McGill University, Montreal, 2.

$\S$ present address : Chemistry Dept., Edinburgh University, Edinburgh, 9.
} 
dissociations or the two recombinations (or possibly both) must be very different. No direct evidence on this point has geen obtained in the course of the present work, but it should be borne in mind when the $A$ factors of $\mathrm{CF}_{3} \cdot$ metathetical reactions are considered.

It might be expected that, by analogy with the reactions of methyl radicals, in the presence of a saturated hydrocarbon $\mathrm{RH}$, trifluoromethyl radicals would undergo the two competing reactions

and

$$
\mathrm{CF}_{3} \cdot+\mathrm{RH} \rightarrow \mathrm{CF}_{3} \mathrm{H}+\mathrm{R} \cdot \text {, }
$$

$$
\mathrm{CF}_{3} \cdot+\mathrm{CF}_{3} \bullet \rightarrow \mathrm{C}_{2} \mathrm{~F}_{6} \text {. }
$$

The rates of formation of $\mathrm{CF}_{3} \mathrm{H}$ and $\mathrm{C}_{2} \mathrm{~F}_{6}$ respectively would then be given by the two expressions :

and

$$
\begin{aligned}
& R_{\mathrm{CF}_{3} \mathrm{H}}=\mathrm{d}\left[\mathrm{CF}_{3} \mathrm{H}\right] / \mathrm{d} t=k_{1}\left[\mathrm{CF}_{3} \cdot\right][\mathrm{RH}] \\
& R_{\mathrm{C}_{2} \mathrm{~F}_{6}}=\mathrm{d}\left[\mathrm{C}_{2} \mathrm{~F}_{6}\right] / \mathrm{d} t=k_{2}\left[\mathrm{CF}_{3} \cdot\right]^{2}, \\
& k_{1} / k_{2} \frac{1}{2}=R_{\mathrm{CF}_{3} \mathrm{H}} / R_{\mathrm{C}_{2} \mathrm{~F}_{6}}^{\frac{1}{2}}[\mathrm{RH}] .
\end{aligned}
$$

whence

The temperature coefficient of this rate ratio is the difference in activation energies $E_{1}-\frac{1}{2} E_{2}$ and the pre-exponential factor is $A_{1} / A_{2} \frac{1}{2}$. The results obtained in this research bear out this expectation.

Hexafluoroazomethane was chosen as a source of trifluoromethyl radicals, both because it is fairly simple to prepare and because its photolysis can be effected by visible (blue) light; thus the range of compounds $\mathrm{RH}$ is not restricted only to compounds which do not absorb in the near ultra-violet. First, it was necessary to investigate the photolysis of hexafluoroazomethane which is described in section (a); next, an attempt was made to determine $k_{1} / k_{2}{ }^{\frac{1}{2}}$ by analysis for $\mathrm{CF}_{3} \mathrm{H}$ and $\mathrm{C}_{2} \mathrm{~F}_{6}$ formed during the photolysis of hydrocarbon + hexafluoroazomethane mixtures, but because of inherent difficulties, this approach was abandoned in favour of a method yielding relative rate constants by the comparison of the rate of a series of reactions of type 1 with reaction (5),

$$
\mathrm{CF}_{3} \cdot+\mathrm{D}_{2} \rightarrow \mathrm{CF}_{3} \mathrm{D}+\mathrm{D} \cdot
$$

This part of the work is described in section $(b)$, followed by the determination of the $\mathrm{CF}_{3}-\mathrm{H}$ bond strength in section $(c)$.

\section{EXPERIMENTAL}

MATERIALS.-Hexafluoroazomethane was prepared by heating ICN and $\mathrm{IF}_{5}$ in a steel bomb at 130 to $140^{\circ} \mathrm{C} .5$ The contents of the bomb were then pumped into a trap containing solid $\mathrm{KOH}$ at liquid nitrogen temperature where any $\mathrm{HF}$ and most of the free iodine produced in the reaction were absorbed; the product could then be handled conveniently in all glass apparatus. The major impurity was stated by Ruff and Willenberg 5 to be bistrifluoromethylamine $\left(\mathrm{CF}_{3}\right)_{2} \mathrm{NH}$ (which probably arises from the presence of $\mathrm{HF}$ in the $\mathrm{IF}_{5}$ ); it was removed by shaking the gas first with dilute hydrochloric acid, which decomposes the impurity to $\mathrm{HF}, \mathrm{HOCN}$ and $\mathrm{CO}_{2}$, and then with dilute sodium hydroxide solution to remove these acid products and any residual iodine. The product was dried over $\mathrm{P}_{2} \mathrm{O}_{5}$ and stored in the dark at liquid nitrogen temperature.

Mass spectrographic analysis showed this product to be essentially $\mathrm{CF}_{3} \mathrm{~N}: \mathrm{NCF}_{3}$, containing some $\mathrm{CF}_{3} \mathrm{I}, \mathrm{SiF}_{4}$ and small amounts of hydrocarbons up to and including $\mathrm{C}_{\text {s. }}$ Photolysis of this material at $25^{\circ} \mathrm{C}$ yielded a mixture of $\mathrm{C}_{2} \mathrm{~F}_{6}$ and $\mathrm{CF}_{3} \mathrm{H}$ containing nearly $40 \% \mathrm{CF}_{3} \mathrm{H}$, showing that the hydrogen-containing impurities were extremely susceptible to $\mathrm{CF}_{3}$. radical attack. Further purification was effected by repeated fractional distillation at temperatures in the range -120 to $-155^{\circ}$ until photolysis yielded a $\mathrm{C}_{2} \mathrm{~F}_{6}$ fraction containing only $1.3 \% \mathrm{CF}_{3} \mathrm{H}$. This material was considered to be sufficiently pure for the purposes of the present investigation; its molecular weight was found to be 168 (after correction for deviation from the gas laws) and the only impurity detectable in the mass spectrum was a trace of $\mathrm{CF}_{3} \mathrm{I}$. 
Hexafluoroazomethane is a faintly greenish gas; b.p. $-31 \cdot 6^{\circ}$; Ruff and Willenberg gave the vapour pressure as

$$
\log _{10} P(\text { in } \mathrm{mm})=(-1196 / T)+7 \cdot 832,
$$

and our measurements are in excellent agreement with this equation in the temperature range -35 to $-80^{\circ}$. They stated that the gas decomposes in the presence of mercury giving $\mathrm{N}_{2}+\mathrm{C}_{2} \mathrm{~F}_{6}$, but we have not confirmed this observation; the gas is stable in the dark, even in the presence of mercury, but is slowly decomposed by daylight. The gas exhibits a very intense absorption in the infra-red spectral region; the principal absorption lines and their relative intensities are given in table 1 . The very weak triplet near $2800 \mathrm{~cm}^{-1}$ could be due to $\mathrm{C}-\mathrm{H}$ vibrations, but their general disposition suggests that it is more likely to be a combination band (we are indebted to Dr. G. D. Meakins for discussion on this point); furthermore, a number of detailed searches of the mass spectrum have failed to reveal the presence of any hydrogen atoms in the product.

TABLE 1.-INFRA-RED ABSORPTION SPECTRUM OF HEXAFLUOROAZOMETHANE

$\begin{array}{lcllcc}\left(\mathrm{cm}^{-1}\right) & \text { intensity } & \left(\mathrm{cm}^{-1}\right) & \text { intensity } & \left(\mathrm{cm}^{-1}\right) & \text { intensity } \\ 2950 & \text { v.w. } & 1860 & \text { w. } & 1084 & \text { s. } \\ 2850 & \text { v.w. } & 1825 & \text { v.w. } & 1079 & \text { s. } \\ 2782 & \text { w. } & 1773 & \text { w. } & 1072 & \text { s. } \\ 2470 & \text { m. } & 1667 & \text { v.w. } & 1034 & \text { m. } \\ 2250 & \text { v.w. } & 1581 & \text { m. } & 1025 & \text { m. } \\ 2202 & \text { m. } & 1562 & \text { m. } & 973 & \text { w. } \\ 2140 & \text { m. } & 1532 & \text { w. } & 949 & \text { m. } \\ 2072 & \text { m. } & 1458 & \text { m. } & 878 & \text { m. } \\ 2022 & \text { m. } & 1404 & \text { s. } & 744 & \text { m. } \\ 1955 & \text { w. } & 1274 & \text { v.s. } & 739 & \text { m. } \\ 1915 & \text { v.w. } & 1210 & \text { v.s. } & 733 & \text { m. }\end{array}$

Note.-Spectra were observed with pressures of 280,14 and $1 \mathrm{~mm} \mathrm{Hg}$ in a $10 \mathrm{~cm}$ absorption cell: v.w. indicates that the absorption can only be detected at $280 \mathrm{~mm}$, whereas v.s. indicates $50-80 \%$ absorption at $1 \mathrm{~mm}$ pressure; w., m., and s. denote intermediate intensities.

Deuterium was prepared by electrolysis of a saturated solution of $\mathrm{Na}_{2} \mathrm{SO}_{4}$ in $99 \cdot 7 \%$ $\mathrm{D}_{2} \mathrm{O}$, and was freed from $\mathrm{O}_{2}$ and $\mathrm{D}_{2} \mathrm{O}$ by passing through a quartz tube containing boiling sodium; mass spectrometer analyses yielded $\mathrm{D}_{2}=96.5 \%, \mathrm{HD}=3.5 \%$. Hydrogen was obtained from a cylinder and was purified using a palladium thimble. The aliphatic hydrocarbons used were standard samples supplied by the Chemical Research Laboratory, Teddington; acetone and benzene were of A.R. grade and the toluene was a pyrolyzed sample. Hexadeuteroacetone was kindly given to us by the National Research Council, Ottawa.

APPARATUS AND PROCEDURE.-Most of the experiments were carried out using a $300 \mathrm{ml}$ quartz reaction vessel which was isolated from the main vacuum system by a mercury cut-off. This vessel was enclosed in an electric furnace, whose temperature could be controlled to $\pm 2^{\circ}$ in the range 30 to $350^{\circ}$, and was irradiated with light from a highpressure mercury lamp for periods of from 3 to $24 \mathrm{~h}$. After irradiation, the contents of the reaction vessel were pumped out and separated by low-temperature fractional distillation; the volume of each fraction was measured before being removed from the apparatus for mass spectrometric analysis.

\section{(a) THE PHOTOLYSIS OF HEXAFLUOROAZOMETHANE}

The photolysis of hexafluoroazomethane at room temperature and $5 \mathrm{~cm}$ pressure leads to the production of nitrogen, hexafluoroethane, a trace of fiuroform (as mentioned above) and a liquid product having a vapour pressure of $20-30 \mathrm{~cm}$ at room temperature $\left(20^{\circ}\right)$. This was shown by mass spectrographic analysis to be $\left(\mathrm{CF}_{3}\right)_{2} \mathrm{~N} . \mathrm{N}\left(\mathrm{CF}_{3}\right)_{2}$; presumably it is formed by the addition of $\mathrm{CF}_{3}{ }^{\circ}$ radicals to the $\mathrm{N}: \mathrm{N}$ double bond in hexafluoroazomethane. The relative volumes of products in one run at room temperature were $\mathrm{N}_{2} 9 \cdot 8, \mathrm{C}_{2} \mathrm{~F}_{6} 1 \cdot 9, \mathrm{CF}_{3} \mathrm{H} 0.025$ and $\left(\mathrm{CF}_{3}\right)_{4} \mathrm{~N}_{2} 7 \cdot 8$; the almost exact material balance shows that all the $\mathrm{CF}_{3}{ }^{\circ}$ radicals are accounted for and that about $80 \%$ of them are lost by addition to the parent compound. At higher temperatures the material balance is not maintained and the liquid product contains the compouna

$$
\left(\mathrm{CF}_{3}\right)_{2} \mathrm{~N} \cdot \mathrm{N}\left(\mathrm{CF}_{3}\right) \cdot \mathrm{N}\left(\mathrm{CF}_{3}\right) \cdot \mathrm{N}\left(\mathrm{CF}_{3}\right)_{2} \text {, }
$$


our identification of these liquid products is based on mass spectrometric evidence, and is confirmed in a paper by Dacey and Young ${ }^{6}$ which appeared after this work was completed. No evidence was found for the formation of any $\mathrm{CF}_{4}$ up to the highest temperatures used $\left(350^{\circ}\right)$; however, above about $150^{\circ}$, small amounts of $\mathrm{CO}_{2}$ and $\mathrm{SiF}_{4}$ were produced by the attack of $\mathrm{CF}_{3} \cdot$ radicals on the quartz. A similar attack was found by Ayscough and Emeléus ${ }^{7}$ in the pyrolysis of $\mathrm{As}\left(\mathrm{CF}_{3}\right)_{3}$ and $\mathrm{Sb}\left(\mathrm{CF}_{3}\right)_{3}$, but Sieger and Calvert ${ }^{8}$ did not find it in their photolysis experiments with trifluoroacetone.

The kinetics of the addition reaction were studied in a subsidiary apparatus : samples of hexafluoroazomethane were sealed in a $170 \mathrm{ml}$ Pyrex cylinder which was placed in a thermostatted air-space whose temperature could be maintained constant to $\pm 1^{\circ} \mathrm{C}$ in the range from room temperature to $-70^{\circ} \mathrm{C}$. After illumination with light from a mercury vapour lamp (for a period of time sufficient to decompose about $5 \%$ of the azocompound), the reaction vessel was re-attached to the main apparatus, the seal broken, and the contents analysed.

In those experiments performed at or below room temperature, the only products were $\mathrm{N}_{2}, \mathrm{C}_{2} \mathrm{~F}_{6}$ and $\left(\mathrm{CF}_{3}\right)_{2} \mathrm{~N} . \mathrm{N}\left(\mathrm{CF}_{3}\right)_{2}$; we have assumed that the production of perfluorotetramethylhydrazine takes place by

$$
\mathrm{CF}_{3} \cdot+\mathrm{CF}_{3} \mathrm{~N}: \mathrm{NCF}_{3} \rightarrow\left(\mathrm{CF}_{3}\right)_{2} \mathrm{~N} \cdot \dot{\mathrm{NCF}}_{3},
$$

which is rate-determining, followed by the fast reaction

$$
\mathrm{CF}_{3} \cdot+\left(\mathrm{CF}_{3}\right)_{2} \mathrm{~N} \cdot \dot{\mathrm{N} C F} \mathrm{~F}_{3} \rightarrow\left(\mathrm{CF}_{3}\right)_{2} \mathrm{~N} \cdot \mathrm{N}\left(\mathrm{CF}_{3}\right)_{2} \text {. }
$$

Thus, the rate constant for the addition is given by

$$
k_{3} / k_{2}^{\frac{1}{2}}=R_{\left(\mathrm{CF}_{3}\right)_{2} \mathrm{~N} . \mathrm{N}\left(\mathrm{CF}_{3}\right)_{2}} / R_{\mathrm{C}_{2} \mathrm{~F}_{6}}^{\frac{1}{2}}\left[\mathrm{CF}_{3} \mathrm{~N}: \mathrm{NCF}_{3}\right] .
$$

The Arrhenius plot of these results is given in fig. 1. A further point, obtained from experiments carried out (in the main apparatus) at $100^{\circ} \mathrm{C}$ also lies on this straight line; at this temperature some perfluorohexamethyltetrazine was formed, presumably by the reaction

$$
2\left(\mathrm{CF}_{3}\right)_{2} \mathrm{~N} \cdot \dot{\mathrm{N} C F} \mathrm{~F}_{3} \rightarrow\left(\mathrm{CF}_{3}\right)_{2} \mathrm{~N} \cdot \mathrm{N}\left(\mathrm{CF}_{3}\right) \cdot \mathrm{N}\left(\mathrm{CF}_{3}\right) \cdot \mathrm{N}\left(\mathrm{CF}_{3}\right)_{2} ;
$$

from a knowledge of the drop in pressure during the reaction and the total quantity of the liquid product, the extent of reaction (3) was obtained leading to the highest temperature point shown in fig. 1. Fitting these results to the Arrhenius equation leads to the expression

$$
k_{3} / k_{2}^{\frac{1}{2}}=3.0 \times 10^{3} \exp [-(3,500 \pm 200) / R T] \text { moles }^{-\frac{1}{2}} \mathrm{~cm}^{\frac{3}{2}} \mathrm{sec}^{-\frac{1}{1}} .
$$

\section{(b) THE REACTION OF $\mathrm{CF}_{3}$ • RADICALS WITH HYDROGEN-CONTAINING COMPOUNDS}

In some earlier experiments, an attempt was made to compare the rates of reactions (1) and (2) by photolyzing hexaffuoroazomethane in the presence of hydrocarbons and comparing the rates of formation of $\mathrm{CF}_{3} \mathrm{H}$ and $\mathrm{C}_{2} \mathrm{~F}_{6}$. However, the extreme ease with which radicals were removed by reaction (3) so reduced the static concentration of $\mathrm{CF}_{3}{ }^{\prime}$ radicals that only minute amounts of $\mathrm{C}_{2} \mathrm{~F}_{6}$ were formed, and it was only by extending the temperature range over at least $200^{\circ} \mathrm{C}$ that even approximate data about the relative activation energies of reactions (1) and (2) could be obtained. ${ }^{2}$ It was therefore decided to investigate only the relative reactivities of a series of compounds $\mathrm{RH}$ towards $\mathrm{CF}_{3^{*}}$ radical attack; this was done by photolyzing about $2 \mathrm{~cm}$ of hexafluoroazomethane in the presence of about $10 \mathrm{~cm}$ of $\mathrm{D}_{2}$ and sufficient $\mathrm{RH}$ to produce a reasonable ratio of $\mathrm{CF}_{3} \mathrm{D}$ to $\mathrm{CF}_{3} \mathrm{H}$ for analytical purposes. Thus the rates of a whole series of reactions were related to the rate of the reaction,

$$
\mathrm{CF}_{3} \cdot+\mathrm{D}_{2} \rightarrow \mathrm{CF}_{3} \mathrm{D}+\mathrm{D} \cdot
$$

from a knowledge only of the ratio of $\mathrm{RH}$ and $\mathrm{D}_{2}$ present, and the ratio of $\mathrm{CF}_{3} \mathrm{H}$ to $\mathrm{CF}_{3} \mathrm{D}$ produced. The latter ratio was determined mass-spectrometrically from the relative abundances of the $\mathrm{CF}_{2} \mathrm{H}^{+}$and $\mathrm{CF}_{2} \mathrm{D}^{+}$peaks, allowing for ${ }^{13} \mathrm{C}$ contributions and making the assumption that the cracking patterns and sensitivities of the two molecules are similar. (Should they differ slightly, this will reflect itself in the relative frequency factors, but the relative activation energies will remain unchanged.) A detailed set of results for the reaction with $\mathrm{H}_{2}+\mathrm{D}_{2}$ mixtures is given in table 2 and fig. 2 , and in fig. 3 the Arrhenius plots for a series of $\mathrm{RH}+\mathrm{D}_{2}$ mixtures are given. We considered it the purpose of this work to explore the whole field of $\mathrm{CF}_{3} \cdot$ radical reactivity, and in consequence, 
most of the Arrhenius plots are based on four or five points; the whole of this data is summarized in table 3 (together with some less reliable data on isobutane, benzene and toluene). For the purposes of calculating absolute values of $E_{1}-\frac{1}{2} E_{2}$, we have chosen Ayscough, Polanyi and Steacie's result ${ }^{12}$ for $\mathrm{CF}_{3}{ }^{\circ}+\mathrm{C}_{2} \mathrm{H}_{6}$ as a standard and all the values given in table 3 , with the exception of those for methane, are related to this determination; the corresponding rate factors for $\mathrm{CH}_{3}{ }^{\circ}$ radical reactions are also given in table 3 for comparison.

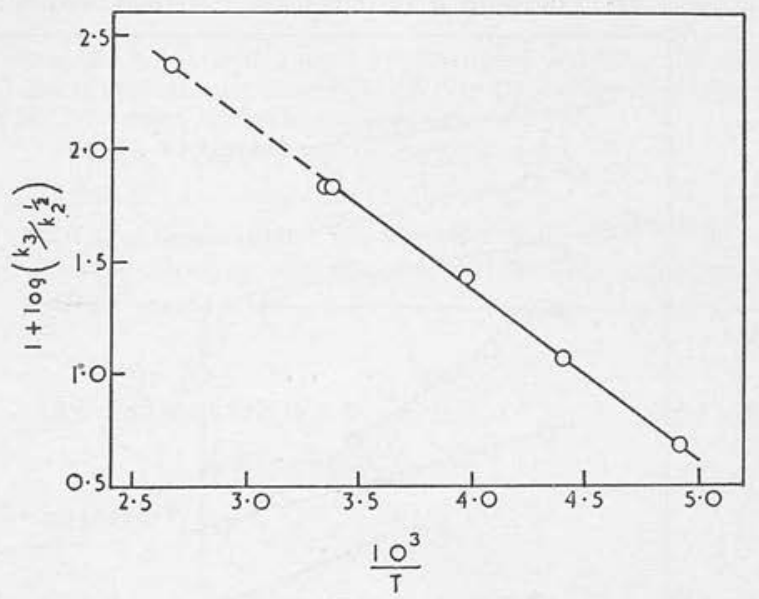

FIG. 1 .

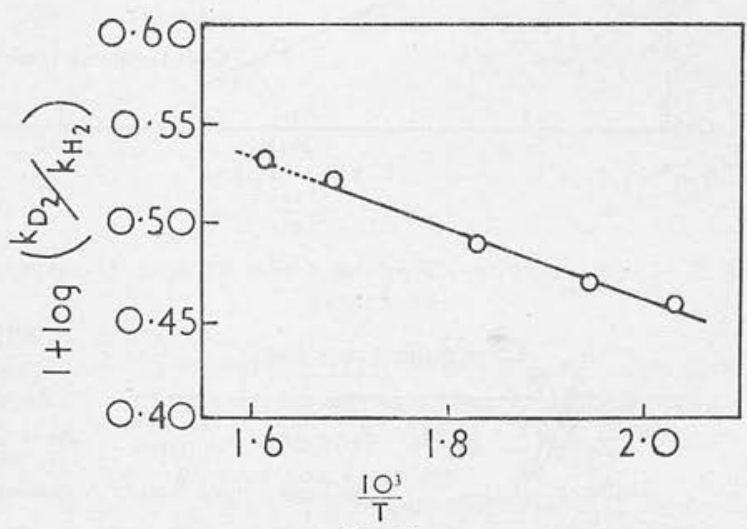

FiG. 2 .

TABLE 2.-THE REACTION OF $\mathrm{CF}_{3} \bullet$ RADICALS WITH HYDROGEN + DEUTERIUM MIXTURES

\begin{tabular}{cccccc} 
temp. ${ }^{\circ} \mathrm{C}$ & time $(\min )$ & $\begin{array}{c}\text { pressure } \mathrm{D}_{2} \\
(\mathrm{~cm})\end{array}$ & $\begin{array}{c}\text { pressure } \mathrm{H}_{2} \\
(\mathrm{~cm})\end{array}$ & $\left.\mathrm{CF}_{3} \mathrm{D}\right] /\left[\mathrm{CF}_{3} \mathrm{H}\right]$ & $k_{5} / k_{1}$ \\
219 & 300 & $12 \cdot 74$ & 3.23 & 1.135 & 0.287 \\
241 & 270 & 9.53 & 2.59 & 1.087 & 0.295 \\
273 & 210 & 8.92 & 4.41 & 0.624 & 0.309 \\
320 & 60 & 8.95 & 6.14 & 0.486 & 0.334 \\
344 & 10 & 9.35 & 4.01 & 0.750 & 0.321 \\
346 & 10 & 7.45 & 4.96 & 0.387 & 0.362 \\
& \multirow{2}{*}{$k_{5} / k_{1}=\frac{\mathrm{d}\left[\mathrm{CF}_{3} \mathrm{D}\right] / \mathrm{d} t t}{\mathrm{~d}\left[\mathrm{CF}_{3} \mathrm{H}\right] / \mathrm{d} t} \frac{\left[\mathrm{H}_{2}\right]}{\left[\mathrm{D}_{2}\right]}=0.69 \exp [-(860 \pm 80) / R T]}$. &
\end{tabular}


These and other results have been corrected for the fact that a proportion of the $\mathrm{CF}_{3} \mathrm{H}$ arises from HD originally present in the $\mathrm{D}_{2}$; the extent of this correction was estimated from a consideration of the results of Whittle and Steacie ${ }^{10}$ on the reactions $\mathrm{CH}_{3}{ }^{*}+\mathrm{HD}$ and $\mathrm{CD}_{3} \cdot+\mathrm{HD}$. Also, in those runs carried out above $320^{\circ} \mathrm{C}$, difficulty was encountered because hexafluoroazomethane decomposes $\left(\rightarrow \mathrm{N}_{2}+2 \mathrm{CF}_{3}{ }^{\circ}\right)$ thermally (at $300^{\circ} \mathrm{C}$ the rate is equivalent to $10 \%$ decomposition in $1 \mathrm{~h} 11)$ : consequently, at $345^{\circ} \mathrm{C}$ an average had to be taken over two runs carried out using complementary mixing procedures (i.e. injection into reaction vessel in the order [substrate $+\mathrm{H}_{2}+\mathrm{D}_{2}$ ] and [substrate $+\mathrm{D}_{2}+\mathrm{H}_{2}$ ]).

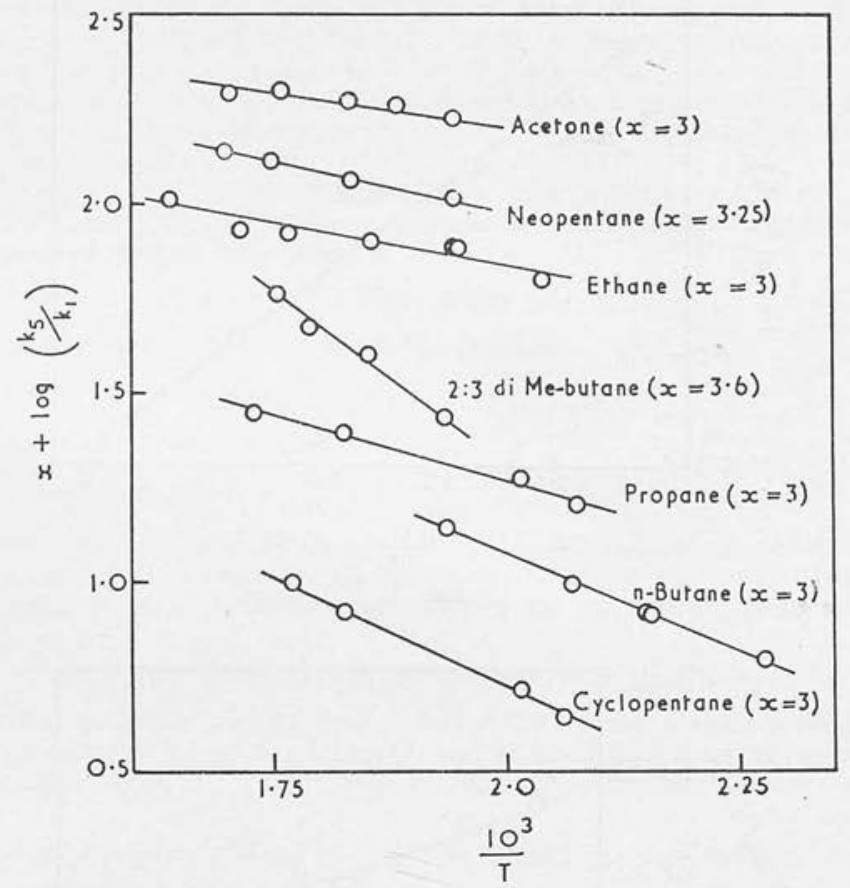

Fig. 3.

Table 3.-Comparison of $\mathrm{CF}_{3} \bullet$ and $\mathrm{CH}_{3} \bullet$ Radical H-abstraction REACTIONS

$\mathrm{CF}_{3} \bullet$ radical reactions

\begin{tabular}{|c|c|c|c|c|c|c|}
\hline \multirow{3}{*}{ RH } & \multirow[b]{2}{*}{$E_{5}-E_{1}$} & \multirow[b]{2}{*}{$A_{5} / A_{1}$} & & \\
\hline & & & $E_{1}-\frac{1}{2} E_{2}$ & $\begin{array}{l}A_{1} / A_{2} \frac{1}{2} \\
\times 10^{-4}\end{array}$ & $E_{1}-\frac{1}{2} E_{2}$ & $\begin{array}{c}A_{1} / A_{2}^{1} \\
\times 10^{-4}\end{array}$ \\
\hline & $\mathrm{kcal} / \mathrm{mole}$ & & $\mathrm{kcal} / \mathrm{mole}$ & $\begin{array}{c}\mathrm{mole}^{-\frac{1}{2}} \mathrm{~cm}^{\frac{3}{2}} \\
\mathrm{sec}^{-\frac{1}{2}}\end{array}$ & $\mathrm{kcal} / \mathrm{mole}$ & $\begin{array}{c}\mathrm{mole}^{-\frac{1}{2}} \mathrm{~cm}^{\frac{3}{2}} \\
\sec ^{-\frac{1}{2}}\end{array}$ \\
\hline deuterium & - & - & $9 \cdot 7$ & 5.8 & $11 \cdot 8$ & $(12 \cdot 9)$ \\
\hline hydrogen & $0.86 \pm 0.08$ & 0.69 & $8 \cdot 8$ & $8 \cdot 4$ & $10 \cdot 0$ & $(21 \cdot 8)$ \\
\hline methane & - & - & $10 \cdot 3 b$ & $9 \cdot 7 b$ & $\sim 13$ & - \\
\hline ethane & $2 \cdot 20 \pm 0.50$ & 0.62 & $7 \cdot 5 b$ & $9 \cdot 4 b$ & $10 \cdot 4$ & 2.8 \\
\hline neopentane & $2 \cdot 10 \pm 0.20$ & 0.47 & $7 \cdot 6$ & 12 & $10 \cdot 0$ & $3 \cdot 0$ \\
\hline propane & $3.5 \pm 0.5$ & 0.60 & $6 \cdot 2$ & $9 \cdot 7$ & - & - \\
\hline n-butane & $4 \cdot 40 \pm 0 \cdot 10$ & 0.97 & $5 \cdot \overline{3}$ & $6 \cdot 0$ & $8 \cdot 3$ & 1.6 \\
\hline cyclopentane & $5.0 \pm 0.2$ & 0.81 & $4 \cdot 7$ & $7 \cdot 2$ & $8 \cdot 3$ & $3 \cdot 6$ \\
\hline isobutane & $\sim 6.7$ & $(8 \cdot 0)$ & $(3 \cdot 0)$ & $(0 \cdot 73)$ & $7 \cdot 6$ & $1 \cdot 5$ \\
\hline 2:3-diMebutane & $8.0 \pm 1.0$ & $16 \cdot 7$ & 1.7 & 0.35 & $6 \cdot 9$ & 1.0 \\
\hline acetone & $1.7 \pm 0.5$ & 0.85 & 8.0 & $6 \cdot 8$ & $9 \cdot 7$ & $6 \cdot 0$ \\
\hline benzene & $\sim 2$ & $(1 \cdot 0)$ & $(7 \cdot 7)$ & $(5 \cdot 8)$ & $9 \cdot 2$ & $0 \cdot 37$ \\
\hline toluene & $3.7 \pm 1.0$ & $1 \cdot 30$ & 6.0 & $4 \cdot 5$ & $8 \cdot \overline{3}$ & $2 \cdot 1$ \\
\hline
\end{tabular}

$a$ methyl radical values from Trotman-Dickenson, ref. (1) and Whittle and Steacie, ref. (10).

$b$ from Ayscough, Polanyi and Steacie, ref. (12). 


\section{(c) THE C-H DISSOCIATION ENERGY IN FLUOROFORM}

It is impossible to understand the factors governing the rates of these $\mathrm{CF}_{3}{ }^{\bullet}$ radical reactions without a knowledge of their thermochemistry. Before this investigation was undertaken, virtually nothing was known with any certainty about the strengths of bonds formed by the $\mathrm{CF}_{3}-\mathrm{gn}$ ap, and in consequence, we have measured $D\left(\mathrm{CF}_{3}-\mathrm{H}\right)$ by the classical kinetic method. We had previously shown ${ }^{9}$ that for the reaction

$$
\mathrm{CF}_{3} \bullet+\mathrm{CH}_{4} \rightarrow \mathrm{CF}_{3} \mathrm{H}+\mathrm{CH}_{3} \bullet \text {. }
$$

$E_{6}-\frac{1}{2} E_{2}$ was in the range $9 \cdot 5 \pm 2 \mathrm{kcal} / \mathrm{mole}$, and this has been confirmed by Ayscough, Polanyi and Steacie 12 who derived a more precise figure of $10.3 \pm 0.5 \mathrm{kcal}$ from experiments in which hexafluoroacetone was photolyzed in the presence of methane; a knowledge of the activation energy of the back reaction

$$
\mathrm{CH}_{3} \bullet+\mathrm{CF}_{3} \mathrm{H} \rightarrow \mathrm{CH}_{4}+\mathrm{CF}_{3} \cdot
$$

is then sufficient to give $D\left(\mathrm{CF}_{3}-\mathrm{H}\right)$ by the relationship,

$$
D\left(\mathrm{CH}_{3}-\mathrm{H}\right)-D\left(\mathrm{CF}_{3}-\mathrm{H}\right)=E_{6}-E_{7} \text {. }
$$

Furthermore, it is now reasonably well established that the isotopic substitution of the

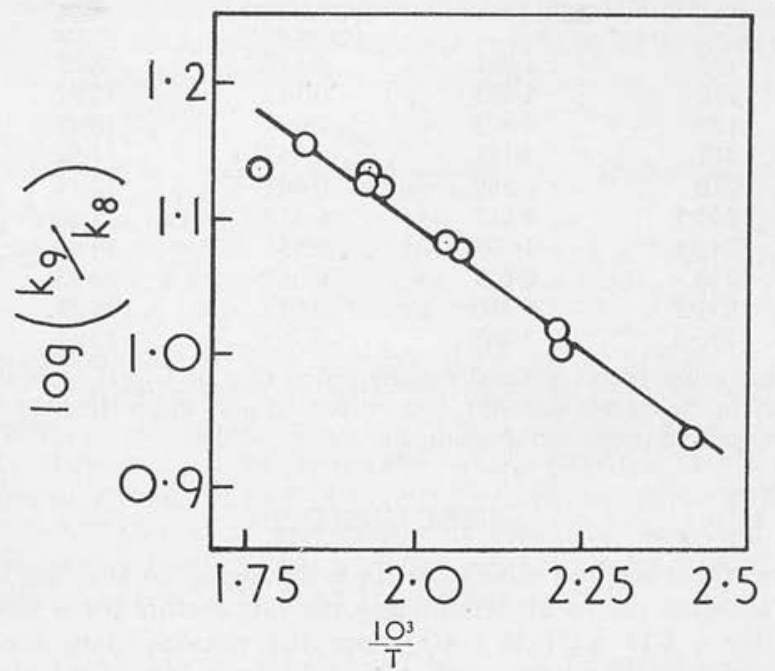

FIG. 4.

three hydrogen atoms in the methyl radical makes very little difference to its reactivity, 10,13 so that we may identify $E_{7}$ with $E_{8}$, the activation energy of the process,

$$
\mathrm{CD}_{3}{ }^{*}+\mathrm{CF}_{3} \mathrm{H} \rightarrow \mathrm{CD}_{3} \mathrm{H}+\mathrm{CF}_{3}{ }^{\bullet},
$$

which is much more eaily measured experimentally.

Mixtures of about $5 \mathrm{~cm}$ of $95 \%$ acetone- $d_{6}$ and some $5-20 \mathrm{~cm}$ of fluoroform were photolyzed at temperatures in the range $140-290^{\circ} \mathrm{C}$; the fraction of the products volatile at $-195^{\circ} \mathrm{C}$ (i.e. $\mathrm{CO}, \mathrm{CD}_{4}$ and $\mathrm{CD}_{3} \mathrm{H}$ ) was separated off, and the ratio of $\left[\mathrm{CD}_{3} \mathrm{H}\right] /\left[\mathrm{CD}_{4}\right]$ was determined mass-spectrometrically. In addition to reaction (8), the $\mathrm{CD}_{3}{ }^{\circ}$ radicals can undergo the reactions

$$
\begin{aligned}
\mathrm{CD}_{3}{ }^{\bullet}+\mathrm{CD}_{3} \mathrm{COCD}_{3} & \rightarrow \mathrm{CD}_{4}+\mathrm{CD}_{3} \mathrm{COCD}_{2}^{\bullet}, \\
\mathrm{CD}_{3} \bullet+\mathrm{CD}_{3} \bullet & \rightarrow \mathrm{C}_{2} \mathrm{D}_{6} .
\end{aligned}
$$

Thus the rate of reaction (8) can be related to the known rate of reaction (9) by the expression

$$
\frac{k_{9}}{k_{8}}=\frac{\mathrm{d}\left[\mathrm{CD}_{4}\right] / \mathrm{d} t}{\mathrm{~d}\left[\mathrm{CD}_{3} \mathrm{H}\right] / \mathrm{d} t} \frac{\left[\mathrm{CF}_{3} \mathrm{H}\right]}{\left[\mathrm{CD}_{3} \mathrm{COCD}_{3}\right]} ;
$$

the results of ten experiments are listed in table 4 and the Arrhenius plot is shown in fig. 4 , leading to the relation $k_{9} / k_{8}=75 \exp [-(1800 \pm 150) / R T]$ (the error quoted being the maximum deviation of the Arrhenius plot). The activation energy of reaction (9) is known relative to that of reaction (10) from work on the photolysis of acetone- $d_{6}$ by Whittle 
and Steacie, 10 and their value of $E_{9}-\frac{1}{2} E_{10}=11.6 \mathrm{kcal} / \mathrm{mole}$ has been confirmed indirectly by McNesby and Gordon. ${ }^{13}$ Using these results, we have

$$
\text { whence } \begin{aligned}
E_{6} & =\left(10 \cdot 3+\frac{1}{2} E_{2}\right) \text { and } E_{7}=E_{8}=\left(11.6+\frac{1}{2} E_{10}-1.8\right), \\
D\left(\mathrm{CF}_{3}-\mathrm{H}\right) & =D\left(\mathrm{CH}_{3}-\mathrm{H}\right)-10 \cdot 3-\frac{1}{2} E_{2}+11.6+\frac{1}{2} E_{10}-1.8 . \\
& =D\left(\mathrm{CH}_{3}-\mathrm{H}\right)-\frac{1}{2} E_{2}+\frac{1}{2} E_{10}-0.5 \mathrm{kcal} / \mathrm{mole} .
\end{aligned}
$$

$E_{10}$ is known to be zero, but there have been numerous suggestions that because of the highly polar nature of the $\mathrm{C}-\mathrm{F}$ bond, there may be a potential barrier to the combination of two $\mathrm{CF}_{3} \cdot$ radicals and that $E_{2}$ may differ considerably from zero (see, e.g., Sieger and Calvert, ref. (8)) ; such arguments are fallacious as it can be shown that a potential barrier to combination will arise only when there is a change in multiplicity of one or more of the atoms in the system; in reaction (2) as in reaction (10), the multiplicities of all centres remain unchanged throughout the course of the combination process. Thus, if we assume that $D\left(\mathrm{CH}_{3}-\mathrm{H}\right)=102 \cdot 5 \pm 1,14$ we have $D\left(\mathrm{CF}_{3}-\mathrm{H}\right)=102 \cdot 0 \pm 2 \mathrm{kcal} / \mathrm{mole}$.

TABLE 4.-THE PHOTOLYSIS OF ACETONE- $d_{6}$ IN THE PRESENCE OF FLUOROFORM

$\begin{array}{cccr}\text { temp. }{ }^{\circ} \mathrm{C} & {\left[\mathrm{CF}_{3} \mathrm{H}\right] /\left[\text { acetone- } d_{6}\right]} & \begin{array}{c}{\left[\mathrm{CD}_{3} \mathrm{H} /\left[\mathrm{CD}_{4}\right]\right.} \\ \text { (corrected) }\end{array} & \begin{array}{c}* \\ 142\end{array} \\ 178 & 1.091 & 0.127 & 8.56 \\ 180 & 1.433 & 0.143 & 10.02 \\ 211 & 0.903 & 0.087 & 10.41 \\ 216 & 3.123 & 0.262 & 11.92 \\ 244.5 & 0.589 & 0.049 & 12.12 \\ 245.5 & 3.517 & 0.258 & 13.63 \\ 246 & 1.803 & 0.133 & 13.56 \\ 271.5 & 0.639 & 0.048 & 13.43 \\ 292.5 & 0.760 & 0.053 & 14.31 \\ & 3.462 & 0.253 & 13.68\end{array}$

* This column has been corrected for the proportion of $\mathrm{CD}_{3} \mathrm{H}$ formed from the $\mathrm{H}$ atom impurity in the heavy acetone; this correction was approximately constant over the whole temperature range and amounted to $0.071 \pm 0.006$.

\section{DISCUSSION}

The competitive method which we have developed in this work provides a simple and accurate means of determining the rate factors for a whole series of reactions, $\mathrm{CF}_{3} \cdot+\mathrm{RH} \rightarrow \mathrm{CF}_{3} \mathrm{H}+\mathrm{R}^{\bullet}$, once the relevant data are known for one such reaction of this type. The only difficulty arises in the preparation of deuterated substandards of sufficient isotopic purity. For example. we have not been able to study the methane reaction by this method because methane is so unreactive that as much $\mathrm{CF}_{3} \mathrm{H}$ would be formed from reaction with the HD impurity in the $\mathrm{D}_{2}$ as from reaction with the methane itself. The correction to be applied would then be too large for the results to be of any value. Some difficulty was experienced also at the other end of the reactivity scale (i.e. with 2:3-dimethylbutane and with isobutane) because they are so much more reactive than $\mathrm{D}_{2}$ : this difficulty can, however, be overcome in principle by the use of a deuterated substandard of intermediate reactivity, for example, $\mathrm{C}_{2} \mathrm{D}_{6}$; we have not performed any experiments of this kind.

The results obtained for the competition between $\mathrm{H}_{2}$ and $\mathrm{D}_{2}$ (see table 2 and fig. 2) are of particular interest. The activation energy for $\mathrm{CF}_{3} \cdot$ radical attack on $\mathrm{D}_{2}$ is greater than for $\mathrm{H}_{2}$ by an amount which is approximately half of the difference in zero-point energy between these molecules, and the ratio of the frequency factors is 0.69 , which is almost exactly equal to the ratio of the relative collision numbers (i.e., $2^{-\frac{1}{2}}$ ) for the two reactions. In view of this result, it seems unlikely that the activation energies for the corresponding $\mathrm{CH}_{3} \cdot$ radical reactions could differ by $1.8 \mathrm{kcal}$ (cf. the values of 11.8 and 10.0 given by Whittle and Steacie ${ }^{10}$ ); note, however, that Whittle and Steacie also found $11 \cdot 1 \mathrm{kcal}$ for the activation energy for $\mathrm{CD}_{3}{ }^{*}+\mathrm{H}_{2}$ which seems more reasonable in comparison 
with the activation energy for $\mathrm{CH}_{3}{ }^{\circ}+\mathrm{D}_{2}$. It can be seen by a comparison of columns 4 and 6 of table 3 that in general the reactions of $\mathrm{CF}_{3}{ }^{\circ}$ radicals have activation energies about 2 or $3 \mathrm{kcal}$ less than the corresponding $\mathrm{CH}_{3}{ }^{\circ}$ radical reactions. (This, too, appears to be true for the addition to the $\mathrm{N}: \mathrm{N}$ double bond, if we compare the value of $3.5 \mathrm{kcal}$ obtained in this work for

$$
\mathrm{CF}_{3} \cdot+\mathrm{CF}_{3} \mathrm{~N}: \mathrm{NCF}_{3}
$$

with that of 6.5 obtained by Jones and Steacie 15 for $\mathrm{CH}_{3}{ }^{\circ}+\mathrm{CH}_{3} \mathrm{~N}: \mathrm{NCH}_{3}$ ). On the other hand, the frequency factor ratios $A_{1} / A_{2} \frac{1}{2}$ for the two sets of reactions are in general very similar but it is difficult at this stage to comment further on this similarity because we cannot quote with any certainty the relative frequency factors for the combination reactions of the two radicals.

The fact that the activation energies for $\mathrm{CF}_{3}{ }^{\circ}$ radical reactions are lower than those for $\mathrm{CH}_{3} \cdot$ radicals is, however, readily understandable in terms of the idea that activation energies and electronegativities are related. ${ }^{2}$ It so happens that reaction (6) is virtually thermoneutral, making possible a direct comparison with three other reactions in which a hydrogen atom is abstracted from the methane molecule. In table 5, the relevant data on these reactions, all of which are thermoneutral to within the experimental error, are presented.

TABLE 5

reaction

$$
\begin{aligned}
& \mathrm{Cl}+\mathrm{CH}_{4} \rightarrow \mathrm{HCl}+\mathrm{CH}_{3^{\prime}} \\
& \mathrm{H}^{\bullet}+\mathrm{CH}_{4} \rightarrow \mathrm{H}_{2}+\mathrm{CH}_{3}^{\bullet} \\
& \mathrm{CF}_{3^{\bullet}}+\mathrm{CH}_{4} \rightarrow \mathrm{CF}_{3} \mathrm{H}+\mathrm{CH}_{3} \bullet \\
& \mathrm{CH}_{3}{ }^{\bullet}+\mathrm{CH}_{4} \rightarrow \mathrm{CH}_{4}+\mathrm{CH}_{3}{ }^{\bullet}
\end{aligned}
$$

$\begin{gathered}\text { Mulliken electronegativity, } \chi \\ (\mathrm{eV})\end{gathered}$
$9 \cdot 5$
$7 \cdot 2$
$>6$
$\sim 6$

It is not suggested that all four reactions form one series (i.e. one cannot use the values of $E$ to derive a value for $\chi$ for the $\mathrm{CF}_{3}{ }^{\bullet}$ radical): however, it is clear that the increase in $\chi$ on going from $\mathrm{H} \cdot$ to $\mathrm{Cl} \bullet$ is accompanied by a substantial decrease in $E$; likewise, on going from $\mathrm{CH}_{3}{ }^{\bullet}$ to $\mathrm{CF}_{3}{ }^{\circ}$ (which is known to be much more electronegative than the methyl radical ${ }^{16}$ ) there is again a significant drop in the value of $E$. This effect will be equally operative throughout the whole series of $\mathrm{CF}_{3}{ }^{\circ}$ reactions studied, so that they all must have activation energies slightly lower than the corresponding $\mathrm{CH}_{3}{ }^{\circ}$ radical reactions.

We wish to thank Mr. V. W. Rowlands of the Widnes Laboratory, I.C.I. General Chemicals Division, Widnes, for performing a number of mass-spectrometer analyses concerned with establishing the purity of the hexafluoroazomethane and with the identification of the products of its photolysis. The work was carried out while one of us (G. O. P.) was in reccipt of a D.S.I.R. maintenance grant.

1 Trotman-Dickenson, Quart. Rev., 1953, 7, 198.

2 Pritchard, Pyke and Trotman-Dickenson, J. Amer. Chem. Soc., 1955, 77, 2629.

${ }^{3}$ Steacie, Atomic and Free Radical Reactions (Reinhold, 2nd Edn., 1954).

4 Trotman-Dickenson, Gas Kinetics (Butterworths, 1955).

5 Ruff and Willenberg, Ber., 1940, 73, 724.

6 Dacey and Young, J. Chem. Physics, 1955, 23, 1302.

${ }^{7}$ Ayscough and Emeléus, J. Chem. Soc., 1954, 3381.

${ }^{8}$ Sieger and Calvert, J. Amer. Chem. Soc., 1954, 76, 5197.

9 Pritchard, Pritchard and Trotman-Dickenson, Chem. and Ind., 1955, 564.

10 Whittle and Steacie, J. Chem. Physics, 1953, 21, 993.

11 Clark and Pritchard, unpublished results.

${ }^{12}$ Ayscough, Polanyi and Steacie, Can. J. Chem., 1955, 33, 743.

13 McNesby and Gordon, J. Amer. Chem. Soc., 1954, 76, 1416.

14 Roberts and Skinner, Trans. Faraday Soc., 1949, 45, 339.

15 Jones and Steacie, J. Chem. Physics, 1953, 21, 1018.

${ }^{16}$ Pritchard and Skinner, Chem. Rev., 1955, 55, 745. 
PRINTED IN GREAT BRITAIN AT THE UNIVERSITY PRESS ABERDEEN 


\section{Preprinted from the Journal of the Chemical Society, October, 1956, (749), pages 3855-3857.}

\section{The Thermal Decomposition of cycloPentyl Bromide.}

By S. J. W. Price, R. Shaw, and A. F. Trotman-Dickenson.

The thermal decomposition of cyclopentyl bromide into cyclopentene and hydrogen bromide has been studied in a static system at temperatures between $300^{\circ}$ and $360^{\circ} \mathrm{C}$. The decomposition is homogeneous and obeys firstorder kinetics in its early stages; the rate constant is given by

$$
k=10^{11 \cdot 9} \exp (-41,400 / \boldsymbol{R} T) \mathrm{sec}^{-1}
$$

The elimination of hydrogen bromide is probably a molecular process, as the addition of cyclohexene has no effect upon the rate.

DURING the past few years the thermal decomposition of many aliphatic bromides has been investigated, chiefly by Maccoll and his collaborators. ${ }^{1,2}$ The majority of these bromides, in the presence of an inhibitor, decompose by a four-centre molecular elimination mechanism into hydrogen bromide and an olefin. One of the compounds which has been found to react in this way is cyclohexyl bromide ${ }^{3}$ The rate constant for its decomposition is given by the Arrhenius equation

$$
k=10^{13 \cdot 5} \exp (-46,100 / \boldsymbol{R} T) \mathrm{sec}^{-1}
$$

The investigation of the decomposition of cyclopentyl bromide was undertaken in the hope that a knowledge of the rate factors, $A$ and $E$ in the Arrhenius equation, would throw light on the features of molecules which determine the rates of molecular elimination reactions. In particular, it was thought that the different degrees of flexibility of the carbon rings might influence the rates.

\section{EXPERIMENTAL}

Materials.-The cyclopentyl bromide was a gift from the Michigan Chemical Company. It was degassed and purified by bulb-to-bulb distillation. No significant quantities of impurity could be detected by vapour-phase chromatography. The cyclohexene, which was similarly degassed, was freed from peroxides by shaking with acid ferrous sulphate solution.

Apparatus.-The decomposition was studied in a bulb of 385 c.c. capacity attached to a conventional vacuum-system ky tubing with a total dead space of approx. 13 c.c. The bulb was contained in a mercury-- apour jacket, whose temperature could be readily controlled by varying the pressure under which the mercury boiled. The temperature of the jacket was determined by reference to standard tables of the vapour pressure of mercury. The reaction was studied by following the change in pressure in the reaction vessel on a mercury manometer. It was found that the hydrogen bromide formed did not appreciably attack the mercury during a run, for the reaction vessel was separated from the manometer by about $30 \mathrm{~cm}$. of $2-\mathrm{mm}$. capillary tubing.

Procedure.-Runs were started by admitting a suitable quantity of the bromide to the reaction vessel from a storage bulb; in some runs a quantity of cyclohexene was also added. Readings of the pressure in the vessel were then recorded at convenient intervals. At the end of some of the runs the quantity of hydrogen bromide formed was determined analytically. It was found that inexplicably erratic and high results were usually obtained when the unseparated products were titrated with alkali, so the following procedure was adopted. First, the products were condensed in a side bulb, and the hydrogen bromide was-separated by low-temperature distillation. Its amount was then determined by pressure measurements and by dissolving the gas in water and titrating the solution for hydrogen and halide ions. The results of the three determinations were always in excellent agreement. When a proper correction was made for the dead space it was found that the analytical results agreed well with degrees of decomposition deduced from the pressure measurements. 
Rate constants were determined in the usual way from first-order plots of the logarithms of the pressure changes against time. The logarithmic plots were strictly linear for the first third of the reaction but thereafter tended to curve. The curvature was probably caused by the increasing importance of the back reaction. The rate constants for a few runs were calculated from the full expression for a first-order reaction opposed by a second-order reaction. The rate constants obtained in this way differed by only about $10 \%$ from those calculated by applying the equation for a simple first-order reaction to the observations made during the first third of the decomposition. All the rate constants reported here were determined by the less tedious procedure.

All runs showed short induction periods. Their lengths corresponded roughly to the time needed for $2-3 \%$ of the bromide to decompose. The presence of cyclohexene appeared to shorten the induction periods slightly.

\section{Results and Discussion}

Preliminary runs in a clean-walled reaction vessel gave first-order rate constants which decreased slowly but steadily from run to run. Maccoll and his collaborators observed similar behaviour with other bromides and attributed the effect to heterogeneous processes. They therefore seasoned their reaction vessels by decomposing allyl bromide in them. This remedy proved effective for cyclopentyl bromide also. It was used after any occasion on which air had been admitted to the reaction vessel. Incidentally, Maccoll's rate constant ${ }^{4}$ for the decomposition of allyl bromide was confirmed.

The first-order nature of the decomposition was demonstrated by studying it with various initial pressures of cyclopentyl bromide. The results obtained for a typical series of runs, all corrected to $356 \cdot 5^{\circ}$, were as follows :

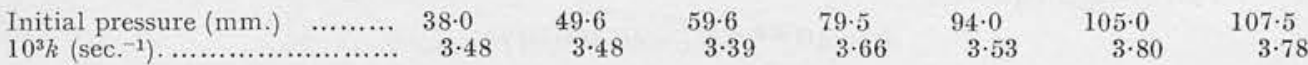

The very small effect on the rate constant of the addition of cyclohexene can be seen from the following Table, in which the observed rate constants are compared with those

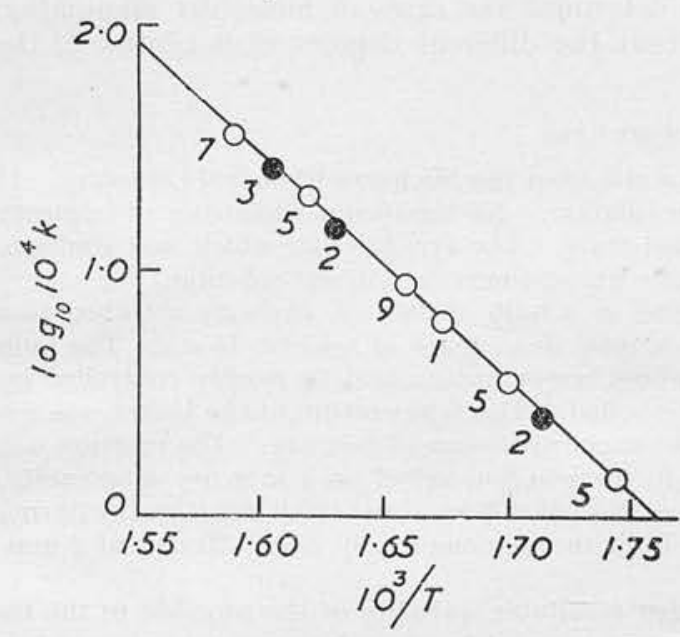

Arrhenius plot for the thermal decomposition of cyclopentyl bromide.

Unpacked reaction vessel.

- Packed reaction vessel.

The figures by the circles indicate the number of runs averaged to obtain each point.

calculated from the Arrhenius equation. The variations in the rates are of the same order as the experimental error.

\begin{tabular}{|c|c|c|c|c|c|}
\hline cycloHexene (mm.) & $20 \cdot 0$ & $30 \cdot 0$ & $10 \cdot 0$ & $9 \cdot 0$ & $40 \cdot 0$ \\
\hline cycloPentyl bromide $(\mathrm{mm}$.$) ..................$ & $60 \cdot 0$ & $72 \cdot 5$ & $64 \cdot 0$ & $48 \cdot 2$ & $38 \cdot 0$ \\
\hline Temp. ........................ & $300 \cdot 7^{\circ}$ & $315 \cdot 2^{\circ}$ & $331 \cdot 3^{\circ}$ & $344 \cdot 5^{\circ}$ & $365 \cdot 5^{\circ}$ \\
\hline$k$ (obs.) $/ k$ (calc.). & 1.05 & 0.95 & $1 \cdot 02$ & 0.98 & $0 \cdot 91$ \\
\hline
\end{tabular}

Seven runs were carried out with the reaction vessel packed with Pyrex tubing so that the surface/volume ratio was increased from 0.9 to $2.0 \mathrm{~cm} .^{-1}$. The results of these runs are distinctively plotted alongside the other results in the Figure. It can be seen that there is no evidence for any heterogeneous contribution to the reaction in an aged vessel. 
The results of all the runs are shown on an Arrhenius plot in the Figure. The Arrhenius equation was derived by a least-squares treatment of the results for all the individual runs. The results are best expressed by the equation :

$$
k=10^{11 \cdot 9} \exp (-41,400 / \boldsymbol{R} T) \mathrm{sec}^{-1}
$$

Our experiments indicate that this is the rate constant for the homogeneous gas-phase molecular elimination of hydrogen bromide from cyclopentyl bromide.

The rate constant for this decomposition at $380^{\circ}\left(0.010 \mathrm{sec}^{-1}\right)$ is very slightly greater than that $\left(0.008 \mathrm{sec}^{-1}\right)$ for the similar decomposition of cyclohexyl bromide. This conclusion is of interest in view of a recent important suggestion ${ }^{5}$ that the rate constants for the molecular elimination of hydrogen bromide from aliphatic bromides should run parallel to the rate constants for the elimination of bromide ions from the bromides by the $S_{N} 1$ mechanism. No measurements on the rates of the $S_{\mathrm{N}} 1$ reactions of cyclopentyl and cyclohexyl bromide have been reported. It has been found, ${ }^{6}$ however, that the $S_{\mathrm{N}} 1$ reaction of 1-methylcyclopentyl chloride in $80 \%$ aqueous ethanol at $25^{\circ}$ is 125 times more rapid than the corresponding reaction of 1-methylcyclohexyl chloride. Evidently the parallelism between the rates of the $S_{N} 1$ reactions and the molecular eliminations breaks down in this instance. Probably the cause is the different natures of the strains in the two types of transition states.

The University, Edinburgh 9.

[Received, May 30th, 1956.]

1 Harden and Maccoll, $J$., 1955, 2454, and ref. 4.

2 For similar reactions, see Trotman-Dickenson, " Gas Kinetics," Butterworths, London, 1955.

3 Green and Maccoll, $J ., 1955,2449$.

4 Maccoll, J., 1955, 965.

5 Maccoll and Thomas, Nature, 1955, 176, 392

- Brown and Borkowski, J. Amer. Chem. Soc., 1952, 74, 1894. 
[Reprinted from the Journal of Physical Chemistry, 60, 1367 (1956).]

Copyright 1956 by the American Chemical Society and reprinted by permission of the copyright owner.

\title{
THE REACTIONS OF CHLORINE ATOMS-A TEST OF THE TRANSITION STATE THEORY
}

\author{
By J. H. Knox and A. F. Trotman-Dickenson \\ Chemistry Department, The University, Edinburgh \\ Received March 9, 1956
}

\begin{abstract}
The relative $A$ factors for reactions of the type $\mathrm{Cl}+\mathrm{RH}=\mathrm{HCl}+\mathrm{R}$ have been calculated on the assumptions of the transition state theory. A comparison of these values with the accurate experimental data reveals considerable discrepancies.
\end{abstract}

The transition state theory of chemical kinetics has been applied with fair success to the calculation of the order of magnitude of the Arrhenius $A$ factors of bimolecular reactions. ${ }^{1}$ Little more can however be claimed for two reasons: firstly, doubtful assumptions as to the configurations of the activated complexes had to be made which led to considerable uncertainty in the calculated values, and secondly, experimental results of sufficient accuracy to sustain an unambiguous test were not available. The usual errors in the measurement of activation energies of these reactions were, under the most favorable conditions, of the order of $\pm 300 \mathrm{cal} . / \mathrm{mole}$. The corresponding error in the $A$ factor is then $10^{ \pm 0.2}$ (about $\pm 60 \%$ ).

In the present paper, relative $A$ factors calculated from transition state theory are compared with those determined experimentally by $\mathrm{us}^{2,3}$ for the competitive reactions of chlorine atoms with several hydrocarbons. Calculated $A$ factor ratios are also given for a number of reactions which have

(1) A. F. Trotman-Dickenson, "Gas Kinetics," Academic Press, Inc., New York, N. Y., 1955.

(2) H. O. Pritchard, J. B. Pyke and A. F. Trotman-Dickenson, J. Am. Chem. Soc., 77, 2629 (1955).

(3) J. H. Knox, Chem. and Ind., 1631 (1955). not yet been studied but which we hope to investigate in due course. These reactions of chlorine atoms offer a number of advantages for such a study. In the first place there is much less doubt about the configuration of the activated complexes in reactions of atoms than in the corresponding reactions of free radicals, there being no uncertainty about the free rotation of the radical in the former case. Secondly, the activation energies of the reactions are low and may therefore be measured with very small absolute errors (although the percentage error will be of the usual magnitude). It may furthermore be assumed that in such cases the bond lengths $\mathrm{C}-\mathrm{H}-\mathrm{Cl}$ will vary little from complex to complex and that the $\mathrm{C}-\mathrm{H}$ and $\mathrm{C}-\mathrm{Cl}$ bond lengths will be only slightly longer than those in normal molecules. Thirdly, by employing a competitive technique, relative $A$ factors can be determined with unusual precision. In the most favorable cases relative activation energies have been measured to within $30 \mathrm{cal}$./mole giving relative $A$ factors to within $5 \%$.

These relative $A$ factors can therefore provide a stringent test of the transition state theory since not only can they be measured experimentally with 
high precision but they may also be calculated with high accuracy making use of fewer assumptions than are required in the calculation of absolute values.

According to transition state theory the relative $A$ factors for the competitive reaction of chlorine atoms with methane and ethane are given by the equation

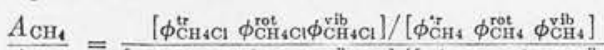

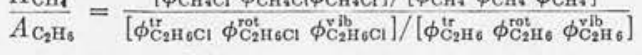

$$
\begin{aligned}
& =\exp \left[\frac { 1 } { R } \left(\Delta S_{\mathrm{CH}_{4}}^{\mathrm{tr}}-\Delta S_{\mathrm{C}_{2} \mathrm{H}_{6}}^{\mathrm{t}}+\Delta S_{\mathrm{CH}_{4}}^{\mathrm{rot}}-\Delta S_{\mathrm{C}_{2} \mathrm{H}_{6}}^{\mathrm{rot}}\right.\right. \\
& \left.\left.+\Delta S_{\mathrm{CH}}^{\mathrm{vib}}-\Delta S_{\mathrm{C} 2 \mathrm{He}}^{\mathrm{vbb}}\right)\right]
\end{aligned}
$$

where the partition functions, denoted by $\phi$ 's, are measured from the ground state of the parent molecule and of the complex, respectively. The activation energy appropriate to these theoretical $A$ factors is therefore the activation energy at absolute zero which may be denoted $\Delta E_{0}^{\circ}$. The $\Delta S$ values are the entropies of activation appropriate to the translational, rotational and vibrational degrees of freedom. In the above expression for the $A$ factors the transmission coefficients have been omitted, and the symmetry numbers are taken to be included in the rotational partition functions. If the partition functions are evaluated without the symmetry numbers the values for the $A$ factors are those for individual hydrogen atoms. Denoting such factors by $A^{\prime}$ the above equation can be written

$\frac{A^{\prime}{ }_{\mathrm{CH}_{4}}}{A_{\mathrm{C}_{2} \mathrm{H}_{6}}}=\left\{\frac{M_{\mathrm{CH}_{4} \mathrm{Cl}} / M_{\mathrm{CH}_{4}}}{M_{\mathrm{C}_{2} \mathrm{H}_{6} \mathrm{Cl}} / M_{\mathrm{C}_{2} \mathrm{H}_{e}}}\right\}^{3 / 2} \times$
$\left\{\frac{(A B C)_{\mathrm{CH}_{4} \mathrm{Cl}} /(A B C)_{\mathrm{CH}_{6}}}{(A B C)_{\mathrm{C}_{2} \mathrm{H}_{6} \mathrm{Cl}} /(A B C)_{\mathrm{C}_{3} \mathrm{H}_{6}}}\right\}^{1 / 2} \times \exp \left[\frac{1}{R}\left(\Delta S_{\mathrm{CH}}^{\mathrm{vib}}-\Delta S_{\mathrm{C} 2 \mathrm{H}}^{\mathrm{vib}}\right)\right]$

where $M$ 's are the molecular weights of the various substances and the product $(A B C)$ is the product of the moments of inertia about the three principal axes of the molecules. While the masses are known exactly, the values of $(A B C)$ are not known with the same precision because of the slight uncertainty (probably less than $0.2 \AA$.) as to the $\mathrm{C}-\mathrm{H}-\mathrm{Cl}$ distances. Values of $(A B C)$ can however be calculated to any degree of accuracy once a configuration has been accepted. Since any error in the $\mathrm{C}-\mathrm{H}-\mathrm{Cl}$ distances will affect the $(A B C)$ 's of all complexes in the same sense and roughly in the same proportion, any error of choice will largely cancel out. There are three likely sources of error in comparing the calculated values with the experimental ones. The calculation of the vibrational entropy term is not possible with any certainty. It will however almost certainly be small. The vibrational entropies of methane and ethane are both less than 1.e.u. and the vibrational entropies of activation will therefore be much smaller than 1 e.u. Differences in vibrational entropies of activation as between say methane and ethane will be even smaller and probably not greater than \pm 0.1 e.u. The vibrational term which might at first sight appear to result in large uncertainty in the calculation of the theoretical $A$ factor should not therefore contribute more than about $\exp 0.1 / R$, that is, about $5 \%$ uncertainty.

In these calculations the eontributions from intternal rotations in the parent molecules and the complexes have been neglected. The appropriate allowance may readily be made only in the simplest cases where the rotators are symmetrical tops. In the case of ethane, for example, the contribution to the entropies of the parent and the complex due to free internal rotation are, ignoring the symmetry factor, 5.06 and 5.66 e.u., respectively. An error of about $30 \%$ may therefore be introduced in the particular case of ethane/methane by ignoring internal rotation. For higher homologs the contributions due to changes in internal rotation will be smaller than this. In the cases considered we are moreover concerned with restricted rotation rather than free rotation, and the effect of neglecting rotations is thus further reduced.

Lastly, there is likely to be a discrepancy between the theoretical and experimental $A$ factors resulting from the fact that the experimental activation energy and the theoretical activation energy differ according to the equation

$$
\Delta E_{\exp }=\Delta E_{0}{ }^{\circ}+\int_{0}^{T} \Delta C_{\mathrm{v}} \mathrm{d} T
$$

giving $\quad A_{\text {exp }}=A_{\text {calc }} \exp [(\mathcal{S} \Delta C \mathrm{v} / \mathrm{d} T) / R T]$

The difference in $\Delta C_{\mathrm{v}}$ for two similar reactions will however be very small since the translational and rotational specific heat changes will be identical for the two reactions and only the changes in vibrational specific heats will be important. As with the vibrational entropy contributions, these will be very small indeed.

We therefore conclude that the major factors influencing the relative $A$ factors for two similar reactions are the changes in the translational and rotational entropies. Errors of up to some 5\% are introduced by ignoring the vibrational contributions, and rather more by ignoring internal rotation. The latter is however never likely to be more than about $20 \%$, even in an extreme case such as the comparison of the chlorinations of methane and ethane.

The details of the calculations are given below and a summary of the results appears in Table I. It already has been shown ${ }^{2}$ that $A$ factors of the right order of magnitude may be calculated for these chlorination reactions so that considerable interest attaches to the much more accurate values found for the relative $A$ factors. These are given in Table II where they are compared with the experimentally determined values. Examination of the table reveals that the simple transition state theory predicts only approximately the relative $A$ factors and that the discrepancy between the calculated and the experimental values is in the sense that too large an $A$ factor is predicted for the lighter relative to the heavier molecules except in the indirect comparison of neopentane with isobutane where the mass difference is relatively small. These discrepancies (factors of up to ten) are well without both experimental error and any reasonable estimate of the theoretical error in our calculations. They may possibly be resolved in terms of transmission coefficients which we have neglected, but as yet no general method has been suggested by which such allowance might be made. The calculations show clearly the limits of the application of the simple transition state theory, and 
TABLE I

Translational and Rotational Entropies

\begin{tabular}{|c|c|c|c|c|}
\hline Compound & $S_{\text {trans }}$ & $\begin{array}{l}\log _{10} \\
A B C^{a}\end{array}$ & $\sigma$ & $S_{\text {rot }}$ \\
\hline $\mathrm{Cl}$ & 36.6 & 0 & . & 0 \\
\hline $\mathrm{H}_{2}$ & 28.1 & $\overline{1} .68^{b}$ & 2 & 4.1 \\
\hline $\mathrm{H}_{2}-\mathrm{Cl}$ & 36.8 & $0.89^{b}$ & 1 & 11.0 \\
\hline $\mathrm{CH}_{4}$ & 34.3 & 1.56 & 12 & 10.3 \\
\hline $\mathrm{CH}_{4}-\mathrm{Cl}$ & 37.8 & 4. 29 & 3 & 19.3 \\
\hline $\mathrm{C}_{2} \mathrm{H}_{6}$ & 36.1 & 3.62 & 18 & 14.2 \\
\hline $\mathrm{C}_{2} \mathrm{H}_{6}-\mathrm{Cl}$ & 38.9 & 5.78 & 3 & 22.7 \\
\hline $\mathrm{C}_{3} \mathrm{H}_{8}$ & 37.2 & 4.84 & 18 & 17.0 \\
\hline $\mathrm{C}_{3} \mathrm{H}_{8}$ cond. ${ }^{c}$ & 37.2 & 4.65 & 18 & 16.5 \\
\hline$p-\mathrm{C}_{3} \mathrm{H}_{8}-\mathrm{Cl}$ (a) & 39.0 & 6.36 & 3 & 24.0 \\
\hline$p-\mathrm{C}_{3} \mathrm{H}_{8}-\mathrm{Cl}$ (a) cond. & 39.0 & 6.26 & 3 & 23.8 \\
\hline$p-\mathrm{C}_{3} \mathrm{H}_{8}-\mathrm{Cl}$ (b) & 39.0 & 6.35 & 3 & 24.0 \\
\hline$p-\mathrm{C}_{3} \mathrm{H}_{8}-\mathrm{Cl}(\mathrm{b})$ cond. & 39.0 & 6.31 & 3 & 23.9 \\
\hline$s-\mathrm{C}_{3} \mathrm{H}_{8}-\mathrm{Cl}$ & 39.0 & 6.47 & 9 & 22.1 \\
\hline$s-\mathrm{C}_{3} \mathrm{H}_{8}-\mathrm{Cl}$ cond. & 39.0 & 6.43 & 9 & 22.0 \\
\hline iso- $\mathrm{C}_{4} \mathrm{H}_{10}$ & 38.1 & 5.76 & 81 & 16.1 \\
\hline iso- $\mathrm{C}_{4} \mathrm{H}_{10}$ cond. & 38.1 & 5.46 & 81 & 15.4 \\
\hline$p$-iso- $\mathrm{C}_{4} \mathrm{H}_{10}-\mathrm{Cl}$ (a) cond. & 39.5 & 6.91 & 9 & 23.1 \\
\hline$p$-iso- $\mathrm{C}_{4} \mathrm{H}_{10}-\mathrm{Cl}$ (b) cond. & 39.5 & 6.75 & 9 & 22.7 \\
\hline$t$-iso- $\mathrm{C}_{4} \mathrm{H}_{10}-\mathrm{Cl}$ & 39.5 & 6.93 & 81 & 18.7 \\
\hline$t$-iso- $\mathrm{C}_{4} \mathrm{H}_{10}-\mathrm{Cl}$ cond. & 39.5 & 6.79 & 81 & 18.4 \\
\hline $\mathrm{C}\left(\mathrm{CH}_{3}\right)_{4}{ }^{d}$ & 38.8 & 6.18 & 324 & 14.3 \\
\hline $\mathrm{C}\left(\mathrm{CH}_{3}\right)_{4}-\mathrm{Cl}^{d}$ & 40.1 & 7.33 & 27 & 21.9 \\
\hline $\mathrm{CF}_{3} \mathrm{H}$ & 38.7 & 5.11 & 3 & 21.2 \\
\hline $\mathrm{CF}_{3} \mathrm{H}-\mathrm{Cl}$ & 40.0 & 6.86 & 3 & 26.2 \\
\hline $\mathrm{CCl}_{3} \mathrm{H}$ & 40.1 & 6.88 & 3 & 26.2 \\
\hline $\mathrm{CCl}_{3} \mathrm{H}-\mathrm{Cl}$ & 41.1 & 7.73 & 3 & 28.2 \\
\hline
\end{tabular}

a Units of $A B C$ are [molecular weight $\left.\times \AA . .^{2}\right]^{3}$. ${ }^{b}$ These values are $\log _{10} A$ where $A$ is the moment of inertia. " "cond." stands for the condensed $\mathrm{CH}_{3}$ approximation.

${ }^{d}$ The molecule was treated as a series of spherical shells.

TABLE II

Relative A Factors for Chlorine Atom Reactions

$$
\begin{aligned}
& \text { Compounds } \\
& \mathrm{X} \quad \mathrm{Y}
\end{aligned}
$$

Hydrogen/methane

Methane/ethane

Ethane/neopentane

Ethane/chloroform

Ethane/fluoroform

p-Propane/sec-propane (a)

p-Propane/sec-propane (b)

$p$-isobutane/ $t$-isobutane (a)

$p$-isobutane/ $t$-isobutane (b)

\section{Ethane/propane ${ }^{c}$}

Ethane/isobutane ${ }^{c}$

a Calculated for the complete molecule. " ${ }^{b}$ Calculated using the condensed approximation. cThese results are given in terms of the molecule as a whole because no experimental distinction was made between the different types of hydrogen atoms. invite further work on other series of reactions which might likewise be compared with theoretical predictions.

The Calculations.-Values for the translational and rotational entropies have been calculated for each of the reactants and complexes studied. The translational entropies were calculated from the Sackur-Tetrode equation; the values are given in Table I. The values obtained for the rotational entropies depend upon the precise configurations assumed for the molecules (see below). These calculations of the moments of inertia can be considerably simplified if the hydrogen atoms of the methyl groups are "condensed" into the appropriate carbon atom; each methyl group is then treated as a mass of 15 located at the center of gravity of the original methyl group. Some examples of such condensations are given in Table I, and it can be seen from Table II that this simplification yields values of the relative $A$ factors which are only slightly different from those obtained by more laborious means.

The Configurations. - It was assumed throughout that the carbon valency angles were all equal to $109.5^{\circ}$. In the linear $\mathrm{C}-\mathrm{H}-\mathrm{Cl}$ groups of the activated complexes the $\mathrm{C}-\mathrm{H}$ distance was taken as $1.15 \AA$. and the $\mathrm{H}-\mathrm{Cl}$ as $1.45 \AA$.; other bond lengths assumed were $\mathrm{C}-\mathrm{C} 1.54 \AA$., $\mathrm{C}-\mathrm{H} 0.98 \AA$ А., $\mathrm{C}-\mathrm{F} 1.36 \AA$. and $\mathrm{C}-\mathrm{Cl} 1.76 \AA$. The following points may be mentioned in connection with the configurations of individual reactants and complexes.

Propane.-Calculations were made for two different configurations of the complex obtained by attack of the chlorine atom at the primary position: (a) in which the chlorine atom in the complex is at the greatest possible distance from the third carbon atom (i.e., with the $\mathrm{C}-\mathrm{H}-\mathrm{Cl}$ bond parallel to the opposite $\mathrm{C}-\mathrm{C}$ bond) (b) in which the chlorine atom is as close as possible to the third carbon atom.

Isobutane.-Calculations were again made for two configurations of the complex: (a) in which the chlorine atom was at the greatest possible distance from the tertiary hydrogen atom (i.e., the $\mathrm{C}-\mathrm{H}-\mathrm{Cl}$ bond parallel to the tertiary $\mathrm{C}-\mathrm{H}$ bond); (b) in which the chlorine atom is as close as possible to the tertiary hydrogen atom.

Neopentane.-This molecule was treated as a central atom of mass 12 surrounded by two spherical shells one of mass 48 and radius $1.54 \AA$. and the other of mass 12 and radius $2.20 \AA$; t the chlorine atom in the complex was taken to be a distance of $3.65 \AA$. from the central carbon atom. 
PRINTED IN DENMARK

Acta Cryst. (1957). 10, 34

\title{
The Crystal Structure of Nitramide, $\mathrm{NH}_{2} \mathrm{NO}_{2}$
}

\author{
By C. A. Beevers and A. F. Trotman-Dickenson \\ Chemistry Department, University of Edinburgh, Scotland
}

(Received 28 June 1956)

\begin{abstract}
The structure of the unstable crystals of nitramide, $\mathrm{NH}_{2} \mathrm{NO}_{2}$, has been investigated. The monoclinic unit cell has dimensions $a=6 \cdot 65, b=4 \cdot 79, c=7 \cdot 86 \AA, \beta=112^{\circ} 24^{\prime}$, and the space group is $A 2 / a$. Good agreement $\left(R=16 \frac{1}{2} \%\right)$ is obtained for all reflexions with one index zero and for all the planes with $k=1$. The parameters chosen are $\mathrm{N}_{\mathrm{I}}$ at $(0 \cdot 250,0 \cdot 575,0), \mathrm{N}_{\mathrm{II}}$ at $(0 \cdot 250,0 \cdot 866,0)$, $\mathrm{O}$ at $(0.367,0.466,0.137)$, whilst the probable hydrogen positions are $(0.42,0,0 \cdot 08)$. The hydrogen atoms did not show up in the $b$-axis difference maps (although these showed evidence of anisotropic movements of the nitrogen and oxygen atoms) but there were indications of the hydrogen positions in the other two difference maps.
\end{abstract}

\section{Introduction}

The high melting point and low volatility of nitramide indicate a high degree of hydrogen bonding in the crystal. Because the compound contains a high proportion of hydrogen atoms to heavier atoms, it appeared that a study of the crystal structure might have provided interesting information on the $\mathrm{N}-\mathrm{H}-\mathrm{O}$ hydrogen bond. Furthermore, it was hoped that the study would throw light on the disputed question of the structure of the compound.

The chemical and physical properties of nitramide indicate (Bell \& Trotman-Dickenson, 1949) that in solution it is predominantly in the form of $\mathrm{NH}_{2} \mathrm{NO}_{2}$ molecules, the structure originally suggested by Thiele $\&$ Lachmann (1895). However, a small proportion of the dissolved molecules probably have the tautomeric structure NH.NOOH suggested by Pedersen (1934).

The present work indicates that the structure of the crystals is that shown in Fig. 1, and suggests that the formula $\mathrm{NH}_{2} \mathrm{NO}_{2}$ is to be preferred although it proved difficult to locate the hydrogen atoms precisely. All the presumed hydrogen bond distances are rather long, each amide nitrogen having six $\mathrm{N}-\mathrm{O}$ distances of $3 \cdot 1 \AA$.

\section{Experimental details and unit cell}

The nitramide was synthesized by the method of Marlies, LaMer \& Greenspan (1939) (we are indebted to $\mathrm{Mr}$ J. S. Slater for this preparation). The nitramide was dissolved in anisole at about $25^{\circ} \mathrm{C}$. to form a saturated solution. This was stored in a refrigerator $\left(6^{\circ} \mathrm{C}\right.$. $)$ at which temperature the crystals precipitated out. They were kept under these conditions for several months. When mounted on a goniometer head in the $\mathrm{X}$-ray camera the crystals completely disappeared in 24 hours.

The crystals have the shape of laths of a few millimetres length and of width about $0.4 \mathrm{~mm}$. and thickness $0.2 \mathrm{~mm}$. Many were striated parallel to the long dimension. They show a parallel extinction. It was not easy to find good single crystals, but, when found, $\mathrm{X}$-ray photographs showed them to be monoclinic, with the unique $(b)$ axis parallel to the length. The dominant form was $\{10 \overline{1}\}$ referred to the axes given below. The axial lengths were calculated from the position on the films of moderately high order spots. The cell found was:

$$
\begin{gathered}
a=6 \cdot 65 \pm 0 \cdot 03, \quad b=4 \cdot 79 \pm 0 \cdot 03, \quad c=7 \cdot 86 \pm 0 \cdot 03 \AA . \\
\beta=112^{\circ} 24^{\prime} .
\end{gathered}
$$




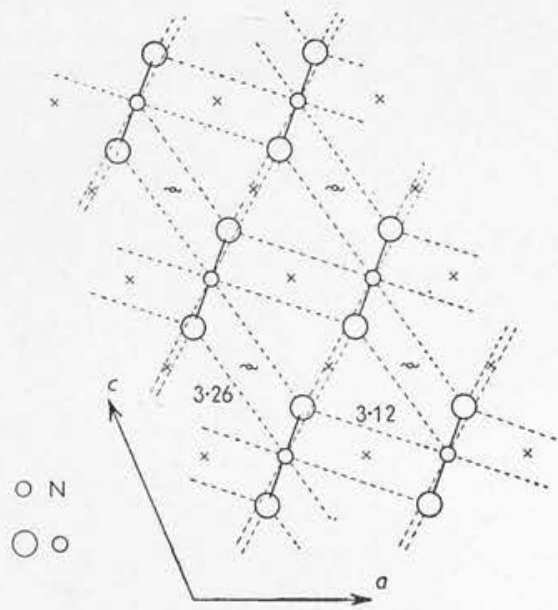

(a)

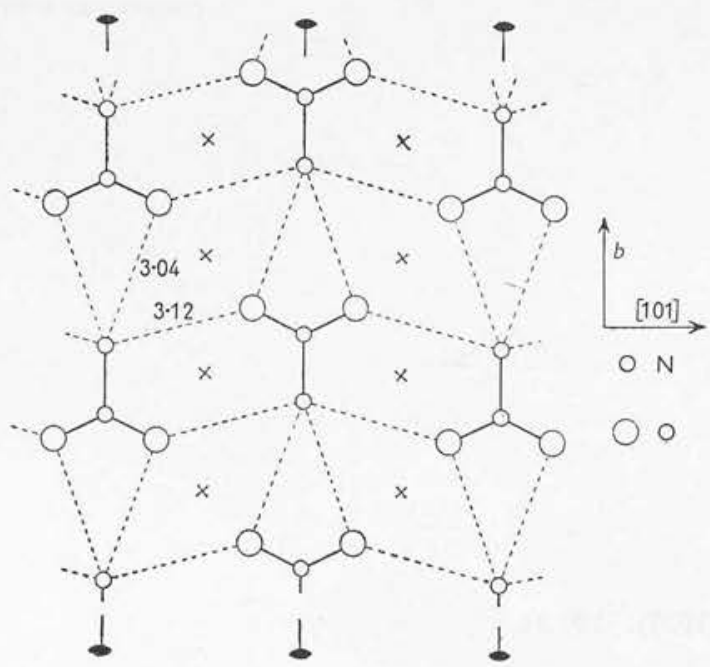

(b)

Fig. 1. (a) Projection of the structure down the $b$ axis. The two nitrogen atoms are superimposed in the positions of the twofold axes. The broken lines show distances between the atoms of the different molecules. $(b)$ One of the approximately flat sheets of molecules parallel to the $(10 \overline{1})$ plane, the broken lines showing the bonding between molecules in the plane.

This cell contains 4 molecules of $\mathrm{NH}_{2} \mathrm{NO}_{2}$, the observed density being 1.783 g.cm. ${ }^{-3}$. The calculated density agrees with this to 1 part in 4000 .

Photographs were obtained about the three principal axes. The $b$-axis films included Weissenberg photographs of zero and first layer lines, one being a multiple-film exposure of the zero layer line. The $a$-axis photographs were a number of oscillation photographs for adjustment purposes and a zero-layer-line Weissenberg exposure. About the $c$ axis a set of oscillation photographs were obtained. Spots were visible on the photographs up to the limit of $\mathrm{Cu} K \alpha$ radiation. The specimens used were chopped to a roughly cylindrical shape about the three axes, using a razor blade.

\section{Space group and method of analysis}

The $a$-axis zero-layer-line Weissenberg photograph showed that the $(0 \mathrm{kl})$ spots are present only when $(k+l)$ is even. The $b$-axis photographs show that the $(h 0 l)$ spots are present only when $h$ and $l$ are both even, and that the $(h 1 l)$ spots are present only when $l$ is odd. These absences are explained by the rules that $(h k l)$ is present only when $k+l$ is even, and $(h 0 l)$ is present only when $h$ is even. These rules suggest as space group either $A / a$ or $A 2 / a$. The more symmetrical space group was chosen as it possesses the necessary number of general positions (eight) for the oxygen and hydrogen atoms and puts the nitrogens on to special positions. This situation provides a very simple problem, and as a satisfactory structure was reached on this assumption a detailed consideration of structures based on $A / a$ was considered unnecessary.

The space group $A 2 / a$ contains centres of symmetry, rotation axes, screw axes and two kinds of glide plane perpendicular to the $b$ axis. The general equivalent points are

$$
(0,0,0) \text { and }\left(0, \frac{1}{2}, \frac{1}{2}\right), \pm(x, y, z),\left(\frac{1}{2}+x, \bar{y}, z\right) .
$$

The nitrogen atoms cannot be situated on the centre: of symmetry, so that they must be placed on the rotation axes. Neglecting the hydrogen atoms for the time being, we are left with only one oxygen to find in the $b$-axis projection. This was done by means of the Patterson projection using the $(h 0 l)$ planes. This projection showed one $2 \mathrm{~N}-\mathrm{O}$ peak which gives the $(x, z)$ coordinates of the oxygen with respect to the nitrogens. Assuming an N-O distance of $1.2 \AA$ wit then obtained the $y$ parameter difference between I and $\mathrm{O}$, and assuming an N-N distance of $1.45 \AA$ tre could also get the $y$ parameter difference between the nitrogens. Then, from the $(0 k 0)$ intensities, we deduced the absolute values of the $y$ coordinates of all th: atoms. These were used to calculate the $(h k 0)$ and $(0 k l)$ intensities, and gave excellent agreement. Refine ment was carried out by Fourier difference maps dow all three axes.

On the $b$-axis difference map there were typical 'clover-leaf' patterns, suggesting some anisotropy the heat motion of the two nitrogen atoms and als of the oxygen atom. This heat motion is a maximu in a direction roughly perpendicular to the plane of the molecule, i.e. perpendicular to $(10 \overline{1})$. The hydroget atom did not show up clearly on the $b$-axis projection possibly owing to the heat-motion effects and to it: being quite near the oxygen position, but the pars meters given for the hydrogen atom are reasonabl: from the other two projections.

Table 1 shows calculated and observed $F$ values fol the $(h 0 l),(0 k l)$ and $(h k 0)$ planes. The accuracy 
Table 1. Observed and calculated $F$ values of nitramide

\begin{tabular}{|c|c|c|}
\hline$h$ & $F_{0}$ & $F_{c}$ \\
\hline 0 & 35 & 33 \\
\hline & $8 \cdot 5$ & -5.6 \\
\hline & 29 & 28 \\
\hline & 29 & 26 \\
\hline $2 \overline{1}$ & 24 & -21 \\
\hline & 22 & -26 \\
\hline & $1 \cdot 7$ & $0 \cdot 8$ \\
\hline & 18 & -13 \\
\hline & 73 & -81 \\
\hline & 45 & -41 \\
\hline & 11 & 7 \\
\hline & 30 & -25 \\
\hline & 34 & -31 \\
\hline & $6 \cdot 4$ & $-6 \cdot 4$ \\
\hline 41 & 21 & 22 \\
\hline & $4 \cdot 7$ & $3 \cdot 2$ \\
\hline & $7 \cdot 7$ & $4 \cdot 8$ \\
\hline & 37 & 45 \\
\hline & 31 & 35 \\
\hline & $7 \cdot 0$ & -5.6 \\
\hline & 20 & 18 \\
\hline & 38 & 33 \\
\hline & 9 & 10 \\
\hline 6 & $4 \cdot 8$ & -2.4 \\
\hline & 27 & -27 \\
\hline
\end{tabular}

highest for the $(h 0 l)$ planes since the crystal habit is difficult for the other two projections. The $(h k 0)$ intensities are the least accurate of all, being derived only from oscillation photographs. The reliability index $R$ is $16 \frac{1}{2} \%$ for all these planes. Intensity values were also calculated for the $k=1$ planes and showed good agreement.

\section{Description of the structure}

The parameters finally chosen are:

$\begin{array}{lccc} & x & y & z \\ \mathrm{~N}_{\mathrm{I}} & 0.250 & 0.575 & 0 \\ \mathrm{~N}_{\text {II }} & 0.250 & 0.866 & 0 \\ \mathrm{O} & 0.367 & 0.466 & 0.137\end{array}$

with a probable hydrogen position of $(0 \cdot 42,0,0 \cdot 08)$. Fig. $1(a)$ shows a projection of the structure down the $b$ axis, and gives the position of the nitrogen and oxygen atoms. The planar molecules are inclined at $6^{\circ}$ to $(10 \overline{1})$ and thus form almost flat layers parallel to this plane. One of these layers is shown in Fig. 1(b), and the remarkable number of $\mathrm{N}_{11}-\mathrm{O}$ bonds is shown in this figure: each $\mathrm{N}_{\Pi}$ is bonded to four oxygen atoms in the sheet, and each oxygen to two $\mathrm{N}_{\text {II }}$ atoms. Between different sheets the $\mathrm{N}_{\mathrm{iI}}-\mathrm{O}$ distances are $3 \cdot 28$ and $3 \cdot 5 \AA$, but there is one $\mathrm{N}_{\mathrm{I}}-\mathrm{O}$ distance of $3 \cdot 12 \AA$. Probably this involves a van der Waals repulsion which is responsible for the departure of the molecules from the exact $(10 \overline{1})$ plane.

$F_{c}$
-29
$0 \cdot 8$
-10
-29
-12
23
$2 \cdot 4$
$4 \cdot 8$

$F_{c}$
-38
29
$7 \cdot 2$
-19
$-0 \cdot 6$
45
$2 \cdot 0$
-18
12
14
-25
$9 \cdot 1$
$-1 \cdot 8$
-18

k $l$

40

0

11

29

12

$4 \cdot 8$

$5 \cdot 2$

$\begin{array}{ll}5 & 6 \\ 5 & 1\end{array}$

3

60

0
2

\begin{tabular}{cl}
$F_{o}$ & \multicolumn{1}{c}{$F_{c}$} \\
0 & $-2 \cdot 0$ \\
17 & -14 \\
22 & -22 \\
$6 \cdot 0$ & $-4 \cdot 4$ \\
0 & $-4 \cdot 2$ \\
$8 \cdot 4$ & $7 \cdot 7$ \\
0 & $3 \cdot 4$ \\
0 & $-0 \cdot 5$ \\
0 & $-5 \cdot 0$
\end{tabular}

$h \quad k$

$F_{o}$

$F_{c}$

$\begin{array}{ll}1 & 2\end{array}$

4
6

21

$5 \cdot 2$

19

0
55

0

19

8

12

$7 \cdot 8$

0
17

The interatomic distances and angles found within the molecule are:

$$
\begin{gathered}
\mathrm{N}_{\mathrm{I}}-\mathrm{N}_{\mathrm{II}}=1 \cdot 40, \mathrm{~N}_{\mathrm{I}}-\mathrm{O}=1 \cdot 18, \mathrm{O}-\mathrm{O}=2 \cdot 13 \AA, \\
\mathrm{O}-\mathrm{N}_{\mathrm{I}}-\mathrm{O}=129^{\circ} .
\end{gathered}
$$

These agree well with the dimensions of the nitro group obtained from other determinations, and the $\mathrm{N}_{\mathrm{I}}-\mathrm{N}_{\text {II }}$ distance suggests that this bond is single.

Other interatomic distances are:

within one sheet, between molecules separated by $b$ :

$$
\mathrm{O}-\mathrm{N}_{\text {II }}=3.04 \AA \text {; }
$$

between molecules side by side:

$$
\mathrm{O}-\mathrm{N}_{\text {II }}=3 \cdot 12 \AA \text {. }
$$

The hydrogen atoms lie roughly between these two bonds. Between separate sheets are the following interatomic distances:

$$
\mathrm{O}-\mathrm{N}_{\text {II }}=3 \cdot 26, \mathrm{O}-\mathrm{N}_{\text {II }}=3 \cdot 50, \mathrm{O}-\mathrm{N}_{\mathrm{I}}=3 \cdot 12 \AA .
$$

\section{References}

Bell, R. P. \& Trotman-Dickenson, A. F. (1949). J. Chem. Soc. p. 1288.

Marlies, C. A., LaMer, V. K. \& Greenspan, J. (1939). Inorganic Syntheses, vol. 1, p. 68. New York: MeGrawHill.

Pedersen, K. J. (1934). J. Phys. Chem. 38, 581.

Thiele, J. \& Lachmann, A. (1895). Liebigs Ann. 288, 267. 


\section{RECENT DEVELOPMENTS OF GAS KINETICS}

\section{A. F. TROTMAN-DICKENSON}

The University, Edinburgh

The theoretical framework of gas kinetics has developed little since before the war, but much significant experimental work has been reported. This article outlines the most important developments in the study of the kinetics of homogeneous gas reactions which have taken place since 1945. Particular attention has been paid to elementary reactions whose study is now possible with the aid of novel techniques. It seems probable that development will continue along these lines.

CHEMICAL kinetics, the science of the rates of chemical reactions, is one of the two major branches of physical chemistry. Gas kinetics is that part of the subject which is concerned with the reactions of gases.

The most straightforward reason for kinetic investigations is the urge to find out by the measurement of rates, what happens in a particular reacting system. More specific reasons are to find the best conditions for a synthesis, to discover the mechanism of a reaction, or to determine the strength of a bond. The ultimate aim is to ascertain why reactions occur at the rate they do. This goal is still a long way off but gas reactions seem to offer the best path by which to reach it. Much is known of the motions of molecules in gases and there are few complications such as solvation and adsorption effects. Progress in the subject may therefore best be surveyed in relation to this goal.

The selection for discussion of the period since the 1939-45 war is partly a matter of convenience. Very little work was carried out during the war but there has been great activity in the field ever since. A crude analysis of the references from two books indicates the volume of work that has been published. Both books surveyed the state of knowledge at the time at which they were written. Of 2100 references in E. W. R. STEACIE's comprehensive Atomic and Free Radical Reactions ${ }^{1} 900$ were published after the end of 1945 ; 450 out of 810 references in A. F. TROTMANDiCKENSON's Gas Kinetics ${ }^{2}$ were published since 1945. Roughly equal numbers of papers have come from Canada, the United States and the United Kingdom and very few from other countries.

\section{ELEMENTARY REACTIONS}

The majority of the systems that are investigated by the worker in gas kinetics are now known to be chemically complex. That is, the final products are not formed by a single reaction but are the overall result of a series of elementary reactions. These elementary reactions are so called because they are believed to occur exactly as indicated by the appro- priate chemical equation. No series of constituent reactions need be postulated to describe them. This insistence on the fundamental importance of elementary reactions has been a distinguishing feature of work in gas kinetics since the war. Before the war reasonably successful attempts were made to explain many overall chemical changes which were observed in terms of elementary reactions. The recognition of the importance of chain reactions consisting of the repetition of the same simple elementary reactions was a major achievement. At present much research is deliberately planned to yield information on specific elementary reactions.

This work is now possible because of technical advances, particularly in analysis. The most generally useful analytical tools have been the low temperature still, the mass-spectrometer and, to a lesser extent, the infra-red spectrometer. These devices were perfected during the war by workers in oil companies, being required for analytical control in the production of high octane petrol.

If an elementary reaction involves one molecule it is said to be unimolecular and its rate constant, $k$, is expressed in sec. ${ }^{-1}$. The rate constant of a bimolecular reaction is expressed in $\mathrm{mole}^{-1} \mathrm{~cm}^{3}$ sec. ${ }^{-1}$, and the rate constants of the comparatively few termolecular reactions are expressed in mole ${ }^{-2}$ $\left(\mathrm{cm}^{3}\right)^{2} \mathrm{sec}^{-1}$. The variation of the rate constant of a reaction with temperature may be expressed by the equation

$$
k=A \exp (-E / R T)
$$

where $R$ is the gas constant and $T$ the absolute temperature. $A$ is known as the $A$ factor, $E$ as the activation energy, and $A$ and $E$ together are known as the rate factors of the reaction. All theoretical calculations of $k$ involve the separate consideration of $A$ and $E$.

\section{TRANSITION STATE THEORY}

H. Eyring, M. Polanyi and their co-workers developed the transition state theory of chemical reactions in the years immediately preceding the war. This theory is the most generally successful that has 
yet appeared. It postulates that reactants must pass through a definable critical state of high energy (the transition state or activated complex) before they become products (see Figure l). It then states that:

$$
A=\frac{R T}{N h} \exp (\Delta S \ddagger / R) \approx 10^{13} \exp (\Delta S \ddagger / R)
$$

where $N$ is Avogadro's number and $h$ is Planck's constant. The entropy of activation, $\Delta S_{\ddagger}^{\ddagger}$, is the difference between the entropy of the activated complex and that of the reactants. The accuracy of the calculation of these entropies is dependent upon the information available about the physical

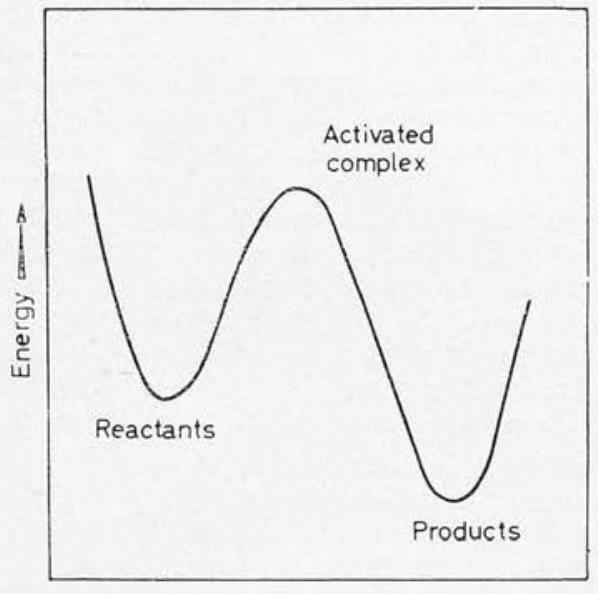

Reaction coordinate $\longrightarrow$

Figure 1

properties of the reactants and the complex. There is always some uncertainty as to the precise configuration of the complex but this rarely causes an uncertainty in $A$ greater than a factor of 10 .

In principle the activation energy may be calculated by quantum mechanics but the calculation is prohibitively involved. Eyring and Polanyi showed that $E$ was generally of a magnitude which was consistent with the knowledge of potential energy curves derived from spectroscopy. This has been a great aid to understanding.

Most elementary gas reactions may be classified under one of three headings:

(l) Decomposition-combination $\mathrm{AB}=\mathrm{A}+\mathrm{B}$

(2) Transfer $\quad \mathrm{A}+\mathrm{BC}=\mathrm{AB}+\mathrm{C}$

(3) Addition to double bonds - the

decomposition of radicals $\quad \mathrm{A}+\mathrm{B}=\mathrm{C}=\mathrm{A}-\mathrm{B}-\mathrm{C}-$ Free radicals are involved in all except the first class of reaction.

D. H. R. BARTON, A. MACCOLL, and their collaborators have studied, in the past ten years, the thermal decomposition of many alkyl chlorides and bromides. The rates of the reactions were found to depend markedly upon the structure of the alkyl groups. The decompositions do not involve free radicals, for the products result from the rearrangement of four-membered cyclic transition states of type $I$.<smiles>Br[IH]I</smiles><smiles>CCCCC</smiles>

The halides are not unique in decomposing in this way, the decompositions of many other compounds are similar but they have not been so systematically investigated. Cyclic transition states (with $6 \mathrm{mem}-$ bers) are also involved in Diels-Alder reactions, as is shown for ethylene and butadiene $(I I)$. Evidence is now accumulating that the addition of methylene biradicals to paraffins involves a transition state with only three members (III). No satisfactory explanation has yet been advanced for the great variations in the rates of decomposition of the different alkyl halides.

The other important class of decompositions includes those reactions in which an atom or radical splits off from a normal molecule. Hardly any of these reactions were accurately studied before the 1939-45 war, though it was shown that according to the transition state theory the activation energy of the decomposition should be approximately equal to the strength of the bond broken. Great interest attaches to the strengths of bonds. First, they are quantities which one would expect a satisfactory theory of valence to predict. Second, they are needed for the interpretation of the energetics of radical reactions. The recent experimental studies have largely been made possible through the development of flow techniques, by M. SzWARC following Polanyi, particularly with the use of toluene as a carrier gas to trap the reactive radicals. There appear to be many reactions, such as the decomposition of ethyl benzene into methyl and benzyl, for which the activation energy is equal to the bond strength. In these cases $A$ is usually equal to $10^{13}=1.5 \mathrm{sec} .^{-1}$ which is the expected magnitude for a reaction in which the configuration of the transition state is thought to be very similar to that of the initial state. Several reactions are known, however, that either have an $A$ factor greater than $10^{14.5} \mathrm{sec}^{-1}$ or an activation energy greater than the 
accepted bond strength or both. Sometimes the large $A$ factor may be plausibly ascribed to a large increase in entropy in passing from the initial to the transition state, as may occur when ethane approaches the state of two freely rotating methyl groups. This explanation does not always account satisfactorily for the high values of $A$ and it throws no light on the problem of the high values of the activation energy.

Very few rate constants of combination reactions have been measured because of the difficulty of determining the concentrations of radicals which are usually of the order of $10^{-10}$ mole $\mathrm{cm}^{3}$. The few reactions of simple radicals which have been investigated all appear to have rate constants of about $10^{13.5} \mathrm{~mole}^{-1} \mathrm{~cm}^{3} \mathrm{sec}^{-1}$ and very low activation energies.

Most of the reactions in the second group which have been investigated involve the transfer of a hydrogen atom, though Polanyi measured the rates of many reactions of the type

$$
\mathrm{Na}+R \mathrm{Cl}=\mathrm{NaCl}+R
$$

before 1939 and the work has since been extended. The investigator has to solve three problems before the rate constant of a transfer reaction can be measured. It is necessary to find a suitable source of atoms or radicals, to devise methods of determining their concentrations and to measure the rates of formation of the significant products. Hitherto photolytic sources of radicals have proved most convenient because of the ease with which they are controlled. The other problems have been successfully solved for systems involving chlorine atoms, methyl radicals, trifluoromethyl radicals and ethyl radicals, though extensive work has only been carried out on the first three. Some typical results are presented in Table 1.

There are a number of features which call for comment. First, the $A$ factors are of the order predicted by the transition state theors. Second, the activation energies are very much lower than the strengths of the bonds broken; this can also be understood in terms of the theory. Third, the general trend towards lower activation energies as the bonds get weaker is expected. However, the interpretation of the results on these simple reactions still presents many problems. In particular, the polar nature of the transition states is evidently important but no quantitative treatment has been proposed.

The third group of reactions has been much less fully investigated, although the addition of radicals to unsaturated compounds is the same reaction as the chain carrying steps in liquid phase polymerizations whose rates have been much measured. This is not because the reactions are of little theoretical interest, but because of the difficulties inherent in their study. The decompositions of radicals containing three or more carbon atoms are difficult to study because suitable sources of free radicals have not been

Table 1. The Rate factors of the reactions $X+R H=$ $X \mathrm{H}+\mathrm{R}$

\begin{tabular}{|c|c|c|c|c|c|}
\hline \multirow{2}{*}{\multicolumn{2}{|c|}{$R$}} & \multicolumn{3}{|c|}{$x$} & \multirow{2}{*}{$D(R-\mathrm{H}$} \\
\hline & & $\mathrm{Cl}$ & $\mathrm{CH}_{3}$ & $\mathrm{CF}_{3}$ & \\
\hline $\mathrm{H}$ & $\begin{array}{l}\text { (a) } \\
\text { (e) }\end{array}$ & $\begin{array}{r}13 \cdot 9 \\
5 \cdot 5\end{array}$ & $\begin{array}{l}11 \cdot 5 \\
11 \cdot 1\end{array}$ & $\begin{array}{r}11 \cdot 6 \\
8.8\end{array}$ & 104 \\
\hline $\mathrm{CH}_{3}$ & $\begin{array}{l}\text { (a) } \\
\text { (e) }\end{array}$ & $\begin{array}{r}13.4 \\
3.9\end{array}$ & $\begin{array}{l}11 \cdot 2 \\
12 \cdot 8\end{array}$ & $\begin{array}{l}11 \cdot 8 \\
10 \cdot 3\end{array}$ & 103 \\
\hline $\mathrm{C}_{2} \mathrm{H}_{5}$ & $\begin{array}{l}(a) \\
(e)\end{array}$ & $\begin{array}{r}14.1 \\
1.0\end{array}$ & $\begin{array}{l}11 \cdot 3 \\
104\end{array}$ & $\begin{array}{r}11.7 \\
7.5\end{array}$ & 98 \\
\hline sec $-\mathrm{C}_{4} \mathrm{H}_{3}$ & $\begin{array}{l}(a) \\
(e)\end{array}$ & $\begin{array}{r}14.3 \\
0.7\end{array}$ & $\begin{array}{r}11 \cdot 0 \\
8 \cdot 3\end{array}$ & $\begin{array}{r}11 \cdot 2 \\
5 \cdot 1\end{array}$ & 94 \\
\hline tert $-\mathrm{C}_{4} \mathrm{H}_{9}$ & $\begin{array}{l}(a) \\
(e)\end{array}$ & $\begin{array}{r}14.3 \\
0.9\end{array}$ & $\begin{array}{r}10 \cdot 9 \\
7 \cdot 5\end{array}$ & $\begin{array}{r}11 \cdot 2 \\
4.7\end{array}$ & 90 \\
\hline neo- $\mathrm{C}_{5} \mathrm{H}_{11}$ & (a) & $\begin{array}{r}14.1 \\
0.7\end{array}$ & $\begin{array}{l}11 \cdot 3 \\
10 \cdot 2\end{array}$ & $\begin{array}{r}11.8 \\
7.6\end{array}$ & 98 \\
\hline References & & 3,4 & 1,2 & $5,6,7,8$ & 1. 2 \\
\hline
\end{tabular}

(a) is $\log A$ in mole ${ }^{-1} \mathrm{~cm}^{3} \sec ^{-1},(e)$ is $E$ in $\mathrm{kcal}_{\text {mole }}^{-1}, D(R-\mathrm{H})$ is the strength of the $R H$ bond in $\mathrm{kcal}_{\text {mole }}^{-1}$

developed. Photolyses which have been so useful as sources of smaller radicals are not generally satisfactory. When a large molecule is photolysed it rarely splits simply into the required radicals. The analytical problems to be solved are, therefore, formidable. Consequently the interpretation of the necessarily incomplete information is uncertain. Similar analytical difficulties have beset the study of the addition of small free radicals to unsaturated compounds. Nevertheless Steacie and his collaborators have obtained evidence that the activation energies of these reactions are low. The $A$ factors are about $10^{11} \mathrm{~mole}^{-1} \mathrm{~cm}^{3} \mathrm{sec}^{-1}$, which is the expected order of magnitude. Unfortunately these results seem to be in conflict with the scanty data on the complementary decompositions.

The rates of these decompositions and those in the first group of reactions may depend upon the rate at which energy is transferred between molecules at low pressures. The effect occurs because, although the decompositions only involve one molecule, that molecule can only acquire the energy necessary for reaction by collision with other molecules. The first satisfactory theoretical treatment of this behaviour 
was given by F. A. LiNdemann and C. N. HinshelwooD in the twenties. For several years much attention was paid to the verification of the original theories and the various extensions and improvements. However, in the period immediately preceding the war, little work was done on the topic. After the war, interest revived, first because it was felt that the original experimental work was not satisfactory, and second because some problems of high speed flight involved a knowledge of energy transfer. Consequently much of the original work has been re-examined using modern methods. Furthermore, new direct techniques involving the electronic recording of transient phenomena have been developed for following very rapid reactions. As a result of these two approaches a fairly satisfactory picture of the factors which determine the rate at which energy is transferred between molecules is beginning to emerge. Generally the early theories have survived the test very well.

OXIDATION AND COMBUSTION

One major field of research in gas kinetics remains to be considered. It is that of oxidation and combustion. All homogeneous reaction systems involving oxygen are very complex, furthermore, it is often difficult to eliminate complicating heterogeneous effects. As a result, the study of oxidations is still in a primitive stage despite the importance of the subject and the immense amount of work which has been devoted to it. During the thirties Hinshelwood and N. SEMENOV successfully accounted for the form of the experimental results in terms of special types of branched chain reactions. Since the war many attempts have been made to determine the nature of the elementary reactions which make up the chains. No reaction scheme has yet been generally accepted. It seems possible that further advances will be made by isolating some of the likely elementary reactions for study in systems which do not contain molecular oxygen. This is the procedure which has proved successful in the elucidation of the simpler, but analogous, chain decompositions of organic compounds.

\section{POSSIBLE FUTURE DEVELOPMENTS}

No theoretical advances of the first importance have been made in the last ten years. Work during this period has resulted in the notable accumulation of many reliable measurements of rates. It seems that this pattern of development will continue. The outstanding theoretical need is for a method of calculating activation energies. Enough is now known of this problem in quantum mechanics for the difficulty of solving it to be realized. On the other hand, the prospect of more and better determinations of significant rate constants is excellent. Electronic methods are being increasingly used to study reactions that are complete in a fraction of a second and are too fast to be followed by simpler techniques. R. G. W. Norrish and G. PORTER have developed flash photolysis whereby sufficiently high radical concentrations to permit direct measurement may be momentarily generated. Another method of measuring the concentrations of free radicals which will certainly be further exploited depends upon the direct attachment of a reactor to the ionization chamber of a mass-spectrometer. Increasing attention is being paid to the unexplored class of reactions which occur at the very high temperatures that can be generated by shock waves. The study of the reactions of molecules that have been raised to a known electronic or vibrational state is just beginning; these states correspond to immensely high ambient temperatures. Much of the preliminary work has been done in Russia. The molecules are often excited by the absorption of light; if the light is monochromatic, all the excited molecules will be in the same known electronic and vibrational state. However, none of these approaches is likely to yield such important results as the further development of conventional investigations through the use of gas chromatography. This method of analysis has been described recently by one of its originators A. T. JAMES $^{9}$. It is now a simple matter to analyse the products of a complex reaction system very completely. Hitherto such analyses could only be performed with very costly equipment. Moreover, they took so long that no one would attempt the many repetitions needed to establish a rate constant. During the next few years it should be possible, with gas chromatography, to investigate thoroughly the reactions of radicals containing more than three carbon atoms and the transfer of atoms other than hydrogen.

\section{REFERENCES}

${ }^{1}$ Steacie, E. W. R. Atomic and Free Radical Reactions 2nd Edn Reinhold: New York, 1954

2 Trotman-Dickenson, A. F. Gas Kinetics Butterworths Scientific Publications: London, 1955

${ }^{3}$ Ashmore, P. G. and Chanmugam, J. Trans. Faraday Soc. 49 (1953) 254

4 Pritchard, H. O., Pyke, J. B., and TrotmanDickenson, A. F. J. Amer. chem. Soc. 77 (1955) 2629

5 Ayscough, P. B., Polanyi, J. C., and Steacie, E. W. R. Can. J. Chem. 33 (1955) 743

6 - and Steacie, E. W. R. ibid 34 (1956) 103

7 - J. chem. Phys. 24 (1956) 944

${ }^{8}$ Pritchard, G. O., Pritchard, H. O., Schiff, H. I., and Trotman-Dickenson, A. F. Trans, Faraday Soc., 52 (1956) 849

9 JAMES, A. T. Endeavour 15 (1956) 73, see also Phillips, C. Gas Chromatography Butterworths. Scientific Publications: London, 1956 
[Reprinted from "The School Science Review," No. I25, November 1953] 


\title{
THE TEACHING OF CHEMICAL KINETICS
}

\author{
By A. F. TROTMAN-DICKENSON
}

Chemistry Department, The University, Manchester 13

Not long ago I agreed to talk to a school science society on recent developments in chemical kinetics, especially on those connected with free radicals. One of the difficulties was to decide what knowledge I could assume the audience to possess. To obtain information on this point I read the chapters on kinetics in some eight or ten widely-used school texts on physical chemistry. The experience was rather shattering, for these chapters contained a very large number of errors, many of them common to several books. As far as I could judge, the chapters on kinetics were unique in this respect, for the rest of the books were, when allowing for the necessary simplifications, substantially correct and up-to-date. The probable cause of the trouble is the lack of any modern, conveniently available text on kinetics, on which the authors could rely. Accordingly, it seemed that a few suggestions might be helpful.

An almost universal error is the failure to distinguish clearly (or at all) between order and molecularity. Modern practice which is universally accepted among workers in the field is straightforward and could well be adopted in schools: it may be briefly stated. The order of a chemical reaction describes the mathematical form in which the experimental observations are best cast. Thus a first order reaction involving the formation or disappearance of a substance " $M$ " can be described in terms of one concentration variable. For instance the reaction :

$$
\mathrm{A}+\mathrm{B}+\ldots \rightarrow \mathrm{X}+\mathrm{Y}+\ldots
$$

is said to be first order if :

$$
-\frac{d[\mathrm{~A}]}{d t} \equiv-\frac{d[\mathrm{~B}]}{d t} \equiv \frac{d[\mathrm{X}]}{d t} \equiv \frac{d[\mathrm{Y}]}{d t}=k[\mathrm{~A}] \text { or } k^{\prime}[\mathrm{B}]
$$

where $[\mathrm{M}]$ represents the concentration of the species $\mathrm{M}$. If the value of $k$ or $k^{\prime}$ is dependent upon the concentration of some substance whose concentration does not effectively change during the course of the reaction, the behaviour is sometimes described as pseudo-first order. Many examples of this are to be found in the literature of acid-base catalysis. This usage 
is best avoided as it is liable to lead to confusion ; if equation (I) is satisfied by the experimental observations, the reaction should be described as first order.

Similarly a reaction is described as being second order if the experimental results best fit a relation of the type :

$$
-\frac{d[\mathrm{~A}]}{d t} \equiv-\frac{d[\mathrm{~B}]}{d t} \equiv \frac{d[\mathrm{X}]}{d t} \equiv \frac{d[\mathrm{Y}]}{d t}=k[\mathrm{~A}][\mathrm{B}]
$$

The definition of third and fourth order reactions is exactly parallel. It may be noted, though probably no one will want to teach this at school, that reactions of fractional order are possible, and do in fact occur, as in the thermal para- to ortho-hydrogen conversion or the decomposition of ozone catalysed by nitrogen pentoxide.

From what has been said it is clear that the order of a reaction does not necessarily describe the mechanism by which the reaction takes place. During the last twenty years emphasis has increasingly been laid upon the study of the elementary chemical reactions which go to make up the overall chemical process that is normally observed. Thus the thermal combination of hydrogen and bromine which may be represented by the stoichiometric equation :

$$
\mathrm{H}_{2}+\mathrm{Br}_{2} \rightarrow 2 \mathrm{HBr}
$$

is known to take place by the mechanism:

$$
\begin{aligned}
\mathrm{Br}_{2} & \rightleftarrows 2 \mathrm{Br} . \\
\mathrm{Br}+\mathrm{H}_{2} & \rightarrow \mathrm{HBr}+\mathrm{H} . \\
\mathrm{H}+\mathrm{Br}_{2} & \rightarrow \mathrm{HBr}+\mathrm{Br} . \\
\mathrm{H}+\mathrm{HBr} & \rightarrow \mathrm{H}_{2}+\mathrm{Br} .
\end{aligned}
$$

Each of these individual steps is called an elementary reaction, by analogy with the definition of an element, because it cannot be split up into a series of simpler chemical processes. Incidentally this is a good example of the limitations of the concept of the order of a chemical reaction, for the rate of formation of hydrogen bromide is given by the expression :

$$
\frac{d[\mathrm{HBr}]}{d t}=\frac{k\left[\mathrm{H}_{2}\right]\left[\mathrm{Br}_{2}\right]^{\frac{1}{2}}}{\mathrm{I}+m \frac{[\mathrm{HBr}]}{\left[\mathrm{Br}_{2}\right]}}
$$

obviously no simple order can be assigned to this process.

Each of the reactions (I), (2), (3) and (4) is an elementary reaction. Each of the reactions (2), (3), (4) is a bimolecular reaction because each only involves two molecules. The two molecules would have a finite probability of reaction if they alone were enclosed in a box. Similarly a unimolecular reaction is one in which the chemical change of a molecule can take place in the absence of all other molecules (the question of energy transfer is irrelevant for the present purpose). The connection between the idea of an elementary reaction and the idea of molecularity can thus 
be seen. If an elementary reaction can be isolated, its order and molecularity will be the same. It is only correct to talk about the molecularity of an elementary process, therefore the use of the term molecularity implies a knowledge or assumption of the mechanism of the reaction. To recapitulate, to say that a reaction is unimolecular means that one specified molecule alone takes part in the reaction, bimolecular means that only two specified molecules take part in the reaction, termolecular three, tetramolecular four, etc., in each case it is implied that the reaction is thought to be elementary. The order of a reaction merely describes the experimental findings, the molecularity postulates a mechanism which may subsequently be shown to be incorrect.

The second point I have to make concerns the examples which are almost universally quoted of reactions of different order and molecularity, especially the examples of gas reactions. The examples are often not well chosen, for the reactions considered are usually known to be much more complicated than the authors imply and are unsuitable for presentation in schools. The decomposition of nitrogen pentoxide is frequently quoted as an example of a unimolecular [sic] reaction. Sometimes the mechanism associated with Daniels is given, namely:

$$
\begin{aligned}
\mathrm{N}_{2} \mathrm{O}_{5} & \rightarrow \mathrm{N}_{2} \mathrm{O}_{3}+\mathrm{O}_{2} \\
\mathrm{~N}_{2} \mathrm{O}_{3} & \rightarrow \mathrm{NO}+\mathrm{NO}_{2} \\
\mathrm{NO}+\mathrm{N}_{2} \mathrm{O}_{5} & \rightarrow 3 \mathrm{NO}_{2}
\end{aligned}
$$

Mee (195I) gives as an alternative a mechanism apparently contrived by himself :

$$
\begin{aligned}
& \mathrm{N}_{2} \mathrm{O}_{5} \rightarrow \mathrm{N}_{2} \mathrm{O}_{4}+\mathrm{O} \\
& \mathrm{O}+\mathrm{O} \rightarrow \mathrm{O}_{2}
\end{aligned}
$$

Now a proposed mechanism of a reaction can never be shown to be correct, at most it can be shown that no simpler mechanism would fit the experimental facts, but it is quite possible to prove that a mechanism is incorrect. The second mechanism is obviously incorrect, for the first step is known from measurements of heats of formation to be about $5^{6} \mathrm{Kcal}$. endothermic while the overall activation energy of the decomposition is only $24.7 \mathrm{Kcal}$. The first mechanism was proved to be incorrect by Ogg (1947), who proposed the mechanism which is now accepted:

$$
\begin{aligned}
\mathrm{N}_{2} \mathrm{O}_{5} & \rightarrow \mathrm{NO}_{3}+\mathrm{NO}_{2} \\
\mathrm{NO}_{3}+\mathrm{NO}_{2} & \rightarrow \mathrm{NO}_{2}+\mathrm{NO}+\mathrm{O}_{2} \\
\mathrm{NO}+\mathrm{NO}_{3} & \rightarrow 2 \mathrm{NO}_{2}
\end{aligned}
$$

However, the reaction is quite unsuitable for presentation to school children unless the teacher is prepared to describe the use of radioactive tracers, the effect of isotopic substitution on the vibrational spectra of molecules, the use of the cathode ray oscillograph in the study of chemical reactions, etc. It takes one hour to deal with the reaction when lecturing to third-year undergraduates taking Honours Chemistry. 
The other examples which I have found quoted as unimolecular reactions include the pyrolyses of acetone, acetaldehyde, propionaldehyde, dimethyl ether, diethyl ether, azomethane, azoisopropane and sulphuryl chloride and the racemization [sic] of pinene. All these reactions except the last are known to occur at least in part by free radical chain mechanisms which have not yet been completely elucidated. Only in a few cases have the products of the reactions been analysed so that it is not known whether a simple stoichiometric equation for the reaction can be written or not. The products of the azomethane decomposition are certainly complicated.

The isomerization of pinene is probably a homogeneous unimolecular reaction but it is an unfamiliar compound which seems to react by a rather unusual intramolecular process (Burwell, 195I). For these reasons none of the reactions is really suitable for didactic purposes.

This looks bleak. However, there are a number of homogeneous unimolecular gas reactions which occur cleanly and which have been fully investigated. Unfortunately they are not well adapted for classroom demonstration, but at least do involve fairly simple molecules and might well be introduced into elementary texts.

(I) The isomerization of cyclopropane to proplyene:

$$
\mathrm{CH}_{2}^{\mathrm{CH}_{2}-\mathrm{CH}_{2}} \rightarrow \mathrm{CH}_{3}-\mathrm{CH}=\mathrm{CH}_{2}
$$

occurs at a convenient rate at about $490^{\circ} \mathrm{C}$. It is followed by analysis for the propylene formed either by selective oxidation with potassium permanganate, selective hydrogenation on a nickel catalyst or by absorption of the olefin by mercuric acetate.

(2) The decomposition of cyclobutane to ethylene:

$$
\underset{\mathrm{CH}_{2}-\mathrm{CH}_{2}}{\mathrm{CH}_{2}-\mathrm{CH}_{2}} \rightarrow{ }_{2} \mathrm{C}_{2} \mathrm{H}_{4}
$$

occurs at a convenient rate at $450^{\circ} \mathrm{C}$. It is followed either by the pressure change or by analysis for the ethylene by absorption with mercuric acetate. A similar reaction of perfleorocyclobutane is also known.

(3) The decomposition of $t$-butyl chloride to isobutene and hydrogen chloride :<smiles>C=C(C)CCl</smiles>

occurs at a convenient rate at $300^{\circ} \mathrm{C}$. and may be followed by the pressure change or by analysis for the hydrogen chloride. The decomposition of $t$-butyl bromide at $250^{\circ} \mathrm{C}$. is exactly similar.

There are comparatively few gas phase reactions involving ordinary molecules which are good examples of bimolecularity. The outstanding examples are still the decomposition of hydrogen iodide and the combination 
of hydrogen and iodine. Another example is the synthesis of perfluorocyclobutane from tetrafluorethylene. The decomposition of nitrous oxide which is sometimes quoted as an example of a bimolecular reaction seems more likely to be a unimolecular reaction, whose rate is controlled by the process of energy transfer at normal pressures.

The first order reactions in solution which are usually cited, such as the rearrangement of $\mathrm{N}$-chloracetanilide, the inversion of sucrose, the mutarotation of glucose and the hydrolyses of esters are none of them unimolecular. In fact, there are very few unimolecular reactions in solution. All the above reactions have disadvantages from the point of view of the teacher, even as examples of first order reactions, compared with the gas reactions, because if a more thoughtful pupil enquires how the reaction actually occurs, the teacher will have to embark on a lengthy explanation of a complex process.

Finally I should like to suggest that teachers might consider the advantages of free radical reactions as object lessons in kinetics. These reactions are formally very simple and the pupil should be able to visualize the process immediately. This is not so for, say, the rearrangement of $N$-chloracetanilide. There are three types of free radical reaction which are useful for the present purpose, examples of these are :

$$
\begin{aligned}
\mathrm{RR}^{\prime \prime} & \rightarrow \mathrm{R}^{\prime}+\mathrm{R}^{\prime \prime}, & \mathrm{C}_{6} \mathrm{H}_{5} \mathrm{CH}_{2}-\mathrm{CH}_{3} \rightarrow \mathrm{C}_{6} \mathrm{H}_{5} \mathrm{CH}_{2}-+\mathrm{CH}_{3}- \\
\mathrm{R}^{\prime}+\mathrm{R}^{\prime \prime} & \rightarrow \mathrm{R}^{\prime} \mathrm{R}^{\prime \prime}, & \mathrm{CH}_{3}+\mathrm{CH}_{3} \rightarrow \mathrm{C}_{2} \mathrm{H}_{6} . \\
\mathrm{R}^{\prime} \mathrm{Y}+\mathrm{R}^{\prime \prime} & \rightarrow \mathrm{R}^{\prime}+\mathrm{R}^{\prime \prime} \mathrm{Y}, & \mathrm{CH}_{3}+\mathrm{C}_{6} \mathrm{H}_{5} \mathrm{CH}_{3} \rightarrow \mathrm{CH}_{4}+\mathrm{C}_{6} \mathrm{H}_{5} \mathrm{CH}_{2} . .
\end{aligned}
$$

It can be seen that a reaction of type (6) is formally the reverse of a reaction of type (5) and in practice it is frequently profitable to consider the equilibria formed by such pairs of reactions.

Reaction (5) is a unimolecular, homogeneous reaction and has been investigated at temperatures around $600^{\circ} \mathrm{C}$. Large numbers of this type of reaction are known and have been accurately studied, a short list of these is given in Table I. An excellent review of this type of reaction has been written by M. Szwarc (1950) who was personally responsible for many of the investigations. The frequency factors and activation energies calculated from the Arrhenius equation

$$
k=\mathrm{A} e^{-\mathrm{E} / \mathrm{RT}}
$$

for these reactions and also for those mentioned previously are given in the table.

These free radical reactions may very well be used as illustrations if the concept of activation energy is to be introduced to the pupils, for both the activation energies and frequency factors can be given simple physical meanings. The activation energy in these reactions corresponds to the strength of the bond broken, that is to the heat of the reaction. The simple qualitative generalization follows that the stronger the bond is, the higher the activation energy will be and the higher the temperature will be to which the compound must be heated before it will decompose at a given rate. 
All the frequency factors of the free radical reactions in Table I are about ${ }^{10}{ }^{13} \mathrm{sec}^{-1}$, which is of the order of the stretching frequency of a single bond. It will be realized that after the required amount of energy to break a bond has been concentrated in the bond a certain time will elapse before the bond is stretched to such a length that it may be said to be broken. We may imagine two balls on a spring vibrating when suddenly sufficient energy is released in the system to break the spring. If at this moment the balls are just starting to move together, a complete vibration period will elapse before the spring breaks. The energy may be introduced at any moment during the vibration period so that the average life of the system after the energy has been introduced will be half the period of vibration. This, of course, is over-simplified but the most detailed theory predicts that the frequency factor $\mathrm{A}$ should be equal to the weighted root mean square frequency of all the vibrational frequencies in the molecule. There are special reasons why two of the decompositions to ordinary saturated molecules should have rather high frequency factors.

The rates of very few bimolecular reactions of type (6) have been measured because of the considerable experimental difficulties. However, it has been found that the rate constant for the combination of methyl radicals and ethyl radicals with their own kind are of the order of $10^{14}$ mole ${ }^{-1}$ c.c. sec. ${ }^{-1}$. Rate constants of this magnitude correspond to the combination on every collision of two radicals with kinetic-theory collision cross-sections, hence we may conclude that these reactions have no activation energy. This conclusion is supported by measurements of temperature coefficients. It is entirely plausible that the combination of two radicals each having a free valence should involve no barrier because they "fit" each other. Reactions of this type might serve in the introduction of students to the collision theory of chemical kinetics despite some obvious disadvantages.

The third type of reaction (7) may well be used to illustrate the important case of bimolecular reactions to which there is an energy barrier. Unfortunately the interpretation of reactions of this type is not straightforward, but some useful generalizations may be made. In Table II it can be seen that the A factor in the Arrhenius equation for the reaction of atoms with molecules approaches the collision frequency for molecules with kinetictheory collision diameters (approximately $4 \times \mathrm{IO}^{14}$ mole $^{-1}$ c.c. sec. ${ }^{-1}$ ). Thus more support is found for the simple collision theory. The reactions of the more complicated radicals have lower frequency factors. It is plausible and not entirely misleading to ascribe this lowering to the need for more precise orientation of the molecules in collision in these cases. This idea of orientation is an over-simplification but it is hardly feasible to introduce the more accurate concept of entropy.

It is interesting to note that the activation energies for the attack of methyl radicals on the alkanes are monotonously graded, passing, from methane, to compounds containing primary hydrogen atoms only, to those 
containing secondary hydrogen atoms, to those containing tertiary hydrogen atoms. This behaviour is observed in the attack of other radicals and atoms. The strengths of the relevant $\mathrm{C}-\mathrm{H}$ bonds in some of these compounds are known and provide support for the reasonable conclusion that for a series of very similar compounds the activation energies of reactions of the type

$$
\mathrm{CH}_{3}+\mathrm{RH} \rightarrow \mathrm{CH}_{4}+\mathrm{R}
$$

will be lower the weaker are the $\mathrm{R}-\mathrm{H}$ bonds. This rule must be applied with great caution as it is not universally applicable.

These free radical reactions may all be understood in terms of some simple generalizations which are admittedly over-simplified but are based on a solid foundation of truth. If the attention is concentrated entirely upon reactions involving ordinary saturated molecules it is impossible to convey any simple ideas on the important subject of why different chemical reactions take place at different velocities.

TABLE I

UNimolecular DECOMPOSITIONS

\begin{tabular}{|c|c|c|c|c|}
\hline REAction. & & & Kcal./Mole. & $\begin{array}{c}\log _{10} \mathrm{~A} \\
\text { sec. }\end{array}$ \\
\hline $\begin{aligned} \text { Cyclopropane } & \rightarrow \text { Propylene } \\
\text { Cyclobutane } & \rightarrow{ }_{2} \mathrm{C}_{2} \mathrm{H}_{4} \\
t-\mathrm{C}_{4} \mathrm{H}_{9} \mathrm{Cl} & \rightarrow \mathrm{HCl}+i-\dot{\mathrm{C}}_{4} \dot{\mathrm{H}}_{8} \\
t-\mathrm{C}_{4} \mathrm{H}_{9} \mathrm{Br} & \rightarrow \mathrm{HBr}+i-\mathrm{C}_{4} \mathrm{H}_{8}\end{aligned}$ & $\dot{.}$ & 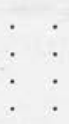 & $\begin{array}{l}65 \cdot 0 \\
62 \cdot 8 \\
41 \cdot 4 \\
40 \cdot 5\end{array}$ & $\begin{array}{l}\text { I } 5.17 \\
\text { I } 5 \cdot 71 \\
\text { I } 2 \cdot 4 \\
\text { I } 3.3\end{array}$ \\
\hline $\begin{aligned} \phi \mathrm{CH}_{3} & \rightarrow \phi \mathrm{CH}_{2}+\mathrm{H} . \\
\phi \mathrm{CH}_{2} \mathrm{Br} & \rightarrow \phi \mathrm{CH}_{2}+\mathrm{Br} . \\
\phi \mathrm{C}_{2} \mathrm{H}_{5} & \rightarrow \phi \mathrm{CH}_{2}+\mathrm{CH}_{3} \\
\phi \mathrm{CH}_{2} \mathrm{NH}_{2} & \rightarrow \phi \mathrm{CH}_{2}+\mathrm{NH}_{2}\end{aligned}$ & $\dot{.}$ & 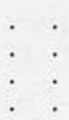 & $\begin{array}{l}77 \\
51 \\
63 \\
59\end{array}$ & $\begin{array}{l}\text { I3.3 } \\
\text { I } 3.0 \\
\text { 1 } 3.0 \\
\text { 1 } 2.8\end{array}$ \\
\hline
\end{tabular}

TABLE II

Bimolecular Atom Transfer Reactions

\begin{tabular}{|c|c|c|c|}
\hline REACTION. & & $\underset{\text { Kcal./Mole. }}{\mathrm{E}}$ & $\begin{array}{l}\text { A } \\
\text { mole }^{-1} \text { c.c. sec. }{ }^{-1}\end{array}$ \\
\hline $\begin{aligned} \mathrm{Br}+\mathrm{H}_{2} & \rightarrow \mathrm{H}+\mathrm{HBr} . \\
\mathrm{Br}+\mathrm{CH}_{4} & \longrightarrow \mathrm{CH}_{3}+\mathrm{HBr} \\
\mathrm{Br}+\mathrm{CH}_{3} \mathrm{Br} & \longrightarrow \mathrm{CH}_{2} \mathrm{Br}+\mathrm{HBr} \\
\mathrm{Na}+\mathrm{C}_{2} \mathrm{H}_{5} \mathrm{Cl} & \rightarrow \mathrm{NaCl}+\mathrm{C}_{2} \mathrm{H}_{5}\end{aligned}$ & $\begin{array}{l}\dot{5} \\
\dot{5} \\
\dot{ }\end{array}$ & $\begin{array}{l}17 \cdot 5 \\
18 \cdot 3 \\
16 \cdot 1 \\
10 \cdot 2\end{array}$ & $\begin{array}{l}7 \times 10^{13} \\
4 \times 10^{13} \\
3 \times 10^{13} \\
5 \times 10^{14}\end{array}$ \\
\hline $\begin{aligned} \mathrm{CH}_{3}+\mathrm{CH}_{4} & \rightarrow \mathrm{CH}_{4}+\mathrm{CH}_{3} \\
\mathrm{CH}_{3}+\mathrm{C}_{2} \mathrm{H}_{2} & \rightarrow \mathrm{CH}_{4}+\mathrm{C}_{2} \mathrm{H}_{5} \\
\mathrm{CH}_{3}+n-\mathrm{C}_{4} \mathrm{H}_{10} & \rightarrow \mathrm{CH}_{4}+\mathrm{C}_{4} \mathrm{H}_{9} \\
\mathrm{CH}_{3}+i-\mathrm{C}_{4} \mathrm{H}_{10} & \rightarrow \mathrm{CH}_{4}+\mathrm{C}_{4} \mathrm{H}_{9}\end{aligned}$ & 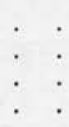 & $\begin{array}{r}12 \cdot 8 \\
10 \cdot 4 \\
8 \cdot 3 \\
7 \cdot 6\end{array}$ & $\begin{array}{l}1 \cdot 9 \times 10^{11} \\
2 \cdot 2 \times 10^{11} \\
2 \cdot 0 \times 10^{11}\end{array}$ \\
\hline
\end{tabular}

\section{REFERENCES}

Burwell, R. L. (1951), F. Amer. Chem. Soc., 73, 446r.

Met, A. J. (r95I), Physical Chemistry (Heinemann).

OgG, R. A. (1947), F. Chem. Physics, 15, 337.

Szwarc, M. (I950), Chem. Rev., 47, 75 . 
Printed in Great Britain by Butler \& Tanner Ltd., Frome and London and Published by John Murray (Publishers) Ltd. 
A METHOD FOR THE STUDY OF CHLORINE ATOM REACTIONS. THE REACTION Cl $+\mathrm{CH}_{4} \rightarrow \mathrm{CH}_{3}+\mathrm{HCl}$ Sir:

The reactions of chlorine with hydrogen and the hydrocarbons are chain reactions and as such their over-all rates are extraordinarily sensitive to the presence of traces of impurities, the condition of the reaction vessel and the intensity of the absorbed light in photochemical systems. Consequently, the many attempts which have been made to determine the rate constants of the elementary reactions of chlorine atoms, particularly those of type 1 , have met with disproportionately little success.

$$
\mathrm{Cl}+\mathrm{RH}=\mathrm{HCl}+\mathrm{R}
$$

However, the rate constant of the reaction 2 is known ${ }^{1}$ to be given by $k_{2}=10^{13.9} \exp$. $(-5500 \pm$ $200 / R T$ ) moles $^{-1}$ cc. sec. ${ }^{-1}$. So that if the rate of

$$
\mathrm{Cl}+\mathrm{H}_{2}=\mathrm{HCl}+\mathrm{H}
$$

reaction 2 can be compared with that of reaction 1 in the same reaction system, $k_{1}$ may be found without having to make a direct estimate of chlorine atom concentrations: we have done this and determined $k_{1}$ for the reaction with methane in the following way.

Measured quantities of methane and hydrogen were sealed up in a $160 \mathrm{cc}$. Pyrex reaction vessel together with some $2.55 \times 10^{-4}$ mole of chlorine, which is frozen out. The reaction is started by placing the vessel in a liquid or vapor bath which raises its temperature very rapidly. After a short interval to allow the vessel to attain the desired temperature, it is strongly illuminated. When a convenient period has elapsed the vessel is re-attached to a vacuum system and the residual hydrogen and methane separated from the products by low temperature distillations and adsorption in silica gel and measured.

The available evidence indicates that the hydrogen atoms and radicals formed will react with chlorine molecules for these reactions probably take place on every collision and hence the rate constants are approximately one hundred times those of any competing process, so that reactions 1 and 2 are the only ones by which methane and hydrogen are removed or formed. Then it can be readily shown ${ }^{2}$ that if

$-\mathrm{d}\left[\mathrm{CH}_{4}\right] / \mathrm{d} t=k_{1}\left[\mathrm{CH}_{4}\right][\mathrm{Cl}]$ and $-\mathrm{d}\left[\mathrm{H}_{2}\right] / \mathrm{d} t=k_{2}\left[\mathrm{H}_{2}\right][\mathrm{Cl}]$ then

$$
k_{1} / k_{2}=\log \left\{\left[\mathrm{CH}_{4}\right]_{\mathrm{i}} /\left[\mathrm{CH}_{4}\right]_{\mathrm{i}}\right\} / \log \left\{\left[\mathrm{H}_{2}\right]_{\mathrm{i}} /\left[\mathrm{H}_{2}\right]_{\mathrm{f}}\right\}
$$

where the subscripts refer to the initial and final concentrations of the reactants. The reproducibility of $k_{1} / k_{2}$ for various ratios of methane to hydrogen is shown in the table. In Fig. 1 the logarithm of $k_{1} / k_{2}$ is plotted against $10^{3} / T$. The curvature of the points which is very small for a temperature range from $0^{\circ}$ to $215^{\circ}$ may be partially due to the effective temperature of the reaction being slightly below that of the bath at the

(1) P. G. Ashmore and J. Chanmugam, Trans. Faraday Soc., 49, 254 (1953).

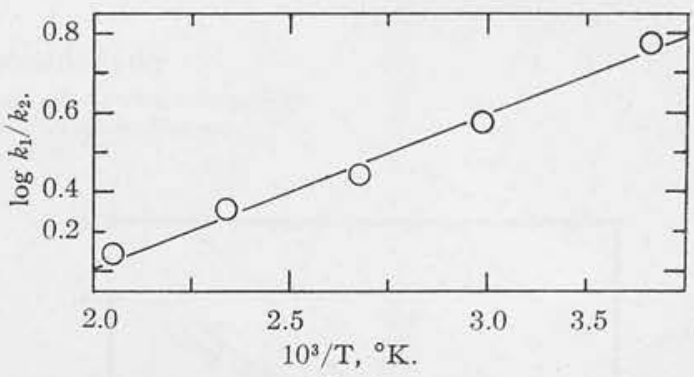

Fig. 1.

higher temperatures. However, it seems that this can cause only a very small error in the slope of the line. It can be seen that the variation of $k_{1} / k_{2}$ with temperature is given by $k_{1} / k_{2}=10^{0.59} \exp$ $(-1700 / R T)$. Hence $k_{1}=10^{14.5} \exp (-3800 /$ $R T)$ mole $^{-1}$ cc. sec. ${ }^{-1}$.

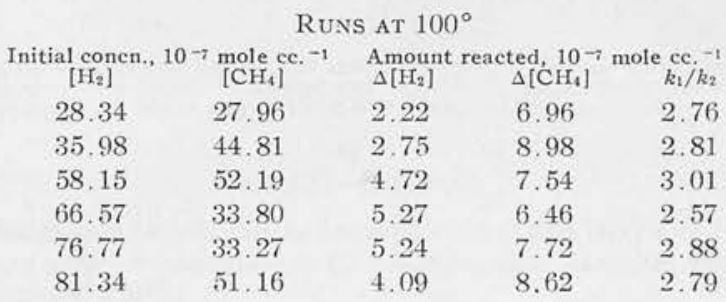

Assuming that the standard entropy of the methyl radical is 45.5 e.u. and that the strength of the $\mathrm{CH}_{3}-\mathrm{H}$ bond is $102.5 \mathrm{kcal} / \mathrm{mole}$ at $25^{\circ}$, we can make use of the approximate relation $k=$ $\exp \left(\Delta S^{\circ} / R\right) \exp \left(-\Delta H^{\circ} / R T\right)$ which neglects the small variations of $\Delta S$ and $\Delta H$ with temperature. Then we find for the equilibrium constant of reaction 1

$$
K_{1}=10 \exp (1000 / R T)
$$

Therefore the rate constant, $k_{-1}$, of the reverse reaction is $k_{-1}=10^{13.5} \exp (-4800 / R T)$ mole $^{-1}$ cc. sec. ${ }^{-1}$ which is equal to $10^{11.0}$ mole $^{-1}$ cc. sec. ${ }^{-1}$ at $150^{\circ}$. At this temperature Cvetanovic and Steacie $^{3}$ find $k_{-1}=10^{10.4}$ mole $^{-1}$ cc. sec. ${ }^{-1}$; although they report an activation energy of only $2.3 \mathrm{kcal}$./mole for reaction $(-1)$. However, their activation energy is based on points at $25^{\circ}$ and $150^{\circ}$ only and it is known that the study of the reactions of methyl radicals derived from the photolysis of acetone at low temperatures tends to yield low values for the activation energies. ${ }^{4}$

With slight modifications this method can be adapted to the study of many other chlorine atom reactions. The results will be reported in full when the program of work is complete.

\section{H. O. PRITChaRd} J. B. PYKE

The UnIVERstry

MANCHESTER, ENGLAND

A. F. TROTMAN-DICKENSON Received NOVEMBer 30,1953

(2) W. M. Jones, J. Chem. Phys, 19, 78 (1951).

(3) R. J. Cvetanovié and E. W. R. Steacie, Can. J. Chem., 31, 158 (19.53).

(4) A. J. C. Nicholson, This Journal, 73, 3981 (1951).

(5) E. I. du Pont de Nemours \& Co., Niagara Falls, N. Y. 


\title{
The Photolysis of Acetaldehyde
}

\author{
G. O. Pritchard, H. O. Pritchard, and A. F. Trotman-Dickenson \\ Chemistry Department, The University, Manchester, England
} (Received January 5, 1953)

$\mathrm{T}$ HE high temperature photolysis of acetaldehyde using the rotating sector technique has been studied by Dodd. ${ }^{1}$ From a consideration of his results and those of other workers, he concluded that all the available data led to $10^{12.8 \pm 0.4} \mathrm{~T}$ $X \exp [(-10.7 \pm 0.5) / R T]$ for the rate constant of the chainpropagating step, where the units are mole, cc, and sec. However it seemed ${ }^{2}$ that, in view of the relative rates of formation of methane and ethane in the low temperature photolysis, all high values for the activation energy of the reaction of methyl with acetaldehyde (generally believed to be the rate determining propagation step) should be viewed with suspicion, because the preexponential factor would have to be $10^{2}$ greater than had ever been found for a methyl radical reaction of that type.

Recently the rate constant of the reaction

$$
\mathrm{CH}_{3}+\mathrm{CH}_{3} \mathrm{CHO} \stackrel{k_{1}}{\rightarrow} \mathrm{CH}_{4}+\mathrm{CH}_{3} \mathrm{CO}
$$

has been found by Volman and Brinton ${ }^{3}$ to be $4.2 \times 10^{10} \mathrm{~T}^{\text {b }}$ $X \exp [(7.5 \pm 0.3) / R T]$ from studies of the decomposition of di-t-butyl peroxide in the presence of acetaldehyde, combined with the value for the rate constant for the recombination of methyl radicals found by Gomer and Kistiakowsky, ${ }^{4}$ on which all rate constants referred to hereinafter are based.

We have recalculated the data reported by Danby, Buchanan, and Henderson ${ }^{5}$ on the amounts of methane and ethane formed in the photolysis of acetaldehyde at $300^{\circ} \mathrm{C}$ and find that $k_{1}=1.22$ $\times 10^{9}$.

Additional values of $k_{1}$ may be obtained by combining Majury and Steacie's $s^{6}$ value of $k_{2}=9.4 \times 10^{11} \exp (11.8 / R T)$,

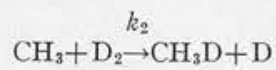

with Davison and Burton's ${ }^{7}$ values for $k_{1} / k_{2}$ at different temperatures.

A considerably less accurate point may be deduced making certain plausible assumptions from the work of Blacet and Brin$\operatorname{ton}^{8}$ which seems to be the only data on the production of methane and ethane at low temperatures.

All these data, which have not been correlated before, are shown in Fig. 1. Bearing in mind the separate pieces of work upon which the values depend, the consistency is very satisfactory. This shows first that the older photolytic data cannot be interpreted as simply as had been supposed, and secondly, that the values of $k_{2}$ obtained by Davison and Burton using acetaldehyde as a radical source are in effective agreement with those of Steacie.

The most likely cause of the discrepancy between the value of $E_{1}$ and the temperature coefficient of the chain propagation in the photolysis is that the chain step cannot be written

$$
\mathrm{CH}_{3}+\mathrm{CH}_{3} \mathrm{CHO} \rightarrow \mathrm{CH}_{4}+\mathrm{CH}_{3}+\mathrm{CO}
$$

but must be split into reactions (1) and (3)

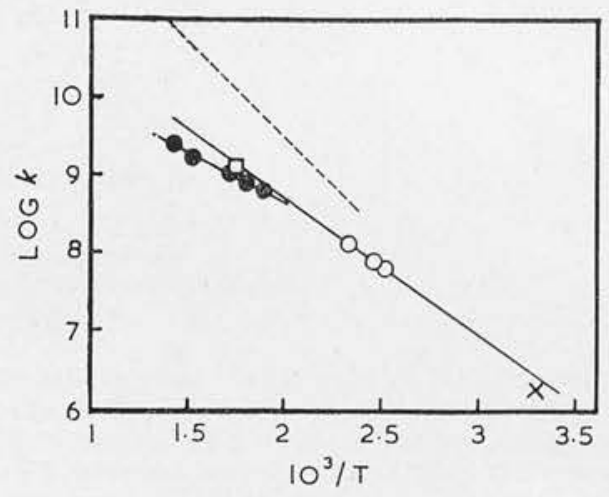

Fic. 1. Arrhenius plot for the reaction of methyl radicals with acetal dehyde. .... Dodd: $O$ Volman and Brinton: Danby. Buchanan, and Henderson; $\times$ Blacet and Brinton; Davison and Burton.

$$
\mathrm{CH}_{3} \mathrm{CO} \rightarrow \mathrm{CH}_{3}+\mathrm{CO} \text {. }
$$

This distinction will only be important if $k_{1}\left[\mathrm{CH}_{3} \mathrm{CHO}\right]$ is of the same order of magnitude as $k_{3}$. Assuming as a maximum value that $k_{4}=5 \times 10^{13}$,

$$
2 \mathrm{CH}_{3} \mathrm{CO} \stackrel{k_{1}}{\rightarrow}\left(\mathrm{CH}_{3} \mathrm{CO}\right)_{2} \text {, }
$$

we may estimate from the work of Howland and Noyes ${ }^{2}$ a maximum value for $k_{3}$ at $25^{\circ} \mathrm{C}$ of $4 \mathrm{sec}^{-1}$ which may be compared with $k_{1}\left[\mathrm{CH}_{3} \mathrm{CHO}\right]=10 \mathrm{sec}^{-1}$ at the same temperature and $100-\mathrm{mm}$ acetaldehyde pressure. Since $E_{3}$ is probably low, this near equality may persist over a considerable range of temperature. Furthermore, the kinetics deduced from the two assumptions may be almost indistinguishable if the rate equation for the decomposition should be written as $k_{3}{ }^{\prime}\left[\mathrm{CH}_{3} \mathrm{CO}\right] P$ where $P$ is the total pressure of the system. This is very likely in view of the simplicity of the acetyl radical ${ }^{10}$ and the low value of $E_{3} / R T$.

Hence we conclude that little reliance should be placed upon the rate constants determined by the rotating sector, because the method is notoriously inaccurate when the precise mechanism of a reaction is not well defined.

' R. E. Dodd. J. Chem. Phys. 18, 234 (1950); Trans. Faraday Soc. 47, $56(1951)$

A. F. Trotman-Dickenson and E. W. R. Steacie, J. Phys. Colloid. Chem. 55. 908 (1951),

i D. H. Volman and R. K. Brinton. J. Chem. Phys, 20, 1764 (1952).

4 R. Gomer and G. B. Kistiakowsky, J. Chem. Phys. 19. 85 (1951)

5 Danby, Buchanan, and Henderson. J. Chem. Soc, 1951, 1426. The photolysis rates in Table II are in $\mathrm{mm} / \mathrm{min}$; private communication from Dr. Danby.

Dr. Tant. G. Majury and E. W. R. Steacie, Can. J. Chem. 30, 800 (1952).

7 S. Davison and M. Burton, J. Am. Chem. Soc. 74, 2307 (1952). Only the runs of 2 or 3 -min duration have been considered.

the runs of 2 or 3 -min duration have been considered.
8 F. E. Blacet and R. K. Brinton, J. Am. Chem. Soc. 72, 4715 (1950)

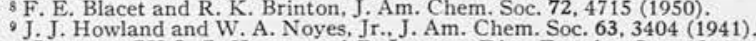
10 Compare $\mathrm{CH}_{3} \mathrm{I}, \mathrm{C}$. Horrex and R. Lapage, Disc. Faraday Soc. 10, 233 (1951), and $\mathrm{CH}_{2} \mathrm{CO}, \mathrm{G}$. B. Kistiakowsky and W. L. Marshall, J. Am. Chem. Soc. 74,88 (1952). 
Reprinted from The Journal of Chemical Physics, Vol. 22, No. 5, 944-945, May, 1954 Printed in U. S, A.

\title{
The $\mathrm{C}-\mathrm{C}$ Bond Dissociation Energies in Cyclanes
}

\author{
H. O. Pritchard and A. F. Trotman-Dickenson \\ Chemistry Department, University of Manchester, Manchester 13, England
}

(Received December 4, 1953)

$I^{N}$ a recent letter Seubold ${ }^{1}$ has claimed to have estimated the $\mathrm{C}-\mathrm{C}$ bond dissociation energies in the cyclanes from cyclopropane to cyclononane to an accuracy of approximately $\pm 2 \mathrm{kcal}$ and, moreover, has claimed that the calculated values agree with existing experimental data. We wish to point out first that the method by which he estimates the bond strengths in cyclopropane and cyclobutane is unsuitable, and second, that he has neglected important experimental evidence on these compounds. Our objections may be summarized as follows.

1. It has been tacitly assumed that the activation energies of the reverse reactions by which the biradicals form cyclanes are zero; this is unrealistic. Seubold has estimated the heat of formation of the trimethylene and cis-tetramethylene biradicals in which the $\mathrm{C}-\mathrm{C}-\mathrm{C}$ bond angles are tetrahedral and hence calculated the heats of the reactions by which these radicals are formed from the cyclanes. He then identifies the heats of these reactions with the dissociation energies of the $\mathrm{C}-\mathrm{C}$ bonds. However, a bond is usually said to be broken when the attraction between the two centers is of the order of $k T$. It is not known, and there appears to be no reliable way of estimating at what $\mathrm{C}-\mathrm{C}-\mathrm{C}$ angle the attractive force between the centers is of this order, but there is no reason to suppose that this point is reached when the angles in the radicals are exactly tetrahedral: it can hardly be so for both compounds even if it is true for one. Probably, there is still considerable strain in the radicals when the configuration is such that the bond strengths are of the order of $k T$, at which point the activation energies of the recombinations are zero. These strained radicals will have higher heats of formation which would yield higher values for the calculated $\mathrm{C}-\mathrm{C}$ bond dissociation energies. Conversely, the reactions by which the biradicals with tetrahedral angles form cyclanes may have substantial energies of activation. An attempt to calculate this energy barrier, based on an empirical strain-energy-bond-angle relationship, led to the conclusion that it would be negligible; ${ }^{2}$ this conclusion is probably invalid, however, because of the significant deviations in the cyclopropane and cyclobutane bond lengths from the alkane values, ${ }^{3}$ which were not taken into account in the calculation.
2. It is unjustifiable to correlate, as Seubold does, the low "heat of dissociation" of cyclopropane with the ease of reaction of cyclopropane and its derivatives. The isomerization of cyclopropane to propylene occurs cleanly at about $490^{\circ} \mathrm{C}$ with an activation energy of $65 \mathrm{kcal}$ and an $A$ factor of $10^{15.17} .^{4,5}$ Despite the application of sensitive tests no evidence can be found for the existence of biradicals in the system $;{ }^{6}$ moreover, there are good theoretical reasons for supposing that the fission of the $\mathrm{C}-\mathrm{C}$ bond is not the rate-determining step in the isomerization. ${ }^{7}$ Similarly, there is no evidence that biradicals are formed when cyclobutane decomposes to ethylene for which the activation energy is 62.8 kcal and the $A$ factor $10^{15.71} \mathrm{sec}^{-1}$. When gases such as toluene or hydrogen are added to the reaction system, no effects compatible with the presence of free radicals are observed. ${ }^{2,8}$ The $A$ factors for dissociation into biradicals are not likely to be less than $10^{13} \mathrm{sec}^{-1}$ in either case, so that if the proposed radical processes had activation energies of 65 and $63 \mathrm{kcal}$, respectively, the reactions would occur to the extent of about $\frac{1}{2}$ percent by such mechanisms, which would be readily observable. Thus, we should place lower limits of 65 and $63 \mathrm{kcal}$ on the respective dissociation energies, at variance with our general experience of these compounds. In actual fact, such arguments tell us nothing about dissociation energies, because both radical mechanisms would show quasiunimolecular falloff in the pressure range used for the activation energy determinations, $, 4,5,8$ and until the extent of such falloff is calculated, we are precluded from placing any limits on the $\mathrm{C}-\mathrm{C}$ dissociation energies in cyclopropane and cyclobutane.

1 F. H. Seubold, J, Chem. Phys, 21, 1616 (1953).

2 Pritchard, Sowden, and Trotman-Dickenson, Proc. Roy. Soc. (London) A218. 416 (1953).

C. A. Coulson, J. Phys. Chem. 56, 314 (1952).

4T. S. Chambers and G. B. Kistiakowsky, J. Am. Chem. Soc. 56, 399 (1934).

s E. S. Corner and R. N. Pease, J. Am. Chem. Soc. 67, 2067 (1945). 6 Pritchard, Sowden, and Trotman-Dickenson, Proc. Roy. Soc. (London) A217, 563 (1953).

7 N. B. Slater, Proc. Roy. Soc (London' A218, 224 (1953).

8 F. Kern and W. D. Walters, Proc. Nat1. Acad. Sci. (Washington) 38, 937 (1952). 
Reprinted from Chemistry and Industry, 1954, pp. 1046-1047

THE C-C BOND DISSOCIATION ENERGY IN CYCLOBUTANE

\author{
H. O. Pritchard
}

Chemistry Department, The University, Manchester

and

\section{A. F. Trotman-Dickenson}

E. I. du Pont de Nemours \& Co., Niagara Falls, N.Y.

Recently there has been some discussion ${ }^{1}$ of the C-C bond dissociation energies in the cyclanes, particularly in cyclopropane and cyclobutane. We wish to draw attention to a method of estimating the dissociation energy of cyclobutane which has been neglected. Burwell $^{2}$ has proposed an ingenious mechanism to explain the products formed in the isomerization of $\alpha$-pinene. Since a similar mechanism ${ }^{3}$ explains the products formed in the isomerization of $\beta$-pinene, we may have considerable confidence that it is correct. The first step in both of these mechanisms is the fission of a substituted cyclobutane ring to yield a biradical. The activation energies for the reactions which may be equated with the dissociation energies are $44^{4}$ and $49^{3} \mathrm{kcal}$. respectively. Now to a first approximation $\alpha$-(I) and $\beta$-(II) pinene bear the same relation to cyclobutane (III) as propane (IV) does to 4,4 -dimethyl-Ipentene $(\mathrm{V})$

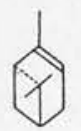

(1)

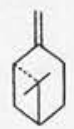

(II)

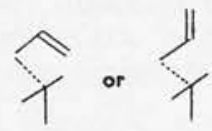

(

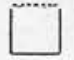

(III)

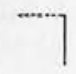

(IV)
: the bonds to be broken are dotted. The heats of formation of propane and of the radicals ${ }^{5}$ formed from (IV) and (V) have been measured and that of 4,4dimethyl-I-pentene may be estimated as $-19.3 \mathrm{kcal}$./ mole from the known ${ }^{6}$ heats of formation of 4 -methyl-Ipentene $(-\mathrm{II} \cdot 7)$, 2-methylpentane $(-4 \mathrm{I} \cdot 7)$ and 2,2-dimethylpentane $(-49 \cdot 3)$. Hence it can be shown that the dissociation energies of the bonds in propane and (V) are 82 and $54 \mathrm{kcal}$./mole respectively. Therefore, if the dissociation energy of the cyclobutane bond in the pinenes is $46 \mathrm{kcal}$./mole, that in cyclobutane is $46+82-54=74 \mathrm{kcal}$. $/$ mole. This may be regarded as a minimum value, for the pinene molecules are presumably more strained than cyclobutane.

If the "normal" C-C bond has a strength of $85 \mathrm{kcal} . / \mathrm{mole}$ the strain energy in cyclobutane, which is $26 \mathrm{kcal}$. $/ \mathrm{mole}^{7}$, lowers the bond dissociation energy by about II kcal./mole. Consequently the activation energy for the internal combination of the biradical is $15 \mathrm{kcal}$.

These figures show that it is extremely unlikely that the decomposition of cyclobutane into two ethylene molecules, which has an activation energy of only $62.8 \mathrm{kcal}$. and a frequency factor of $10^{15.71} \mathrm{sec}^{-1}$ involves the formation of a biradical intermediate. It is probably a straightforward molecular decomposition.

\section{Received fune 29, 1954}

\section{References}

1 Seubold, F. H., f. chem. Phys., I954, 22, 945; Pritchard, H. O. \& Trotman-Dickenson, A. F., ibid., 944

2 Burwell, R. L., f. Amer. chem. Soc., 195I, 73, $446 \mathrm{I}$

${ }^{3}$ Hawkins, J. E. \& Vogh, J. W., f. phys. Chem. 1953, 57, 902

- Smith, D. F., f. Amer. chem. Soc., 1927, 49, 43

5 Szwarc, M., Discuss. Faraday Soc., 1951, 10, 336

${ }^{6}$ Rossini, F. D., et ai. Selected properties of Hydrocarbons, Carnegie Press, Pittsburgh, 1953

7 Pritchard, H. O., Sowden, R. G. \& Trotman-Dickenson, A. F., Proc. roy. Soc., 1953, A, 218, 416 
THE PHOTOLYSIS OF HEXAFLUOROAZOMETHANE AND THE REACTIONS OF $\mathrm{CF}_{3}$ RADICALS WITH METHANE AND $n$-BUTANE

\author{
By G. O. Pritchard and H. O. Pritchard
}

Chemistry Department, The University, Manchester

and

\section{A. F. Trotman-Dickenson}

Chemistry Department, The University, Edinburgh

Hexafluoroazomethane was prepared by heating ICN with $\mathrm{IF}_{5}$ in a steel bomb at $130^{\circ} \mathrm{C} . ;^{1}$ after purification, the product was shown by mass-spectrographic analysis to contain only $\mathrm{CF}_{3} \mathrm{I}$ as impurity. Photolysis of this gas at room temperature by light from an unfiltered high-pressure mercury arc yielded $\mathrm{N}_{2}$ (9.8 vol.), $\mathrm{C}_{2} \mathrm{~F}_{6}$ (I.9 vol.) and $\left(\mathrm{CF}_{3}\right)_{4} \mathrm{~N}_{2}$ (7.8 vol.); at $200^{\circ}$, the photolysis was accompanied by a decrease in total pressure and the products contained a fairly involatile liquid $\left(\mathrm{CF}_{3}\right)_{2} \mathrm{~N} \cdot \mathrm{N}\left(\mathrm{CF}_{3}\right) \cdot \mathrm{N}\left(\mathrm{CF}_{3}\right) \cdot \mathrm{N}\left(\mathrm{CF}_{3}\right)_{2}$. No appreciable amount of $\mathrm{CF}_{3} \mathrm{H}$ was formed at either temperature provided that the reaction vessel was isolated from the vacuum system by a mercury cut-off, and even up to $350^{\circ}$ no $\mathrm{CF}_{4}$ was formed. However, above about $150^{\circ}$ small amounts of $\mathrm{CO}_{2}$ and $\mathrm{SiF}_{4}$ were produced by the attack of $\mathrm{CF}_{3}$ radicals on the quartz reaction vessel; attack on Pyrex was much less so that most of the experiments were carried out in a glass vessel.

In order to study the reactions of $\mathrm{CF}_{3}$ radicals with hydrocarbons, $2 \mathrm{~cm}$. of hexafluoroazomethane was photolysed in the presence of $10-20 \mathrm{~cm}$. of hydrocarbon at temperatures of $30-350^{\circ}$, the ratio of $\mathrm{CF}_{3} \mathrm{H}$ to $\mathrm{C}_{2} \mathrm{~F}_{6}$ in the products being determined by massspectrographic analysis. The quantities of these two gases formed in any one run were very small because of the addition of the majority of the $\mathrm{CF}_{3}$ radicals to the unsaturated hexafluoroazomethane; this addition sets serious limits on the accuracy of the method.
The results were fitted to the expression

$$
\mathrm{k}_{1} / \mathrm{k}_{2}{ }^{\mathrm{t}}=\left[d\left(\mathrm{CF}_{3} \mathrm{H}\right) / d \mathrm{t}\right] /\left[d\left(\mathrm{C}_{2} \mathrm{~F}_{6}\right) / d \mathrm{t}\right]^{\mathrm{d}}[\mathrm{RH}]
$$

based on the assumed reaction scheme

$$
\begin{array}{lllll}
\mathrm{CF}_{3}+\mathrm{RH} \rightarrow \mathrm{CF}_{3} \mathrm{H}+\mathrm{R} & \ldots & \ldots & \ldots \\
\mathrm{CF}_{3}+\mathrm{CF}_{3} \rightarrow \mathrm{C}_{2} \mathrm{~F}_{6} & \ldots & \ldots & \ldots & . .
\end{array}
$$

and it was found that if $\mathrm{k}=\mathrm{A} \exp (-\mathrm{E} / \mathrm{RT}), \mathrm{E}_{1}-\frac{1}{2} \mathrm{E}_{2}$ $=9.5 \pm 2 \mathrm{kcal} . / \mathrm{mole}, \mathrm{A}_{1} / \mathrm{A}_{2}^{+} \approx 3 \times 10^{4} \mathrm{~mole}-\frac{1}{\mathrm{t}}$ c.c. ${ }^{\frac{1}{t}}$ sec. ${ }^{-1}$ for methane and $\mathrm{E}_{1}-\frac{1}{2} \mathrm{E}_{2}=5 \cdot 5 \pm \mathrm{I} \mathrm{kcal}$. $/ \mathrm{mole}$, $\mathrm{A}_{1} / \mathrm{A}_{2}{ }^{\frac{1}{2}} \approx \mathrm{I} \cdot 5 \times 10^{4} \mathrm{~mole}^{-1}$ c.c. ${ }^{\frac{1}{2}}$ sec. ${ }^{-\frac{1}{2}}$ for $n$-butane; it was further found that $\mathrm{CF}_{3}$ radicals reacted with hydrogen about ten times as fast as with methane at $220^{\circ}$. The results suggest that the activation energies of the hydrogen abstraction reactions of $\mathrm{CF}_{3}$ radicals are about $3 \mathrm{kcal}$. $/$ mole lower than those of the corresponding $\mathrm{CH}_{3}$ radicals. $^{2}$ If $\mathrm{A}_{2}$ is equal to the A-factor for the combination of $\mathrm{CH}_{3}$ radicals, then the values of $\mathrm{A}_{1}$ are very similar to those found for the corresponding $\mathrm{CH}_{3}$ radical reactions.

It would appear difficult to improve significantly upon the accuracy of these results because the rapid addition of $\mathrm{CF}_{3}$ radicals to hexafluoroazomethane reduces their concentration so severely that the rate of formation of $\mathrm{C}_{2} \mathrm{~F}_{6}$ cannot be accurately determined; the method could however, be applied successfully if a less unsaturated source of $\mathrm{CF}_{3}$ radicals were employed. We do not intend to investigate the present approach further.

We are very much indebted to $\mathrm{Mr}$. V. W. Rowlands of the Widnes Laboratory, I.C.I. General Chemicals Division, Widnes, for carrying out the mass-spectrometer analyses.

\section{Received March I5, 1955}

\section{References}

${ }^{1}$ Ruff, O. \& Willenberg, W., Ber. dtsch. chem. Ges., 1940, 73, 724

${ }^{2}$ Trotman-Dickenson, A. F., Quart. Rev. chem. Soc., Lond., 1953, 7 I98 
Reprinted from Chemistry and Industry, 1955, p. 896

\section{THE C-H BOND DISSOCIATION ENERGY IN FLUOROFORM}

\author{
By G. O. Pritchard and H. O. Pritchard \\ Manchester University
}

\author{
H. I. Schiff \\ McGill University
}

\section{and A. F. Trotman-Dickenson \\ Edinburgh University}

The heat of the reversible reaction

$$
\mathrm{CF}_{3}+\mathrm{CH}_{4} \underset{\mathrm{E}_{\mathrm{r}}}{\stackrel{\mathrm{E}_{\mathrm{f}}}{\rightleftharpoons}} \mathrm{CF}_{3} \mathrm{H}+\mathrm{CH}_{3},
$$

which is the difference between the $\mathrm{C}-\mathrm{H}$ dissociation energies in $\mathrm{CH}_{4}$ and $\mathrm{CF}_{3} \mathrm{H}$, may be obtained by measuring the difference in activation energy between the forward and reverse reactions. Recent experiments ${ }^{1,2}$ on the relative rates of the two reactions

and

$$
\mathrm{CF}_{3}+\mathrm{CH}_{4} \longrightarrow \mathrm{CF}_{3} \mathrm{H}+\mathrm{CH}_{3}
$$

$$
\mathrm{CF}_{3}+\mathrm{CF}_{3} \longrightarrow \mathrm{C}_{2} \mathrm{~F}_{8} \text {. . }
$$

have given $\left(E_{1}-\frac{1}{2} E_{2}\right)=9.5 \pm 2$ and $10.3 \pm 0.5 \mathrm{~kg}$.cal. mole, respectively; hence, using the more exact determination, $\mathrm{E}_{\mathrm{f}}=\left(\mathrm{IO} \cdot 3+\frac{1}{2} \mathrm{E}_{2}\right) \mathrm{kg} . \mathrm{cal}$. $/$ mole.

We have obtained a value for $\mathrm{E}_{\mathrm{r}}$ by measuring the activation energy of the reaction between $\mathrm{CD}_{3}$ radicals and fluoroform in the following way. Mixtures of about $5 \mathrm{~cm}$. pressure of $\left[\mathrm{D}_{6}\right]$ acetone $\left(\sim 5 \%\left[\mathrm{D}_{5}\right]\right)$ and $5-20 \mathrm{~cm}$. of fluoroform were photolysed at temperatures from $140-290^{\circ} \mathrm{C}$. in a 250 c.c. quartz bulb; the fraction of the products volatile at liquid $\mathrm{N}_{2}$ temperature, i.e. $\mathrm{CO}, \mathrm{CD}_{4}$ and $\mathrm{CD}_{3} \mathrm{H}$, was separated off and the ratio of $\mathrm{CD}_{3} \mathrm{H} / \mathrm{CD}_{4}$ was determined mass-spectrometrically. The principal $\mathrm{CD}_{3}$ radical reactions are

$$
\begin{aligned}
& \mathrm{CD}_{3}+\mathrm{CD}_{3} \cdot \mathrm{CO} \cdot \mathrm{CD}_{3} \longrightarrow \mathrm{CD}_{4}+\mathrm{CD}_{2} \cdot \mathrm{CO} \cdot \mathrm{CD}_{3} \\
& \mathrm{CD}_{3}+\mathrm{CD}_{3} \longrightarrow \mathrm{C}_{2} \mathrm{D}_{6} \\
& \mathrm{CD}_{3}+\mathrm{CF}_{3} \mathrm{H} \longrightarrow \mathrm{CD}_{3} \mathrm{H}+\mathrm{CF}_{3} . .
\end{aligned}
$$

After allowing for the $\mathrm{CD}_{3} \mathrm{H}$ formed from the hydrogen impurity in the heavy acetone (about $7-8 \%$ of the amount of $\mathrm{CD}_{4}$ and approximately constant over the whole temperature range), the rate constant ratio

$$
\begin{aligned}
\frac{k_{3}}{k_{5}}=\frac{d\left[\mathrm{CD}_{4}\right] / d t}{d\left[\mathrm{CD}_{3} \mathrm{H}\right] / d t} \cdot \frac{\left[\mathrm{CF}_{3} \mathrm{H}\right]}{\left[\mathrm{CD}_{3} \cdot \mathrm{CO} \cdot \mathrm{CD}_{3}\right]} \\
=75 \exp (-[1800 \pm 150] / \mathrm{RT})
\end{aligned}
$$

was obtained by applying the method of least squares to the results of ten experiments i.e. $\mathrm{E}_{3}-\mathrm{E}_{5}=\mathrm{I} \cdot 80 \pm$ $0.15 \mathrm{~kg}$.cal. $/$ mole (the error quoted being the maximum possible error of the Arrhenius plot). Direct measurements on the photolysis of $\left[\mathrm{D}_{6}\right]$ acetone yield ${ }^{3}$ the value $\left(\mathrm{E}_{3}-\frac{1}{2} \mathrm{E}_{4}\right)=\mathrm{II} \cdot 6 \mathrm{~kg}$. cal. $/$ mole (also confirmed indirectly from a comparison ${ }^{4}$ of the reaction of $\mathrm{CD}_{3}$ radicals with normal and $\left[\mathrm{D}_{6}\right]$ acetone $)$; thus $\mathrm{E}_{5}=\left(\mathrm{II} \cdot 6-\mathrm{I} \cdot 8+\frac{1}{2} \mathrm{E}_{4}\right)$ $\mathrm{kg}$. cal./mole. Assuming that there is no significant difference between the activation energies of the reactions of $\mathrm{CD}_{3}$ or $\mathrm{CH}_{3}$ radicals with fluoroform, we may identify $\mathrm{E}_{5}$ with $\mathrm{E}_{\mathrm{r}}$, hence $\mathrm{E}_{\mathrm{r}}=\left(9 \cdot 8+\frac{1}{2} \mathrm{E}_{4}\right) \mathrm{kg}$. $\mathrm{cal}$./mole. Using these results,

$$
\begin{aligned}
& \mathrm{D}\left(\mathrm{CH}_{3}-\mathrm{H}\right)-\mathrm{D}\left(\mathrm{CF}_{3}-\mathrm{H}\right)=\mathrm{E}_{\mathrm{f}}-\mathrm{E}_{\mathrm{r}}=\mathrm{I0} \cdot 3+\frac{1}{2} \mathrm{E}_{2} \\
& -9 \cdot 8-\frac{1}{2} \mathrm{E}_{4} \\
& \text { whence, if } \mathrm{E}_{2}=\mathrm{E}_{4} \text { and } \mathrm{D}\left(\mathrm{CH}_{3}-\mathrm{H}\right)=\mathrm{ro2} \cdot 5 \pm \mathrm{I} \\
& \mathrm{D}\left(\mathrm{CF}_{3}-\mathrm{H}\right)=\mathrm{IO2} \cdot 0 \pm 2 \mathrm{~kg} . \mathrm{cal} . / \mathrm{mole} .
\end{aligned}
$$

From a comparison of the heats of formation of $\mathrm{CF}_{3} \mathrm{Cl}^{5}{ }^{5} \mathrm{CH}_{4}$ and $\mathrm{CH}_{3} \mathrm{Cl}$ we can estimate $\Delta \mathrm{H}_{\mathrm{f}}\left(\mathrm{CF}_{3} \mathrm{H}\right)$ to be $-169 \mathrm{~kg}$. cal. $/$ mole which leads to a value of $\Delta \mathrm{H}_{\mathrm{f}}\left(\mathrm{CF}_{3}\right)=-\mathrm{II} 9 \mathrm{~kg}$. cal. $/$ mole; combining this with $\Delta \mathrm{H}_{\mathrm{f}}\left(\mathrm{C}_{2} \mathrm{~F}_{6}\right)=-303 \mathrm{~kg}$. cal. ${ }^{5}$ gives $\mathrm{D}\left(\mathrm{CF}_{3}-\mathrm{CF}_{3}\right)=65$ $\mathrm{kg}$. cal./mole.

Our results may also be used to gain some information about the combination of $\mathrm{CF}_{3}$ radicals. From the work of Ayscough, Polanyi and Steacie, ${ }^{2}$ and Whittle and Steacie, ${ }^{3}$ we have $A_{1} / A_{2}{ }^{\frac{1}{2}}=9.7 \times 10^{3}$ and $A_{3} / A_{4}{ }^{3}=$ $\mathrm{I} \cdot 2 \times 1 \mathrm{O}^{5} \mathrm{~mole}^{-1}$ c.c..$^{\frac{1}{3}}$ sec. $^{-1}$, , respectively, and from the present work $A_{3} / A_{5}=75$. The entropy change in reaction $I$ must be very small indeed so that $A_{f}$ must equal $A_{r}$, whence $A_{4} \approx 35 A_{2}$ if $A_{r}$ and $A_{5}$ are assumed to be the same.

Received May 16, I955

\section{References}

${ }^{1}$ Pritchard, G. O., Pritchard, H. O. \& Trotman-Dickenson, A. F., Chem. \& IND., I955, 564

${ }^{2}$ Ayscough, P. B., Polanyi, J. C. \& Steacie, E. W. R., Canad. f. Chem., 1955, 33, 743

${ }^{3}$ Whittle, E. \& Steacie, E. W. R., F. chem. Phys., I953, 21, 993

${ }^{4}$ McNesby, J. R. \& Gordon, A. S., f. Amer. chem. Soc., $1954,76,1416$

${ }^{5}$ Kirkbride, F. W. \& Davidson, F. G., Nature, Lond., 1954, 174, 79 
Reprinted from Chemistry and Industry, March 2, 1957, p. 268

\section{THE REACTIONS OF METHYLENE}

\section{By J. H. Knox and A. F. Trotman-Dickenson}

Department of Chemistry, University of Edinburgh

Recent investigations of systems containing methylene indicate that this radical reacts directly with paraffin hydrocarbons to yield the next higher homologue. For example, with ethane

$$
\mathrm{CH}_{2}+\mathrm{C}_{2} \mathrm{H}_{6}=\mathrm{C}_{3} \mathrm{H}_{8} \ldots \text { (1) }
$$

It appears that this is an elementary reaction and that no intermediate radicals are involved. The transition state may be formulated<smiles>CCC</smiles>

where the bonds being formed are represented by dotted lines and the bond being broken by a broken line. No complete kinetic studies of reactions of this type have so far been published but results reported by Doering et al. ${ }^{1}$ indicate that the attack of methylene on the hydrogen atoms in $n$-pentane and 2: 3-dimethylbutane is statistical within experimental error over a considerable temperature range $\left(-80^{\circ}\right.$ to $30^{\circ} \mathrm{C}$ ). That is $n$-pentane yields $n$-hexane, 2-methylpentane and 3-methylpentane in the ratio $3: 2: 1$, and $2: 3$-dimethylbutane yields $2: 3$-dimethylpentane and $2: 2: 3$-trimethylbutane in the ratio $6: 1$. These results are not as would be expected on the basis of transition state theory.

At $298^{\circ} \mathrm{A}$. the entropy of $\mathrm{CH}_{2}$ may be calculated to be $47 \cdot 7$ e.u. on the assumption that the molecule contains two unpaired electrons and that the vibrational contribution is negligible. The entropy of the activated complex must be close to that of the hydrocarbon of the same formula after subtraction of the contribution for the rotation of one methyl group (about 1.7 e.u.), and after making an adjustment for the change in molecular symmetry. For reaction (1) we thereby obtain a calculated A factor ${ }^{2}$

$$
\mathrm{A}_{1}=10^{10.15} \mathrm{~mole}^{-1} \mathrm{~cm}^{3} \mathrm{sec}^{-1}
$$

The calculation may be repeated for other hydrocarbons but it is more revealing to calculate the relative A factors for pairs of reactions. These quantities may be obtained experimentally with great accuracy and the calculated values involve no assumptions as to the entropy of the attacking radical. The following illustrative results have been obtained by the procedure outlined above.

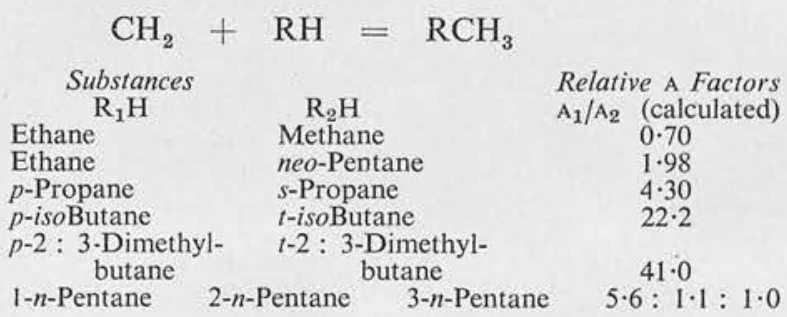

The attack on the different $\mathrm{C}-\mathrm{H}$ bonds in the same molecule are regarded as distinct reactions and are represented by the prefixes " $p$," " $s$," " $t$," etc.

In the two cases where there is direct experimental evidence, namely 2 : 3 -dimethylbutane and $n$-pentane, the calculated and experimental values show considerable discrepancies which appear to be well without both the experimental and probable theoretical errors. Considerable interest thus attaches to a more extensive study of the reactions of methylene, particularly with the simpler hydrocarbons.

Received February 1, 1957

\section{References}

1 Doering, Buttery, Lauchlin \& Chaudhuri, J. Amer. chem. Soc., 1956, 78, 3224

2 Glasstone, Laidler \& Eyring, " Theory of Rate Processes," 1941. (New York: McGraw-Hill) 
Mr. G. Boocock and Dr. H O. Pritchard (Manchester University) and Dr. A. F. Trotman-Dickenson (E.I. du Pont de Nemours and Co., Inc., Niagara Falls) (communicated): In view of the remark made by Dr. K.E. Russell, we would like to describe some recent experiments on active nitrogen. We have followed the decay of the afterglow in a 20-1. flask at room temperature using a photomultiplier to measure the light emitted. Assuming that the glow was caused indirectly by the recombination of nitrogen atoms and that its intensity was proportional to the rate of the termolecular combination of nitrogen atoms, we intended to study the effect of adding known pressures of various foreign gases to the glowing system. We found that, in any one run, the rate of decay of the glow conformed well to the kinetic equation deduced from the assumed mechanism.

As it was not possible to reproduce the rate of decay from one run to another for any given pressure, we adopted the following procedure : the glow was started and the light intensity was followed for a period long enough to establish its rate of decay; a known pressure of nitrogen was added and the light intensity was again followed to establish the new rate of decay; then a further lot of nitrogen was added and the decay rate was again determined. In this way we showed

1 Rayleigh, Proc. Roy. Soc. A, 1940, 176, 1, 16.

that the rate of decay was approximately proportional to the pressure of nitrogen. We then tried to determine the relative efficiencies of nitrogen and argon by initiating the glow in pure nitrogen, then adding a known pressure of argon, and later still adding the same pressure of nitrogen, following the light intensity at each stage to establish the various rates of decay. Unfortunately, the addition of about $2 \mathrm{mms}$ of argon to the glowing nitrogen caused a marked colour change towards the red; reinvestigation revealed that even the addition of nitrogen changed the colour, but in this case towards the blue. We did not study the effect of temperature variation, but it is not unlikely that if pressure affects the colour of the afterglow, then the temperature will also affect it, suggesting that it is unwise to draw any conclusions from Lord Rayleigh's experiments about the possible curvature of $\log k$ against $1 / T$ plots for atom combination reactions. Indeed, it is still doubtful if the combination of nitrogen atoms is being followed when the decay of the glow is studied. 


\section{GENERAL DISCUSSION}

Dr. H. O. Pritchard and Mr. R. G. Sowden (Manchester University, and Dr. A. F. Trotman-Dickenson (E.I. du Pont de Nemours and Co., Inc., Niagara Falls), (communicated): We have tried to extend our measurements on the rate of isomerization of cyclopropane at $490^{\circ} \mathrm{C}$ down to a pressure of about $0.005 \mathrm{~mm}$ using a flow technique; this pressure is a factor of 20 lower than is indicated by Dr. H. S. Johnston in fig. 6 of his paper. In our original experiments ${ }^{1}$ the lowest pressure we could use $(0.067 \mathrm{~mm})$ was determined by the fact that we only had a 2-I. reaction vessel and were not able to analyze less than $60 \mathrm{~mm}^{3}$ of cyclopropane - propylene mixture. We therefore tried to obtain a sufficient sample for analysis by circulating cyclopropane, using a mercury diffusion pump, from a 20-1. reservoir at room temperature via a preheater at $450^{\circ} \mathrm{C}$, through the 2-1. reaction vessel at $490 \mathrm{C}$, the pumping speed being varied from about 20-1./min to $1-1 . / \mathrm{h}$ by inserting various capillaries (these speeds refer to the cold gas); apart from these capillaries, the system was constructed from wide-bore tubing and care was taken that there should be no significant build-up of pressure anywhere in the system. But a McLeod gauge attached directly to the reaction vessel read about $10 \%$ low when the gas was being circulated. We were never able to adjust the system so that the rate of reaction was independent of pumping

1 Pritchard, Sowden and Trotman-Dickenson, Proc. Roy. Soc. A, 1953, 217, 563.

speed; at the highest pumping speeds, no measurable reaction had occurred after circulating for $24 \mathrm{~h}$, indicating that the mean temperature attained by the gas was at least $40^{\circ} \mathrm{C}$ below that of the reaction vessel. The reaction appeared to be clean in this pressure range so long as there was no leak of air into the system and providing that all mercuric oxide deposits were removed by treatment with moist $\mathrm{HCl}$ vapour; both propylene and cyclopropane were unaffected by the discharge which occasionally occurred in the mercury circulating pump. Thus we conclude that althougin in theory the gas should heat up quite quickly to the temperature of the reaction vessel, in practice it is not a simple matter to design a flow system to work at such low pressures, for reactions of any speed ; the discrepancy between the pressures measured under flowing and static conditions is probably indicative of the flaw in this type of experiment. 
Proofs to:

A. F. Mrotruanomickenson,

Chemistry Bepartment,

West Hains Koad,

Edinburgh 9.

vetal-Caxbon Bonds 1. The Pyrolyses of Dimethy1 Mexcury and Dinethy2 Caimiun.

by SoJ.W. PICE and A.F. ThOTMAH-DICKEASOW, Chemistry Deportment, The University, Ediriburgh.

Short t1tie: Dimethyl mercury and dimethyl cadniun.

I11ustrations:

2 figures 
The thermol decompositions of dimethyl mercury and dimethyl cadmiun have been stuched by the toluene carrier technique between $465^{\circ}$ and $608^{\circ} \mathrm{C}$, and $469^{\circ}$ and $571^{\circ} \mathrm{C}$ respectively. The progress of the reactions were followed by measuring the hydrogen, methane, ethylene and ethene formed. The resuits obtoined with dinethyl mercury may be expressed by

$$
10 \mathrm{gs} 0 \mathrm{k} / \mathrm{sec}^{-1}=13.1-\left(50,100^{4}-1000 / 2 \cdot 303 \mathrm{NT}\right) \text { at } 16 \mathrm{mas}
$$
in excelient agreenent with previous deterninations and with dimethyl cadiatum by

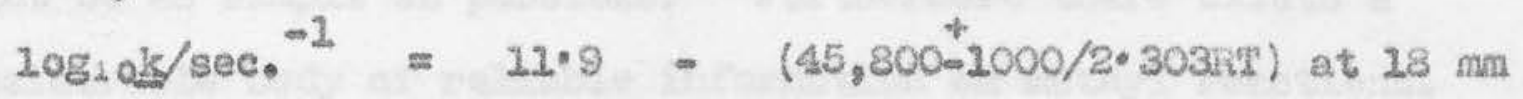

In both cases $\mathrm{k}$ was markecly dependent upon the total pressure. The ectivation energies may be equated with the heats of reactions (1)

$$
\mathrm{X}\left(\mathrm{CH}_{3}\right)_{3}=\mathrm{XCH}_{3}+\mathrm{CH}_{3}
$$

Hence, by therrochenistry, the heat of reaction

$$
\mathrm{xCH}_{3}=\mathrm{X}+\mathrm{CH}_{3}
$$

is $7 \cdot 2$ kcal.mole ${ }^{-1}$ for mercury and 20.2 kcel.mole ${ }^{-1}$ for cadnium. These are the mininum dissociation energies for the bonds. 
Littie is known of the dissociation energies of the metalcax'bon bonds in the metalile alkyl.s. This paper describes an attenpt to deternine the dissociation energies of the bonds in dinethyl mereury and dinethyl cadnzun by a kinetic method, It is hoped that information on other compounds will be reported in Later papers. The reasons for selecting these compounds for study may be breifly stated. Lethy? derivatives were selected so that the reactions of the radicals released on decoraposition might be 2.5 simple as posstble. Furthermore there exists a constiderable body of relieble information on methyl reactions. The mexcuxy compound was selected because it hes been the stbject of a coraprehensive study by a very stinliar aethoc ${ }^{2}$ to the one employed in the present work. There is excellent agreement between the results obtained in the two Investigations. Dinethyl cadnitum was selected because of its great similerity to dissethyl mercury.

\section{FWPIRTIEITYSAJ.}

Materials.-Dlmethyl mercury was prepared from mercuric chloride and methyl magnesium Lodide ${ }^{2}$. The crucle product was dried $\left(\mathrm{CaCl}_{2}\right)$ and twice frectionated. The fraction boiling at $93: \mathrm{C}$ at $758 \mathrm{mn}$ was stored under vacuun at room temperature. Analysis by ges chronatogrephy shoved a maximum of 0.2 impurity. Dlmethy 3 cedmlun was prepared by the action of anhydrous 
cadmium chloride on nethyl mgnesium lodide ${ }^{3}$. The chioride was added Irom a conical rlask connected to the reection vessel by a short length of $1^{\prime \prime}$ dianeter rubber tubing. The cruae product Was twice Ixactlonated and the fraction boiling at $70^{\circ} 4^{\circ} \mathrm{C}$ at $240 \mathrm{~mm}$ was stored uncer vecuun at $-183^{\circ} \mathrm{C}$.

Toluene was puxifled by paseing sulphux-free toluene twice through a cuartz tube at $870^{\circ} \mathrm{C}$ and 25 fin pressure. The product was then fractionated and thoroughly degassed before use. Appratus - The experiments were corried out in a typical toluene-cervier 1 ow systen in which the roaction zome was $155 \mathrm{~cm}^{3}$. In the runs with the vessel packed with quartz tubing the surface exea in the zone was increased by a factor of five and its volume reduced to $127 \mathrm{~cm}^{3}$. The reaction products were separated in a stenderd low-temperature trap system and measured in a gas burette. The hydrogen was esthmated by oxidation in a copper oxide tube. The ethylene content of the ethene was determined by gas chromatography (we are much indebted to Mr. J. Falconer for these anelyses:.

Except as noted in the tables, the flov of alky3 Iasted for 30 min, during each run, preceded and followed by 5 min. Ilow of toluene alone. Contact tines were calculated on the assumption thet the Ideal gas law was obeyed by a.1. substanees within the reaction zone. The rate constants vere calculated from the usual sirst-order equation. 


\section{RBSUTSS ATID DISCUSSICH.}

A possibie nechenism Lox the decomposition of the metali1c alky $2 \mathrm{~s}$ in the presence of toluene $1 \mathrm{~s}$ as follows ${ }^{1}$

$$
\begin{aligned}
& \mathrm{x}\left(\mathrm{CH}_{3}\right)_{\mathrm{s}}=\mathrm{XCH}_{3}+\mathrm{CH}_{3} \\
& \mathrm{XCF}_{5}=\alpha+\mathrm{CH}_{3} \\
& \mathrm{CH}_{6}+\mathrm{C}_{6} \mathrm{H}_{5} \mathrm{CH}_{9}=\mathrm{CH}_{6}+\mathrm{C}_{6} \mathrm{H}_{6} \mathrm{CH}_{2} \\
& 2 \mathrm{CH}_{3}=\mathrm{C}_{2} \mathrm{H}_{6} \\
& 2 \mathrm{C}_{6} \mathrm{H}_{6} \mathrm{CHA}_{2}=\left(\mathrm{C}_{0} \mathrm{H}_{5} \mathrm{CH}_{\mathrm{g}}\right)_{\mathrm{a}}
\end{aligned}
$$

The desults contalned in tables 1 and 2 moy be discussed in terms of this nechanism, in which it ds asswned that reaction (2) is very meh fasted than roaction (2).

According to the nechanism the number of noles of ethane thalf the mumber of aoles of methane formed during a rum should be equal to the runber of moles of the alkyl which have decomposed. Using this measure of the progress of the reactions it was found that the decomposition of dinethyl cadnium obeys Plsst order kinetics at a constant total preasure in the system (see runs 7, 8, 19, 20, 21, $30,32,37$ ). In generel in this work less ettention was paid to the deteils of the dinethyl nercury decomposition. The experinents were prinarily caxried out to check the finding of Coweniock, Polanyi and Werhurst ${ }^{2}$ and to extend them slightly. Experiments with ainethyl cadmiun in the packed reaction veasel indicated that the 
deconposition was homogeneous, as the packing eaused no appreciable change in the rirst-order rate constant.

The proposed mechtnisa for the decomposition will oniy be valid if reaction (6) can be neglected as a possible

$$
\mathrm{CH}_{3}+\mathrm{C}_{6} \mathrm{HH}_{8} \mathrm{CH}_{3}=\mathrm{C}_{6} \mathrm{H}_{3} \mathrm{CH}_{2} \mathrm{CH}_{8}
$$

means by which methyl radicals sight be removed from the system. Ko hes not been measured so there is no direct evidence on this polnt. Two Lacts, however, have been established, neither of which is conpatible with reaction $(6)$ being very Important in this system. Fusst, the rate constants, as derdved, are independent of the rate of release of methyl radicals linto the system this has been checked by using various pressures of dimethyl cadmium while keeping the other conditions constant. Second, a run carried out at $595^{\circ} \mathrm{C}$ with a contact time of 5.6 sec. produced methane and ethane in quantities corresponding to $98.7 \%$ decongositson of the alkyl; this ahowed that no methyl radicals were renoved by sice reactions. Fuxthernore, the 4. fector of reaction (o) may be calculated fros the results of Szware 5 and reasonable estinates of the entroples of the methyl and benzy 3 racicals $s^{6}$. Hence $i t$ is round that $A_{6}=10^{9.5}$ mole $^{-1} \mathrm{~cm}^{3} \mathrm{sec}^{-1}$ which is the meximum posetble velue of $\mathrm{k}_{\mathrm{g}}$. A reection with such a 10w aste constant cannot corpete stceessfully with reactions (3) or (4).

The rate constants for the decompositions depend mexkedy on the 
total pressure in the reaction systen, This is shown in Fig. 1. The reactions are obviousiy being investigated under conditione such that the rete of exexcy trensfer is not surrictent to mointein the high pressure rate conotant. This is to be expected for molecties conteining only three heavy atons. Accordingly the mejority of the runs with each alkyl were done near one pressure and corrected to this selected pressure by making use of the empirically deteriined relation betwees the rate contants and the pressure.

Values of $\mathrm{kg} / \mathrm{ks}_{\mathrm{e}}$ were derived from the quantities of nethane and ethane formed and the pressure of tolusene. It was found that this retio also depended upon pressure as is showa in Fig. 1. The variation must be abcribed to the varlation in $\mathrm{k}_{4}$ as $\mathrm{k}_{3}$ should not depend upon pressure. This veritetion of $\mathrm{k}_{4}$ with pressure bas been observed in stucies of the photolysts of acetone at lower tergeretures but also at 20 wer pressures, ${ }^{7,8}$. This is in cualttative agreenent with the predictions of the theory of uninolectules reactions 9

Axrhenius plots of the rate constants exe givers in Fig. $z_{0}$ The straight lines correspond to:

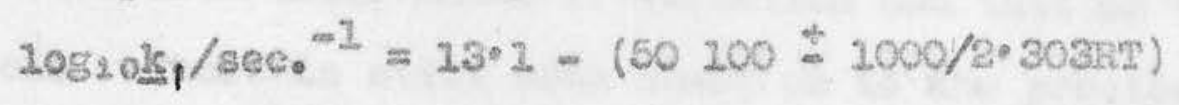

for al ethyl mercury at 26 man pressure:

$$
\log _{10 \mathrm{~L}_{1}} / \mathrm{sec}^{-1}=11.9-(45800 \pm 1000 / 2 \cdot 303 \mathrm{RT})
$$

for dinethyl cadmium at $18 \mathrm{~mm}$ pressure

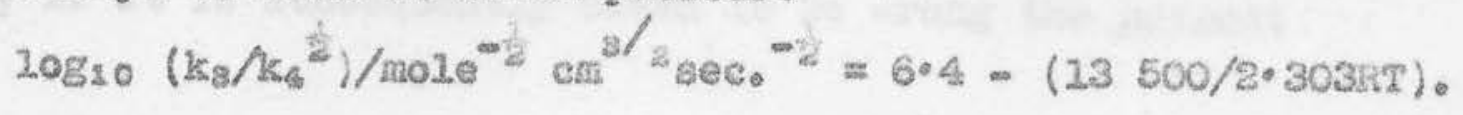


The results with dinethyl mercury are in excellent agreement with those of eerifier workers.

The coneequences of studying the reactions at pressures at which the rates are a function of pressure aust be examined before eextain conclustons can be drewn Prom these zesults. High pressure A. fector's cammot be deanced the true A factors my be anything up to ten times the A factore in these Arrhentus equations. Activation energtea depend much less markedly upon pressure. The activation energies at high pressures are unlikely to be more than 1 kcal grebter than those given here. $I_{4}=0$ okes. wole ${ }^{-1}$ at high pressures, consequently it should have a negative value (though probab1y a sme11 one) under the present conditions. $\mathbb{E}_{4}$ would certatinly not be expected to be sufficiently low to reconelle the present values of $\mathrm{k}_{2} / \mathrm{ks}_{4}$ with those deternined at lower tenperatures? Probably the values given here are not very reliable because of difreulties assochated with the precise definition of the reaction voluive.

The sun of the boxd strexgthis in these mettallic alky 1 s may be caleviated from theis heats of formation and that of the methyl radical. There is still some doubt as to the prectse strength of the C-II bond in methane. $D\left(\mathrm{CH}_{3}-\mathrm{H}\right)$ moy however be conveniently taken to be $202 \cdot 5 \mathrm{keal} \cdot$ mole $e^{-1}$ no exror need then be assigned to this velue if it is subsequentiy shown to be wrong the present 
caleulations may readily be adjusted. If the reasured activation energles are equated with the dissociation energies of the firgt aethylacaxbon bonds $\left(D_{2}\right)$, the following table mey be compileds

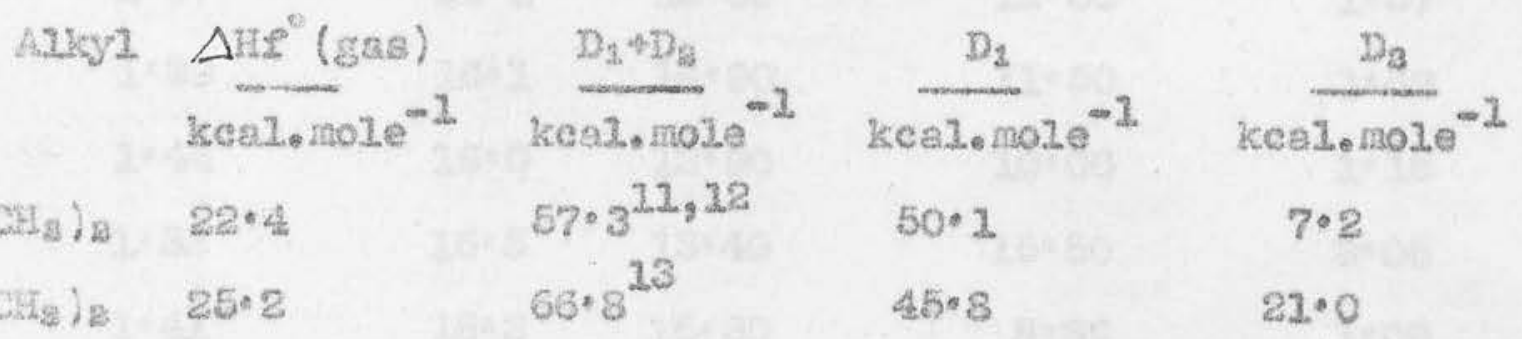

In construeting this table two essumptions are tacitiy made. First, that the metal aton released in the deconposition is in its ground electroxic state. Second, that the addition of a methyl redicel to a metel stom (reectione2) is a process with zero energy of activations Blther or both of these assunptions may be invalid. $D_{8}$ must therefore be regarted as a mintinum value, On the other hand these values of $\mathrm{D}\left(\mathrm{X}-\mathrm{CH}_{3}\right)$ are high cormared with the known values of $D(x-i H)$, that is for mereury and ken womole ${ }^{-1}$ for cacmiun ${ }^{14}$. A furz discusetion of the significance of these results may be postponed unil more netallic alkyls have been investigated. 
gable 2. The Pyrolysila of Damethyl Mercury.

Bux

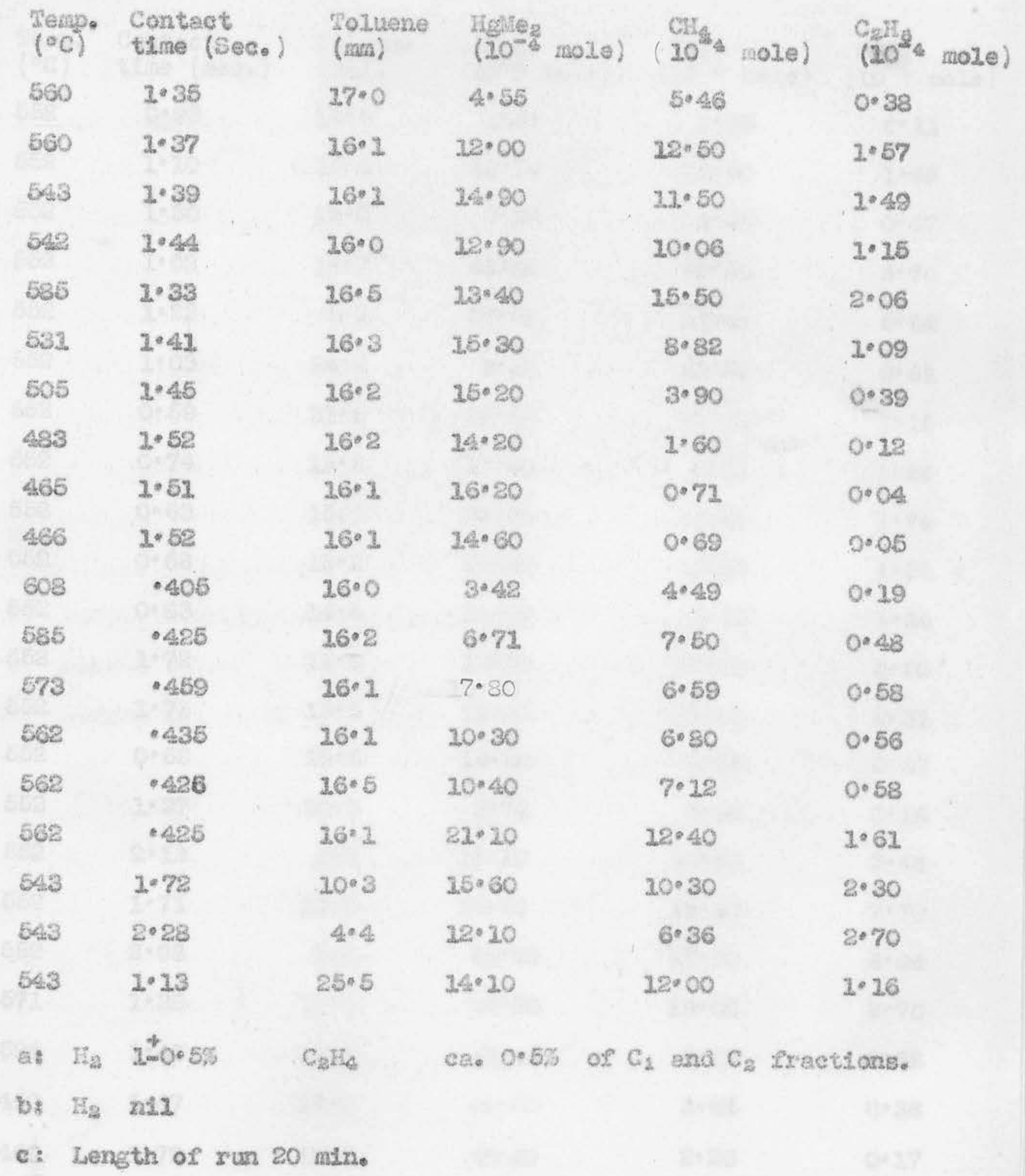


Table 2. The Pyrolysis of Dimethyl Cadmium.

\begin{tabular}{|c|c|c|c|c|c|}
\hline $\begin{array}{l}\text { Temp. } \\
(\circ \mathrm{C})\end{array}$ & $\begin{array}{l}\text { Contact } \\
\text { time (sec.) }\end{array}$ & $\begin{array}{l}\text { Toluene } \\
\text { (mm) }\end{array}$ & $\begin{array}{l}\text { Callea } \\
\left(10^{-4} \text { Miole }\right)\end{array}$ & $\left(10^{\mathrm{CH}_{4}}\right.$ mole $)$ & $\left(10^{-2}\right.$ mole $)$ \\
\hline 552 & $0 \cdot 93$ & $15 \cdot 6$ & $1 \cdot 52$ & 0.88 & $0 \cdot 11$ \\
\hline 552 & $1 \cdot 10$ & $15 \cdot 6$ & $18 \cdot 70$ & $12 \cdot 60$ & $1 \cdot 55$ \\
\hline 552 & $2 \cdot 30$ & $18 \cdot 2$ & $9 \cdot 20$ & $8 \cdot 80$ & 0.57 \\
\hline 552 & $1 \cdot 02$ & $18 \cdot 7$ & $48 \cdot 80$ & $28 \cdot 50$ & $6 \cdot 70$ \\
\hline 552 & $1 \cdot 23$ & $5 \cdot 2$ & $27 \cdot 40$ & $10 \cdot 80$ & $5 \cdot 64$ \\
\hline 552 & $1 \cdot 03$ & $24 \cdot 4=$ & $9 \cdot 66$ & $10 \cdot 50$ & $0 \cdot 41$ \\
\hline 552 & 0.59 & $21 \cdot 8$ & $25 \cdot 60$ & $15 \cdot 90$ & $1 \cdot 15$ \\
\hline 552 & 0.74 & $13 \cdot 2$ & $17 \cdot 20$ & $8 \cdot 60$ & $1 \cdot 28$ \\
\hline 552 & 0.63 & 1514 & $26 \cdot 60$ & $14 \cdot 40$ & $1 \cdot 74$ \\
\hline 552 & $0 \cdot 68$ & $13 \cdot 8$ & $21 \cdot 60$ & $11 \cdot 10$ & $1 \cdot 55$ \\
\hline 552 & 0.83 & $14 \cdot 4$ & $14 \cdot 90$ & $8 \cdot 40$ & $1 \cdot 34$ \\
\hline 552 & $1 \cdot 72$ & $18 \cdot 0$ & $19 \cdot 30$ & $18 \cdot 60$ & $2 \cdot 22$ \\
\hline 552 & $1 \cdot 73$ & $18 \cdot 6$ & $19 \cdot 30$ & $17 \cdot 80$ & $2 \cdot 31$ \\
\hline 552 & 0.62 & $18 \cdot 6$ & $16 \cdot 30$ & $8 \cdot 85$ & 0.87 \\
\hline 552 & $1 \cdot 37$ & $20 \cdot 0$ & $3 \cdot 78$ & $3 \cdot 94$ & $0 \cdot 16$ \\
\hline 552 & $2 \cdot 13$ & $6 \cdot 3$ & $18 \cdot 10$ & $10 \cdot 90$ & $3 \cdot 48$ \\
\hline 552 & $1 \cdot 71$ & $10 \cdot 0$ & $19 \cdot 90$ & $15 \cdot 10$ & $3 \cdot 70$ \\
\hline 552 & $2 \cdot 08$ & $5 \cdot 8$ & $22 \cdot 20$ & $12 \cdot 30$ & $6 \cdot 06$ \\
\hline 571 & $1 \cdot 38$ & $17 \cdot 0$ & $17 \cdot 30$ & $19 \cdot 00$ & $2 \cdot 70$ \\
\hline 524 & $1 \cdot 43$ & $18 \cdot 3$ & $14 \cdot 40$ & $6 \cdot 83$ & $0 \cdot 68$ \\
\hline 490 & $1 \cdot 47$ & $17 \cdot 5$ & $23 \cdot 00$ & $3 \cdot 64$ & $0 \cdot 32$ \\
\hline 469 & $1 \cdot 72$ & $18 \cdot 6$ & $24 \cdot 90$ & $2 \cdot 20$ & $0 \cdot 17$ \\
\hline 469 & $5 \cdot 55$ & $19 \cdot 9$ & $14 \cdot 90$ & $3 \cdot 62$ & 0.47 \\
\hline
\end{tabular}


Table 2 continued.

\begin{tabular}{|c|c|c|c|c|c|}
\hline $\begin{array}{l}\text { Tenpo } \\
\text { (oc) }\end{array}$ & $\begin{array}{l}\text { Contact } \\
\text { Aline (sec.) }\end{array}$ & $\begin{array}{l}\text { 2oluene } \\
\text { (ma) }\end{array}$ & $\begin{array}{l}\text { Cartes }_{3} \\
\left(10^{-4} \text { Mole }\right)\end{array}$ & $\left(10^{-3}\right.$ mole) & $\begin{array}{l}\mathrm{C}_{2^{2}{ }_{6}} \\
\left(10^{-6} \text { mole }\right)\end{array}$ \\
\hline 501 & $5 \cdot 57$ & $1.3 \cdot 5$ & $14 \cdot 30$ & $8 \cdot 34$ & $1 \cdot 65$ \\
\hline 524 & $3 \cdot 47$ & $16 \cdot 5$ & $1.9 \cdot 90$ & $14: 80$ & $3 \cdot 30$ \\
\hline 522 & $4 \cdot 03$ & $17 \cdot 6$ & $20 \cdot 70$ & $9 \cdot 60$ & $0 \cdot 93$ \\
\hline 480 & $8 \cdot 05$ & $19 \cdot 3$ & $21 * 20$ & $8 \cdot 48$ & $2 \cdot 16$ \\
\hline 469 & $6 \cdot 60$ & $29 \cdot 3$ & $20 \cdot 00$ & $5 \cdot 30$ & 0.87 \\
\hline 572 & $0 \cdot 64$ & $27 \cdot 0$ & $22 \cdot 22$ & $17 \cdot 80$ & $2 \cdot 23$ \\
\hline 517 & $3 \cdot 42$ & $18: 8$ & $79 \cdot 20$ & $12 \cdot 80$ & $2 \cdot 17$ \\
\hline 508 & $3 \cdot 00$ & $19 \cdot 0$ & $24 \cdot 20$ & $10 \cdot 70$ & $1 \cdot 97$ \\
\hline
\end{tabular}

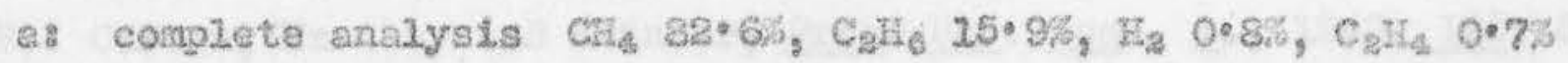
b: packed vessed.

c: $\mathrm{H}_{2} \quad 1.25 \pm 0.25 \%$ of $C_{1}$ fraction.

di Length of rus 20 mins 
Table a continued.

\begin{tabular}{|c|c|c|c|c|c|}
\hline $\begin{array}{l}\text { genp: } \\
\left({ }^{\circ} \mathrm{c}\right)\end{array}$ & $\begin{array}{l}\text { Contact } \\
\text { t.ine (sec.) }\end{array}$ & $\begin{array}{l}\text { Toluene } \\
\text { (mai) }\end{array}$ & $\begin{array}{l}\mathrm{Calle}_{3} \\
\left(10^{-4} \text { Hole }\right)\end{array}$ & $\left(10^{-/ 4}\right.$ mole & $\begin{array}{c}\mathrm{C}_{2} \mathrm{H}_{6} \\
\left(10^{-4}\right. \\
\text { mole }\end{array}$ \\
\hline 501 & $5 \cdot 57$ & $18 \cdot 5$ & $14 \cdot 30$ & $8 \cdot 34$ & $1 \cdot 65$ \\
\hline 524 & $3 \cdot 47$ & $26 \cdot 5$ & $3.9 \cdot 90$ & $14: 80$ & $3 \cdot 30$ \\
\hline 522 & $4 \cdot 03$ & $17 \cdot 6$ & $30 \cdot 70$ & $9 \cdot 60$ & 0.98 \\
\hline 490 & 5.05 & $29 \cdot 3$ & $21 \cdot 20$ & $8 \cdot 48$ & $2 \cdot 16$ \\
\hline 460 & $6 \cdot 60$ & $10 \cdot 3$ & $20 \cdot 00$ & $5 \cdot 30$ & 0.87 \\
\hline 572 & 0.64 & $27 \cdot 0$ & $22 \cdot 22$ & $17 \cdot 80$ & $2 \cdot 23$ \\
\hline 517 & 3.42 & $18 \cdot 9$ & $19 \cdot 10$ & $12 \cdot 80$ & $2 \cdot 17$ \\
\hline 503 & $3 \cdot 00$ & $19 \cdot 0$ & $24 \cdot 20$ & $10 \cdot 70$ & $1 \cdot 97$ \\
\hline
\end{tabular}

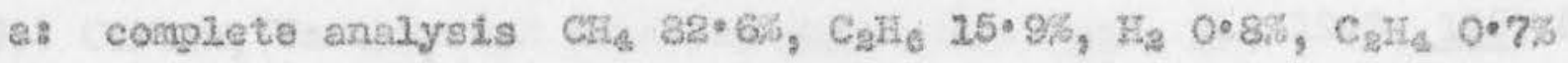

b: packed vessel

c: $\mathrm{H}_{2} \quad 1.25 \pm 0.25 \%$ of $C$, fraction.

di Length of rus 20 mins 


$$
-13=
$$

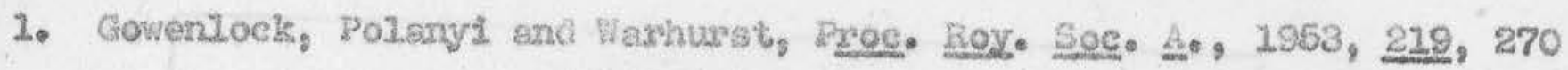

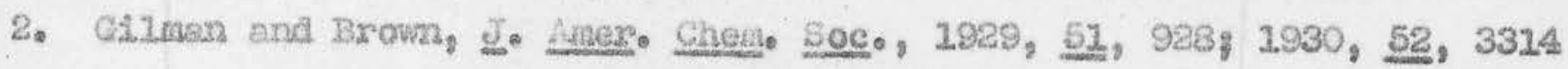
3. Amdereon and Teylor, do Phys. Chem, 1962, 56, 151

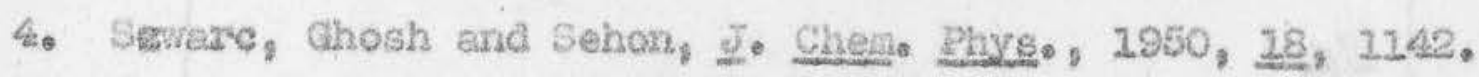

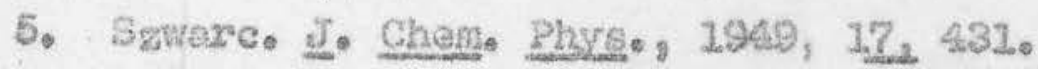

6. Trotmenmicicenson, J. Chem. Phxs, 1053, 21, 211.

7. K2atiakowsiky and Roberts, 1bide, 1953, 21, 1637.

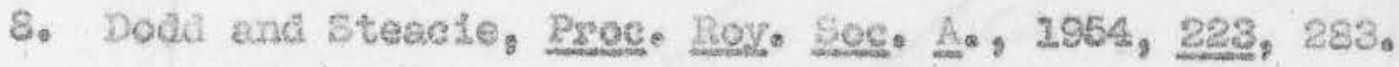

9. Jrotmen-DLcisenson, Ges Kineties, Butterworths, London, 1955.

10. Trotmen-Dickenson and Steacie, L. Cheg: Phys., 1951, 29, 329.

12. Eext3ey, Pritcherd and \$kinner, Ireas. Saradgy Soc., 1950, 46, 1019. 12. Cerson, Carson and Wimshurst, Heture, 1952, 170, 320.

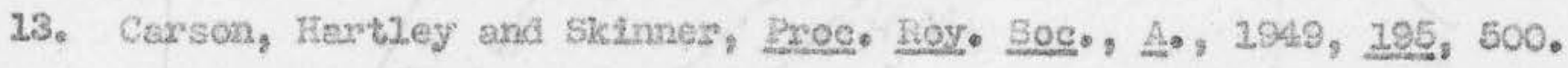
We also Trans. Eareday 5oc, $1949,45,1159$.

14. Cottre11. The Strength of ChemLed Bonds, Butterwoxths, London, 1954. 


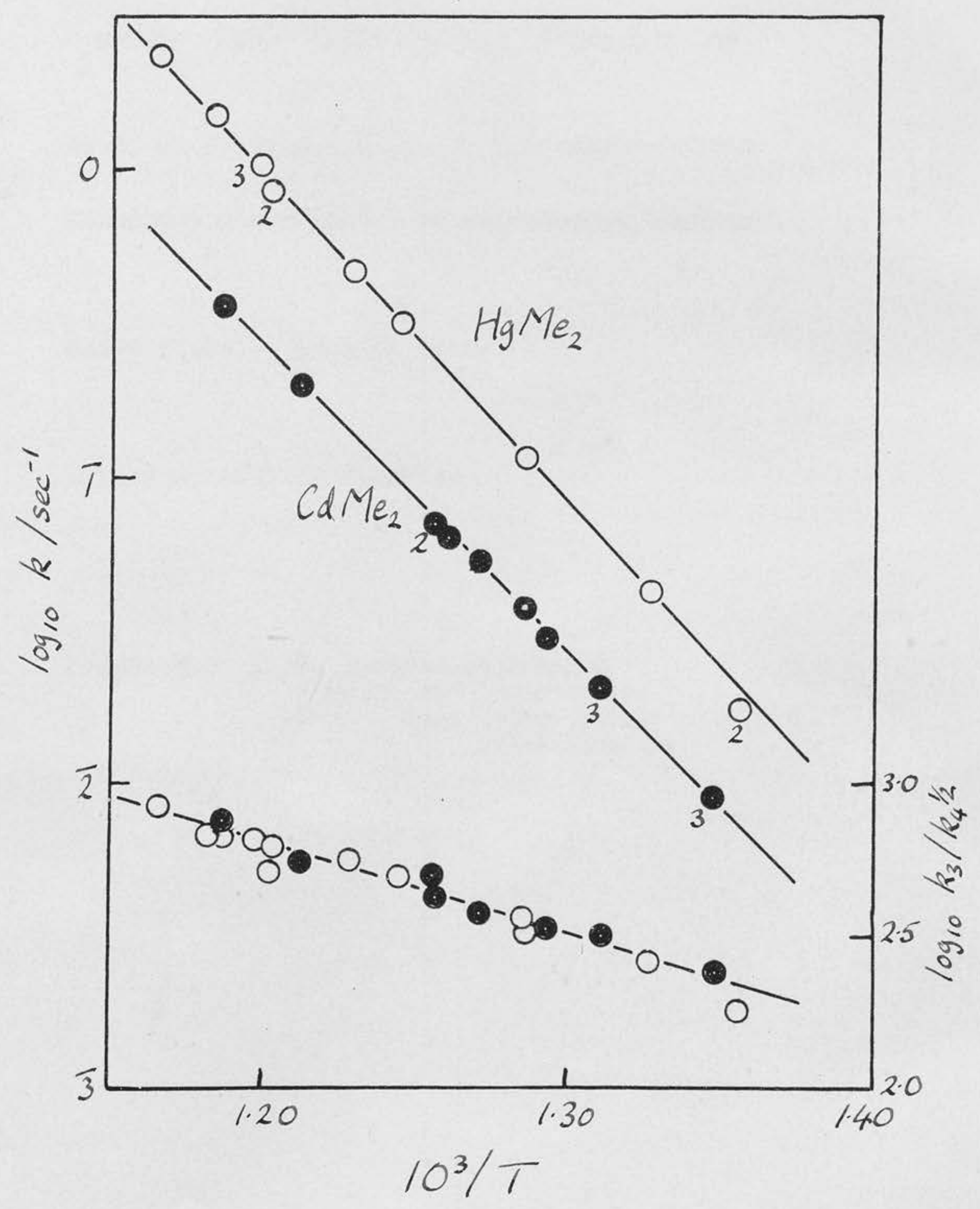

Fig 2 


\section{METAL-CARBONY BONDS 2. WHE PYROLYSIS OF \\ DIMFPHY, ZINC.}

by S. J. W. Price and A. F. Trotman-Dickenson

Chemistry Department, The Univexsity, Easnburgh.

Short title: Dimethyl Zine.

Illustrations: 2 flgures.

Proofs to: A. F. Trotunan-Dickenson, Chernistry Depertment, West Mains Koad, Edinburgh, 9. 
The themal decomposition of dimethyl zinc has been studied by the toluene carrier technique between 573 and $827^{\circ} \mathrm{C}$. The progress of the reaction was rollowed by measuring the hyarogen, methane, ethylene and ethane formed. The decomposition occurs in two steps

$$
\mathrm{Zn}\left(\mathrm{CH}_{3}\right)_{2}=\mathrm{ZnCH}_{3}+\mathrm{CH}_{3}
$$

folzowed by $\mathrm{ZnCH}_{3}=\mathrm{Zn}+\mathrm{CH}_{3}$

$$
\begin{aligned}
& \log _{20} \mathrm{k}_{1} / \mathrm{sec}^{-1}=11.25-(47200 \pm 1000 / 2.303 \mathrm{RT}) \text { at } 16 \mathrm{~mm} \\
& \log _{10 \mathrm{k}} / \mathrm{sec}^{-1}=6.8-(35000 / 2.303 \mathrm{RT}) \text { at } 16 \mathrm{~mm}
\end{aligned}
$$

Both rate constants are markedly dependent on the pressure in the system. The activation energies may be equated with the bond strengths, hence $D_{2}=47.2, \quad D_{3}=35, \quad D_{2}+D_{2}=82$ k. eal.mole ${ }^{-1}$. Themochemistry yields $D_{2}+D_{R}=82.9 \mathrm{kcal} \cdot \mathrm{mole}^{-1}$. 
The surst paper in this series'described the themal decomposition of dimethyl mercury and dimethyl cadmium.

The present paper on the decomposition of almethyl zinc completes the study of the alkyls of sultable group II metals. No previous investigetion of this pyrolysis has been reported.

\section{EXPERTMTW2AI。}

MATIRIALS. - Dimethyl zine was prepared by the resction of methylfodide with a freshly prepared atnc-copper couple $e^{2} 3$. Traces of methyl lodlde were renoved from the erude product by passing the vapour flve times over a fresh portion of the couple at $150^{\circ} \mathrm{C}$. A fraction boliling between $46.4^{\circ}$ and $46.5^{\circ} \mathrm{C}$, at $758 \mathrm{~mm}$. was collected. Three weighed samples were decomposed with afrowater or alr alone and the restarul methyl lodide deternined by gas chromatography. Notall the methyl 1odide was renoved but 1 amounted to considerably less than $1 \%$ of the semples. The alkgl was stored under vacuum at $-196^{\circ} \mathrm{C}$.

APPARAFUS。 - The apparatus and procedure were essentially the some as those employed in Part $1^{1}$.

\section{RESULTS AND DISCUSSTON.}

The complete experimental results are given in Table 1. Their satiafactory interpretation depends upon the selection of the correct mechanism for the system. 
It was expected that the mechenim for the decomposition of dimethylaine would be very similar to that for the decomposition of dimethyl mercury and dimethyl cadntum:

$$
\begin{aligned}
\mathrm{Zn}\left(\mathrm{CH}_{3}\right)_{2} & =\mathrm{ZnCH}_{3}+\mathrm{CH}_{3} \\
\mathrm{ZnCH}_{3} & =\mathrm{Zn}+\mathrm{CH}_{3} \\
\mathrm{CH}_{3}+\mathrm{C}_{6} \mathrm{H}_{6} \mathrm{CH}_{3} & =\mathrm{CH}_{4}+\mathrm{C}_{6} \mathrm{H}_{5} \mathrm{CH}_{8} \\
2 \mathrm{CH}_{3} & =\mathrm{C}_{2} \mathrm{H}_{6} \\
2 \mathrm{C}_{6} \mathrm{H}_{5} \mathrm{CH}_{2} & =\left(\mathrm{C}_{6} \mathrm{H}_{5} \mathrm{CH}_{2}\right)_{2}
\end{aligned}
$$

The $\mathrm{XCH}_{3}$ radicel formed by the othex two alkyls decomposed so raplay that it could be assumed that two methyl radicals were formed from each molecule that underwent reaction (1). Fowever, $1 t$ was soon found that this assumption was not tenable for alnethyl zinc. It appeared that even as high as $670^{\circ} \mathrm{C}$, reaction (2) did not occur to any great extent under the prevaliling condtitions. OnIy above $730^{\circ} \mathrm{C}$. was reaction (2) an important source of methyl radioal. Accordingly the decompositions of dimethyl zine andnethyl alne were treated as suecessive reactions. At the highest temperatures Q.11 the dimethyl zine was converted to methyl zine in a very amall Praction of the contact time. The rate of decomposition of methyl. zinc could then readily be determined; the only interference ceme from the decomposition of the toluene carrier. At low temperatures the decomposition of methyl zine was negligible and the decomposition of dimethyl zinc could be simply treated as a unimolecular reaction yielding one methyl radical. At internediate temperatures the appropriate treatment for successive reactions of comparable rate had to be applied. The detalled methods of calculating were as 
as follows:

(a) The high temperature ranges ( $\left.\underline{k}_{2}\right)$. The amount of $\mathrm{CH}_{4}$ produced was found by anelysis of the $\mathrm{CH}_{4}-\mathrm{H}_{\mathrm{g}}$ fraction, a correction then had to be applied for the $\mathrm{CH}_{4}$ produced by the decomposition of the toluene earrier. This correction was obtained from stware's ${ }^{4}$ expression for the rate constant

$$
\log _{10} \mathrm{~K} / \mathrm{sec}^{-1}=13.5-(77500 / \mathrm{RT}) \text {, }
$$

assuning that the ratio of $\mathrm{H}_{2}$ : $\mathrm{CH}_{4}$ produced was in the ratio of 1.5:1. An experiment on the pyrolysis of pure toluene at $783^{\circ} \mathrm{C}$. ylelded a value of $\mathrm{K}$ in good agreementwith this expression; the ratio $\mathrm{H}_{\mathrm{g}}$ : $\mathrm{CH}_{4}$ was eractly $1.5: 4$. The percentage decomposition of methyl zine was thenequal to $\frac{\text { corrected moles of methane }+2 \times \text { moles of ethane } \times 100}{\text { moles of dimethyl zine used. }}-100$ First-order rate constants were calculated from these percentage decompositions. This calculation implies that the dimethyl zine is converted to methyl aine immediately it enters the reaction zone.

(b) The low temperature range $\left(\mathrm{k}_{1}\right)$. $\mathrm{k}_{1}$ was calculated from the usual formula for buccessive unimolecular reactions:

$$
\mathrm{CH}_{4}+2 \mathrm{C}_{2} \mathrm{H}_{6}=\mathrm{Zn}\left(\mathrm{CH}_{3}\right)_{2} \text { used }\left\{2-\frac{k_{1}}{k_{1}-k_{2}}\left(e^{-k_{1} t}+e^{-k_{2} t}\right)\right\}
$$

The equation was solved for $x_{1}$ by the method of successive approximetions. The values obtained were not very sensitive to the value selected for $\underline{k}_{2}$ as the percentage decomposition of the Znchs was of the order of $1 \%$ at $597^{\circ} \mathrm{C}, 3 \%$ at $648^{\circ} \mathrm{C}$, and 6, at $701^{\circ} \mathrm{C}$. 
5 (cont)

The method of calculation depends upon the assumption that the zinc methyl radicals which do not decompose do not react in any other way while within the decomposition reaction zone. Presumably they eventually form stable saturated molecules in some cooler portion of the apparatus. No alternative assumption that was in accordance with the experimental findings and involved plausible reactions could be discovered. 
6.

The ratios $\underline{\underline{k}}_{3} / \underline{k}_{4}{ }^{\frac{1}{2}}$ were determined in the usual. way assuming that the reactions took place unlformly throughout the reaction zone.

The rate constants $\underline{k}_{2}, \underline{k}_{2}$ and the ratio $\mathfrak{k}_{3} / \mathrm{k}_{4}{ }^{\frac{1}{2}}$ were found to be maxixedly dependent upon the total pressure in the reaction system, as shown in Fig. 1. This was not due to any heterogeneous reaction. Packing the vessel with silica tubing so as to increese the surface:volume ratio by a factor of five had no appreclable effect on the rates as is shown in Figure $\mathscr{q}_{0}$ So that the rate constants might be comparable, all that were determined in the region of $16 \mathrm{~mm}$. pressure were corrected empirically to $16 \mathrm{~mm}$. pressure. The resulting values of the rate constants, together with four determined at $5 \mathrm{~mm}$. pressure, are plotted on an Arrhenius diegram (Fig. 2). At $16 \mathrm{mn}$. total pressure

$$
\begin{aligned}
& \log _{10} \underline{k}_{a} / \mathrm{sec}^{-1}=11.25-(4.7200 \pm 1000 / R T) \\
& \log _{10 \mathrm{ka}} / \mathrm{sec}^{-1}=6.86-(35000 / \mathrm{RT}) \text {, and at low tempera. }
\end{aligned}
$$
tures $\log _{10}\left(k_{0} / \mathrm{s}_{4}\right) \operatorname{mol}^{-\frac{1}{2}} \mathrm{~cm}^{3 / 2} \mathrm{sec}^{-\frac{1}{2}}=6.30-(13000 / \mathrm{RT})$. At 5 mo total pressure

$$
\log _{20} \mathrm{k}_{\mathrm{a}} / \mathrm{sec}^{-1}=11.03-(47300 / \mathrm{RT})
$$

The values of $\underline{k}_{1}$ and $\underline{A}_{1}$ at infinite pressure could only be determined. from experiments over a far wider range of pressures than could be reached with our apparatus. Reaction (2) was apparently studied. in 1ts 'second-order' region; that $1 \mathrm{~s}, \underline{\mathrm{k}}$ is afrectly proportional to the total pressure as is shown in Fig. 1. If toluene and zlne methyl are equaliy effective in energy transfer, then the rate 


\section{7.}

constant may be written

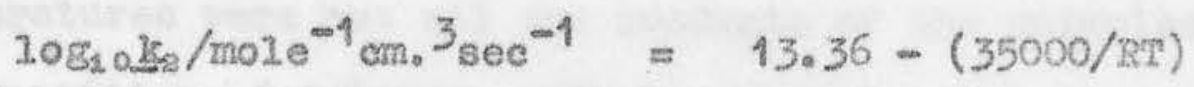

The values of $\mathrm{k}_{\mathrm{s}} / \mathrm{k}_{\mathrm{s}}{ }^{\frac{4}{2}}$ obtained at high temperetures are clearly not consistent with those at lower temperatures. The reliability of both sets of deteminations of the rate constents is doubtrul because of the difficulty of defining the reaction zone. However, the low temperature results and the variation with pressure are in excellent agreement with those obtained with dimethyl mercury and dimethyl eadmium ${ }^{1}$.

The tests which can be spplied in a flow system to demonstrate the adequacy of a mechanism are rather $11 \mathrm{mited}$. This is especially so when, as in the present case, the rates of the unimoleculax reactions are partially determined by the rate of energy transfer. Those tests which were applicable confirmed the mechanism.

From the quantity of methane (corrected) and ethane formed 1t was deduced that $98 \%$ of the possible number of nethyl radicels were released in passing dimethyl zinc through the systen at $812^{\circ} \mathrm{C}$. with a contact time of 6 seconcs. The proportion that may be derived from the rate constants given above is $98.5 \%$. This is direct eviaence that reaction (6) is unimportanto. As a further check the

$$
\mathrm{C}_{6} \mathrm{H}_{5} \mathrm{CH}_{2}+\mathrm{CH}_{3}=\mathrm{C}_{6} \mathrm{H}_{5} \mathrm{C}_{9} \mathrm{H}_{5}
$$

contret time was vaxied by approximately a factor of ten in one sertes of runs $(1-45)$.

The rather 1 arge guantities of hydrogen fomed at the higher 
8.

temperatures vere not 0.11 the products of the unimolecular decomposition of toluene. It is possible that they were formed by the decomposition of benzyl. radicals and of dibenzyl. A mal1 quant1ty is probably formed by the decomposition of ethene into ethylene and hydrogen. Por this reason the othylone was treated as ethene in ealculating the pate constants. If this Is unjustifiable the error introduced is mall because the $\mathrm{C}_{2}$ fraction is mach smaller then the amount of methane.

The apparent activation energy of a unimolecular reaction 1 s a function of the pressure at which it is deternined if the rate of the reaction is itself a function of pressure. However, for small moleeules the difference between the activation energies determined in the 'second order' region and at high pressures is not greate Until more information is avallable it is reasonable to auppose that the activation energies found at $16 \mathrm{~mm}$ differ 1ittle from the high pressure values. These activation energies may be equated with the heats of reaction if the back reactions (conbination of atoms and redicala) have no activation energies. Onthis assumption the following values of the bond strengths may be obtained

$$
\begin{aligned}
& \mathrm{D}\left(\mathrm{CH}_{3}-\mathrm{ZnCH}_{3}\right)=D_{4}=47.2 \pm 1 \mathrm{k} \mathrm{cal} \cdot \mathrm{mole}^{-1} \\
& \mathrm{D}\left(\mathrm{Kn}-\mathrm{CH}_{3}\right)=\mathrm{D}_{8}=35 \mathrm{k} \mathrm{cal} . \mathrm{mole}
\end{aligned}
$$

No useful egtimate of the probable error of the second value can be made ( 3 to $5 \mathrm{k}$ eal.mole $e^{-1}$ is probably a pair flgure). 
Hence, $D_{1}+D_{2}=82 \mathrm{k} \mathrm{cal} \cdot \operatorname{mole} e^{-1}$

This cuantity may also be derived from the heat of formation of dimethyl zind ${ }^{5}\left(-13.3 \mathrm{k} \mathrm{cal} . \mathrm{mole}^{-1}\right)$, of the zinc atom and of the methyl redical (based upon $\mathrm{D}\left(\mathrm{CH}_{3}-\mathrm{H}\right)=102.5 \mathrm{k}$ cel. mole ${ }^{-1}$. From these quantities

$$
D_{3}+D_{2}=82.9 \mathrm{k} \mathrm{cal} \cdot \mathrm{mole} \mathrm{e}^{-1} \text {. }
$$

The agrecment with the kinetic estimate is meaninglessly good as exrors ofta $\mathrm{k}$ cal.mole-1 shoula be assigned to both figures. However, they do Indicate that when dimethyl zine decomposes, the zine atom is released in its ground state.

The results which have been obtalned from ous studies of the pyrolysis of the dimethyl compounds of the group II metals may be summaxized as follows:

\begin{tabular}{|c|c|c|c|c|}
\hline & $D_{2}$ & 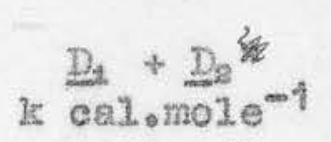 & $D_{2}$ & $2(X-\pi)^{6}$ \\
\hline $\mathrm{HIg}\left(\mathrm{CH}_{3}\right)_{2}$ & 50 & $57.3^{*}$ & 7 & 9 \\
\hline $\mathrm{Ca}\left(\mathrm{CH}_{3}\right)_{\mathrm{B}}$ & 46 & $66.8 *$ & 21 & 16 \\
\hline $\mathrm{Zn}\left(\mathrm{CH}_{3}\right)_{2}$ & 47 & $82(82.9)^{*}$ & 35 & 20 \\
\hline
\end{tabular}

From thermochemistry assuming $\mathrm{D}\left(\mathrm{CH}_{\mathrm{O}}-\mathrm{H}\right)=102.5 \mathrm{k}$ cal. mole $\mathrm{e}^{-1}$.

A fuzl discussion of these figures may be postponed until more experimental results are avaliable. It is, however, interesting in comnection with the problem of $D\left(\mathrm{CH}_{0}-\mathrm{CO}\right)$ and $D(I I-C O)$ to note that for cednium and zinc $D\left(X-\mathrm{Cr}_{8}\right)$ is greater than $D(X-H)$. 
1. Price and Trotmen-Dickenson, Trans. Farnday Soces 1957.

2. Renshaw and Greenlaw, J. Amer, Chem, Soc., 1920, 42, 1472.

3. Banford, LevI and Newitt, J. Chem, Socs, $1946,68,468$.

4. Szware, J. Chem. Physe, 1948, 16, 128.

5. Long and Norrish, Phil. Trans, $1949,24,1 A_{2} 587$.

6. Cottrell, The Strength of Chemical Bonds. 
Table 1. The Pyrolysis of Dimethyl Zine.

\begin{tabular}{|c|c|c|c|c|c|c|c|}
\hline Run & Temp. & Toluene & t & $\mathrm{CH}_{2}$ & $\mathrm{C}_{8} \mathrm{HI}_{6}$ & $\mathrm{H}_{2}$ & znlle $_{2}$ \\
\hline No. & ${ }^{\circ} \mathrm{C}$ & $(\mathrm{mm})$ & (sec) & & $10^{-4}$ & mole & \\
\hline 1 & 597 & $22 \cdot 4$ & 6.74 & 14.40 & 0.73 & - & 18.2 \\
\hline 2 & 597 & 12.5 & 9.00 & 11.70 & 1.25 & - & 17.1 \\
\hline 3 & 597 & 7.2 & 10.85 & $9 \cdot 4.6$ & 2.41 & - & 17.3 \\
\hline 4. & 597 & 28.5 & 4.99 & 13.50 & 0.40 & - & 17.4 \\
\hline 5 & 597 & 16.0 & 4.73 & 11.00 & 0.57 & - & 17.9 \\
\hline 6 & 597 & 9.8 & 5.66 & 9.34 & 0.94 & - & 16.8 \\
\hline 7 & 597 & 26.5 & 3.53 & 10.70 & 0.27 & - & 17.1 \\
\hline 8. & 597 & 6.6 & 6.30 & 8.58 & 1.50 & - & 18.0 \\
\hline 9 & 597 & 16.5 & 1.13 & 3.72 & 0.04 & - & 18.3 \\
\hline 11 & 597 & 5.8 & 1.50 & 4.04 & 0.13 & - & 18.2 \\
\hline 12 & 597 & 4.6 & 1.44 & 2.76 & 0.19 & - & 19.1 \\
\hline 13 & 597 & 10.0 & 1.17 & 3.60 & 0.13 & - & 18.4 \\
\hline 14 & 597 & 16.5 & 0.98 & 12.36 & 0.61 & - & 72.0 \\
\hline 15 & 597 & 16.5 & 0.97 & 6.32 & 0.16 & - & 35.5 \\
\hline 17 & 648 & 16,6 & 0.94 & 12.00 & 0.20 & 0.10 & 19.0 \\
\hline 18 & 672 & 16.8 & 0.89 & 16.60 & 0.28 & 0.15 & 20.0 \\
\hline 19 & 672 & 16.3 & 0.90 & 46.20 & 0.31 & 0.15 & 19.6 \\
\hline 20 & 672 & 5.8 & 1.11 & 13.85 & 0.65 & 0.10 & 19.5 \\
\hline 24 & 672 & 5.3 & 1.15 & 13.60 & 0.70 & 0.10 & 19.2 \\
\hline 22 & 672 & 16.4 & 0.91 & 15.80 & 0.25 & 0.15 & 18.1 \\
\hline 23 & 701 & 16.6 & 0.86 & 18.20 & 0.30 & 0.30 & 18.5 \\
\hline 24. & 701 & 16.5 & 0.86 & 17.10 & 0.31 & 0.30 & 17.7 \\
\hline 25 & 701 & 16.0 & 0.87 & 18.10 & 0.37 & 0.30 & 18.5 \\
\hline 29 & 624 & 16.0 & 0.93 & 4.90 & 0.05 & - & 13.9 \\
\hline $30^{a}$ & 672 & 16.3 & 0.75 & 14.00 & 0.26 & 0.10 & 18.4 \\
\hline $31^{2}$ & 624. & 16.2 & 0.84 & $7 \cdot 30$ & 0.28 & - & 21.4 \\
\hline
\end{tabular}


Table 1. (conto)

\begin{tabular}{|c|c|c|c|c|c|c|c|}
\hline $32^{a}$ & 672 & 16.1 & 0.78 & 14.50 & 0.32 & 0.10 & 18.9 \\
\hline $33^{2}$ & 701 & 16.1 & 0.74 & 17.40 & 0.39 & 0.20 & 13.8 \\
\hline 40 & 658 & 46.3 & 2.06 & $12 * 55$ & 0.29 & 0.15 & 17.0 \\
\hline 44 & 658 & 16.3 & 0.99 & 12.10 & 0.24 & 0.15 & 17.0 \\
\hline 42 & 573 & 16.0 & 1.10 & 1.18 & 0.01 & - & 12.9 \\
\hline 43 & 700 & 16.6 & 0.90 & 17.30 & 0.23 & 0.30 & 47.4 \\
\hline 26 & 730 & 16.6 & 1.01 & 19.9 & 0.44 & 0.60 & 18.2 \\
\hline 27 & 730 & 16.3 & 1.04 & 19.9 & 0.47 & 0.60 & 18.7 \\
\hline $3 t^{2}$ & 755 & 16.8 & 0.72 & 24.6 & 0.56 & 3.00 & 19.7 \\
\hline $35^{a x}$ & 793 & 16.8 & 1.20 & 25.8 & $1.4,0$ & 4.10 & 19.4 \\
\hline $36^{8}$ & 793 & 16.4 & 0.73 & 23.3 & 0.90 & 6.90 & 19.1 \\
\hline $37^{\mathrm{a}}$ & 825 & 16.0 & 0.71 & 25.3 & 1.02 & 11.90 & 18.7 \\
\hline 38 & 827 & 16.0 & 0.90 & 24.67 & 0.97 & 11.90 & 47.8 \\
\hline 39 & 762 & 16.3 & 0.88 & 19.5 & 0.49 & 2.70 & 16.7 \\
\hline 44 & 758 & 16.1 & 0.89 & 19.1 & 0.60 & 2.20 & 17.2 \\
\hline $4.5^{6}$ & 783 & 15.8 & 0.89 & 27.8 & 1.52 & 4.70 & 20.6 \\
\hline 47 & 783 & 6.3 & 0.60 & 20.4 & 0.80 & 2.60 & 17.7 \\
\hline $48^{b}$ & 783 & 9.5 & 1.27 & $22 \cdot 5$ & 1.03 & 3.20 & $17 \cdot 2$ \\
\hline 49 & 783 & 15.8 & 0.95 & 25.8 & 0.77 & 5.70 & 46.9 \\
\hline 50 & 783 & 16.2 & 0.97 & 7.96 & 0.31 & 3.04 & 5.7 \\
\hline $51^{\circ}$ & 825 & 16.2 & 0.91 & 16.85 & 0.74 & 8.95 & 11.2 \\
\hline
\end{tabular}

a: Furs in pecked resction vesed.

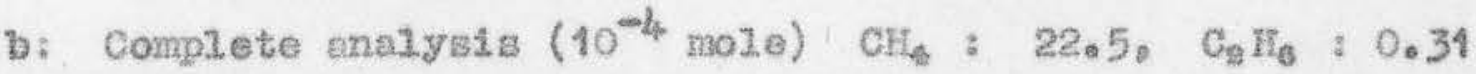
c: Run 20 minutes. $\mathrm{H}_{2}: 3.20, \quad \mathrm{C}_{2} \mathrm{H}_{4}: 0.72$ 


\section{CAPIONS.}

Fig. 1. The variation of the rate constants with pressure. Open eireles: the decomposition of dimethyl zine $\left(597^{\circ} \mathrm{C}\right.$ ) . the decomposition of methyl

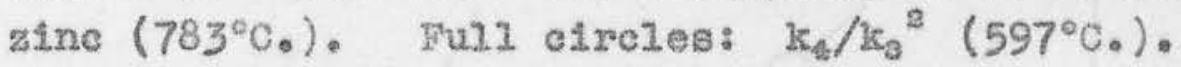

Fig. 2. Arrhenius plots for the decomposition of dimethyl and methyl zine and the reaction of methyl radicals with toluene. The figures beside the points indicate the number of runs averaged to obtain the value plotted; superscripts, runs in a packed vesse1; subscripts, suns in an unpacked vessel. Full circles: $k_{3} / k_{4}^{\frac{1}{2}}$. 


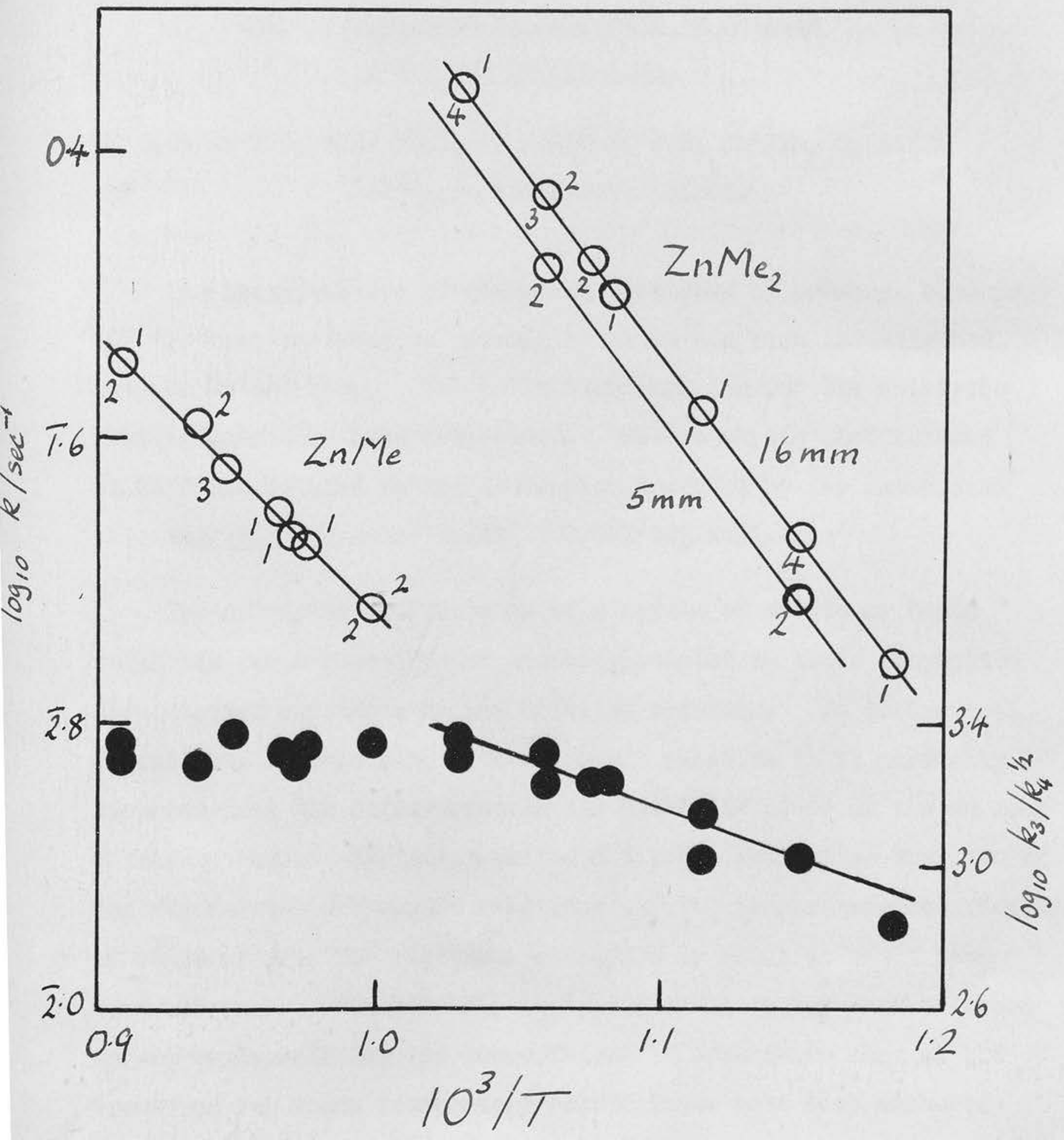

Fig 2. 
Proolis to A.F. Frotman-Dikbenson,

Chenistry Depestuent,

vese Rajins Rosd.

Hilnbargh \%。

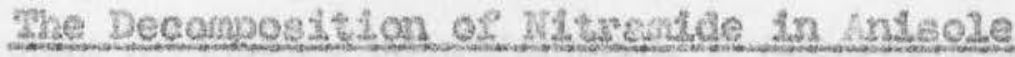

\section{estazysed. by Anjlines.}

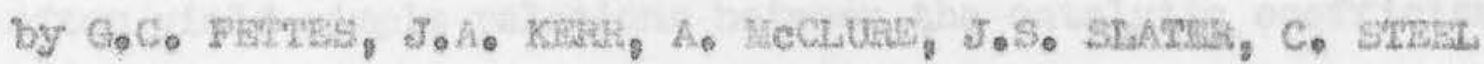

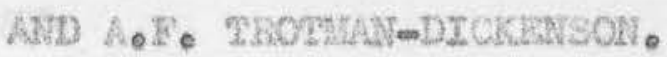

The decamposttion of ziteremide eatajysed by prtmagy, steondery enct cegtiexy enilines in enisole colution hes been investigeted betreen to and $55^{\circ} \mathrm{C}$. The ectivation energies for the cetalytic coefidelents have been detemined. The eatalytle coeficients et $250 \mathrm{c}$ are related to the activation energles by the expression

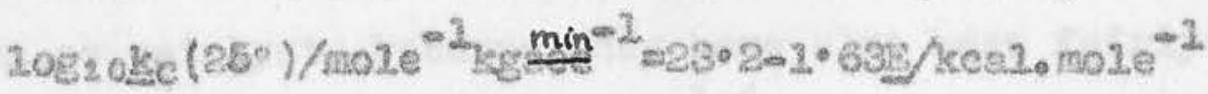

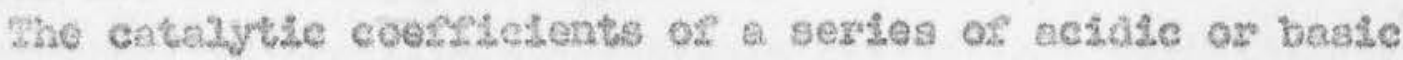
cetelysts for a reaction are romally related to thely respective dissocletion eonstents by the Bronsted reletion In theoretieal discusetone of this kind of sree energy reletion 1t 1 a generally supposed that the differonces in the catalytic power of the various cetalyets can be attributed to the different activation energles of the fundanental protolytic reactions ${ }^{2}$. The tonperature coefrLelerts of comparatively few reactions eatalysed by aclds or bases have been neasured. Conseguenty it Lis asfieult to gay whether there Is axy real. basts for the supposttion. Furtherwore rost of the reactions for whlch temesattre coexlicients heve been measured have been studied in aqueous solution. It is known that ionic 
processes in acueous solution trequently do not conform to the simplest types of energy reletionship. Accordingly it is not surprising thet the results obtained with aqueous solutions do not often yield slmple relations between the catalytic coefficients end activation energy.

This work was undertaken to obtain results in a solvent which does not readily form hydrogen bonds. The decomposition of aitranice was chosen because 1 t hes beer very fuly investigated end may easily be collowed'. Arsisole is a convenient solvent Which may easily be supliclently purleled and in which a consider able anount of woxk has been done. The substituted anilines were chosen as catalyats because they have elso been faixly fully studied and are readily avaliable 104 .

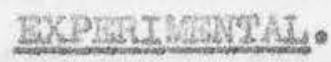

Meterlals. The anisole was dried (CaCha) and fractionated on an $18^{\text {hi }}$ column packed with glass helices. Several batches were purifled ali behaved similaxly. The anlines were distilled over potassiun hydroxide peliets under reduced preavure and stored In seeled contalners. The altremide was prepered by the method of Maxiles, Lamex and Greengpen 5 and stored $12 n$ a zeerigerator as a Bolution in anisole.

Apporatus and Procedure. The rus were cerried out in reaction 
vessels similax to those of Bell and Caldin ${ }^{3}$. The fastex xums were corried out jn vessels with taps, the slower rung were carried out in sealed vessels. The veasels were placed in a glass-fronted thermostat which could be maintained to $00.02^{\circ} \mathrm{C}$ and were agttated by percussion. Ireaction mixtures were made up by veight. Fisst a convenjent quantity of catalyst (or catalyst solution for the stronger bases) vas weighed in a welghing bottle. Surslelent anisole to nake approximately age of mixturs was then adced. Finaly 8 c.c. of nitramide solution was added immedistely before the mixture was introciuced into the reaction vessel.

The rums vere followed by observing the increase in the preseture of the evolved gas. Fixst order plots were then orawn, based or the pressure of gas after complete reaction. In the slowest runs the reaction vessels were pleced in a varm bath to bring the reaction to completion overnight. The rate constants were decuced from the obeervations taiken duxing the firgt two half-lives of the reactions, after which some of the plots talied off. The cetalytic coefilezerts of the bases were found to be a function of the concentration of the solutions. The extrapolations devised by Bel1 and Frotman-Diekenson ${ }^{3}$ were used to obtaln the true coepreients.

\section{BESUT TS.}

The results of the kinetic measurements are shown on the 
Arrhenius plots (Rig. Ia and $1 \mathrm{~b}$ ) which show the cetalytic coefficients from the individual runs and the extrapolations eaployed. The results are sumarized in trable I. Generally the yesults agree very well with those of Bell and Trotman-Dickenson ${ }^{3}$ and Beli. and Caldin". Those obtaired with m-chloraniline are the only exceptions. We can sugest no reason for the discrepancy; the ldentity of the present material was conflrmed by measurement of 1 ts refractive index and of the melting point of 1 ts acetyl derivative. The accuracy of the determination of the activation energies camot be read1y assessed because of the neea for the extrapolation. An exror of $\$ 0.3 k c a l \cdot m o l e^{-1}$ may reasonably be assigned.

\section{DISCUSSTOAs.}

The activation energies of the catalytic coefricient axe plotted against the catalytic coefricient of the various bases et $25 \circ \mathrm{C}$ in $5 \mathrm{Lg}$. 2. All except Q-chloraniline lie on a straight line given by $\log _{10}\left(26^{\circ} \mathrm{C}\right)=23 \cdot 2-1 \cdot 63$. The deviation of the orthosubstituted compound is not surprising? many free energy relationshipe break down for orthomcoinpounds. The slope of the line in Fig. 2 differs maxkedy from thet which would be obtained (shown (atted) If all the aifferences between the catolytic coeficlents coula be attributed to varlations in activation energy. The line representing the variation of $\log _{0} \underline{k}_{c}$ with $\underline{E}$ deviates Irom the 
'theoretical' slope, which corresponds to a constant value of A, for meny series of reactions. Usually the slope is too great, that is Bystematic ehanges in $A$ compengate for the varlations in - In the present reaction the reverse occurs: A Is not constant It veries so as to reinforce the changes in E.

The fact that the activation energies of the primaxy, secondery and tertioxy bases (with the exception of owchloreniline) obey the sente $x^{2}$ letionghip lends sone support to the interpretation of the basic strength of anines, as measured in aqueous solutions, which has been suggested by Bel1 and Trotmen-Dickenson ${ }^{2}, 6$ 


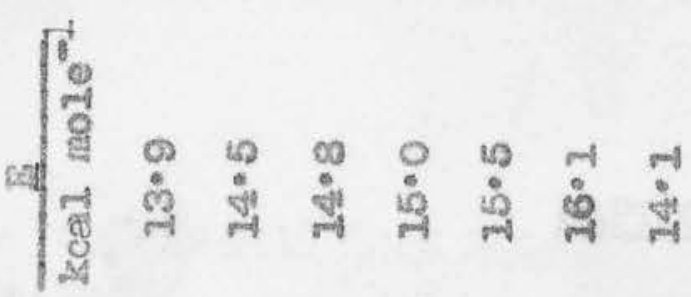

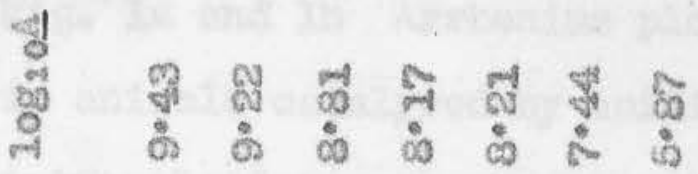

1

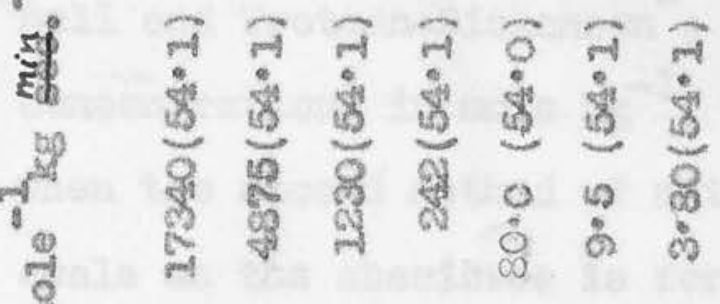

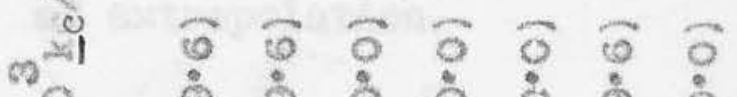

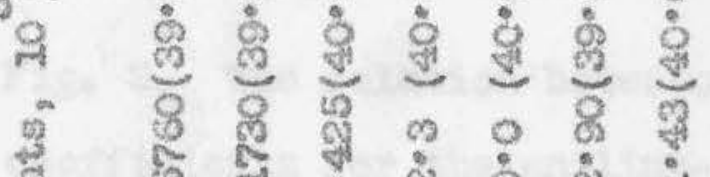

+

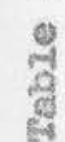

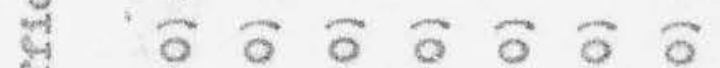

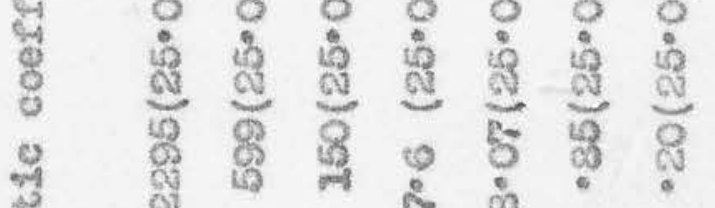

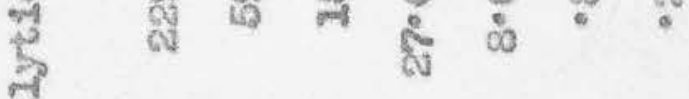

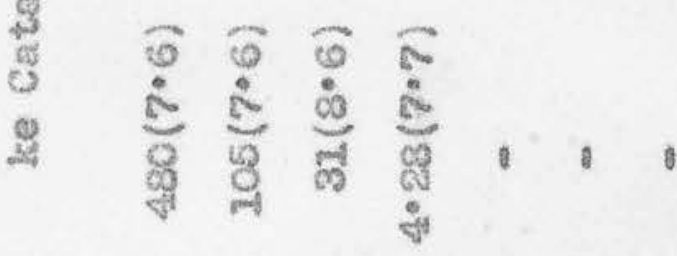

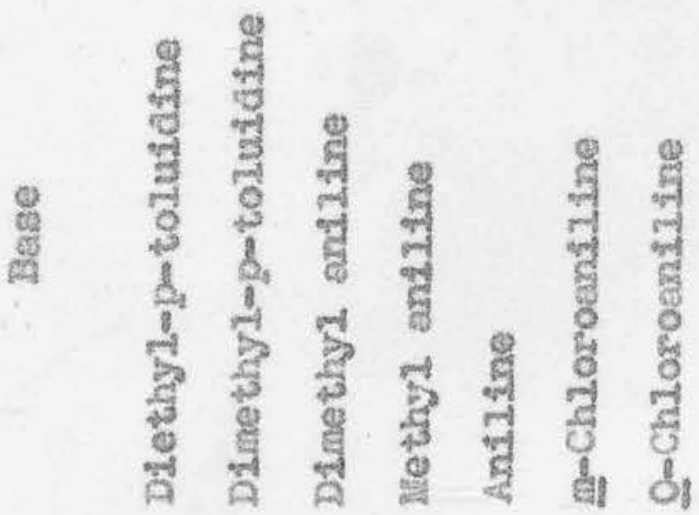




\section{CAPYTONS}

IIg. 12 and ib Azrhenitus plots for the decomposition of nitramide in anisole entalysed by anilines. The individul points and the extrapoletions ore shown. Open cixcless this work, filzed circles: Be11. and Trotmen-Dickenson ${ }^{3}$ sçuares: Bell and Caldin ${ }^{2}$. A11 concentrations in mole $\mathrm{kg}^{-1}$. Inxeept where the scale $1 \mathrm{~s}$ marked b whers the aecond method of extrapolation wes used, the coneentration scole on the abscissae is for $1 / \mathrm{N} b$ corresponding to the first method of extrapolation.

3ig. 2. Lhe relation between ectivation energies and catalytic coefflcients for the antine-catelysed decomposition of nitramide. 
1. Be11, Actä Base Catelysis, Oxford, 2941.

2. Bell and Caldin, Irans, Faraday Soc., 1951, 47, 50.

3. Bell and Trotman-Dlekenson, ปू, 1949, 1288.

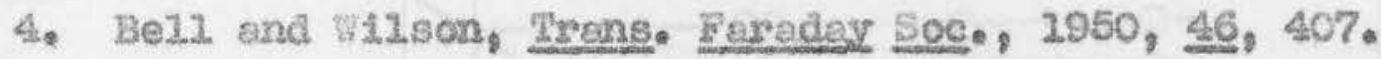

5. Harlies, Lemer and Greensper, Inorganie Symthereg.

6. Trotian-Dickenson, I., 1949, 1293, 


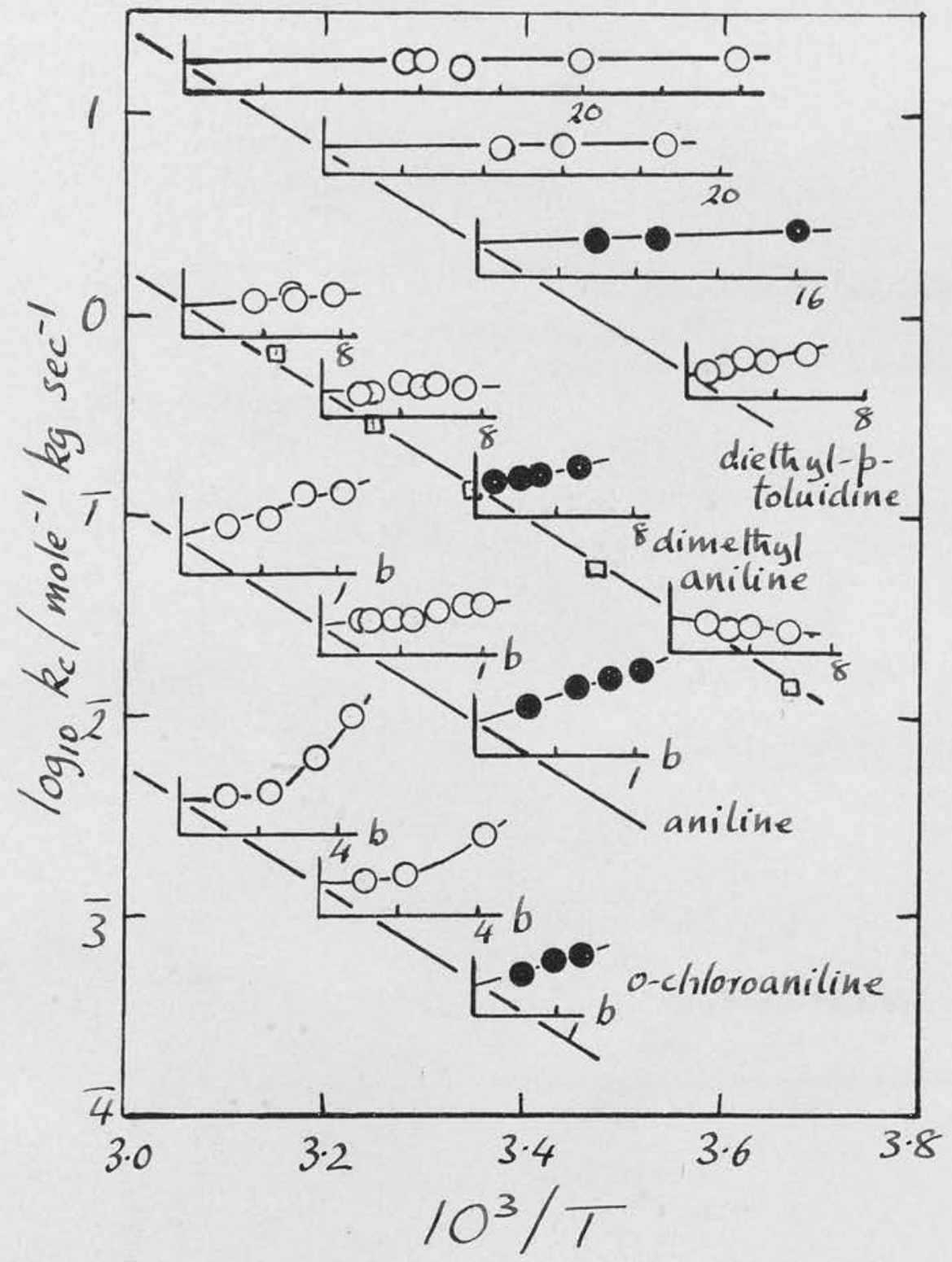

Figl 


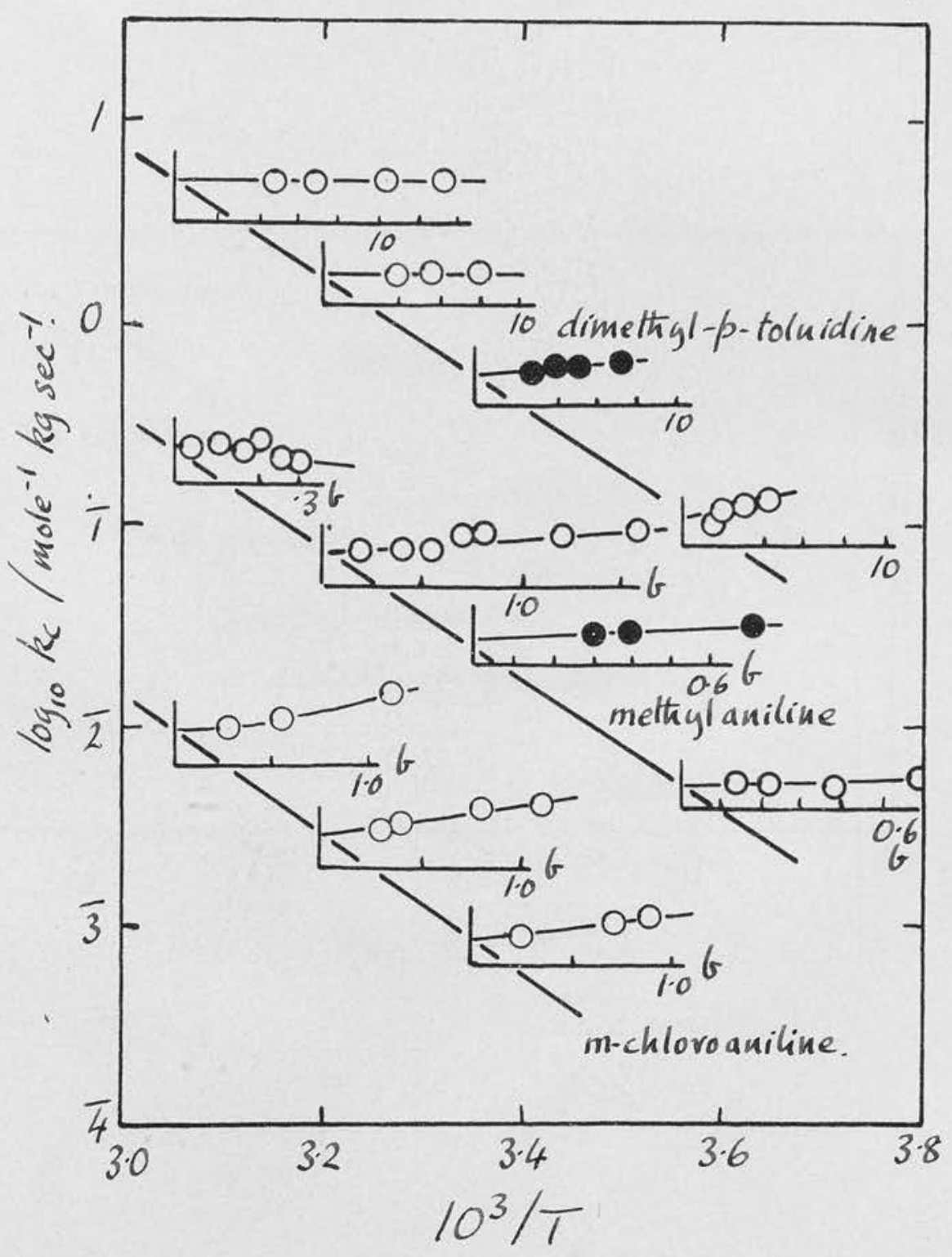

Figl 


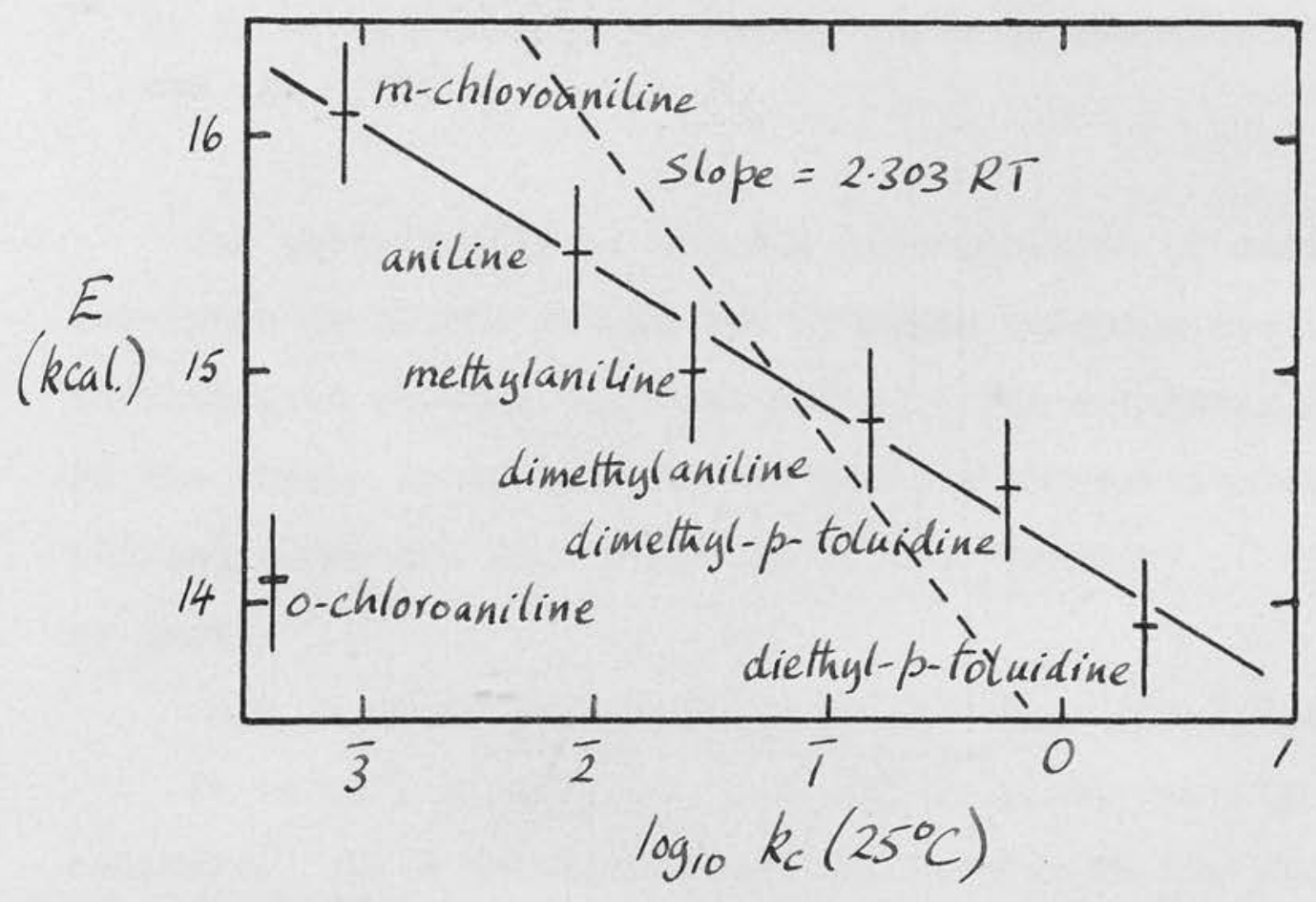

Fig 2. 
Prooss to: A. F. Irotman-DLcikenson, Department of Chemistry, The University, West Hoins Road, Jainburgh, 9.

\section{THE PHOTODDCORPOSITYON OF ACEMATDEFYDE}

\section{CATALYSED BY 2 BIOZS.}

By R. No BIRRELL, R, F. SUITH, A. F. TROMUAN-DICRBTSOH and H. WIIKIF。

The photo-initiated thermal decomposition of acetaldehyde catalysed by alsane thiols and hydrogen exlphide hes been investigated between $168^{\circ}$ and $396^{\circ} \mathrm{C}$. The eatalytic epfect of the thiols is independent of thes concentration over a 1 imsted renge and is a function of the atrueture of the thiol so that

$$
\mathrm{H}_{2} \mathrm{~S}>\mathrm{CH}_{3} \mathrm{SH}>\mathrm{C}_{8} \mathrm{H}_{5} \mathrm{SH}>\left(\mathrm{CH}_{3}\right)_{8} \mathrm{CSH}>\left(\mathrm{CH}_{3}\right)_{3} \mathrm{CSH}
$$

It 1 s well established that thlols react readily vith freo radicals. This property finas applieation in the use of thiols as chain twanefer agents in rree radicel polymerisation. However, very fow kinetic stuales of reactions involving thiols and thiyl radicals have been reported. The only comprehensive study of thiol catalysis appears to be that of Berrett and Waters! They investigated the catalysis of the chain decarboxylation of several satureted allphatic aldehydes by alkane thiols, In the 11quid phase. The reaction chelns were instiated by the themel decomposition of aimethyl-ad' -azo-1so- 
butyrate and a.'-azo-2so-butyronitrile. They supposed that the catalyais could be attributed to the aupercesston of the zeection $\left(1^{p}\right)$

$$
\mathrm{R}+\mathrm{RCHO}=\mathrm{RH}+\mathrm{R}+\mathrm{CO}
$$

by the Paster eyele $\left(2^{\circ}, 3^{\prime}\right)$

$$
\begin{aligned}
R+r S H & =R H+r S \\
r S+R E H O & =r S H+R+C O
\end{aligned}
$$

The predominant chain eerrying step in the high tempereture photo-1nitiated decomposition of acetaldehyde in the vapour phase is almost certainly $(1)^{\mathrm{s}}$

$$
\mathrm{CH}_{3}+\mathrm{CH}_{3} \mathrm{CHO}=\mathrm{CH}_{3}+\mathrm{CH}_{0}+\mathrm{CO} \text { (1). }
$$

It appeared to be of Interest to study the erfect of adding thiols to the systern, to wee if (1) would be superseded by the reactions equivalent to $\left(2^{\prime}\right)$ and $\left(3^{\prime}\right)$. Ixperiments were therefore carried out with a number of thiols over a range of tempersture. It was hoped that infomation would be obtained on the effect of atructure on the reactivity of the thiols and on the relative rete constents of the reactions.

\section{EXPKRTIEYYAL.}

Materiols: The acetaldehyde was propared by the distillation of paraldehycle containing a 11ttle sulphuric acld: 1t was thoroughly degassed before use, and stored as a gas in a blackened bulb. The hyorogen suiphido was genexated in a KIpp's apparatus, dried and degassed before use. The thiols 
were comnereiel sangles; they were thoroughly degassed.

Apperatus: The reactions were carried out in two very simliar Pyrer reaction vessels, of about $200 \mathrm{coc}$. each, placea side by side In an electric fumace with a quariz window. They were 111 uminated by the full 21 ght from a medium pressure mercury are which was allowed to warm up for at least twenty minutes before a mun. The lemp was run continuously throughout a sertes of runs. Some runs with methene thiol were carried out with twin quartz cells. One of the cells was connected to a mercury manometer. The other was connected to a di-g-butyl phthalate menometer for the measurement of the mall quantities of thiol and to a Bourdon gauge with optleal lever for the measurement of the total pressure. It was found that when the cells were rilled to the same pressure of /acetalcehyde, the difference in the rates of photolysis was not signifleent. The cells, manometers and storage bulbs were attached to a conventional. vacuun 11 ne.

Procedure: A convenient pressure of thiol was adnitted to one of the cells. Identical partiol pressures of acetelchyde were then admitted to both cells. The dead space was small, so that the measured pressures of reactants corresponded elosely to the composition of the mixtures in the cells. After a lapse of a Sev minutes to allow the gases to come up to temperature, light was adnitted to the cells. The change in total pressure in each 
was then followed on a manoneter. Measuronents of the total pressures were made at conveniently spaced intervals.

\section{RESUTRS and DISCUSSION.}

It has been established by mexay workers that the products of the photo-initiated thermal decomposition of acetaidehyde are almost exclusively methane and coxbon monozide. In confirmation of this we found that the pressure in the vessel containing pure acetaldehyde approxinately doubled when the run was carried to completion. The witimate pressure increase in the vessel conteining the thiol was always about $10 \%$ less then the initiel partigl pressure of acetoldehyde.

The catelytic erfect of the thiol was deternined from observations taken at the beginning of the reaction. The time teken for an increase in pressure equal to one-pifth of the Initial pressure of acetaldehyde was measured for the catelysed and uneatalysed syster. It was found that substantialiy the seme ratio was obteined if the initial alopes of the decomposition curves were measured or altematively the ratios of the times taken to reach some other smell degree of decanposition.

Host woric was carried out with methane thiol as the catalyst. It was found that at a given temperature and pressure of acetaldehyde the eatalytic effect of the thiol increased as its concentration was increased. Then the catalytic effeet remained constent over a considerable range of concentration. Finalig, 
When the thiol concentration was about three-quarters of the aceteldohyde concentration, the ratio Inereased at low light Intensities. The variation of the ratio with coneentration 1. shown In Figure 1. Nis the points shown were obtained with an Indital pressure of $10 \mathrm{~cm}$ of acetaldehycle and with the seme Incident 1ight Intensity. It was found that in the concentretion range represented by the flat portion of the curve no alteration in the ratio was brought about by doubling the aldehyde concentration or by vaxying the Incident light intensity by a fretor of four. The values of the constant rate retion were determined at five temperatures between $189^{\circ}$ and $396^{\circ} \mathrm{C}$. The values obtained have boen plotted on the Axphenius plot, Figure 2.

Similax results were obteined from the experiments in guarta reaction vessels, though the rate ratios were always somewhat higher. It is 1 ikely that some reaction chains were initiated by the photolysis of the thiol by the unfiltered light from the mercuxy are.

similar experiments were carried out with exch of the other thiols. Again it was sound that for hydrogen sulphide and othane thiol, the rate ratio increased with increasing thiol concentration until it reached a constant value, Figure 1. With ethane thiol as the catalyst the rate ration were indegendent of a vertation in absorbed light intensity of a fector of nine. The interpretation of the results with hydrogen sulphide ls more 


\section{6.}

uneertain. A alight induetion period was evident at low light intensities and high concentrations of the sulphide. The rate xatios corresponding to the platesu are plotted agalnat temperature for both eatelysts in Fig. 2.

The catalytic behaviour of propane-2-thiol and 2-methylpropane-2-thiol is shown in F1gure 1. A constant rato ratio 1.3 never malntalned over any considerable range of concentration, though the rate ratios are independent of a variation of light Intensity of a factor of four. For purposes of comparison the maximum rate ratlos for these catalysts are plotted against temperature in Plgupe 2. At temperatures above $300^{\circ} \mathrm{C}$. 2 small quantity of 2-methyl-propene-2-thlol reduced the rate of the decomposition of acetaldehyde to negifgible proportions. Bropane-2-thiol behaved in the sane manner at temperatuzes about $4.0^{\circ} \mathrm{C}$. higher. There was no evidenee that this inhibition was eaused by producte of the thermal decomposition of the thiols.

The mechenim of the photo-indtiated thernel decomposition of acetaldehyde has ofter been written as:

$$
\left.\begin{array}{rl}
\mathrm{CH}_{3} \mathrm{CHO}+\mathrm{h \nu} & =\mathrm{CH}_{3}+\mathrm{HCO} \\
\mathrm{HCO} & =\mathrm{H}+\mathrm{CO} \\
\mathrm{H}+\mathrm{CH}_{3} \mathrm{CHO} & =\mathrm{H}_{2}+\mathrm{CH}_{3}+\mathrm{CO}
\end{array}\right\} \text { Fats }_{0}
$$

It is now known thet this is not a complete description of the reaction system, but it certalnzy represents the principel 


\section{7.}

reactions correctly. A mechanian similas to that proposed by Bassett and laters is adequate to cover the facts of the catalysis by methane thiol. The ateps immediately consequent upon the absorption of light are followed by:

$$
\begin{aligned}
& \mathrm{CH}_{3}+\mathrm{CH}_{3} \mathrm{SH}=\mathrm{CH}_{4}+\mathrm{CH}_{9} \mathrm{~S} \\
& \mathrm{CH}_{3} \mathrm{~S}+\mathrm{CH}_{3} \mathrm{CHO}=\mathrm{CH}_{3} \mathrm{SH}+\mathrm{CH}_{3} \mathrm{SH}+\mathrm{KCO}+3 \\
& 2 \mathrm{CH}_{3} \mathrm{~S}=\mathrm{CH}_{3} \mathrm{~S} \cdot \mathrm{S} \cdot \mathrm{CH}_{3}
\end{aligned}
$$

Disulphides have been found in the products of thiol catalysed reactions at low temperatures, which lends support to reaction 5.

It is a necessery feature of the mechanism that $k_{B}$, the rate constent for reaction 2 should be very much greater then $k_{1}$ or $k_{3}$. Unpublished results of $M r J$. A. Kerr in this Iaboratory Indicate that at low temperatures $k_{a}$ is at least fifty times $k_{1}$.

Solution of the steady state equations ylezds (noglecting the decomposition in the instiating step)

$-d\left[\mathrm{CH}_{8} \mathrm{CHO}\right] / \hat{d} \mathrm{t}=\mathfrak{k}_{2}\left(\mathrm{I}_{0} / \mathrm{k}_{4}\right)^{\frac{1}{2}}\left[\mathrm{CH}_{3} \mathrm{CHO}\right]$

for the uneatalysed reaction, and

$-\mathrm{d}\left[\mathrm{CH}_{3} \mathrm{CHO}\right] / \mathrm{at}=\mathrm{k}_{3}\left(\mathrm{I}_{0} / \mathrm{k}_{5}\right)^{\frac{1}{2}}\left[\mathrm{CH}_{3} \mathrm{CHO}\right]$

$$
\begin{aligned}
\text { Rate ratio } & =\frac{\mathrm{k}_{3}\left(\mathrm{I}_{0} / \mathrm{k}_{\mathrm{g}}\right)^{\frac{1}{2}}\left[\mathrm{CH}_{3} \mathrm{CHO}\right]}{k_{1}\left(\mathrm{I}_{0} / \mathrm{k}_{4}\right)^{\frac{1}{2}}\left[\mathrm{CH}_{3} \mathrm{CHO}\right]} \\
& =\left(\mathrm{k}_{3} / \mathrm{k}_{8}^{\frac{1}{2}}\right) /\left(\mathrm{k}_{1} / \mathrm{k}_{4}{ }^{\frac{1}{2}}\right)
\end{aligned}
$$


This equation should apply. to the rate gatios in the reglon where they are independent of the thiol concentration. The rate ratio probably initially increases with thiol concentration because, at the lowest ratios, reaction 218 not sufficiently fastex than peaction $1_{0}$

Since $k_{1}$ and $k_{4}$ are known ${ }^{3,4}$, $k_{3} / k_{3}{ }^{\frac{1}{2}}$ may be evaluetect. From the tempereture coefficient of the rate ratio

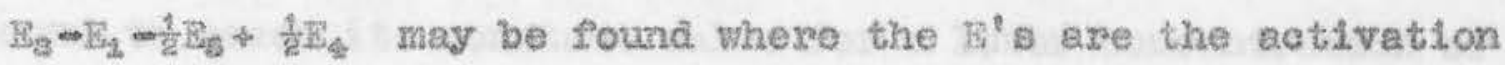
energles of the reactions.

Kence, assuming

$$
\begin{aligned}
& 20 \mathrm{~g}_{20} \mathrm{k}_{1} / \mathrm{mole}^{-1} \mathrm{~cm}^{3} \sec ^{-1}=12.1-(8400 / 2.303 \mathrm{RT}) \\
& 20 \mathrm{~g}_{10} \mathrm{k}_{4} / \mathrm{male}^{-1} \mathrm{~cm}^{3} \sec ^{-1}=13.3
\end{aligned}
$$

we find $\mathrm{E}_{3}-\frac{1}{2} \mathrm{~F}_{5}=6800 \mathrm{eal}$.

Host conbinations of small free redicals have very low activation energies and A factorg of about $10^{13.3}$ nole $^{-1} \mathrm{~cm}^{3} \mathrm{sec}^{-1}$. $/$ mole $\mathrm{Cm}^{3} \mathrm{sec}^{-1}$

Assuming $\log _{20} \mathrm{k}_{\mathrm{K}} \mathrm{h}=13.3$

$$
\log _{\mathrm{a}} \mathrm{k}_{\mathrm{S}} / \mathrm{mole}^{-1} \mathrm{~cm}^{3} \mathrm{sec}^{-1}=11.9-(6800 / 2.303 \mathrm{RR})
$$

This value of $k_{3}$ is probably relleble. The only cause for doubt is the fact that the seme simple mechani gan will not describe the behavioux of the other th101s. However, the rate ret1os with oach of the catalysts were independent of their concentretion over a dotectoble range, and slso of the absorbed light intensity. 


\section{9.}

These frets can only be readily interpreted on the sssumption that reaction $2^{\prime}$ represents the fote of virtueliy aliz the alikyl rodicals released into the assten, Therefore it soens probable that a mecheniax substentialiy parallel to that for metheme thiol. holds for the other compounds, but thet other side reactions must occux. In these circurastences 1t is impossible to derive rate constents for the elenentary reactions. The rate ratio was found to reach 1 ts constent velue sor a lower concentration of methene thiol then for hycrotgen sulphide. From sueh evidence the apparent order of reactivity for methyl radicels with the thiols (reaction $2^{\prime}$ ) mey be delued to be

$$
\left(\mathrm{CH}_{3}\right)_{3} \mathrm{CEH}>\left(\mathrm{CH}_{3}\right)_{8} \mathrm{CHSH}>\mathrm{C}_{2} \mathrm{H}_{6} \mathrm{SH}>\mathrm{CH}_{9} \mathrm{SH}>\mathrm{H}_{2} \mathrm{~S}
$$

This order is the opposite to that for the catalytie erfect of the thiols $\left(k_{3} / k_{5} \frac{1}{2}\right)$. This 1a quite understendable. The pirst reaction would presumably be favoured by a weakening of the S-li bond, whereas the second would be favoured by its strengthening.

We exe Indebted to the British Petroleum Cormany for a grant in ald of this work.

Depertment of Chems stry, The University.

Båinburgh. 


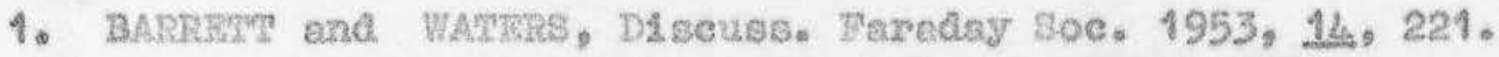

2. STrACIX, "Atomic and Broe Radicel Reactions", Reihola, New Yorik, end Ra.. 195\%.

3. DODD, Cor, J. Chem, 1955, 33, 699.

4. SHKPए, J. Chem, Phys, , 1956, 24, 939. 


\section{Captions.}

I18. 1. Typleal variations or eatalytic effect with concentration.

F4g. 2. Axrhenius plot for the catalytic effect of the thiols. 


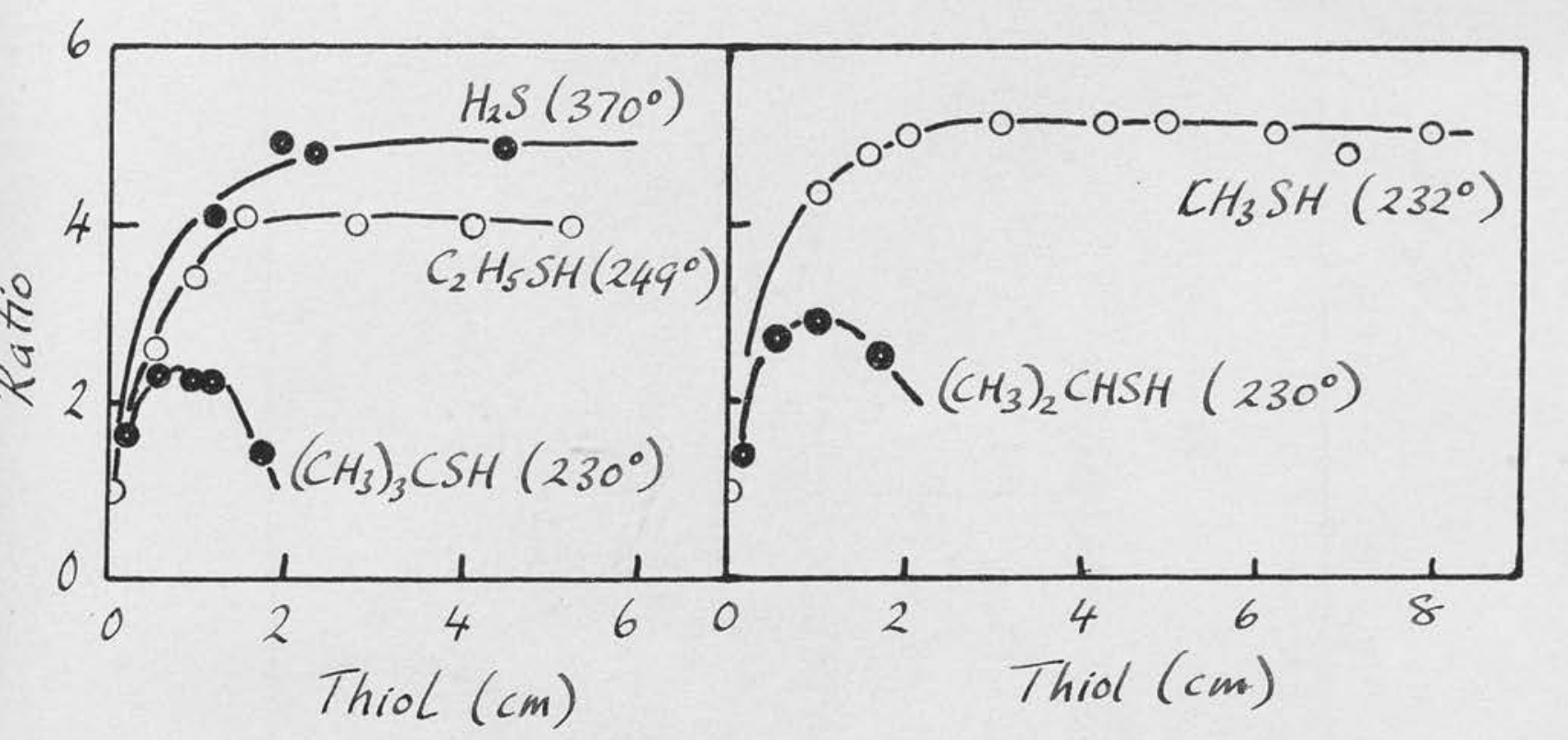

Fig I 


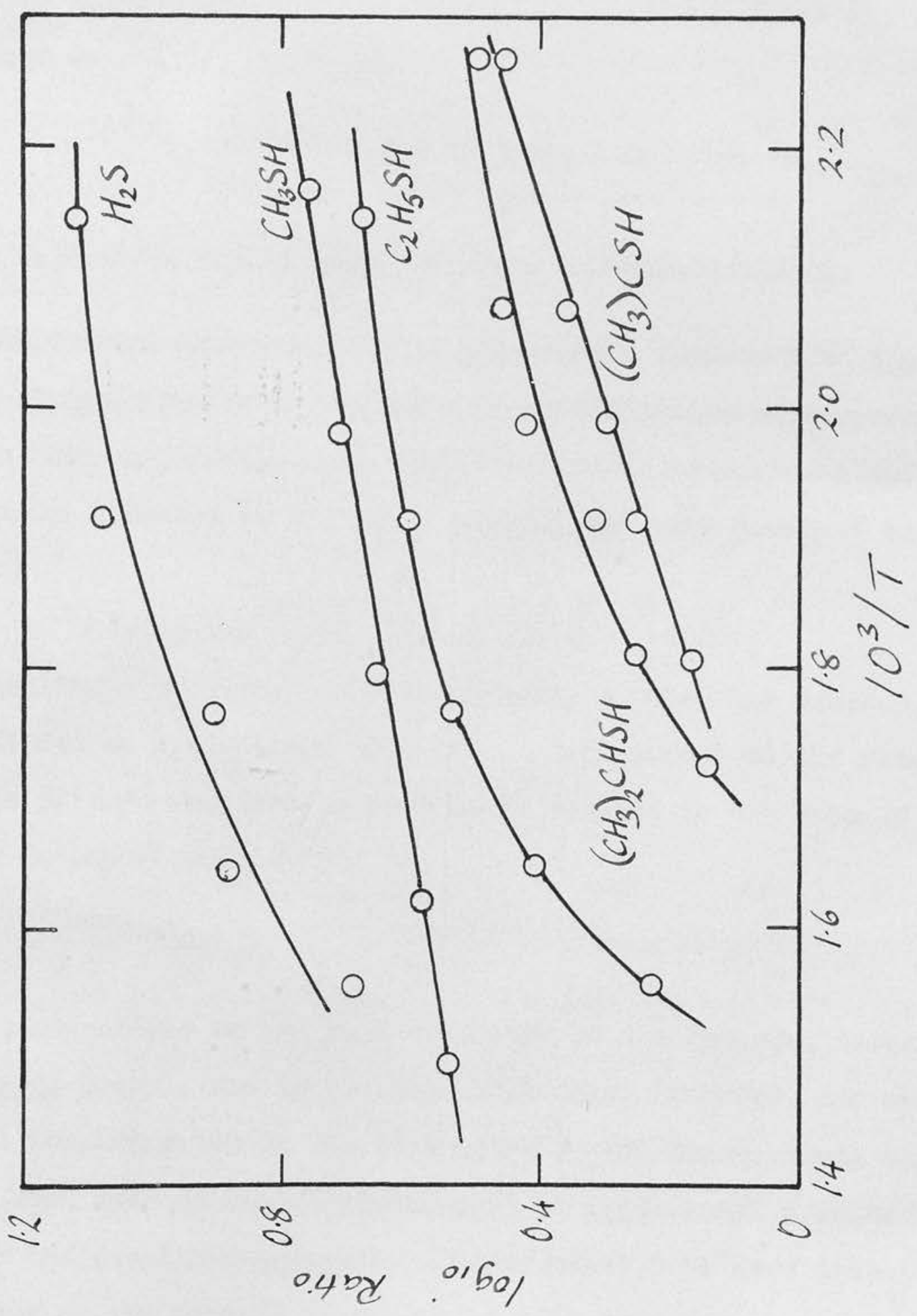


Froofs to A.F. Trotman-Dickenson,

Chemistry Department,

West Neins Eoad,

Bdinburgh 9.

The Pyrolysis of terto-butyl formate.

by E. GORDON, S.J. W. PRTCE and A.F. THOMMAN-DICKMNSON.

The thertal decomposition of tert.-butyl formate into 1so-butene and formic acid has been studied in a static system at temperatures between $230^{\circ}$ and $300^{\circ} \mathrm{C}$. The decomposition is homogeneous end obeys Pirst-orter kinetics in its eexiy stages the rate constant is given by

$$
20 \mathrm{~g}_{10 \mathrm{k}} / \mathrm{sec}^{-1}=11 \cdot 1-(34600 / 2 \cdot 303 \pi x)
$$

The elimination of formic acid is probably a roleculas process, as the addition of eyclohexene has a very small effect on the rate. The gate of this reaction is reasonably related to the rates of sindier decompositions.

Determinations of the rate constants of the decompositions of ethyl, sec.-propyl, and tert, -butyl chlorides, bromides, and acetates heve all been regorted in the 1iterature ${ }^{1}$. Mo measurements appear to have been made on the decompositions of tert-butyl formate although the ethyl and sec.-propyl dexivatives have been investigated. The objeet of the present study was to fill this gap. 
Yaterials. - The tert.-butyl formate was specially prepared for use in this Inventigation by Dx. Ce Barkenbus of the University of Kentueiky according to the method devised by hat. Fhe material was thoroughly degassed and stored in a dxy ice bath. It was found that at temperaturea appreclably above room tenperature and in the absence of a drying agent the 11quid rapialy decomposed, apporentiy into $\mathbf{i s g - b u t e n e ~ a n d ~ f o r m i c ~ a c i d . ~ T h e ~ g x e l o h e x e n e , ~ w h i c h ~}$ wos almo degassed, was sreed from peroxides by shaking with acid ferrous sulphate solution.

Apperstus - The cecomposition was studied in a Pyrex bulb of $355 \mathrm{c.c}$. capacity attached to a conventionel veruar ststem by heated tubing with a total dead space of epprox, $13 \mathrm{coc}$. The umpacked bulb had a surfece/volume retio of $0.9 \mathrm{~cm}^{-1}$, when 1 t wes packed with fire pollwhed Pyrex tubing the ratio was $3 \cdot 0 \mathrm{~cm}^{-1}$. The butb was contained in a mercury-vapour jacket, whose tempexatuxe could be readiy controlled by varying the pressure under which the mercury bolled. The termperature of the jecket was determmed, yeference to standard tables of the vapour pressure of mercury. The reaction was studied by following the change in pressure in the reaction vessel on a mercury menome ter.

Procecure- - Rums were strated by adnitting a suitable quantity of the formate to the reaction vessel from the storage buib, in some runs 
cyclohexine was also: sdaled. Readings of the pressure in the vessel were then recorded at conventent intervals. Rate constents were determined from flrst-order plots of the logerithns of the pressure changes against time, based on the assumption that complete reaction corresponded to a coubling of the pressure. The logerithmie plots were strictiy linear for the Plrst $70-80 \%$ of the reactions at the higher teaperetures but thereafter tended to curve slightiy. aro Induction periods were observed.

\section{MESULg and DTSCUSBION.}

Ierto-butyl fomate was presuned to yleld formic acid and isombutene es the primary products of the decomposition. This presumption is based upon the known ease with which these groducts are formed in the liculd in the presence of a trace of acta and upon the analogy with the decompositions of the other formates. It was difricult to check this by anelysis, because of the ropidity with which the 1lovid decorposet. Several experiments were done with a trap system in which the formate and formic acid were condensed in a trap cooled in a dry-jee bath and the 1so-butene In a trap cooled in 11quid oxygen. The 1so-Dutene was then transferred bacis into the reaction system and 1ts pressure masurea. The percentage decompostiton based on the formation of Iso-butene was then calculated. The results of a series of rums at $251^{\circ} \mathrm{C}$ were as follows Percentege decomposition by pressure rise $11.4 \quad 1900 \quad 30.0 \quad 41.0$ Percentoge decomposition by iso-butene $\quad \begin{array}{lllll}7 \cdot 9 & 14 \cdot 4 & 30 \cdot 0 & 39 \cdot 0\end{array}$ 
The method of anelysis wes not very satisfactory, but there appears to be littile doubt as to the nature of the decomposition. Finns which were followed for many half-lives never yielded a pressure greater then twice the initial pressure. This is evidence that the formic acld doea not decompose at these low temperatures.

The linearity of the logexithmic plots denonstrated the first-order nature of the decomposition which wes confirmed by doing runs with different initiel pressures of the formate between 3.8 and $10 \cdot 3 \mathrm{~cm}$. No systematic trend nor variation of the rate constents outside the limit of experimentel exror was observed.

Fig. I is an Arxhenfus plot of the rate constants for the thermel decomposition. The best straight line was calculated by the method of least scueres glving equal weight to each rung the points shown in the figure are the mean values obtalned at each temperatuxe. The results are best expressed by

$$
10 \mathrm{~g} 10 \mathrm{k} / \mathrm{sec}^{-1}=11 \cdot 1-(34,600-900 / 2 \cdot 303 \pi \mathrm{T})
$$

Wwo sacts showed the decomposition to be honogeneous. Wirst, no conditioning of the reaction vessel was needed before reproducible results were obtained. Second, paeking the reaction vessel did not affect the rate constants as is shown In Fig. I where the mean results obtained in the packed vessel are plotted.

The absence of on induction period and the negligible erfect of packing the veasel indicate that the deconposition is molecular 
and does not involve free redicals. This was confirmed by adding eyclohexene to the aysten. The addition of between 20 and $50 \mathrm{per}$ cent of cyclohexene appeared to recuce the rate of decomposition very alighty, but the lovering wos of the sane order as the experinentel scattex. The results obtained with eyclohexene are also shown in $\mathrm{Fig}$. I.

The activation energy of this deconposition is markedily lower than those for the decomposition of ethyl. formate (44.1kcal. mole ${ }^{-1}$ )

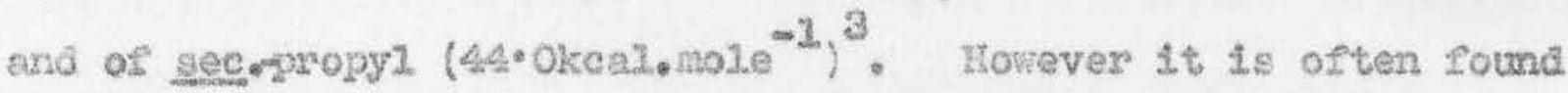
to be more enlightening to conpare the vartation of the rate conistants of a sertes of reactions rather than their A Lactors and activation energies. Such a compartion is made for several series of ethyz, sec foropyl and tert.-butyl esters in FIg. 2. A11 of these decompostulons are thought to be moleculer. The rate constants are conrected to $380^{\circ} \mathrm{C}$ and are expressed in terns of the rate constant of the ethyl ester which has been assigned the value tunity. In the figure the logartithens of the rate constants are plotted againgt the logerithing of the rate constents for the decomposition of the ethyl, sec.-propyl and terte-butyl bromides. The line labelled 'hydrides' represents the rate constants for the decompositions of ethyl bromide, n-propyl bromide and iso-butyl bromide. It is evident that the same factors control the rates of each series of reactions. 
We are grently Indebted to Drs C. Bexkerbus for the sample of the tertio-butyl. Iornate and to the Bxitish Detroleun Company fox a gaxt.

Cheniecry Depariment,

The Univexsity,

Edinbuxgh 9 . 


\section{CAPIXYUS.}

Fig. 1. Arrhemins plot for the themel deconposition of tert. - buty2 fomate.

- Unpackea vessel

6 Pecked vessel

* Unpaciced vessel with the addition of exclohexene. The figures by the clrcles indicate the number of rums averaged to obtain each pointa

Fig. 2. The relation between the sates of the moleculas decompositions of various ethyl, sec. -propyl and tert. -butyl dexivatives. 


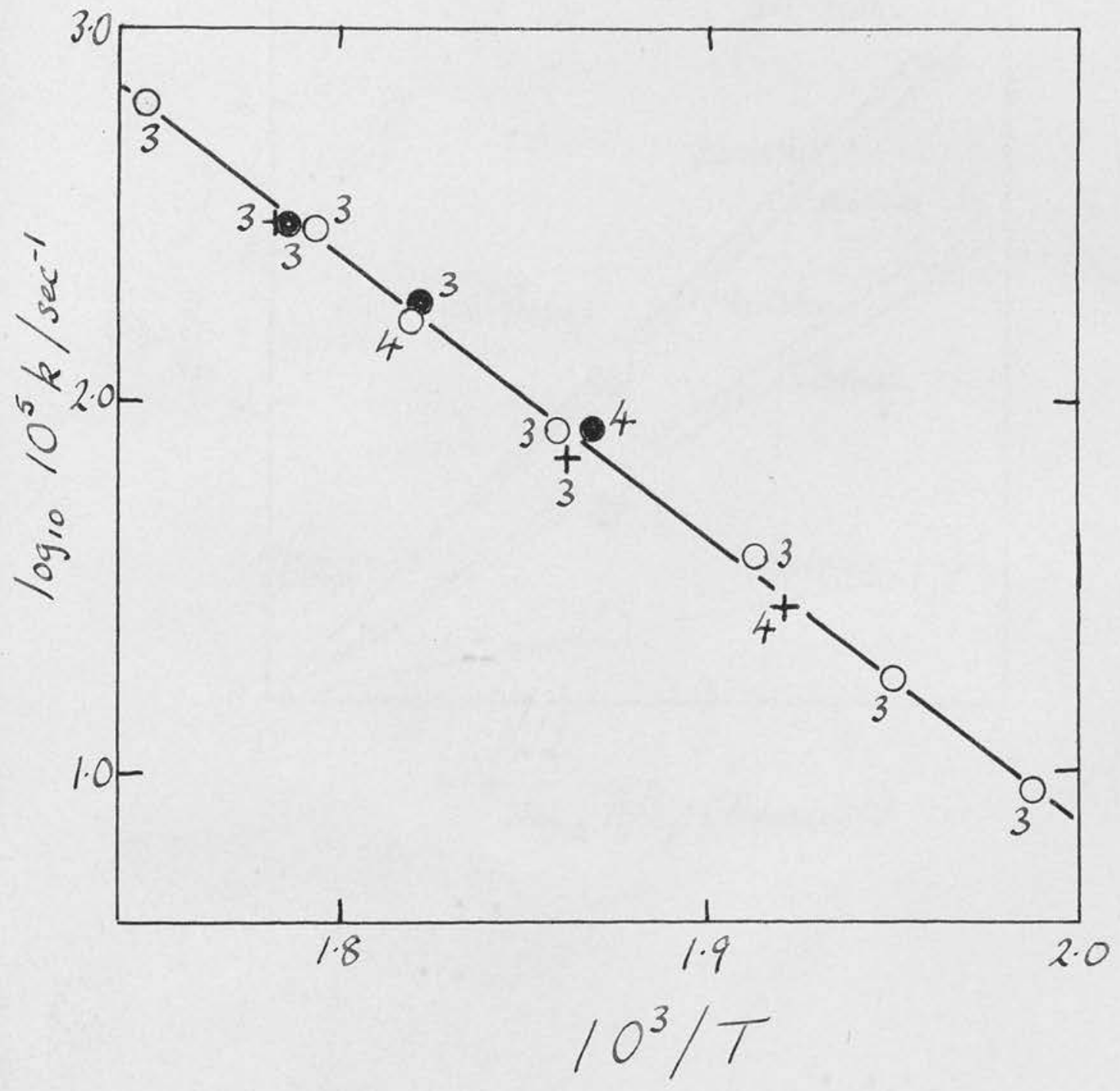

Fig 1. 


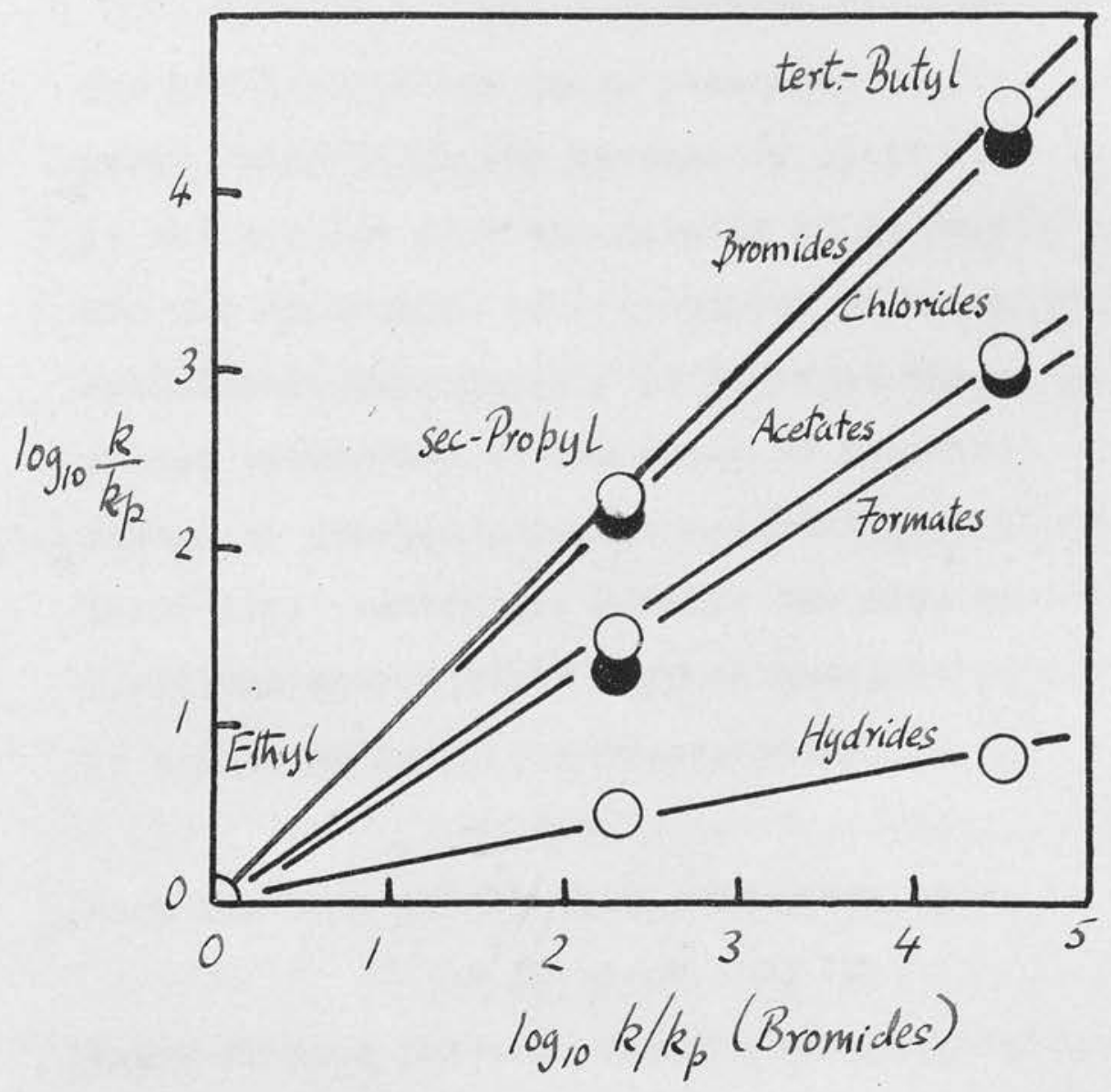

7 ig 2 
Proofs to: A.F.Trotman-Dickenson,

Chemistry Department,

West Mains Road,

Edinburgh 9

THE STUDY OF RADICAI, REACTIONS BY COMPETITIVE METHODS

by J.E.Knox and A.F.Trotman-Dickenson

The bimolecular gas phase reactions of free radicals

merit study primarily because of their formal simplicity.

At the present time the methods of measuring rate constants are far in advance of the methods by which they may be calculated. Consequently it is right that much effort should be devoted to the study of reactions that are simple enough to provide possible material for the evaluation of theoretical estimates. Ideally the raje constants of these reactions should be determined absolutely. If the reaction of a free radical is represented by

$$
\text { A. }+M_{1}=P_{1}
$$

then its rate constant, $k_{1}$, is given by

$$
\left.R_{1}=k_{1} \text { (A) ( } \mathbb{R}_{1}\right)
$$

where $R_{1}$ is a suitable measure of the progress of the reaction. The rate constant may be determined over a range of temperature and its temperature dependence may be expressed. a.s

$$
k_{1}=A_{1} \exp \left(-E_{1} / R T\right) \text {. }
$$

The greatest success in the calculation of rate constants has from attempts that have been made to predict the $A$ factors and the activation energies independently. Calculations based upon the transition state theory yield A factors which are of the correct order of magnitude. Activation energies may also be understood in terms of the 
transition state theory but they cannot be calculated from first principles with useful accuracy.

The evaluation of $\mathrm{k}_{1}$ involves the deternination of three quantities:

(a) The concentration of the normal reactant $\mu_{1}$.

(b) The concentration of the free radical $A$.

(c) The progress of the reaction, $R_{1}$.

(a) The concentration of $M_{1}$ in the reaction mixture may readily be measured and may be maintained effectively constant throughout the reaction if the percentage conversion is kept low.

(b) The concentration of the free radeal $\mathbb{A}$ cannot in general be directly determined. Usually it an only be found by the measurement of a concurrent reaction whose rate constant is known or may reasonably be assumed. This is the essence of the competitive mothod. In the present paper we shall only be concerned with cases in which the molecularity of the standara reaction with respect to A is the same as that of the reaction whose rate constant is to be measured, and is of the same kind. As an example we may considex the two reactions:

$$
\begin{aligned}
& A+M_{1}=P_{1} \\
& A+M_{2}=P_{2}
\end{aligned}
$$

If these two reactions occur simultaneously in a reaction vessel, then

$$
R_{1}=k_{1}(A)\left(M_{1} H \text { and } R_{2}=k_{2}(A)\left(M_{2}\right)\right.
$$

hence

$$
\frac{k_{1}}{k_{2}}=\frac{R_{1}}{R_{2}} \frac{\left(M_{2}\right)}{\left(M_{1}\right)}
$$


Thus the ratio of the rate constants may be determined without measuring $(A)$. If $k_{1}$ is known then $k_{2}$ may be determined absolutely. It frequently happens that this is the most convenient way of determining a series of rate constants, $k_{2}$, even for systems in which it might be possible to apply the methods by which $k_{1}$ was absolutely determined. The competitive method has the additional advantage that it is unnecessary to maintain the concentration of constant throughout the duration of a run.

(c) The problem is thus reduced to one of measuring the rates of the reactions, $R_{1}$ and $R_{2}$. Together with our colleagues we have obtained reasonably satisfactory solutions in three different ways:

(1) When the reactions to be studied are hydrogen abstraction reactions, then distinctive products may be obtained for measurement if one of the substrates is deuterated. This approach has been used in the study of the reactions of trideuteromethy ${ }^{1}$ and trifluoromethy ${ }^{2}$ radicals.

(2) The amounts of $M_{1}$ and $M_{2}$ consumed may be determined. This approach has been used in the study of the reactions of chlorine atoms ${ }^{3}$.

43) The amounts of products formed by the released substrate radical may be determined. This approach has also been used in the study of the reactions of chlorine atoms 4 and adapted to the study of the reactions of methylene. 1. The Reactions of Trideuteromethyl Radicals'. The most 
Thus the ratio of the rate constants may be determined without measuring (A). If $k_{1}$ is known then $k_{2}$ may be determined absolutely. It frequently happens that this is the most convenient way of determining a series of rate constants, $k_{2}$, even for systems in which it might be possible to apply the methods by which $k_{1}$ was absolutely determined. The competitive method has the aditional advantage that it is unnecessary to maintrin the concentration of constant throughout the duration of a run.

(c) The problem is thus reduced to one of measuring the rates of the reactions, $R_{1}$ and $R_{2}$. Together with our colleagues we have obtained reasonably satisfactory solutions in three different ways:

(1) When the reactions to be studied are hydrogen abstraction reactions, then distinctive products may be obtained for measurement if one of the substrates is deuterated. This approach has been used in the study of the reactions of trideuteromethyl ${ }^{1}$ and trifluoromethy ${ }^{2}$ radicals.

(2) The amounts of $M_{1}$ and $M_{2}$ consumed may be determined. This approach has been used in the study of the reactions of chlorine atoms ${ }^{3}$.

43) The amounts of products formed by k the released substrate radical may be determined. This approach has also been used in the study of the reactions of chlorine atoms ${ }^{4}$ and adapted to the study of the reactions of methylene. 1. The Reactions of Trideuteromethyl Radicals'. The most 
convenient source of txideuteromethyl radicals is the photolysis of hexadeuteroacetone. At temperatures above $120^{\circ} \mathrm{C}$ the photolysis may satisfactorlly be represented by

$$
C D_{3} \mathrm{COCD}_{3}+h \nu=2 C D_{3}+\mathrm{CO}
$$

The methyl radicals then react as follows:

$$
\begin{aligned}
& C D_{3}+C D_{3} \mathrm{COCD}_{3}=\mathrm{CD}_{4}+6 D_{2} C O C D_{3} \\
& \text { and } \quad 2 \mathrm{CD}_{3}=\mathrm{C}_{2} \mathrm{D}_{6}
\end{aligned}
$$

Kistiakowsky and Roberts ${ }^{5}$ have studied this system using the method of intermittent illumination and hence found that the absolute value of the rate constant of reaction (1) is given by

$$
\log _{10} \mathrm{k}_{1} / \mathrm{mole}^{-1} \mathrm{~cm}^{3} \mathrm{sec}^{-1}=11.6-(10300 / 2.3 \mathrm{RT})
$$

In the presence of a hydrogen-containing compound the following additional reaction occurs

$$
\mathrm{CD}_{3}+\mathrm{RH}=\mathrm{CD}_{3} \mathrm{H}+\mathrm{R}
$$

Following the argument given above, we have

$$
k_{2} / k_{1}=\left(\mathrm{R}_{C_{3} H} / R_{C D_{4}}\right)\left(\left[\mathrm{CD}_{3} \mathrm{CO} D_{3}\right] /[\mathrm{RH}]\right) \text {. }
$$

The ratio of $\mathrm{CD}_{3} \mathrm{H}: \mathrm{CD}_{\text {烈 }}$ may readily determined by the analysis of the non-condensable fraction of the products with a mass-spectrometer. The intense parent peaks of the two methane ions at mass 19 and 20 are free from interference from the ions of the other molecules that may be present. A particular virtue of this method is that methane produced by side reactions such as the decomposition of radicals will not be deuterated and will not interfere. The absence of the need to analyse for ethane is also convenient if the reactions of ethylene and other low - 
boiling compounds are to be studied. It is usually assumed that the rate constants of the reactions of deuteromethyl radicals are very similar to those of the reactions of ordinary methyl radicals; this identity has not yet been experimentally established. Examples of some rate constants that have been determined by thas method are given in Table 1. The method is particularly suitable for the measurement of the rate constants for reactions with a series of very similar compounds such as the alkenes. The relative values of the rate constants are probebly very accurate. Taken in conjunction with results that have been ontained with the alkanes, thes figures show that the high reactivity of the higher alkenes is associated with the presence of the $\alpha$-methylenic hydrogen atoms. The reactivity of these hydrogen atoms varies in the order

$$
\text { primary }<\text { secondary }<\text { tertiary. }
$$

The reactions of Irifluoromethyl Radicals. ${ }^{2}$ There are two reasonably satisfactory sources of trifluoromethyl raicals, hexafluoroacetone and hexafluoroazomethane. Although hexafluoroacetone is now known to offer considerable advantages we used hexafluoroazomethane because it is readily prepared from lodine penta fluoride and lodine cyanide. When it is photolysed the following reactions occur:

$$
\begin{aligned}
\mathrm{CF}_{3} \mathrm{NNCF}_{3}+h \nu & =2 \mathrm{CF}_{3}+\mathrm{H}_{2} \\
2 \mathrm{CF}_{3} & =\mathrm{C}_{2} \mathrm{~F}_{6} .
\end{aligned}
$$

There is also some addition of trifluoromethyl radicals to the double bond, but no abstraction of fluorine atoms to yield $\mathrm{CF}_{4}$ takes place. In the presence of a hydrogen- 
containing compounds $/ \mathrm{CF}_{3} \mathrm{H}$ is formed by the reaction

$$
\mathrm{CF}_{3}+\mathrm{RH}=\mathrm{CF}_{3} \mathrm{H}+\mathrm{R}
$$

In order to study a series of such abstractions we added deuterium to the system and used the reaction

$$
\mathrm{CF}_{3}+\mathrm{D}_{2}=\mathrm{CF}_{3} \mathrm{D}+\mathrm{D}
$$

a.s a reference reaction. By the usual argument

$$
k_{1} / k_{2}=\left(R_{C_{3} H} / R_{C F_{3} D}\right)\left(\left[D_{2}\right] /[R H]\right)
$$

The ratio $\mathrm{CF}_{3} \mathrm{H}: \mathrm{CF}_{3}$ D may be readily determined with a mass-spectrometer because the ions that are predominantly produced by electron impact are $\mathrm{CF}_{2} \mathrm{H}^{+}$and $\mathrm{CF}_{2} \mathrm{D}^{+}$. The reference reaction was calibrated against the reaction of trifluoromethyl radicals with ethane; the ra constant for this reaction was determined absolutely by Ayscough, Polanyi and Steacie ${ }^{6}$; it is given by

$$
\log _{10} \mathrm{k} / \mathrm{mole}^{-1} \mathrm{~cm}^{3} \mathrm{sec}^{-1}=11.7-(7500 / 2.3 \mathrm{RT}) \text {. }
$$

Some results obtained by this method are shown in Table 2. Ayscough and Steacie have obtained results that are in excellent agreement with several of these.

The activation energies given in parentheses are those for the reactions of unsubstituted methyl radicals with the substrated. It can be seen that the reactions of trifluoromethyl radicals have activation energies that are generally lower by 2 to $3 \mathrm{kcal} / \mathrm{mole}$. The A factors of the two sets of reactions differ very little.

2. The Reactions of Chlorine Atoms. Several factors combine to make it impossible to study the reactions of chlorine atoms by the methods that have been used to study the reactions of bromine atoms or of small free radicals. The conc- 


\section{7}

entrations of chlorine atoms cannot be determined by measuring the rate at which they dimerize because the atoms are generally produced by dissociation of the element which is present in the system in considerable quantities. Owing to the high reactivity of chlorine atoms the reaction chains in chlorinations are very long and consequently difficult to reproduce. It is therefore impossible to rely simply on the known dissociation constant of the diatomic molecule to estimate the concentration of atoms and hence the rate constants in the way that Kistiakowsky, Van Artsdalen and their coworkers 7 did when investigating brominations. Fortunately, however, it has been possible, by a series of ingenious arguments, to show that the rate constant of the reaction

$$
\mathrm{Cl}+\mathrm{H}_{2}=\mathrm{HCl}+\mathrm{H}
$$

is given by $\log _{10} k_{1}=13.9-(5500 / \mathrm{RT} \cdot 2.303)$.

If light is shone on a system condaining chlorine, hydrogen and a hydrogen-containing compound. RH, the following reaction also occurs

$$
\mathrm{Cl}+\mathrm{RH}=\mathrm{HCl}+\mathrm{R}
$$

The hydrogen atoms and radicals, $R$, react with chlorine molecules to yield chlorides and chlorine atoms. It is not convenient to measure the relative rates of the reactions by introducing deuterium into the compound $\mathrm{RH}$, because of the difficulty of measuring the ratio of $\mathrm{HCl}$ to $\mathrm{DCl}$. However the amounts of hydrogen and RH consumed may be measured. Then if the percentage conversion is kept low and the reaction chains are long, we may write 


$$
k_{1} / k_{2}=\left(-R_{H_{2}}^{\prime}-R_{R H}\right)\left([\mathrm{RH}] /\left[\mathrm{H}_{2}\right]\right) .
$$

In this way $k_{2}$ may be found.

It is not convenient to compare the reactions of all hydrogen-containing compounds with the hydrogen reaction, because the differences in rates are excessively large. Accordingly one progresses stepwise down a series of compounds. The results that have been obtained in this way are shown in Table 3.

Two points in these results are worthy of note. First the A factors of these reactions closely approach the rate of collision that may be calculated from the kinetic theory of gases. Second the activation energies are extremely low and vary little with the structure of the compounds. 3. The Reactions of Chlorine Atoms, A second method of investigating the reactions of chlorine atoms has certain advantages over method 2. It depends upon the measurement of the amounts of the alkyl chlorides formed by the reaction of the alkyl radicals with chlorine nolecules.

$$
\begin{aligned}
& \mathrm{R}_{1}+\mathrm{Cl}_{2}=\mathrm{R}_{1} \mathrm{Cl}+\mathrm{Cl} \\
& \mathrm{R}_{2}+\mathrm{Cl}_{2}=\mathrm{R}_{2} \mathrm{Cl}+\mathrm{Cl}
\end{aligned}
$$

These reactions follow inevitably on

$$
\begin{aligned}
& \mathrm{Cl}+\mathrm{R}_{1} \mathrm{H}=\mathrm{R}_{1}+\mathrm{HCl} \\
& \mathrm{Cl}+\mathrm{R}_{2} \mathrm{H}=\mathrm{R}_{2}+\mathrm{HCl}
\end{aligned}
$$

Accordingly

$$
\frac{k_{1}}{k_{2}}=\frac{R_{R_{1} C_{1}}}{R_{R_{2} C l}} \cdot \frac{\left[R_{2} H\right]}{\left[R_{1} H\right]}
$$

This method has two considerable advantages. First, the relative rates can be measured more accurately since one 
for attack at different positions in the molecules, it is likely that the activation energies themselves are small. This conclusion must be regarded as tentative because the usual factors determining activation energies do not seem to be exerting their normal influence. In particular, attack on the weaker secondary and tertiary $\mathrm{C}-\mathrm{H}$ bonds requires higher activation energies that attack on the strongerprimary bond. Perhaps steric repulsions are, in these cases, more important then bond strengths. Theoretical Considerations.

As has already been stated it is possible to calculate correctly the order of magnitude of the A factors of many simple free radical reactions. Such calculations can only be made exact if the mechanical properties of the activated complexes are fully known, so that their entropies can be determined. In fact only the tranlational entropies can be found exactly. Trial calculations show that the rotational entropies of activated complexes with plausible conformations differ very little. Usually these entropies may be estimated within $0.5 \mathrm{e} \cdot \mathrm{u}$. The evaluation of vibrational entropies presents considerable difficulties as there is no empirical rule for estimating vibrational frequencies.

A possible approach is to consider a series of very similar reactions and attempt to calculate their relative 
A factors. As has been shown the logarithms of these relative values may be determined experimentally with the same proportional accuracy as absolute A factors. It may be supposed that many of the errors that arise because of incorrect assumptions made about the activated complex will cancel out. This approach would therefore appear to be particularly hopeful because the assumptions chiefly have to be made about those portions of the complexes that are common to all the systems. Thus the grouping of $-\mathrm{C}-\mathrm{H}-\mathrm{Cl}$ must be common to the activated complexes of all the chlorine atom reactions.

We have attempted such calculations for the reactions of 10,11

chlorine atoms and methylene, The results obtained for the chlorine atom reactions are shown in Table 6 . The agreement is not satisfactory presumably because the difference in the vibrational entropies of the initial and transition states is not constant for all members of the series, as was assumed.

The predictions that were made about the A factors of methylene reactions ${ }^{11}$ differ even more seriously from the experimental findings. It was assumed that the activated. complex elosely resembled the product molecule with the rotatior of the appropriate methyl group 'frozen'.

Though attempts to calculate the relative A factors of these reactions have met with little success, it is clear that the approach offers a useful way of obtaining fresh information about the activated complex. Presumably some model of the molecules can be found that will yield satis- 
factory agreement. In the same way, the competitive study of reactions yields information which should be useful in a fresh approach to the more difficult problem of the calculation of energies. Perhaps the treatment of $0 \mathrm{gg}$ and Polanyi can be satisfactorily reduced to quantitative terms so that if the absolute activation energy of one member of the reaction series is assumed it will be possible to calculate the relative activation energies of all the other reactions. 
TABLE 1

$\mathrm{RH}$

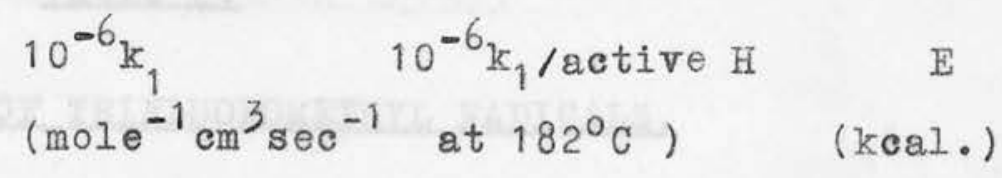

Ethylene

Propylene

2-Butene

iso-Butene

2,3-Dimethyl-2-butene

1-Butene

1 -Pentene

3-Methyl-1-butene

$$
2.9
$$

12

30

26

76

34

35

53

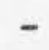

4

5

4

6

17

18

53
10.0

7.7

7.7

7.3

7.8

7.6

7.6

7.4 


\section{Table 3.}

\section{IHE REACTIONS OF CHLORINE ATOMS.}

$\mathrm{RH}$

Methane

Ethane

Propane

iso-Butane

neo-Pentane

eyclo-Pentane

Methylchloride

Ethylchloride

$$
\begin{aligned}
& \text { Log A } \\
& \text { ( mole } \mathrm{em}^{-1} \mathrm{sec}^{-1} \text { ) }
\end{aligned}
$$

$\mathrm{E}$

(keal)

3.9

1.0

0.7

0.9

0.7

0.6

$3 \cdot 4$

$1 \cdot 5$ 
TABLE 4

$\mathrm{R}_{1} \mathrm{H}$

$$
\mathrm{R}_{2} \mathrm{H}
$$

$$
A_{2} / A_{1}
$$

per $\mathrm{H}$ atom

2.45

1.65

2.76
$\left(E_{2}-E_{1}\right)$

( cal.)
Ethane

sec-Propane

tert-iso-Butane

$-2800 \pm 30$

$-445 \pm 30$

D-iso-Butane

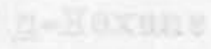

Fantoane

ino- Dutrand

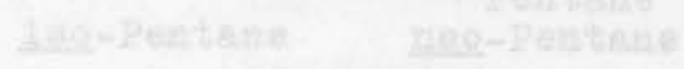




\section{TABLE 5}

THE REACTIONS OF METHYLENE

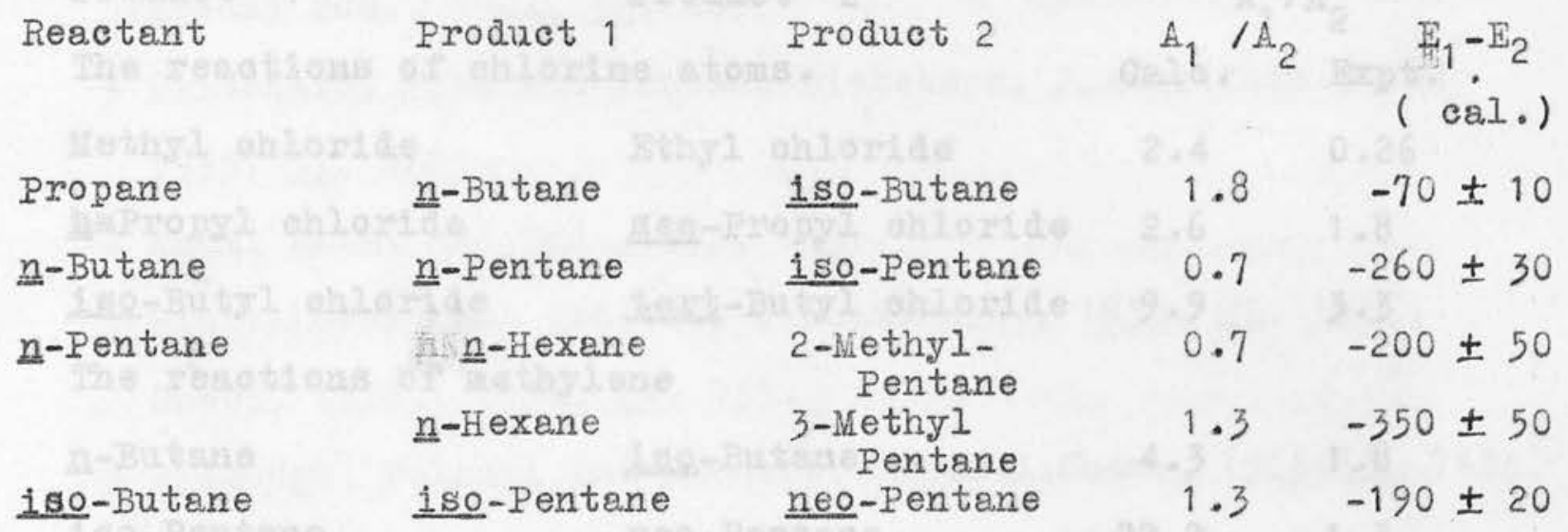




\section{TABLE 6}

CALCULATED AND EXPERIMENTAL A FACTORS

Product 1

Product 2

$A_{1} / A_{2}$

The reactions of chlorine atoms.

Calc. Expt.

Methyl chloride

Ethyl chloride

2.4

0.26

haPropyl chloride

sec-Propyl chloride $2.6 \quad 1.8$

iso-Butyl chloride

tert-Butyl chloride 9.9

3.3

The reactions of methylene

n-Butane

iso-Butane

4.3

1.8

iso-Pentane

neo-Pentane

22.2

1.3

n-Hexane

2-Methylpentane

5.0

0.7

n-Hexane

3-Methylpentane

5.6

1.3 


\section{THE REACTIONS OF METHYLENE}

by J.H.Knox and A.F.Trotman-Dickenson

(Chemistry Department, Edinburgh University)

Grard and Vanpee ${ }^{1}$ have suggested that methylene radicals add directly to alkanes in the gas phase to form higher homologues without the intervention of radicals, such as methyl, with one free valence; they did not study the systema extensively. Doering, Buttery, Lauchlin and Chauduri ${ }^{2}$ have recently investigated the reactions of methylene radicals from the photolysis of diazomethane with n-pentane, 2,5-dimethylbutane and eyclopentane in solution between $-80^{\circ}$ and $30^{\circ} \mathrm{C}$. They find that no cyclohexane is formed from eyclopentane and that the adition of methylene occurs with equal facility across the different types of $\mathrm{CH}$ bond in the alkanes. Thus the amounts of $\underline{n-h e x a n e, ~ 2-m e t h y l p e n t a n e ~ a n d ~ 3-m e t h y l p e n t a n e ~}$ formed from n-pentane are independent of temperature and. are nearly in the ratio of $3: 2: 1$. Calculations based upon the transition state theory do not predict such a simple distribution ${ }^{3}$.

We have measured the proportions of products formed when ketene at about 5 an pressure is photolysed in a Pyrex reaction vessel in the presence of 1 to $5 \mathrm{~cm}$ of alkane at $-80^{\circ}$ to $200^{\circ} \mathrm{C}$. Negligible quantities of methane are produced. The condensable products were analysed by gas-chromatography on a $4 m$ column of firebrick impregnated 
2

proportions products formed are given in the table. In some runs $30-50 \mathrm{~cm}$ of nitrogen was added to the reaction mixture without changing theproportions of the products.

The differences in the activation energies for attack on the various positions in the molecules are very small and hence it is likely that the overall activation energies are also small. The experimental A factors do not agree either with the predictions based on the transition state theory or with a simple statistical distribution. 
The Reactions of Methylene

Typical Reactions:

$$
\begin{aligned}
\mathrm{CHI}_{2}+\text { Propane } & =\text { - Butane } \\
& =\text { iso-Butane }
\end{aligned}
$$

(2)

Reactant

Product 1

Product 2

$A_{1} / A_{2} \quad E_{1}-E_{2}$
(cal.)

Propane

$\underline{n}$-Butane

1so-Butane

$1.8-70 \pm 10$

n-Butane

n-Pentane

iso-Pentane

$0.7 .-260 \pm 30$

ñ-Pentane

n-Hexane

2-Methyl-

Penatne

n-Hexane

3-Methyl-

Pentane

$0.7-200 \pm 50$

$1.3-350 \pm 50$

1so-Butane iso-Pentane

neo-Pentane

$1.3-190 \pm 20$ 
1. Grard and Vanpee, Ann. Mines. Belg., 1950, 49, 46.

2. Doering, Buttery, lauchlin and Chaudhuri, J. Amer. Chem. Soc., 1956, 78, 3224.

3. Knox and Trotman-Dickenson, Chem. and Ind., 195\%, 268. 


\section{The Reactions of Methyl Radicals with Thiols}

by J.A.Kerr and A.F.Trotman-Dickenson

The high reactivity of thiols with free radicals is well known; for this reason thiols are extensively used as chaintransfer agents in polynerisations. Iittle quantitative work on the kineties of their reactions in solution has been reported and still less work appears to have been done in the gas phase. This note records an attempt tp investigate the kinetics of the attack of methyl radicals on thiols (1).

$$
\mathrm{CH}_{3}+\mathrm{RH}=\mathrm{CH}_{4}+\mathrm{R}
$$

The photolysis of acetone was used as the source of methyl radicals. In general the procedure of Trotman-Dickenson and Steacie ${ }^{l}$ was followed. The photolysis was carried out in a Byrex reaction vessel so that no light was absorbed by the thiols. The product gases were analysed with a standard lowtemperature distillation apparatus; the carbon monoxide was oxidised in a copper oxide tube.

Durding the photolysis methane, ethane and carbon monoxide were produced by the following reactions:

$$
\begin{aligned}
\mathrm{CH}_{3} \mathrm{COCH}_{3}+\mathrm{h \nu} & =\mathrm{CH}_{3} \mathrm{CO}+\mathrm{CH}_{3} \\
\mathrm{CH}_{3} \mathrm{CO} & =\mathrm{CH}_{3}+\mathrm{CO} \\
\mathrm{CH}_{3}+\mathrm{RSH} & =\mathrm{CH}_{4}+\mathrm{RS} \\
\mathrm{CH}_{3}+\mathrm{CH}_{3} \mathrm{COCH}_{3} & =\mathrm{CH}_{4}+\mathrm{CH}_{2} \mathrm{COCH}_{3} \\
2 \mathrm{CH}_{3} & =\mathrm{C}_{2} \mathrm{H}_{6}
\end{aligned}
$$

It can be shown that:

$$
\frac{k_{1}}{k_{5}^{1 / 2}}=\frac{R_{c H_{4}}-\left(k_{4} / k_{5}^{1 / 2}\right)[\text { Acetonc }] R_{C_{2} H_{6}}^{1 / 2}}{R_{c_{2} H_{6}}^{1 / 2}[R S H]}
$$


where the $k^{9}$ s are the rate constants of the ractions and $R$ and $\mathbb{R}$ are the rates of formation of the products. The application of this equation involves a lenowledge of $\mathrm{k}_{4}$. The value of this rate constant is uncertain at less than $100^{\circ} \mathrm{C}$ because methane is also formed by additional reactions, probably Including the reactions of the acetyl radica $I^{2}$. The present experiments could not be carried out at temperatures as high $100^{\circ} \mathrm{C}$ because the rate of reaction (1) was so great that it was impossible to obtain reproducible results. Accordingly all the rate constants were determined at $30^{\circ} \mathrm{C}$. The uncertalnties in $\mathrm{k}_{4}$ were unimportant because it is about one thousand times less than $k_{1}$. The results obtained with the higher thiols were not very reproducible. The mean values of $10^{-7} / \operatorname{mole} e^{-1} \mathrm{~cm}^{3} \mathrm{sec}^{-1}$, based on the value of $\mathrm{k}_{5}$ advocated by Shepp ${ }^{3}$ are as follows:

$\begin{array}{llll}\text { MeSH } & 1.8 & \text { EitSH } & 3.5 \\ \mathrm{Pr}^{i} \mathrm{SH} & 4.1 & \mathrm{Bu}^{t} \mathrm{SH} & 5.9\end{array}$

This order of reactivity is the same as that which was deduced form a study of the photodecomposition of acetaldohyde catalysed by thiols ${ }^{4}$. If $\log _{10} \mathrm{~A} / \mathrm{mole}^{-1} \mathrm{~cm}^{3} \mathrm{sec}^{-1}$ for these reactions is of the order of 11.3, as it is for many reactions of methyl, then the activation energies of these reactions

lie between 5.6 and $4.9 \mathrm{kcal} . / \mathrm{mole}$.

1. Trotman-Dickenson and steacie, J.Chem。Phys., 1951,19, 329.

2. Ausloos and Steacie, Canad.J.Chem, 1955, 33, 47.

3. Shepp, J.Chem. Phys。, 1956, 24,939.

4. Birrell, Smith, Trotman-Dickenson and Wilkie, in the press. 